UNIVERSIDADE DE SÃO PAULO

FACULDADE DE FILOSOFIA, CIÊNCIAS E LETRAS DE RIBEIRÃO PRETO DEPARTAMENTO DE PSICOLOGIA

PROGRAMA DE PÓS-GRADUAÇÃO EM PSICOLOGIA

NICHOLLAS MARTINS ARECO

\title{
Avaliação longitudinal do contexto familiar, saúde mental e personalidade de crianças e adolescentes em cuidados oncológicos
}

Tese apresentada à Faculdade de Filosofia, Ciências e Letras de Ribeirão Preto da Universidade de São Paulo como parte dos requisitos para a obtenção do título de Doutor em Ciências. Área: Psicologia em Saúde e Desenvolvimento

Orientador: Profa. Dra. Sonia Regina Pasian

RIBEIRÃO PRETO - SP 



\section{Avaliação longitudinal do contexto familiar, saúde mental e personalidade de crianças e adolescentes em cuidados oncológicos}

Tese apresentada à Faculdade de Filosofia, Ciências e Letras de Ribeirão Preto da Universidade de São Paulo como parte dos requisitos para a obtenção do título de Doutor em Ciências. Área: Psicologia em Saúde e Desenvolvimento

Orientador: Profa. Dra. Sonia Regina Pasian

RIBEIRÃO PRETO - SP 
Autorizo a reprodução e divulgação total ou parcial deste trabalho, por qualquer meio convencional ou eletrônico, para fins de estudo e pesquisa, desde que citada a fonte.

Catalogação na publicação

Serviço de Biblioteca e Documentação

Faculdade de Medicina de Ribeirão Preto da Universidade de São Paulo

Areco, Nichollas Martins

Avaliação longitudinal do contexto familiar, saúde mental e personalidade de crianças e adolescentes em cuidados oncológicos., 2018.

$215 \mathrm{p}$.

Tese de Doutorado, apresentada à Faculdade de Filosofia, Ciências e Letras de Ribeirão Preto da Universidade de São Paulo: Área de Concentração: Psicologia em Saúde e Desenvolvimento.

Orientador: Pasian, Sonia Regina

1. Câncer. 2. Desenvolvimento infantojuvenil.

3. Avaliação Psicológica. 4. Personalidade. 5. Família.

6. Métodos Projetivos. 
Nome: Areco, Nichollas Martins

Título: Avaliação longitudinal do contexto familiar, saúde mental e personalidade de crianças e adolescentes em cuidados oncológicos

Tese apresentada à Faculdade de Filosofia, Ciências e Letras de Ribeirão Preto para obtenção do título de Doutor em Ciências, Área: Psicologia em Saúde e Desenvolvimento

Aprovado em:

Banca Examinadora

Prof. Dr.

Instituição: Assinatura:

Prof. Dr.

Instituição: Assinatura:

Prof. Dr.

Instituição: Assinatura:

Prof. Dr.

Instituição: Assinatura:

Prof. Dr. Instituição: Assinatura: 

À Elizabeth Ranier Martins do Valle e André Jacquemin, por toda sua dedicação ao desenvolvimento da Psicologia nas áreas da Psico-Oncologia Pediátrica e Avaliação Psicológica. Seus exemplos e obras são inspirações para zelarmos pelo primado teórico e técnico no cuidado ao ser humano, sem com isso esquecer a empatia e o afeto. 



\section{AGRADECIMENTOS}

À Profa. Dra. Sonia Regina Pasian, por ter me oferecido a oportunidade de realizar a experiência da formação acadêmica, podendo assim avançar na edificação do conhecimento. A espontaneidade das valorosas lições, a doçura nos cuidados, o estímulo implacável, e a confiança, foram os pilares desta vivência, e hoje são marcas imprescindíveis em minha identidade.

Ao Centro de Pesquisa em Psicodiagnóstico e seus colaboradores, pelo companheirismo e por partilharem do ideal da elaboração do saber. Em especial agradeço à Carmem, Rodolfo, e Fabiana por prestarem valiosa colaboração no desenvolvimento deste estudo

À Ana Luísa Guimarães, pela oportunidade de estarmos juntos no labor de compreender o universo da Oncologia Pediátrica.

À Ana Carolina Rodrigues e Fernanda Garcia, por terem recebido a proposta deste estudo de braços abertos, auxiliado de modo tão sensível na interação com voluntários deste estudo.

Aos amigos Maíra, Rafael, Eduardo, José Egídio, Marina, e André, por compartilharem de forma inestimável a trajetória no Programa de Pós-Graduação, e por sempre me lembrarem que o conhecimento e o afeto não são binários, mas sim indissociáveis.

Às mestras Lícia Barcelos, Érika Okino e Érica Arantes, por serem pontes seguras a garantir a travessia pelos caminhos do meu desenvolvimento pessoal. As horas dedicadas aos conselhos, orientações, risadas, broncas e encorajamento me fizeram crescer, e assim perceber o mundo com mais clareza e profundidade.

Às amigas Larissa Santos e Lilian Luchesi, que nas horas de esmorecimento me deram as mãos para que fosse possível avançar na concretização da tarefa. A gentileza e a leveza de vocês foram fundamentais no processo de construção desta experiência, pois deixaram tudo muito mais divertido e belo. 
Às inestimáveis amigas Vanessa, Flávia, Daniela, Camilla, Marcella, Nathália, Lilian, e Christiane, que compartilharam ideais acerca da Psicologia Hospitalar e da Saúde Pública. Os encontros em torno de debates acalorados, a cumplicidade silenciosa, o carinho perene, e a amizade que nos tornou uma família, foram fundamentais nesta jornada.

À Iara e Alessandro, por me incentivarem a percorrer o encantador caminho dos estudos e práticas da Avaliação Psicológica. Vocês me ensinaram que criatividade, interesse genuíno, aproximação afetuosa, e uma boa pitada de visão crítica, tornam o exercício da nossa profissão e das nossas relações muito mais completos.

Aos meus pais, Celi e Emerson, por me incentivarem ao longo dos anos, não permitindo que esquecesse jamais dos meus sonhos, das minhas ideologias, e da necessidade de lutarmos por um mundo melhor para todos. Nestas páginas que se seguem estão os frutos de tudo que puderam fazer por mim, e que de agora em diante compartilharemos com tantos outros.

À Yuri e Andresa por trazerem a doçura e a fraternidade nos dias de trabalho árduo.

A Gianni, por me ajudar a perceber que assim como em um coro de uma ópera, a música só se torna magnífica se todas as vozes se unem para banhar o ambiente de graça e de luz. Obrigado por estar comigo a todos os momentos, por todos os caminhos.

Aos familiares e amigos que vibraram a cada conquista, torceram em cada desafio, e confiaram nessa empreitada.

À equipe interdisciplinar do Serviço de Oncologia Pediátrica do Hospital das Clínicas da Faculdade de Medicina - USP. Agradeço profundamente a oportunidade de nos unirmos em torno dos mesmos anseios, dos mesmos sentimentos, e da vontade de proteger e defender a vida, compreendendo seu profundo mistério.

Às crianças e adolescentes com câncer, assim como seus familiares. Dedico todos meus esforços para que não percam a esperança que as trevas podem ser dissipadas, e ao amanhecer, o sol da vida banhará incessantemente a jornada existencial de vocês. 
Já podaram seus momentos

Desviaram seu destino

Seu sorriso de menino

Quantas vezes se escondeu

Mas renova-se a esperança

Nova aurora a cada dia

E há que se cuidar do broto

Pra que a vida nos dê

Flor e fruto

(Milton Nascimento) 



\section{RESUMO}

Areco, N. M. (2018). Avaliação longitudinal do contexto familiar, saúde mental e personalidade de crianças e adolescentes em cuidados oncológicos. Tese de Doutorado, Faculdade de Filosofia, Ciências e Letras de Ribeirão Preto, Universidade de São Paulo, São Paulo.

O diagnóstico de neoplasia em crianças e adolescentes, bem como os cuidados oncológicos necessários, impõem aos pacientes e a suas famílias o convívio cotidiano com múltiplos eventos adversos ao desenvolvimento, que podem ser de natureza biológica, psíquica, social e econômica. Essa complexa realidade exigirá recursos e estratégias pessoais e familiares para positivo desfecho, superando situações de vulnerabilidade. Até o momento, apesar do crescente número de casos de câncer, encontra-se reduzida produção científica sistematizada no campo da Psico-oncologia Pediátrica sobre quais variáveis seriam as mais relevantes em termos de efeitos no desenvolvimento infanto-juvenil, embora se reconheça importância dos recursos pessoais (incluindo características de personalidade), sócio-familiares e dos serviços de saúde. Nesse contexto, este trabalho objetivou avaliar longitudinalmente possíveis efeitos da vivência de adoecimento e cuidado oncológico sobre recursos pessoais, familiares e características de personalidade de crianças e adolescentes com câncer. Trata-se de estudo longitudinal, de natureza quantitativa, descritivo-comparativo e interpretativo, a partir de instrumentos de avaliação psicológica. Foram compostos dois de crianças e adolescentes, de sete a 17 anos, de ambos os sexos, bem como seus respectivos pais/responsáveis, compondo amostra de conveniência. O Grupo Clínico (G1, n=30, crianças/adolescentes com diagnóstico de neoplasia há pelo menos um mês) foi retirado de pacientes do Setor de Oncologia e Hematologia Pediátrica de um hospital-escola público, considerado serviço de referência na área. O Grupo de Comparação ( $\mathrm{G} 2, \mathrm{n}=20$, crianças/adolescentes com desenvolvimento típico), foi constituído de modo a ser balanceado em relação a idade, sexo e origem escolar (particular ou pública) a G1. Todos os voluntários (crianças/adolescentes e seus pais/responsáveis) responderam, individualmente e em ambiente adequado para avaliação psicológica, a uma bateria de instrumentos avaliativos, aplicados em dois momentos, nomeados nesse estudo como Fase 1 (recorte transversal) e Fase 2 (recorte longitudinal, após intervalo mínimo de seis meses da primeira avaliação). Os pais/responsáveis responderam a: Critério de Classificação Econômica Brasil, Questionário de Capacidades e Dificuldades (SDQ), Inventário de Recursos do Ambiente Familiar (RAF), Escala de Eventos Adversos (EEA), Escala de Adversidades Crônicas (EAC) e Inventário de Percepção do Suporte Familiar (IPSF). Na criança/adolescente foram administrados: Matrizes Progressivas de Raven (Coloridas ou Escala Geral), Método de Rorschach (Escola Francesa) e Teste das Pirâmides Coloridas de Pfister. A aplicação e a avaliação dos instrumentos seguiram seus respectivos padrões técnico-científicos, realizando-se análises descritivas e comparativas de G1 e G2 (Teste $t$ de Student ou Teste de Wilcoxon, $p \leq 0,05 \%$ ), nas duas fases do estudo. Os resultados apontaram, como síntese das duas fases avaliativas, sinais de preservação dos recursos familiares e cognitivo/afetivos das crianças/adolescentes com câncer, com manutenção do funcionamento adaptativo, embora com impacto negativo na percepção de si e de sua identificação com o humano, tendendo a maior mobilização emocional, com tensão e ansiedade em seus esforços adaptativos, identificados pelos pais/responsáveis como indicadores de dificuldades em termos de saúde mental, comparativamente ao Grupo de Comparação. O Grupo Clínico tendeu a recorrer mais a estratégias defensivas baseadas em mecanismos repressivos e de racionalização, inibindo expressões afetivas no ambiente, favorecendo-lhes adaptação ao contexto de vida. Estes achados empíricos evidenciaram, 
numa perspectiva longitudinal, os recursos e os esforços adaptativos de crianças/adolescentes que convivem com o diagnóstico oncológico, bem como suas famílias. Foi possível apontar a relevância da sistemática avaliação e reavaliação da complexa rede de variáveis envolvidas nesses processos, atestando a contribuição dos métodos projetivos no campo da PsicoOncologia Pediátrica.

Palavras-chave: Câncer, Desenvolvimento Infantojuvenil, Avaliação Psicológica, Personalidade, Família, Métodos Projetivos. 


\begin{abstract}
Areco, N. M. (2018). Longitudinal assessment of Family contexto, mental healt and personality of children and adolescentes under oncological care. Tese de Doutorado, Faculdade de Filosofia, Ciências e Letras de Ribeirão Preto, Universidade de São Paulo, São Paulo.
\end{abstract}

The neoplasia diagnosis in children and adolescentes, as well as the oncological care needed, impose to patients and their families the daily living with multiple adverse events to the development, that may be of biological, psychic, social and economic nature. This complex reality will demand personal and family resources and strategies for a positive outcome, overcoming situations of vulnerability. To date, despite the growing number of cancer cases, there is a reduced systematized scientific production in the field of Pediatric PsychoOncology about what variables would be the most relevant in terms of effects on child and adolescent development, although the importance of personal resources (including personality characteristics), socio-family and health services is recognized. In this contexto, this study aimed to longitudinally assess possible effects of the experience of illness and cancer care on personal, family and personality characteristics of children and adolescents with cancer. This is a longitudinal study, of a quantitative, descriptive-comparative and interpretative nature, based on psychological assessment instruments. The were composed two groups of children and adolescents, from seven to 17 years of age, of both sexes, as well as their respective parents/guardians, composing a convenience sample. The Clinical Group (G1, $\mathrm{n}=30$, children/adolescents with diagnosis of neoplasia for at least one month) was composed from patients of the Oncology and Pediatric Hematology Sector of a public school hospital, considered a reference service in the area. The Comparison Group (G2, $n=20$, children/adolescents with typical development) was constituted in order to be balanced against age, gender and school origin (private or public) to G1. All volunteers (children/adolescents and their parents/guardians) responded, individually and in a suitable environment for psychological assessment, to a battery of assessment instruments, applied in two moments, named in this study as Phase 1 (transversal cut) and Phase 2 (longitudinal cut, after a minimum interval of six months of the first assessment). Parents/guardians responded to: Brazil's Economic Classification Criteria, Capacities and Difficulties Questionnaire (SDQ), Family Environment Resource Inventory (RAF), Adverse Event Scale (EEA), Chronic Adversity Scale (EAC), and Inventory of Perception of Family Support (IPSF). In the child/adolescent were administered: Progressive Matrices of Raven (Colored or General Scale), Method of Rorschach (French School) and Test of Colored Pyramids of Pfister. The application and assessment of the instruments followed their respective technical-scientific standards. Descriptive and comparative analyzes of G1 and G2 (Student's t test or Wilcoxon test, $\mathrm{p} \leq 0.05 \%$ ) were carried out in both phases of the study. The results showed, as a synthesis of the two evaluative phases, signs of preservation of the family and cognitive/affective resources of the children/adolescents with cancer, with maintenance of the adaptative functioning, although with a negative impact on the perception of self and its identification with the human, tending to greater emotional mobilization, with tension and anxiety in their adaptive efforts, identified by parents/guardians as indicators of difficulties in terms of mental health, compared to the Comparison Group. The Clinical Group tended to resort more to defensive strategies based on repressive mechanisms and rationalization, inhibiting affective expressions in the environment, favoring adaptation to the context of life. These empirical findings have evidenced, from a longitudinal perspective, the resources and the adaptive efforts of children/adolescents living with cancer diagnosis, as well as their families. It was 
possible to point out the relevance of systematic assessment and re-assessment of the complex network of variables involved in these processes, attesting the contribution of projective methods in the field of Pediatric Psycho-Oncology.

Key words: Cancer, Child and Adolescent Development, Psychological Assessment, Personality, Family, Projective Methods. 


\section{LISTA DE TABELAS}

Tabela 1. Distribuição dos participantes de grupo clínico $(n=30)$ em função de procedimentos clínicos de cuidado e eventos adversos pertinentes ao adoecimento, nas distintas fases avaliativas.

Tabela 2. Caracterização da amostra (primeira avaliação) em função do grupo, sexo e idade.

Tabela 3. Distribuição (em frequência simples e porcentagem) dos participantes por origem escolar, composição familiar e classificação econômica em função do grupo do estudo.

Tabela 4. Distribuição (em frequência simples e porcentagem) dos participantes em função do nível intelectual (primeira avaliação).

Tabela 5. Resultados médios e comparação estatística dos domínios do Inventário de Recursos do Ambiente Familiar (RAF) na primeira etapa do estudo.

Tabela 6. Resultados médios e comparação estatística da Escala de Eventos Adversos (EEA) e Escala de Adversidades Crônicas (EAC) na primeira avaliação

Tabela 7. Resultados médios e comparação estatística nas diferentes dimensões do Inventário de Percepção do Suporte Familiar (IPSF) na primeira etapa do estudo.

Tabela 8. Resultados médios e comparação estatística dos domínios do Inventário de Recursos do Ambiente Familiar (RAF) na segunda etapa do estudo.

Tabela 9. Resultados médios e comparação estatística da Escala de Eventos Adversos (EEA) e Escala de Adversidades Crônicas (EAC) na segunda avaliação.

Tabela 10. Resultados médios e comparação estatística nas diferentes dimensões do Inventário de Percepção do Suporte Familiar (IPSF) na segunda etapa do estudo.

Tabela 11. Resultados médios e comparação estatística dos dois momentos avaliativos do Grupo Clínico (G1) no Inventário de Recursos do Ambiente Familiar (RAF).

Tabela 12. Resultados médios e comparação estatística dos dois momentos avaliativos do Grupo Clínico (G1) em função da Escala de Eventos Adversos (EEA) e Escala de Adversidades Crônicas (EAC)

Tabela 13. Resultados médios e comparação estatística dos dois momentos avaliativos do Grupo Clínico (G1) a partir do Inventário de Percepção do Suporte Familiar (IPSF). 
Tabela 14. Resultados médios e comparação estatística dos grupos referente ao Questionário de Capacidade e Dificuldades (SDQ) na primeira avaliação.

Tabela 15. Resultados médios e comparação estatística dos grupos referente ao Questionário de Capacidade e Dificuldades (SDQ) na segunda avaliação.

Tabela 16. Resultados médios e comparação estatística dos dois momentos avaliativos do Grupo Clínico (G1) a partir do Questionário de Capacidade e Dificuldades e (SDQ).

Tabela 17. Resultados médios e comparação estatística dos grupos em função da produtividade e ritmo no Rorschach (primeira avaliação).

Tabela 18. Resultados médios e comparação estatística dos grupos em função dos modos de apreensão do Rorschach (primeira avaliação).

Tabela 19. Resultados médios e comparação estatística dos grupos em função dos determinantes do Rorschach (primeira avaliação).

Tabela 20. Resultados médios e comparação estatística dos grupos em função dos conteúdos e banalidades do Rorschach (primeira avaliação).

Tabela 21. Distribuição dos participantes e comparação estatística dos grupos em função das Fórmulas Vivenciais do Rorschach (primeira avaliação).

Tabela 22. Resultados médios (em porcentagem) e comparação estatística dos grupos em função das cores do Teste de Pfister (primeira avaliação).

Tabela 23. Resultados médios (em porcentagem) e comparação estatística dos grupos em função das síndromes cromáticas do Teste de Pfister (primeira avaliação).

Tabela 24. Distribuição dos participantes e comparação estatística dos grupos em função dos parâmetros normativos para cores e síndromes do Pfister (primeira avaliação).

Tabela 25. Resultados médios e comparação estatística dos grupos em relação à Formula Cromática no Teste de Pfister (primeira avaliação).

Tabela 26. Distribuição dos participantes e comparação estatística dos grupos em função da classificação da Fórmula Cromática do Teste de Pfister (primeira avaliação).

Tabela 27. Distribuição dos participantes e comparação estatística dos grupos dos Modos de Execução, Modos de Colocação e Aspecto Formal no Teste de Pfister (primeira avaliação).

Tabela 28. Resultados médios e comparação estatística dos grupos em função da produtividade e ritmo no Rorschach (segunda avaliação). 
Tabela 29. Resultados médios e comparação estatística dos grupos em função dos modos de apreensão do Rorschach (segunda avaliação).

Tabela 30. Resultados médios e comparação estatística dos grupos em função dos determinantes do Rorschach (segunda avaliação).

Tabela 31. Resultados médios e comparação estatística dos grupos em função dos conteúdos e banalidades do Rorschach (segunda avaliação).

Tabela 32. Distribuição dos participantes e comparação estatística dos grupos em função das Fórmulas Vivenciais do Rorschach (segunda avaliação).

Tabela 33. Resultados médios e comparação estatística dos grupos em função das cores do Teste de Pfister (segunda avaliação).

Tabela 34. Resultados médios e comparação estatística dos grupos em função das síndromes cromáticas do Teste de Pfister (segunda avaliação).

Tabela 35. Distribuição dos participantes e comparação estatística dos grupos em função dos parâmetros normativos para cores e síndromes do Pfister (segunda avaliação).

Tabela 36. Resultados médios e comparação estatística dos grupos em relação a Fórmula Cromática no Teste de Pfister (segunda avaliação).

Tabela 37. Distribuição dos participantes e comparação estatística dos grupos em função da classificação da Fórmula Cromática no Teste de Pfister (segunda avaliação).

Tabela 38. Distribuição dos participantes e comparação estatística dos grupos em função dos Modos de Execução, Modos de Colocação e Aspecto Formal no Teste de Pfister (segunda avaliação).

Tabela 39. Resultados médios e comparação estatística das duas avaliações do grupo clínico $(\mathrm{G} 1)$ em função da produtividade e ritmo no Rorschach

Tabela 40. Resultados médios e comparação estatística das duas avaliações do grupo clínico (G1) em função dos modos de apreensão do Rorschach.

Tabela 41. Resultados médios e comparação estatística das duas avaliações do grupo clínico (G1) em função dos determinantes do Rorschach.

Tabela 42. Resultados médios e comparação estatística das duas avaliações do grupo clínico (G1) em função dos conteúdos do Rorschach.

Tabela 43. Distribuição dos participantes do Grupo Clínico e comparação estatística das Fórmulas Vivenciais no Rorschach nos dois momentos avaliativos. 
Tabela 44. Resultados médios e comparação estatística das duas avaliações do grupo clínico (G1) em função das cores no Teste de Pfister.

Tabela 45. Resultados médios e comparação estatística das duas avaliações do grupo clínico (G1) em função das síndromes cromáticas no Teste de Pfister.

Tabela 46. Distribuição dos participantes do grupo clínico $(n=30)$ e comparação estatística das duas avaliações em função dos parâmetros normativos para cores e síndromes do Pfister.

Tabela 47. Resultados médios e comparação estatística das duas avaliações do grupo clínico $(n=30)$ em relação a Fórmula Cromática no Teste de Pfister.

Tabela 48. Distribuição da classificação das Fórmulas Cromáticas do Pfister no Grupo Clínico $(n=30)$ e comparação estatística entre dois momentos avaliativos.

Tabela 49. Distribuição dos participantes e comparação estatística dos dois momentos avaliativos do Grupo Clínico $(n=30)$ em função dos Modos de Execução, Modos de Colocação e Aspecto Formal no Teste de Pfister. 


\section{LISTA DE FIGURAS}

Figura 1. Percurso amostral do grupo clínico $(n=30)$

Figura 2. Distribuição (em porcentagem) dos participantes do Grupo Clínico (n=30) em função do diagnóstico oncológico.

Figura 3. Distribuição dos participantes do Grupo Clínico $(n=30)$ em função do tempo da administração de drogas quimioterápicas (em meses). 55

Figura 4. Percurso amostral do grupo de comparação $(n=20)$. 59 



\section{SUMÁRIO}

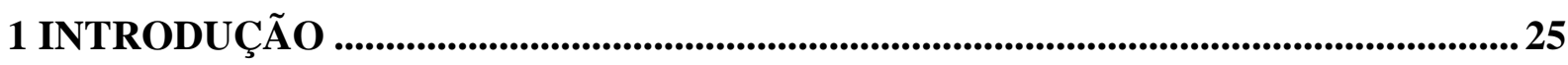

1.1 Ciclo vital na perspectiva da Psicopatologia do Desenvolvimento ................................. 27

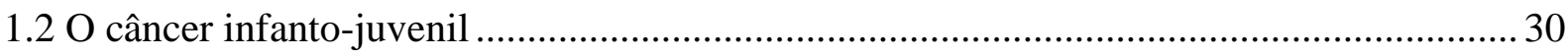

1.3 Família e suporte familiar diante do cuidado oncológico............................................... 33

1.4 Processos adaptativos frente ao câncer infantojuvenil ................................................... 38

2 OBJETIVOS ................................................................................................................................... 43

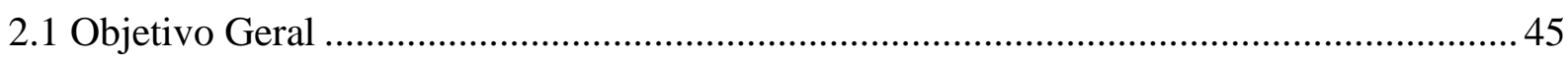

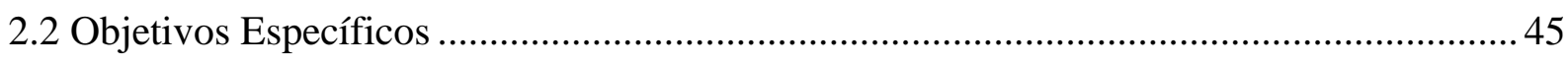

3 MÉTODO ................................................................................................................. 47

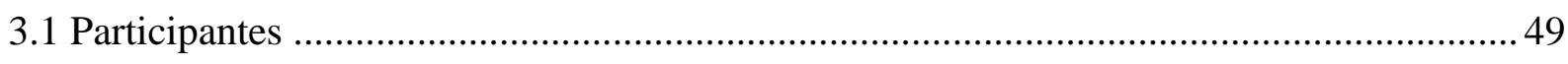

3.1.1 Caracterização do Serviço Clínico em estudo .............................................................. 49

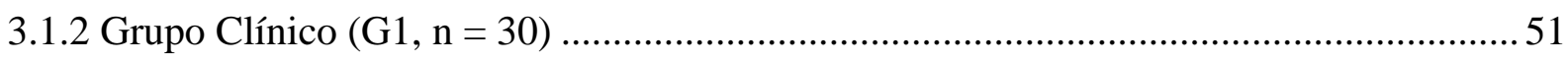

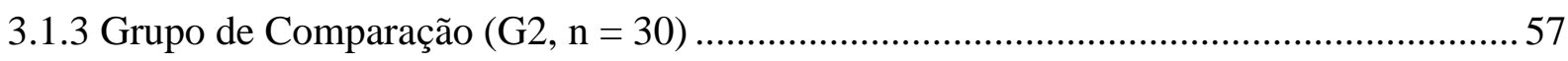

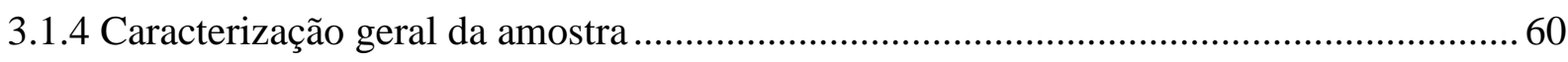

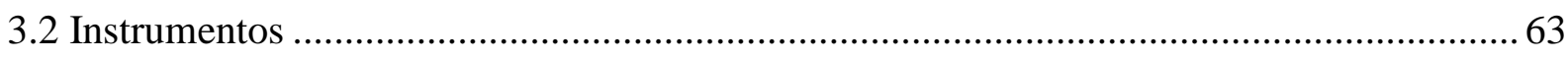

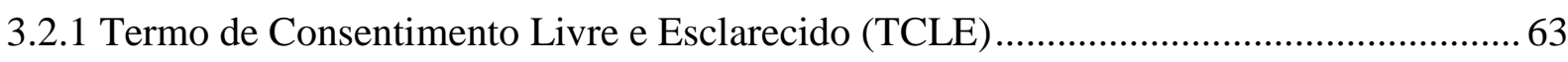

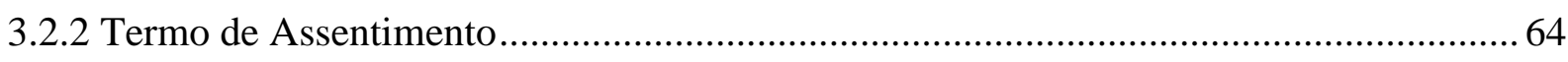

3.2.3 Critério de Classificação Econômica Brasil (CCEB) ...................................................... 64

3.2.4 Matrizes Coloridas Progressivas de Raven e Matrizes Progressivas de Raven (Escala

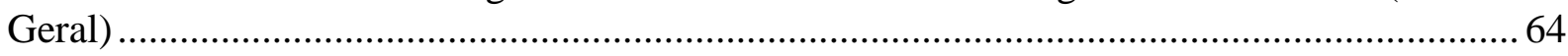

3.2.5 Inventário de Recursos do Ambiente Familiar - RAF (Marturano, 1999)......................65

3.2.6 Escala de Adversidades Crônicas - EAC (Marturano, 1999) .......................................... 65

3.2.7 Escala de Eventos Adversos - EEA (Marturano, 1999)................................................ 66

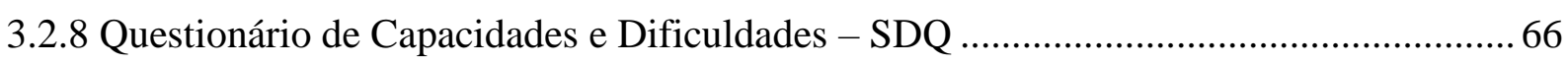

3.2.9 Inventário de Percepção do Suporte Familiar - IPSF.................................................. 67

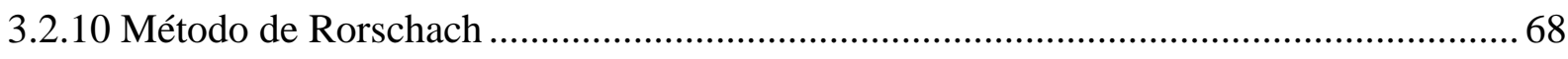

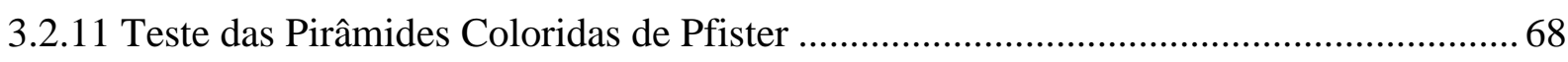

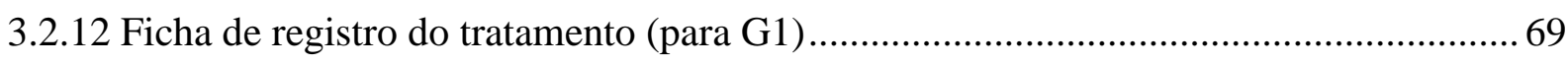

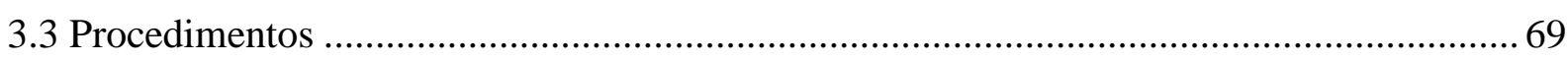

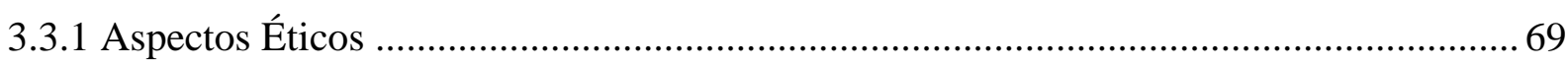

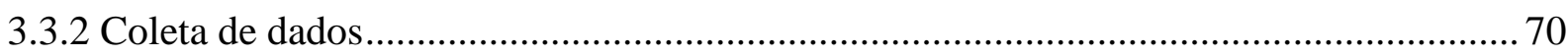




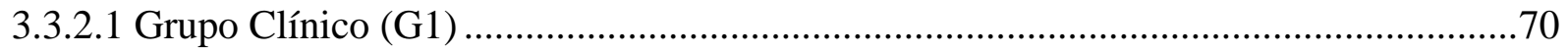

3.3.2.2 Grupo de Comparação (G2) ...............................................................................72

3.3.3 Análise dos resultados.......................................................................................73

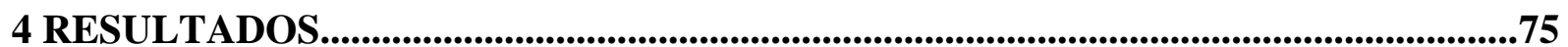

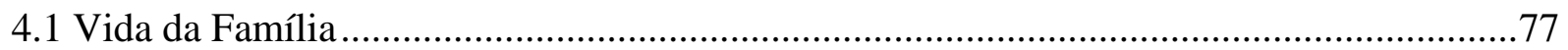

4.1.1 Vida da Família (FASE 1) …………………………………………………....

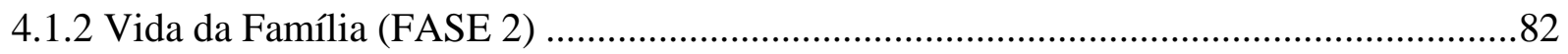

4.1.3 Vida da Família - Comparação FASE 1 e FASE 2 no Grupo Clínico …………………...86

4.1.4 Vida da Família - Síntese .............................................................................................91

4.2 Indicadores de Saúde Mental Infantojuvenil ...................................................................93

4.2.1 Indicadores de Saúde Mental Infantojuvenil (FASE 1) ...................................................93

4.2.2 Indicadores de Saúde Mental Infantojuvenil (FASE 2) ................................................94

4.2.3 Indicadores de Saúde Mental Infantojuvenil - Comparação FASE 1 e FASE 2 no

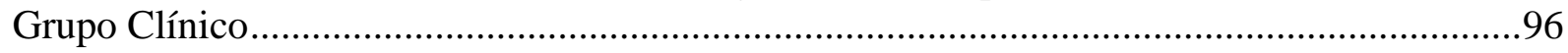

4.3 Indicadores da Personalidade de Crianças e Adolescentes ................................................97

4.3.1 Referentes à primeira avaliação (FASE 1) ..............................................................98

4.3.1.1 Método de Rorschach - Primeira Fase ……...........................................................98

4.3.1.2 Teste das Pirâmides Coloridas de Pfister - Primeira Fase ..........................................108

4.3.2 Referentes à segunda avaliação (FASE 2) ……………………………………….....117

4.3.2.1 Método de Rorschach - Segunda Fase ………………....................................117

4.3.2.2 Teste das Pirâmides Coloridas de Pfister - Segunda Fase..........................................126

4.3.3 Indicadores de Personalidade - Comparação FASE 1 e FASE 2 no Grupo Clínico .....133

4.3.3.1 Método de Rorschach - Comparação Fase 1 e Fase 2 no Grupo Clínico .....................133

4.3.3.2 Teste de Pfister - Comparação Fase 1 e Fase 2 no Grupo Clínico ...............................143

4.3.4 Indicadores da Personalidade de Crianças e Adolescentes - síntese ...............................149

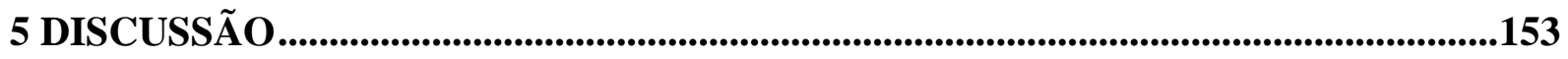

6 CONSIDERAÇÕES FINAIS ...........................................................................................175

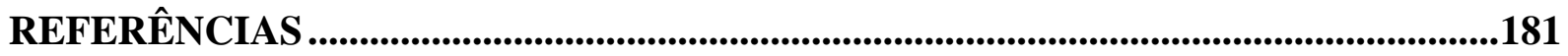

APÊNDICES E ANEXOS …..........................................................................................197 



\subsection{Ciclo vital na perspectiva da Psicopatologia do Desenvolvimento}

Ao descrever o percurso que a pessoa percorre ao longo do ciclo vital, Gessel (1998) compara o desenvolvimento com a extensa trajetória que a humanidade cursou, partindo de seu estado mais primitivo até alcançar o status moderno. Dessa maneira, é possível descrever que o processo evolutivo do homem é continuo e envolve complexa relação multidirecional de ganhos e perdas, bem como a confluência de fatores internos e externos, havendo interação das dimensões orgânicas e genéticas, cognitivas e afetivas, ambientais e sociais, pessoais e interpessoais, culturais e econômicas (Papalia, Olds \& Feldman, 2006).

É importante ressaltar que o interjogo entre aspectos biológicos e ambientais não determina, de forma absoluta e instantânea, o curso do desenvolvimento do ser humano. Assim, como alerta Sroufe (2009), o desencadeamento deste processo não pode ser predito por relações causais simples, mas é preciso levar em consideração o histórico do desenvolvimento da pessoa e o modo pelo qual se integram os variados fatores e eventos que o constitui.

A fim de identificar características e padrões esperados para o desenvolvimento típico do ser humano, a Psicopatologia do Desenvolvimento propõe que seja realizado exame criterioso do processo evolutivo de populações e pessoas que vivenciem realidades marcadas pela anormalidade e permeadas por fatores de risco biopsicossocial, partindo do pressuposto que a patologia seria uma distorção do percurso desenvolvimental natural e saudável. Sobre esta perspectiva, Sameroff (2000) esclarece que o desenvolvimento não é um processo linear, mas multideterminado e multifacetado, com possibilidade de reconhecimento, dentro de quadros patológicos, elementos comuns à normalidade, utilizando a realidade extrema para explorar e apreender quais poderiam ser os fundamentos do desenvolvimento global adequado.

Ainda sobre a Psicopatologia do Desenvolvimento, Cicchetti e Rogosh (2002) apontam que esta abordagem não se satisfaz com o simples levantamento de sintomas pertinentes a determinada desordem no curso evolutivo, mas tem por princípio esclarecer quais bases originam os diversos processos de desenvolvimento. Interessa descrever características marcantes nessas trajetórias específicas, reconhecendo divergências e convergências no desenvolvimento de grupos que se encontram em circunstâncias diversas.

Em suma, esta abordagem confere importância às interações que fenômenos biológicos, psicológicos, sociais e culturais trazem para o indivíduo. Há especial interesse em identificar como a pessoa experimenta os desafios pertinentes aos micros e macros contextos, 
assim como organiza e oferece respostas afetivas, cognitivas, comportamentais e sociais, visando à adaptação diante de vivências estimuladoras em sua trajetória. Para além de conhecer quais recursos e estratégias são favorecedoras do processo de desenvolvimento, também é de suma importância detectar aquelas que se mostram inadequadas e ineficazes, com efeito negativo e desajustado na evolução da pessoa, além de posicionamentos com maior probabilidade de favorecer algum tipo de psicopatologia (Toth \& Cicchetti, 2010).

Com base nessa perspectiva teórica, denomina-se como resiliência o processo de interação entre fatores intrapsíquicos e socioambientais que produziriam condições para a pessoa enfrentar e superar experiências de crise e de intensa fragilidade. Ao discutir este tema, Yunes (2003) aponta que este conceito não se alinha com a ideia de invencibilidade, invulnerabilidade ou resistência, e, portanto, não pode ser compreendido como traço constituinte do indivíduo. A resiliência tem um caráter processual e dinâmico, envolvendo processos psíquicos da pessoa e a interação com seu grupo social e familiar.

Ainda a respeito deste conceito, Luthar, Cicchetti e Becker (2000) salientam que resiliência não envolve fugir do evento estressor ou adverso, mas é preponderantemente engajar-se nele. Implica em respostas positivas do indivíduo às situações de intensa mudança ou de forte fragilidade, com intuito de se adaptar a estas exigências e agruras, de forma a manter o seu curso evolutivo. A qualidade ou tipo de resposta pode variar de pessoa para pessoa, conforme os fatores que constituíram sua experiência de vida e seu desenvolvimento.

Segundo Walsh (2005), resiliência seria definida como "processo ativo de resistência, reestruturação e crescimento em resposta à crise e ao desafio. (...) As qualidades da resiliência permitem às pessoas se curarem de feridas dolorosas, assumirem suas vidas e irem em frente" (p. 4).

Para se abordar o tema da resiliência, há que se pensar em fatores protetores e fatores de risco ao desenvolvimento. Os recursos pessoais disponíveis no contexto do indivíduo e que auxiliam apropriação, enfrentamento e superação de situações de risco são denominados fatores de proteção. Segundo Rutter (1985), estes fatores não têm origem em eventos prazerosos e sua principal característica é auxiliar a pessoa a lidar com a situação de risco, oferecendo respostas adaptativas e de superação. Os fatores de proteção podem ser originários de características próprias da pessoa ou de experiências prévias. Ainda segundo o pesquisador, uma das condições necessárias para promover modificação evolutiva do ser humano é a existência de contextos permeados por atuantes fatores de risco, coexistindo com fatores protetores. 
Santos e Dell'Aglio (2011), ao revisitarem esse último conceito, apontam que há três grandes grupos de fatores de proteção: características de personalidade individual, qualidades do suporte afetivo oferecidos pelo grupo familiar, e suporte social eficaz e atuante. A respeito do suporte familiar, Walsh (2005) argumenta que, além do suporte afetivo, a família pode oferecer vasto campo de elaboração de experiências e respostas positivas diante da situação de crise, vinculados ao sistema de crenças familiares, padrões organizacionais do grupo e processos de comunicação entre seus membros.

Ao tomarem em consideração os fatores de risco, Polleto e Koller (2011) os definem como todo e qualquer tipo de acontecimento ou fenômeno pertinente à história de vida do indivíduo que pode gerar impacto negativo para seu desenvolvimento, aumentando a probabilidade da pessoa manifestar problemas físicos, psicológicos e sociais. Blun (1997) exemplifica que estes fatores podem ser representados pela pobreza, abuso ou maus-tratos, uso abusivo de álcool e entorpecentes, dificuldades de aprendizado, presença de doença mental na família, desestruturação familiar, falta de apoio social, gravidez e maternidade na adolescência, convivência com doenças crônicas, entre outras situações.

É preciso ter consciência que a simples presença do risco não pressupõe a criação de contexto marcado pela vulnerabilidade. Tampouco o próprio risco pode ser estabelecido por meio de direta associação de um fator específico frente à instalação de algum problema ou dificuldade na vida das pessoas, famílias e comunidades. Pelo contrário, o grau e o tipo de impactos produzidos pelo fator de risco tem ação distinta na pluralidade dos indivíduos, além de se alterar conforme seu desenvolvimento e as condições estabelecidas para lidar com eles. Há que se considerar ainda que o tempo e a intensidade de exposição a este fator podem alterar sua reação ao mesmo (Masten, 2001; Paludo \& Koller, 2005). Desta maneira a combinação de fatores de risco de diversas naturezas comporiam mecanismos de risco, que poderiam comprometer as expectativas do desenvolvimento de diferentes âmbitos do ser, culminando em um desfecho desenvolvimental negativo ou desfavorável (Sapienza \& Pedromônico, 2005).

Diante destes apontamentos, é possível considerar que a situação de adoecimento durante a infância e a adolescência expõem a pessoa e seu grupo familiar à diversificada gama de fatores e mecanismos de riscos ao desenvolvimento. Assim, a partir desse momento será tomada, como foco de análise, a incidência de doenças oncológicas nas primeiras fases da vida e seu impacto diante da complexidade do desenvolvimento humano. 


\section{$1.2 O$ câncer infanto-juvenil}

Sob a designação do vocábulo câncer encontra-se amplo conjunto de patologias distintas, mas que têm como característica comum a proliferação de células anômalas em sítios e tecidos que compõem o corpo. Seja pela ação de agentes biológicos, químicos ou físicos advindos do próprio organismo ou do ambiente que o rodeia, essas células sofrem alterações em seu material genético, gerando modificação na produção de proteínas e nas funções enzimáticas responsáveis pela composição celular e suas funções normais. Ademais, apresentam acelerada divisão celular e prolongado período de vida, o que, conjugado com a facilidade em receber irrigação sanguínea, favorece a criação de importantes aglomerados que podem invadir diversos tecidos, formando assim os tumores neoplásicos (Camponero, 2008).

Precedido apenas pelas doenças cardiovasculares, o câncer é a segunda causa de morte por doenças não transmissíveis no mundo todo. Segundo projeções da Organização Mundial da Saúde (WHO), até o ano de 2025 este tipo de enfermidade atingirá aproximadamente 22 milhões de pessoas por ano, levando a morte um número estimado de 13 milhões de indivíduos, dos quais $80 \%$ seriam moradores de países subdesenvolvidos ou em desenvolvimento (WHO, 2014).

No contexto nacional, o Ministério da Saúde apontou ocorrência de 420.000 casos novos no biênio 2016-2017, acrescido de 180.00 casos de manifestações de tumores do tipo melanoma. O perfil epidemiológico do câncer no Brasil segue o padrão encontrado para a América Latina, com predominância do câncer de pele, próstata, mama, cólon e reto, pulmão, estômago e colo de útero (Brasil, 2016). Vale ressaltar que desde o ano de 2003 as doenças neoplásicas são a segunda causa de morte no país, representando $17 \%$ de óbitos na população brasileira.

Diferente do observado em adultos ou idosos, no grupo infantojuvenil as neoplasias malignas originam-se a partir de células embrionárias que apresentam importante ritmo de proliferação, e evoluem de forma mais veloz que neoplasias advindas de células maduras. Por esta razão, o câncer nessa faixa etária tem comportamento mais agressivo e invasivo, entretanto, em contrapartida, mostra-se mais suscetível a tratamento farmacológico e ionizante (Brasil \& Instituto Ronald McDonald, 2009; Reis, Santos \& Thuler, 2007).

No Brasil, as neoplasias pediátricas correspondem a cerca de $1 \%$ a $3 \%$ dos diagnósticos oncológicos, sendo possível classificá-las como doenças raras, embora claramente impactantes. De acordo com o Instituto Nacional do Câncer (INCA), durante o ano de 2016, as neoplasias devem ter atingido cerca de 12.600 pessoas de zero a 19 anos, 
constituindo a primeira causa de morte desencadeada por enfermidades nessa faixa etária. Isto se deve tanto pela gravidade da doença, quanto por intercorrências associadas a ela e ao processo de cuidado oncológico (Brasil, 2016). É possível dizer que os tipos de câncer mais recorrentes nesse grupo etário são: Leucemias, Linfomas, Tumores do Sistema Nervoso Central, Tumores Ósseos, Tumores de Células Germinativas, Sarcomas, Neuroblastoma, Tumor de Wilms e Retinoblastoma (Andréa, 2008; Saint Jude Children's Research Hospital, 2010).

Um dos principais recursos para o controle e combate à doença oncológica é a administração de uma combinação de drogas antineoplásicas, conhecida por quimioterapia. Segundo Neves (2013), esta conjugação de agentes químicos tem por objetivo interferir em diversos mecanismos bioquímicos no ciclo de vida celular, visando à destruição de novas células tumorais, controle e erradicação das formações anômalas. Por ter efeito sistêmico, acaba desencadeando importantes efeitos colaterais, a saber: cansaço, náusea e vômitos, perda de cabelos, depressão do sistema imunológico e nas funções da medula óssea, reações alérgicas e cutâneas. Mesmo em períodos posteriores ao uso das drogas quimioterápicas, estes medicamentos podem trazer comprometimentos cardíacos, pulmonares e neurológicos (Camargo, Lopes \& Novaes, 2000; Hospital do Câncer, 2003).

Outro recurso para o controle e erradicação da enfermidade é a radioterapia. A partir da irradiação ionizante na região afetada, a carga energética absorvida pela célula quebra ligações químicas de enzimas e lipídios presentes em sua constituição, acarretando sua morte (Ladeia, Castro \& Filho, 2010). Para além dessas, outras estratégias são usadas para auxiliar na eliminação das células cancerígenas e na recuperação da saúde do paciente. A primeira delas é a abordagem cirúrgica, sobretudo utilizada em tumores de caráter sólido, e que tem como objetivo a ressecção total ou parcial do tumor ou do tecido comprometido. Outro procedimento que pode ser empregado é o transplante, com destaque para o transplante de medula óssea, utilizado no tratamento de alguns tipos de Leucemia.

A capacitação de profissionais competentes para a detecção de sintomas e sinais típicos do câncer pediátrico, a evolução das técnicas que propiciam o diagnóstico precoce da doença, além do desenvolvimento de novas abordagens que buscam o combate às manifestações neoplásicas e aprimoramento das equipes multidisciplinares voltadas ao cuidado oncológico infantojuvenil, propiciou importantes mudanças nos tratamentos e seus resultados. A taxa de cura do câncer e sobrevida em crianças e adolescentes passou de aproximadamente $40 \%$ na década de 1970 no contexto europeu e norte-americano, para 
índices superiores a 80\% na última década (Camargo \& Kurashima, 2007; Grabois, Oliveira \& Carvalho, 2013).

No Brasil, o indicador de sobrevivência desta população experimenta evolução análoga a de países mais desenvolvidos. É possível verificar que hoje, a cada dez crianças e adolescentes acometidos pelo câncer em nosso país, oito irão usufruir do restabelecimento de sua saúde após o término do tratamento. Entretanto, é preciso considerar que este número não representa padrão absoluto de cura. O tratamento para a Leucemia Linfoide Aguda pode atingir $80 \%$ de sucesso, mas outros tipos de câncer, por seu grau de malignidade, demora do diagnóstico ou dificuldades de resposta ao tratamento, atingem apenas $30 \%$ de chance de sobrevida (Brasil \& Instituto Ronald McDonald, 2009).

Revela-se, desta forma, que tanto o adoecimento quanto o tratamento oncológico representam uma situação complexa, envolvendo não somente os recursos terapêuticos e tecnológicos refinados da Medicina contemporânea, mas a compreensão que o câncer incide sobre os componentes sociais e psicológicos do paciente. Ao passar pelo cuidado oncológico, a criança e o adolescente experimentam as mais diversas situações adversas e vulnerabilizantes. Sua rotina de vida passa a implicar, entre outras experiências: realização de procedimentos invasivos em exames laboratoriais ou administração de medicação via endovenosa ou em intervenções cirúrgicas; rupturas no cotidiano (que passa a ter maior foco no ambiente hospitalar); modificação das relações familiares e sociais; alteração no brincar e na convivência com a escola; modificação da autoimagem; efeitos adversos gerados pelo tratamento, além de momentos agudos de angústia e temor da morte (Mitchell, Clarke \& Sloper, 2006; SIOP, 2009).

Desta maneira é possível apontar que, ao adoecer, o paciente de oncologia pediátrica sofre pressões no processo de desenvolvimento, uma vez que é exposto à extensa gama de riscos biológicos, sociais e psíquicos. Conforme esclarecem Kurtz e Abrams (2011), as reações aos fatores de risco e aos impactos sobre o processo evolutivo variarão conforme o tipo de câncer que acometeu a pessoa, bem como faixa etária do paciente pediátrico, com prevalência das características próprias das conquistas do desenvolvimento até então adquiridas pela criança (em idade pré-escolar, idade escolar ou na adolescência).

Dentro da diversidade de variáveis envolvidas no modo dos indivíduos se adaptarem às vivencias produzidas a partir do diagnóstico de neoplasia, as características de personalidade também exercem reconhecida influência (Diehl \& Hay, 2013; Peres \& Santos, 2009). Quando se focaliza a etapa da infância e da adolescência, as variáveis dos mecanismos adaptativos dos indivíduos diante do quadro oncológico são múltiplas e mutuamente 
relevantes, pois se trata de um período onde as bases estruturais da personalidade estão em formação.

Não obstante, Nascimento, Rocha, Hayes e Lima (2005) esclarecem que as estratégias utilizadas pelos pais e demais familiares no intuito de se adaptarem às repercussões do adoecimento oncológico se constituem como apoio fundamental para o filho enfermo estabelecer possibilidades de lidar com as repercussões biopsicossociais do diagnóstico e consequente processo de cuidado. Assim sendo, a vida do grupo parental e o suporte que a família oferece pode desempenhar, ao longo desta vivência, papel fundamental na organização psíquica da criança e do adolescente com câncer.

Ao considerar a relevância da relação entre a capacidade da família se relacionar com os eventos estressantes e adversos próprios do universo da Oncologia Pediátrica e oferecer apoio à criança e o adolescente que padecem, faz-se relevante examinar essas variáveis a partir da literatura científica da área. Os recursos familiares podem favorecer (ou não) a elaboração psíquica do jovem paciente que vivencia o adoecimento oncológico e cuidado em saúde, elementos a seguir explorados.

\subsection{Família e suporte familiar diante do cuidado oncológico}

Ao se servir de representações gráficas e artísticas, Ariès (1986) desenha a análise acerca da evolução e das transformações no conceito e na vivência da família ao longo da história da civilização ocidental nos últimos séculos, bem como nas modificações da relação deste grupo social com a criança. Segundo as observações tecidas pelo autor, durante a Idade Média, era costume na Europa que os filhos entre sete e nove anos fossem levados ao serviço de outras famílias, com o intuito de aprenderem a executar atividades domésticas e de ofício laboral em uma postura de servidão que chegava a perdurar até dez anos. Nota-se que, tanto entre a classe camponesa quanto entre nobres, a tônica das relações não tinha como foco principal o afeto, mas sim as obrigações sociais e morais, buscando a manutenção da linhagem e do prestígio já obtido por esta.

Ainda segundo este autor, a partir do século XVI, houve uma série de modificações no contexto familiar, impulsionadas por múltiplas variáveis. Entre elas destacou: a difusão da instituição escolar orientada por um conceito moderno de educação; a alteração da cultura de dedicação exclusiva do patrimônio da família para um filho preferido em detrimento dos outros, tomando por base o ideal que todos os filhos devem ser tratados de forma semelhante; a manutenção da proximidade da figura do filho junto a sua família de origem; o fechamento 
do grupo familiar em torno da sua vida privada, passando os acontecimentos domésticos a se distanciarem da vida pública e comunitária, movimento inspirado nas ideias dominantes derivadas da ascensão da burguesia. Esse conjunto de acontecimentos e mudanças permitiu o estabelecimento da criança como figura relevante e merecedora da atenção da família. Passouse a consagrar o afeto como base fundamental das relações estabelecidas entre os diversos componentes do grupo familiar, além do estabelecimento de expectativas dos papéis que estes deveriam desempenhar junto à família (Ariès, 1986).

Todavia, o ideal sacralizado como o hegemônico modelo de família sofre importantes revisões a partir do fim do século XX, passando a manifestar gama variada de constituições, dinâmicas, personagens e papéis. Tomando como ponto de partida a reflexão sobre a manifestação da normalidade ou anormalidade na família contemporânea, Walsh (2016) considera que a grande variabilidade e complexidade de padrões de estabelecimento da família podem gerar a sensação que essa instituição social se encontra ameaçada. Todavia, longe de encontrar seu fim como organização fundamental em nossa civilização, a unidade familiar vivencia revisões em seus princípios, incorporando as mais recentes transformações nas expectativas sobre os papéis de gênero, a ampliação de modalidades de relações afetivas e do estabelecimento de parentalidade. Desse modo, contribui para integrar, na vida cotidiana, ampla diversidade cultural em uma mesma sociedade, bem como a variabilidade da realidade econômica de diversos estratos sociais. Nas palavras de Walsh (2016): "construindo uma variedade de arranjos domésticos e de parentesco, elas estão criando novas estratégias de relacionamento para adequarem suas aspirações e seus desafios, inventando novos modelos de conectividade humana" (p. 23).

Mesmo que no cenário nacional existam controvérsias em torno do tema, com tensões entre diversos grupos socioculturais e choques entre alas mais modernas da sociedade e grupos de origem conservadora, a promulgação da Lei no 11.340, de 2006, em seu Artigo $5^{\circ}$, postula o que deve ser entendido como família no Brasil. De acordo com essa lei, família corresponde à unidade comunitária constituída por pessoas que se ligam por tempo permanente ou transitório, e constituem vínculos tomando por base laços sanguíneos, empatia ou vontade, de forma a estabelecer uma relação de mútuo afeto, sem que os papéis assumidos dentro deste grupo sejam marcados por questões de gênero ou orientação sexual (Brasil, 2006).

Com relação à função da família na vida da pessoa, Bronfenbrenner (2011) postula que, em sua essência, esta estrutura tem como função básica favorecer o desenvolvimento de seus membros pela intermediação entre a pessoa e os micros e macros contextos. Sendo 
assim, a postura de engajamento, dedicação afetuosa e cuidado interessado exercida por membros mais velhos do grupo, oferece apoio para que a criança desenvolva competências para compreender, se adaptar e transformar os diversos cenários com o qual se depara ao longo de sua biografia.

Neste sentido, família poder ser compreendida como um grupo de pessoas que se interessam em promover o bem-estar uns dos outros. Proporciona o exercício de atividades tipicamente humanas, como a manutenção do trabalho, o exercício do intelecto e da afetividade, e o desempenho a contento de funções sociais e fisiológicas ao longo das etapas que compõem o ciclo vital (Bronfenbrener, 1996).

Santos, Martineli e Monteiro (2012) ponderam que, pelo estabelecimento das relações cotidianas e a manutenção de interesse mútuo, ocorre produção de suporte ao indivíduo. Neste sentido, a múltipla organização estabelecida entre os membros de uma família, o investimento de tempo para manter processos interativos que propiciem intimidade e compartilhamento de afetos, a oferta de recursos que se ajustem as reais necessidades da criança, configuram variáveis relevantes. A postura de encorajamento e apoio, ausência de conflitos, associada ao envolvimento dos pais na vida escolar e social dos filhos, pode propiciar o desenvolvimento cognitivo e socioafetivo dos filhos, sendo nomeado como suporte familiar.

A respeito do papel do suporte familiar na vida da criança, Ferriolli, Marturano e Puntel (2007) conduziram um estudo transversal com 100 crianças, com idade variando entre seis e 12 anos e seus familiares, com o intuito de explorar a associação de condições familiares e o risco de desenvolvimento de indicadores de problemas comportamentais ou afetivos que configurassem algum tipo de transtorno mental. Administraram junto aos familiares: Questionário de Capacidades e Dificuldades (SDQ), Inventário de Recursos do Ambiente Familiar (RAF), Escala de Eventos Adversos (EEA), escala de nível socioeconômico e cultural, Inventário de Sintomas de Estresse para Adultos (ISSL) e Inventário de Depressão de Beck (BDI). Identificaram resultados de associação entre a ansiedade na criança e o estresse materno, problemas de conduta e indicadores de organização da rotina diária. Os sintomas de hiperatividade e déficit de atenção mostraram-se relacionados ao processo de supervisão de atividades cotidianas dos filhos exercido pela família, além de importante ligação com instabilidade financeira.

Outros estudos dessa área buscam correlacionar especificidades do comportamento, afetividade e senso social de crianças com a disposição e aproveitamento de recursos ambientais e do contexto doméstico, bem como as relações familiares e práticas educativas. Assim, Wodehouse e McGill (2009), Trivette, Dunst e Hamby (2010), Bolsoni-Silva e 
Loureiro (2011), Anaby, Hand, Bradley, DiRezze, Forhan, DiGiacomo e Law (2013), estabelecem que o suporte familiar pode atuar como importante mediador de eventos adversos ou vulnerabilizantes, tanto no sentido de produzir pressões no desenvolvimento socioafetivo, quanto atuar como recurso para a elaboração de estratégia de adaptação e enfrentamento de experiências extremas.

Com base nessas informações, há que considerar que, ao se deparar com o adoecimento oncológico, a dinâmica da família pode experimentar alterações marcantes. Lopes e Valle (2010) caracterizaram o diagnóstico como tempo de catástrofe, sendo que a partir deste evento é inserida no sistema familiar alta carga emocional. As emoções variam da angústia e do desamparo à esperança, demandando intensos esforços para elaboração destes sentimentos e significados, bem como a compreensão da dinâmica do processo de cuidado oncológico e da rotina da instituição hospitalar, exigindo a reestruturação das relações intragrupo, da rotina da vida cotidiana conhecida, bem como da forma como cada membro da família encara o ente que padece, e a forma como experimentam o desafio do cuidado em face do temor da finitude.

Em complemento, ao revisarem a literatura específica da área, Kohlsdorf e Costa Júnior (2008) apontam que o câncer infantojuvenil é um fenômeno que envolve uma prolongada convivência com procedimentos invasivos e com o ambiente de enfermaria e ambulatório hospitalar. Assim, pelas repercussões que esta experiência pode causar, seria relevante que os pais produzissem respostas comportamentais e afetivas propiciadoras de ajustamento psíquico à situação. No entanto, as reações parentais naturalmente variam de um polo mais organizado e favorecedor, até estratégias de enfrentamento pouco adaptadas que podem se configurar como manifestações de suas próprias psicopatologias.

Para estudar a repercussão do câncer pediátrico sobre a família, Creswell, Wisk, Litzekman, Alchin e Whitney (2014) compararam dois grupos: um com 75 crianças e adolescentes, com idade entre dois a 18 anos, diagnosticados com tumor em sistema nervoso central, bem como seus pais; outro grupo composto por 140 crianças hígidas e seus pais. Buscaram correlacionar o papel de cuidador familiar e condições financeiras à prevalência de depressão nos filhos. Utilizaram uma escala de avaliação de depressão infantil (The Center for Epidemiologic Studies Depression Scale - CES-D10) e uma escala de eventos de vida (Life Events Questionnaire), acrescido de avaliação socioeconômica. Os resultados apontaram que a tarefa do cuidado da criança/adolescente com câncer associou-se de modo relevante à probabilidade de desenvolvimento de sintomas depressivos no paciente, assim como dificuldades financeiras nestas famílias. 
Outro foco de interesse de pesquisadores na área é a interação do modo de adaptação e enfrentamento estabelecido por pais e outros membros da família com o processo de elaboração e resposta aos desafios do adoecimento por parte da criança e adolescente que passa pelo cuidado oncológico. Assim, Robinson, Gerhardt, Vannata e Noll (2007), ao estudarem 95 crianças e seus familiares (97 mães e 77 pais), encontraram forte correlação entre a repercussão afetiva do adoecimento oncológico nos pais com o tipo de percepção de sofrimento de seus filhos. Identificaram ainda que a disponibilidade de recursos do ambiente doméstico funcionou como importante moderador do sofrimento.

Efeito semelhante foi detectado pelo estudo desenvolvido por Hildrenbrand, Clawson, Alderfer e Marsac (2011). Desenvolveram pesquisa qualitativa a partir de entrevistas semiestruturadas com 15 crianças em processo de cuidado oncológico, acompanhadas de seus pais, identificando e agrupando os estressores pertinentes ao acompanhamento especializado em saúde, bem como os tipos de estratégias de enfrentamento. Seus resultados apontaram que as figuras parentais podem ampliar ou limitar o repertório de atitudes e posturas comportamentais e emocionais do filho em resposta às adversidades derivadas da convivência com o câncer pediátrico.

Deste modo é viável apontar para um duplo papel atribuído à família no contexto da oncologia pediátrica. Numa primeira perspectiva, o grupo familiar é alvo de repercussões afetivas, comportamentais, interacionais, sociais e econômicas advindas do confronto com a experiência de adoecimento e cuidado. Numa segunda análise, o grupo familiar pode ser compreendido como instância promotora de condições para a criança e o adolescente conseguirem estabelecer relações favoráveis com os eventos adversos e vulnerabilizantes advindos do câncer e seu universo de relações.

Conforme elucidam Patenaude e Kupst (2005), Murphy, Flowers, McNamara e Young-Saleme (2008), Rosemberg, Baker, Syrjala, Back e Wolfe (2013), Roserbemrg et al. (2014), Klein et al. (2017), mesmo que a família tenha por horizonte a necessidade de lidar rotineiramente com o sofrimento derivado das perdas reais e simbólicas, o ativo oferecimento de apoio familiar ao paciente pediátrico atua como variável favorecedora de positivo desfecho no desenvolvimento infantojuvenil, compatível com o esperado para seu grupo socioeconômico de referência. Deste modo, a comunicação franca, a manutenção da proximidade nas relações interpessoais, a adaptabilidade social, a mediação da família no estabelecimento de papéis sociais, o estímulo à manutenção da rotina habitual, a estimulação das competências do desenvolvimento global, além de atribuição de significado às experiências inerentes ao cuidado oncológico, podem favorecer a adaptação da criança e do 
adolescente. Esse processo, no entanto, fica permeado por situações de risco e adversidade, mas com claras evidências da relevância do suporte familiar para preservar o percurso de vida de crianças e adolescentes em relação ao tipicamente esperado para essa faixa etária.

Esses achados acompanham as concepções das estratégias familiares voltadas à resiliência, tal qual apontam Seibel e Koller (2015) e Walsh (2016). Deste modo o aproveitamento de recursos e rede de apoio sociofamiliar, acrescida de coesão ecológica que pode ser entendida como a possibilidade de pelo menos um adulto estabelecer vínculo e postura protetora e afetivamente engajada, pode oferecer condições para a criança e o adolescente reestabelecerem as condições necessárias para seu desenvolvimento.

Após esta breve exploração acerca da experiência da família no processo de convivência com o adoecimento e cuidado oncológico, passaremos a abordar um terceiro elemento relevante em processos adaptativos. Tratam-se das características pessoais de crianças e adolescentes, conferindo ênfase às variáveis de personalidade em sua relação com eventos e mecanismos protetores às adversidades no contexto do câncer infantojuvenil.

\subsection{Processos adaptativos frente ao câncer infantojuvenil}

Com base nas considerações prévias, buscou-se examinar como a literatura científica compreende a interação dos fatores de risco e de proteção no processo evolutivo da criança e do adolescente, e como características de personalidade podem colaborar com a formação da resiliência ou favorecer a vulnerabilidade. Para tanto foi realizada pesquisa bibliográfica na base de dados MEDLINE e PsycINFO, selecionando publicações em periódicos de língua inglesa, portuguesa e espanhola, utilizando os termos neoplasm, child, adolescent e personality. Devido à especificidade do assunto e a aparente escassez de estudos na área, foi estabelecido um amplo intervalo de tempo de publicação dos estudos, buscando-se, então, por artigos publicados entre o ano de 2004 e 2018.

Foram encontradas 29 publicações relacionando esses termos técnicos, apontando relevante investimento científico nessa área. A análise do conteúdo desses artigos apontou que os estudos se voltam prioritariamente à avaliação do impacto do câncer sobre os familiares, além da inspeção do nível de estresse, ansiedade e depressão em crianças e adolescentes afetados pelo câncer, bem como seus estilos comportamentais adaptativos frente à enfermidade, porém com reduzida explanação sobre características de personalidade. A maioria dessas pesquisas recorreu a escalas e instrumentos de autorrelato como estratégia metodológica da investigação. 
Foi possível notar poucos estudos sistematizados dirigidos ao tema dos possíveis efeitos dos eventos adversos advindos de condições próprias da vivência de intervenções hospitalares e repercussões do cuidado, bem como eventos estressores de natureza psicossocial sobre o desenvolvimento da criança e do adolescente com câncer. Do mesmo modo, as informações sobre o papel da dinâmica e da estrutura da personalidade no processo da construção de estratégias de adaptação à doença e ao seu tratamento, relativas ao processo de resiliência, foram pouco explanadas. A seguir, serão reunidos alguns dos principais achados dos estudos encontrados nesse levantamento da literatura científica, livremente organizados por sua temática central.

Ao tentar compreender a relação entre características de personalidade e qualidade de vida e saúde, Husson, Zebrack, Block, Embry, Aguilar, Hayes-Lattin e Cole (2017) realizaram estudo multicêntrico e longitudinal com 165 adolescentes e jovens adultos em várias etapas após o diagnóstico oncológico. Este grupo foi avaliado por escalas relativas à qualidade de vida, estresse, condições psicossociais, e avaliação da personalidade. Esse processo de investigação apontou que o único traço de personalidade que estaria mais fortemente associado a prejuízos na qualidade de vida seria o neuroticismo. Essa característica de personalidade, de acordo com o estudo, favoreceria propensão à vivência de angústia e ansiedade, sofrimento psíquico que, por sua vez, poderia negativamente influenciar as condições de saúde mental dos pacientes em seu curso de tratamento do câncer.

Trentacosta, Harper, Albrecht, Taub, Phipps e Penner (2016) exploraram a influência da personalidade e temperamento de crianças com o diagnóstico de neoplasia diante de procedimentos invasivos. Participaram desta pesquisa 147 crianças vivenciando processo de assistência em saúde devido à doença neoplásica, bem como seus pais. Eles foram avaliados por escalas e inventários de temperamento e personalidade logo após a entrada no serviço hospitalar e após a realização de exames clínicos caracterizados como invasivos. Como achados principais os autores apontaram que a habilidade de direcionar o foco da atenção mostrou-se positivamente associada a maior resistência egoica. Comentaram que este mecanismo inibitório de autorregulação (controle do foco atencional) propiciaria menos sofrimento diante de procedimentos dolorosos, bem como poderia, em longo prazo, amenizar experiências de ansiedade.

Destaca-se que fatores estressores e eventos adversos emergem na vida do paciente infantojuvenil a partir do aparecimento dos primeiros sintomas de câncer. Isso exige da criança/adolescente, mesmo antes da definição diagnóstica, estratégias para lidar com os desafios que surgem em decorrência da enfermidade e dos cuidados necessários para com sua 
saúde. Nesse processo, Peçanha (2008) argumenta que sinais de positiva adaptação e resiliência podem emergir em diferentes formatos frente ao câncer, assumindo características de realização ostensiva de tarefas e atitudes permeadas por iniciativa, por exemplo. Outra alternativa seria o comportamento de evitação e/ou alteração do afeto associado à experiência psíquica vivenciada, com intuito de modificar a situação que se mostra nociva.

Em seus estudos, Clercq, Fruyt, Koot, Benoit (2004), Phipps (2007) e Williams, Allen e Phipps (2011) descrevem que crianças diagnosticadas com enfermidades neoplásicas apresentaram respostas adaptativas a fatores de risco e situações estressantes que se assemelham aos padrões de resposta de indivíduos saudáveis. Segundo achados desses pesquisadores, muitas vezes essas crianças superam seus respectivos grupos de comparação, alcançando melhor índice de qualidade de vida e níveis adaptativos diante do estresse póstraumático, ansiedade e depressão. Os autores justificaram esses resultados assinalando que pessoas portadoras de câncer na infância adotariam um modelo adaptativo repressivo, além de avaliar positivamente seus sentimentos. Deste modo, haveria baixo nível de angústia e melhor percepção de alterações afetivas e comportamentais, fortalecendo seus recursos desenvolvimentais.

Ao se debruçar sobre o estudo da depressão e do câncer na criança e no adolescente, Dejong e Fobonne (2006) apontaram que a família pode atuar como facilitador do enfrentamento da enfermidade. Argumentaram ainda que a dinâmica e o funcionamento do grupo familiar podem favorecer ou ser um empecilho à adaptação e ao desenvolvimento do paciente ao longo do tratamento. De modo complementar, Durualp e Altau (2012) ponderaram que mesmo sem identificar diferenças significativas entre grupo que convive com o câncer infantojuvenil e grupo saudável, é possível captar indicadores emocionais de intensa mobilização afetiva naqueles expostos aos cuidados oncológicos. Destacaram, por exemplo, detecção clínica de recorrentes indicadores de vivência de raiva, insegurança e impulsividade entre crianças/adolescentes em tratamento de câncer.

Em acréscimo a estes achados, Miller et al. (2009) problematizam a influência das características da personalidade no processo de elaboração da resiliência e na utilização particular dos fatores de proteção para lidar com os mecanismos de risco vividos por crianças e adolescentes com câncer. Argumentam que, além do modelo adaptativo repressivo frente ao processo de vulnerabilização pelo quadro oncológico, estariam também em jogo estratégias de enfrentamento utilizadas em complexos contextos de vida. Nesse sentido, variáveis internas dos indivíduos exerceriam importante influência no processo adaptativo, destacando como facilitadores a capacidade de entusiasmo e de engajamento com seu ambiente, a possibilidade 
do indivíduo vivenciar sensações angustiantes e conflituosas, as tentativas de controle de reações diante do mundo e as sensações vividas em seu íntimo. Por fim, esclarecem que estes recursos estariam sedimentados no conjunto das potencialidades cognitivas, emocionais, comportamentais e fisiológicas presentes na pessoa, sugerindo claro efeito da personalidade nesse processo de enfrentamento do câncer.

Em trabalho dirigido à investigação do câncer em crianças, Harper, Penner, Peterson, Albrecht e Taub (2012) introduzem a relevância de se compreender o processo de resiliência levando em consideração não somente as reações do indivíduo a estímulos estressantes ou desagradáveis, mas o modo pelo qual a família e os pais lidam com o jovem paciente. Os achados desses pesquisadores apontam que o acolhimento e a postura empática dos pais às reações de seus filhos, mantendo-se mais atentos à variabilidade de reações comportamentais e afetivas do familiar, tende a mediar e a favorecer a compreensão e a aceitação, pelas crianças, da vivência de eventos dolorosos e angustiantes pertinentes aos procedimentos terapêuticos necessários.

A partir desta breve exposição de alguns trabalhos identificados em levantamento da literatura científica sobre o tema, torna-se possível detectar lacuna no tocante ao estudo de influências de características da personalidade em crianças e adolescentes com câncer sobre a vivência de elementos de risco e possíveis fatores de proteção presentes em suas experiências. Essa diversidade de estressores e/ou variáveis significativas no desenvolvimento pode ser gerada pelo contexto do cuidado e sofre influência da família e de seus membros que assumem o papel do cuidado, favorecendo ou não a capacidade de elaboração da experiência em prol da proteção do desenvolvimento frente ao câncer infantojuvenil, exigindo investigação aprofundada sobre o tema. Nesse processo são escassos os estudos na área com base em métodos projetivos de avaliação psicológica, recurso sacramentado na literatura internacional para a compreensão da personalidade.

Acrescente-se nesse contexto as considerações de Yunes (2003) mostrando que a resiliência não pode ser compreendida como resultado de estática combinação de traços constituintes da personalidade de um indivíduo. Em linhas gerais, a resiliência pode ser descrita como "resultado do processo dinâmico e contínuo de conciliar características individuais ao ambiente, de forma que descreva a qualidade de interação do sujeito com o meio que o cerca" (Zuccolo, Corchs \& Savoia, 2003, p. 8). Com base nesses argumentos, é possível assumir que o processo de formação da resiliência pode estar intimamente ligado à evolução de características essenciais do indivíduo, na mesma proporção em que se 
estabelecem suas interações com os recursos do ambiente e os sistemas familiares, sociais e culturais em que está imerso.

Ao considerar o conjunto de ponderações prévias, bem como os achados empíricos relativos ao impacto do diagnóstico de neoplasia na trajetória de vida, impondo intensa convivência com fatores de risco ao longo do processo de cuidado oncológico, tornam-se evidentes condições especiais ao processo de desenvolvimento infantojuvenil diante do câncer. Com base nesse contexto, torna-se relevante examinar possíveis repercussões destas complexas vivências na organização psíquica da criança e do adolescente e em seu contexto familiar. Desse modo, o foco da presente investigação científica será o exame de fatores de risco e de proteção ao desenvolvimento, incluindo variáveis relativas a recursos pessoais, familiares e características de personalidade de crianças e adolescentes com câncer, sistematicamente avaliadas ao longo de seis meses de cuidados oncológicos. 



\subsection{Objetivo Geral}

Avaliar, longitudinalmente, possíveis efeitos da vivência de adoecimento e cuidado oncológico sobre características de personalidade de crianças e adolescentes, além de identificar condições de adversidade e proteção presentes em seu ambiente familiar, em comparação a crianças e adolescentes saudáveis e com preservados indicadores típicos do desenvolvimento.

\subsection{Objetivos Específicos}

2.2.1. Identificar e caracterizar recursos ambientais e interativos presentes na família que possam atuar como protetivos ao desenvolvimento da personalidade em crianças e adolescentes com diagnóstico de neoplasia, comparativamente a grupo balanceado de indivíduos com desenvolvimento considerado típico para sua faixa etária.

2.2.2. Caracterizar eventos adversos e crônicos de natureza biológica, psíquica e socioeconômica que possam atingir a dinâmica familiar, produzindo eventual influência na adaptação de crianças ou adolescentes ao tratamento oncológico.

2.2.3. Caracterizar a percepção da família acerca do comportamento e desenvolvimento da criança e do adolescente, buscando retratar indicadores de saúde mental que podem repercutir no processo de adaptação de crianças ou adolescentes ao cuidado oncológico.

2.2.4. Avaliar e descrever características de personalidade de crianças e adolescentes em cuidado oncológico, comparativamente a grupo balanceado de indivíduos com desenvolvimento considerado típico.

2.2.5. Avaliar, de forma longitudinal, possíveis efeitos da experiência de adoecimento e de intenso processo de cuidado hospitalar no desenvolvimento dos recursos de personalidade em crianças e adolescentes com câncer. 

O presente trabalho configura-se como um estudo longitudinal, de natureza quantitativa, descritivo-comparativo e interpretativo, a partir de instrumentos de avaliação psicológica. A investigação envolve dois grupos balanceados de crianças e de adolescentes, contrapondo-se grupo clínico e de comparação, examinados em dois momentos distintos de seu desenvolvimento.

\subsection{Participantes}

Diante dos objetivos deste trabalho, foram constituídos dois grupos de crianças e adolescentes na faixa etária de sete a 17 anos, de ambos os sexos, voluntários devidamente autorizados para o estudo, bem como seus respectivos pais e/ou responsáveis (mediante Termo de Consentimento Livre e Esclarecido: APÊNDICE A, e Termo de Assentimento: APÊNDICE B). Para tornar viável o trabalho, a amostra foi composta por conveniência, respeitando-se os critérios de seleção específicos para cada grupo de participantes, como a seguir descrito. É relevante pontuar que a delimitação numérica dos participantes dos grupos do presente trabalho pautou-se por critério de viabilidade prática, além de atender a condições mínimas necessárias para as análises estatísticas implicadas no cumprimento dos objetivos delineados para a presente investigação científica.

\subsubsection{Caracterização do Serviço Clínico em estudo}

O presente estudo foi desenvolvido junto ao Setor de Oncologia e Hematologia Pediátrica do Hospital das Clínicas da Faculdade de Medicina de Ribeirão Preto (HCFMRP/USP) da Universidade de São Paulo. Essa instituição caracteriza-se como hospitalescola público, integrando a rede do Sistema Único de Saúde (SUS). Apesar de sua abrangência circunscrever 26 municípios do interior do estado de São Paulo situados na macrorregião da cidade de Ribeirão Preto, por ser uma unidade hospitalar de referência no cuidado especializado de doenças graves e situações raras no campo da saúde, recebe pacientes encaminhados pela rede pública de outras regiões do estado e do país.

Dentro do rol de especialidades e serviços de atenção em saúde presentes na instituição, essa conta com uma unidade especializada em pediatria e puericultura denominada HC Criança. Voltado exclusivamente para pacientes de zero a 18 anos, o HC Criança é composto por 72 consultórios e 233 leitos, dispostos em cinco pavimentos por onde se distribuem ambulatório, enfermarias, centro obstétrico, alojamento conjunto, UTI Neonatal 
e UTI Pediátrica. Nesta unidade de pediatria estão à disposição 75 diferentes especialidades, formadas por equipes multiprofissionais, que por sua vez realizam 70 mil consultas mensais, atendendo aproximadamente 350 pacientes por dia (São Paulo, 2017).

É justamente neste contexto que se insere o Setor de Oncologia e Hematologia. Criado no ano de 1982, atualmente é constituído por equipe multidisciplinar composta por profissionais da área da Medicina, Enfermagem, Psicologia, Terapia Ocupacional, Fisioterapia, Odontologia, Nutrição e Serviço Social. No período de janeiro de 2016 a dezembro de 2017, prestou assistência a 250 pessoas de zero a 19 anos por ano, com ingresso de 143 novos casos no público assistido nesse referido biênio.

A assistência hospitalar pode se dar tanto em regime ambulatorial, quanto em enfermaria. O Ambulatório de Oncologia Pediátrica (AOPE) volta-se ao cuidado biopsicossocial de crianças e adolescentes que estão em investigação diagnóstica ou já se encontram em cuidado oncológico com objetivo curativo ou não. Além das consultas especializadas, quando necessário, os jovens pacientes realizam exames laboratoriais ou de imagem, assim como realizam tratamento quimioterápico e radioterápico quando indicado.

O serviço também conta com o Ambulatório de Hematologia Infantil (AHEI), responsável não só por acompanhar pacientes que convivem com enfermidades hematológicas, mas também pessoas que tenham usufruído cuidado oncológico na infância e adolescência e já se encontram fora de tratamento. Esta modalidade de assistência tem por objetivo manter vigilância sobre possíveis recidivas do câncer infantojuvenil, além de acompanhar possíveis efeitos tardios produzidos pelo próprio tratamento.

A unidade de internação é situada na enfermaria pediátrica do HC Criança. Oito leitos são destinados aos usuários desta especialidade que necessitam de maior atenção na investigação diagnóstica, realização de procedimentos cirúrgicos invasivos, utilização de quimioterápicos que exigem maior atenção e monitoramento do estado geral, cuidado a efeitos adversos do próprio tratamento, intercorrências no quadro de saúde ou pioras clínicas, além do cuidado de fim de vida.

A rotina do paciente pediátrico e sua família no Serviço de Oncologia e Hematologia Pediátrica irá sempre variar conforme seu diagnóstico, etapa do cuidado, estado geral e bemestar, focalizando suas necessidades de intervenção em saúde. Portanto, enquanto muitas crianças e adolescentes têm apenas consultas e sessões de quimioterapia quinzenais ou mensais, outros usuários do serviço enfrentam longas internações para administração de 
medicamentos ou devido às intercorrências em seu quadro de saúde, ou têm diversos retornos agendados mais de uma vez na mesma semana.

É importante ressaltar que o Serviço de Oncologia e Hematologia Pediátrica conta com um psicólogo contratado, atuando com carga horária de 30 horas semanais, além de estagiários e aprimorandos que desenvolvem a atividade de ensino e assistência. Entre suas funções está oferecer apoio e assistência para todas as crianças e os adolescentes ali cuidados, bem como seus familiares, dentro dos princípios e modelo da Psicologia Hospitalar. Isso se passa ao longo do período de investigação diagnóstica, comunicação diagnóstica, processo de cuidado oncológico, sobrevivência, recidiva ou cuidado de fim de vida, além de luto dos familiares em todas as dependências da unidade hospitalar. Por meio da atenção individual, familiar, grupal, articulação interdisciplinar com profissionais da equipe, e interação profissional com equipamentos e instituição da rede do município de origem, busca-se promover e proteger as condições do desenvolvimento infantojuvenil em face da experiência de adoecimento e tratamento.

\subsubsection{Grupo Clínico $(G 1, n=30)$}

O Grupo Clínico (G1) desse estudo foi formado por crianças e adolescentes com diagnóstico oncológico e em tratamento no Serviço de Oncologia e Hematologia Pediátrica do Hospital das Clínicas da Faculdade de Medicina de Ribeirão Preto da Universidade de São Paulo (HC-FMRP/USP). O trabalho foi devidamente autorizado por essa instituição, como evidencia o ANEXO 1.

Adotou-se como critério de inclusão neste grupo o tempo mínimo de um mês de definição diagnóstica de neoplasia nos pacientes do referido serviço. Como descrevem Dejong e Fobonne (2006), o momento posterior à notícia diagnóstica exige esforços adaptativos ao novo contexto no qual a pessoa se insere, trazendo importante instabilidade emocional, além de repercussões na organização familiar. Em acréscimo, no prazo de quatro semanas a três meses já são observáveis os efeitos do processo de organização do jovem paciente e sua família diante dos desafios pertinentes a nova rotina de vida imposta pelo tratamento (Eiser, Eiser, \& Stride, 2005; Landolt et al., 2006). Deste modo, justificou-se a adoção do tempo mínimo de diagnóstico para esta pesquisa, uma vez que este período (um mês) é relevante para que se estabeleça o processo de adaptação ao câncer e a seu processo de cuidado, foco do presente trabalho. 
Foram excluídas crianças e adolescentes que receberam diagnóstico de Leucemia Mieloide Crônica, uma vez que após o diagnóstico deste tipo de neoplasia o tratamento assume característica crônica, sem necessitar de internações ou retornos ambulatoriais constantes, com manutenção do cotidiano de vida do paciente e de seus familiares. De forma semelhante, foram desconsiderados potenciais voluntários com diagnóstico de doença neoplásica que comprometa a percepção ou que afete a capacidade cognitiva da criança ou adolescente.

Outro critério de exclusão adotado se refere à etapa do processo de cuidado oncológico em que o jovem paciente se encontrava. Assim, foram excluídos da composição da amostra aqueles em situação de impossibilidade de cura com prejuízo na qualidade de vida e cuidados de fim de vida, durante/após transplante de medula óssea, uma vez que estas vivências podem ser caracterizadas como situações agudas e de excessiva vulnerabilidade para suportarem também o processo de investigação científica. A fim de garantir a preservação de tais condições para inclusão e exclusão de participantes neste grupo amostral, a equipe de assistência em saúde responsável pelo cuidado oncológico foi previamente consultada com o objetivo de fornecer parecer técnico sobre a etapa do tratamento em que o paciente oncológico se encontrava, além de esclarecimentos sobre os impactos da doença neoplásica ou a terapêutica no processo de percepção e cognição do potencial colaborador.

No período de coleta de dados deste trabalho, o serviço de saúde prestava assistência a 100 pacientes, dos quais 35 tinham características compatíveis com o delineado por este estudo. Deste montante, 34 pessoas foram pessoalmente convidadas pelo pesquisador a colaborar, com a recusa de uma criança. Ademais, dois participantes foram excluídos por resultados pouco válidos em um dos instrumentos utilizados (três ou mais recusas no método de Rorschach).

O percurso amostral efetivado no grupo clínico pode ser esquematicamente visualizado na Figura 1. 


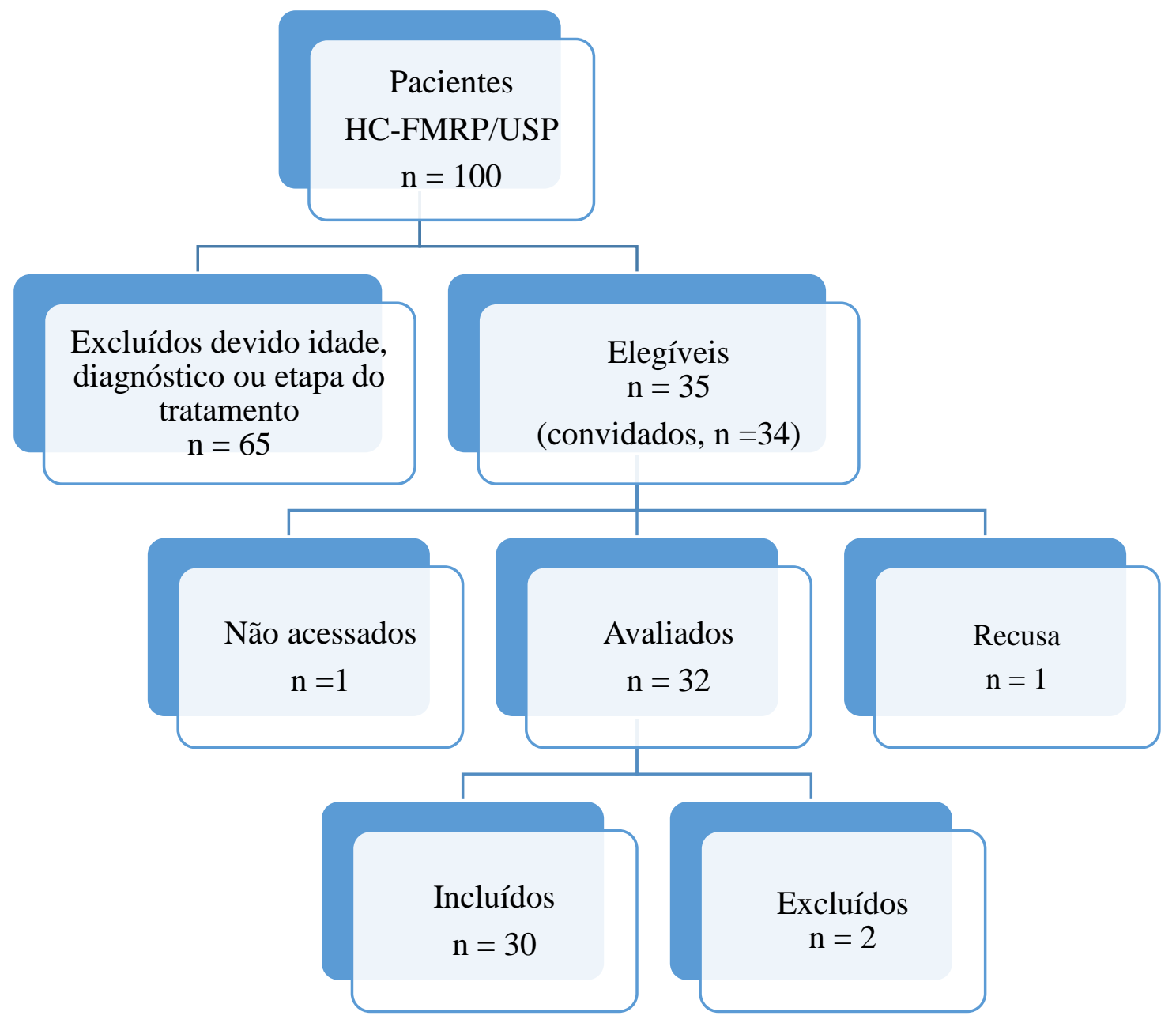

Figura 1. Percurso amostral do grupo clínico $(\mathrm{n}=30)$

O Grupo Clínico (G1) ficou constituído de pacientes com idade média de 12,0 anos $( \pm 2,8)$ na primeira fase do estudo, e 12,6 anos $( \pm 2,8)$ na segunda fase. Com relação à procedência, 93,3\% eram provenientes da região nordeste do estado de São Paulo, e 6,6\% de outras regiões do Brasil.

Ao examinarmos o tempo de diagnóstico de neoplasia entre os participantes do estudo na primeira avaliação (Fase 1), verifica-se que 13 tinham entre um e três meses de descoberta da doença $(43,0 \%)$, nove colaboradores entre quatro e 12 meses $(30,0 \%)$, e oito participantes entre 13 e 31 meses de diagnóstico. Assim, em G1 houve média de 9,3 meses $( \pm 9,1)$ de tempo de detecção da doença. Com relação ao tempo de diagnóstico no período da segunda avaliação (Fase 2), 17 participantes receberam o diagnóstico entre sete a 12 meses (57\%), oito pessoas tinham detectado a doença em um intervalo de tempo entre 13 a 24 meses (27\%), enquanto cinco participantes tinham entre 24 a 35 meses de diagnóstico (16\%). Nesse 
segundo momento avaliativo, o grupo clínico possuía média de 15,4 meses $( \pm 8,9)$ de determinação da doença neoplásica.

Cabe destacar que o diagnóstico oncológico em crianças e adolescentes traz consigo o início imediato da terapêutica. Portanto, o tempo de identificação do tipo de câncer ao qual o paciente pediátrico é portador também corresponde ao tempo de administração do cuidado hospitalar multidisciplinar nesses casos.

No tocante à natureza do diagnóstico clínico, a Figura 2 apresenta a distribuição dos casos em função do tipo de câncer.

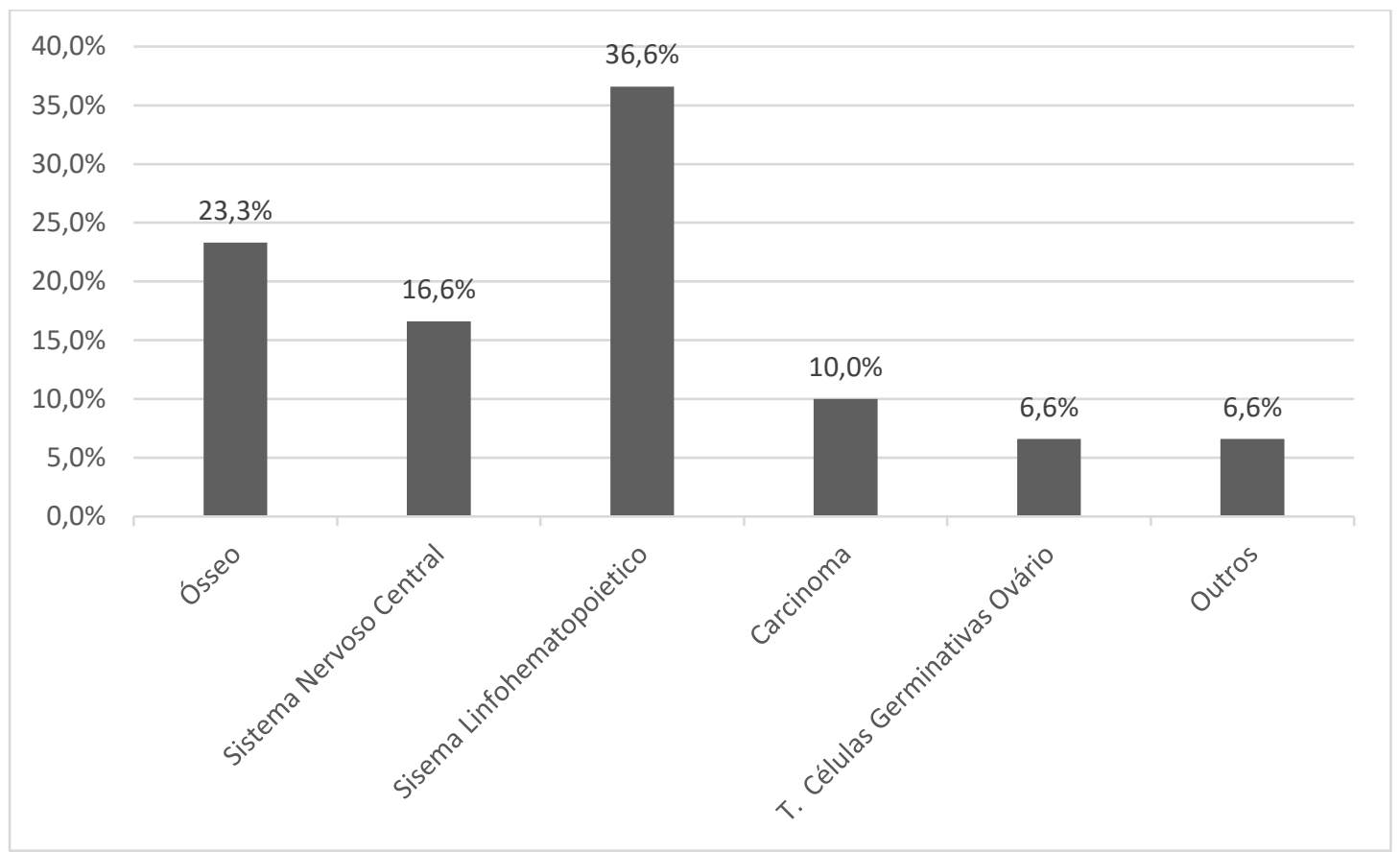

Figura 2. Distribuição (em porcentagem) dos participantes do Grupo Clínico (n=30) em função do diagnóstico oncológico.

Nota-se que, do total dos participantes, 11 apresentavam neoplasia no Sistema Linfohematopoiético, ou seja, Leucemias e Linfomas (36,6\%), sete foram diagnosticados com tumores ósseos (23,3\%), cinco com neoplasias de Sistema Nervoso Central (16,6\%), três com Carcinomas (10,0\%), dois portavam Tumor de Células Germinativas em Ovário (6,6\%), e dois apresentavam outros tipos de diagnóstico oncológico $(6,6 \%)$. Em todos os casos de G1 foi possível a coleta de dados nos dois momentos do estudo, permanecendo o total de 30 participantes nesse grupo.

Por levantamento de informações no prontuário de registro do cuidado oncológico destes pacientes, foi possível determinar o perfil do processo de atenção hospitalar no que 
tange a administração de quimioterápico, realização de radioterapia, abordagens cirúrgicas, internação em Centro de Tratamento Intensivo por complicações no quadro de saúde ou recuperação pós-cirúrgica, recidiva da doença neoplásica, diagnóstico de outras patologias em decorrência ou não de efeitos tardios do tratamento, intercorrências graves no estado de saúde do paciente oncológico pediátrico, término de cuidado oncológico devido à criança ou adolescente serem considerados livres da doença. Com relação ao recebimento de quimioterapia e ao tempo deste tipo de intervenção terapêutica apresenta-se a Figura 3.

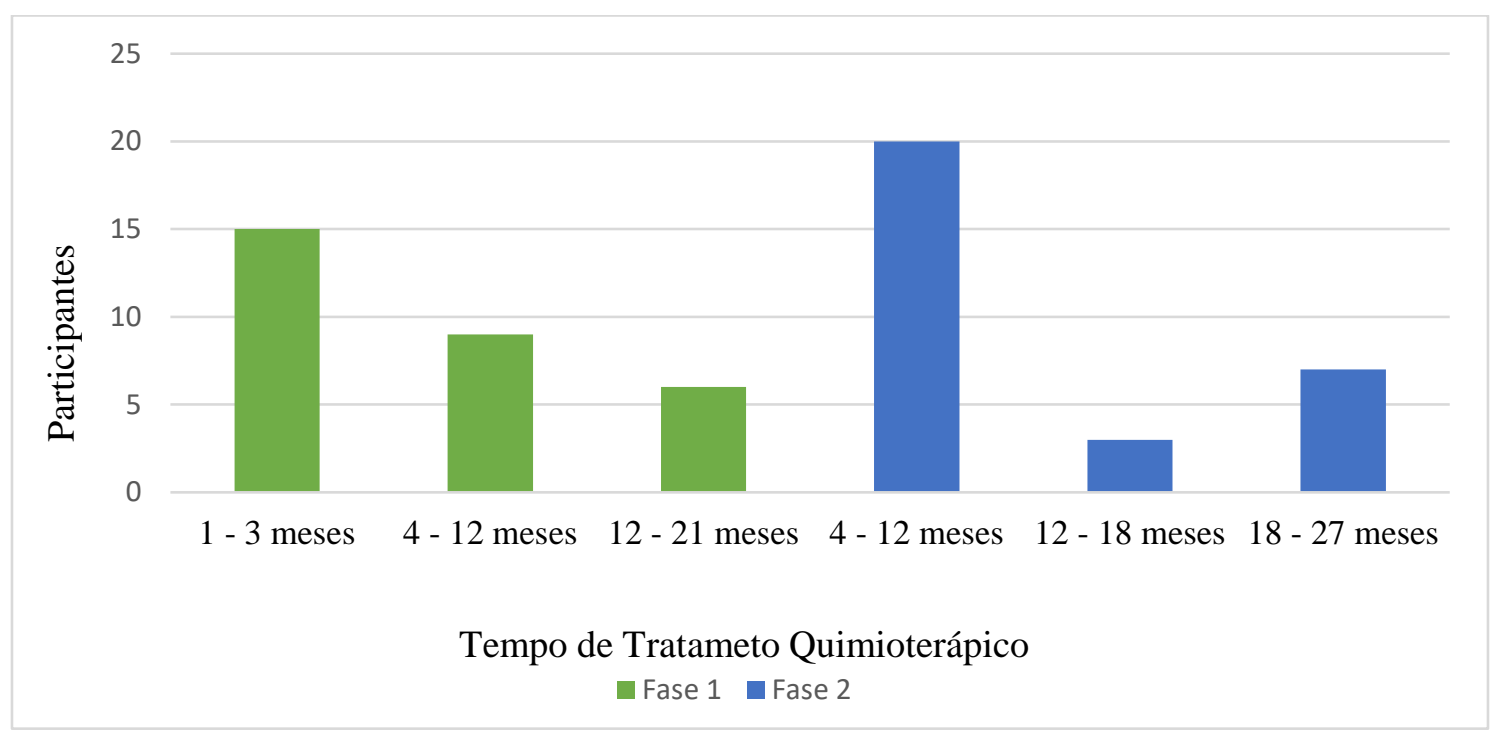

Figura 3. Distribuição dos participantes do Grupo Clínico $(n=30)$ em função do tempo da administração de drogas quimioterápicas (em meses).

Nota-se que as crianças e adolescentes participantes do estudo realizavam tratamento quimioterápico durante as duas etapas avaliativas, observando na Fase 1 maior concentração de colaboradores em início do processo de cuidado oncológico (15 participantes), enquanto nove colaboradores passavam por intervenção medicamentosa entre quatro e 12 meses, e seis voluntários do estudo realizavam quimioterapia há mais de 1 ano. Durante a Fase 2, 20 participantes passavam por este tipo de terapêutica entre quatro e 12 meses, três pacientes entre 12 e 18 meses, e sete voluntários realizavam quimioterapia há mais de 18 meses.

A seguir são apresentadas informações acerca da realização de procedimentos cirúrgicos, radioterapia, internação em CTI, intercorrências graves, outras patologias, e recidiva da doença nos dois momentos avaliativos de G1. Esses dados compõem a Tabela 1. 
Tabela 1. Distribuição dos participantes de grupo clínico $(n=30)$ em função de procedimentos clínicos de cuidado e eventos adversos pertinentes ao adoecimento, nas distintas fases avaliativas.

\begin{tabular}{|c|c|c|c|c|}
\hline \multirow[t]{2}{*}{ Variável } & \multicolumn{2}{|c|}{$\begin{array}{l}\text { Fase } 1 \\
(n=30)\end{array}$} & \multicolumn{2}{|c|}{$\begin{array}{l}\text { Fase } 2 \\
(n=30)\end{array}$} \\
\hline & $f$ & $\%$ & $f$ & $\%$ \\
\hline \multicolumn{5}{|l|}{ Cirurgia } \\
\hline Sim & 13 & 43,3 & 18 & 60,0 \\
\hline Não & 17 & 56,7 & 12 & 40,0 \\
\hline \multicolumn{5}{|l|}{ Radioterapia* } \\
\hline Sim & 3 & 10,0 & 5 & 16,7 \\
\hline Não & 27 & 90,0 & 25 & 83,3 \\
\hline \multicolumn{5}{|c|}{ Internação em CTI } \\
\hline Sim & 3 & 10,0 & 3 & 10,0 \\
\hline Não & 27 & 90,0 & 27 & 90,0 \\
\hline \multicolumn{5}{|l|}{ Recidiva } \\
\hline Sim & 4 & 13,3 & 4 & 13,3 \\
\hline Não & 26 & 86,7 & 25 & 83,3 \\
\hline \multicolumn{5}{|c|}{ Intercorrências Graves } \\
\hline Sim & 8 & 26,7 & 8 & 26,7 \\
\hline Não & 22 & 73,3 & 22 & 73,3 \\
\hline \multicolumn{5}{|l|}{ Outras Patologias } \\
\hline Sim & 3 & 10,0 & 4 & 13,3 \\
\hline Não & 27 & 90,0 & 26 & 86,7 \\
\hline
\end{tabular}

*Expresso em semanas de radioterapia.

Nota-se que o desenrolar do cuidado hospitalar em Oncologia Pediátrica é heterogêneo com relação às abordagens e procedimentos de cuidado, uma vez que este sempre variará conforme o tipo de diagnóstico, a idade do paciente e a evolução da neoplasia. Esta afirmação pode ser exemplificada com a frequência de pacientes que sofreram pelo menos uma abordagem cirúrgica (Fase $1=43,3 \%$ e Fase $2=60,0 \%$ ), uma vez que essa intervenção é costumeiramente empregada no tratamento de tumores sólidos. De modo análogo, a realização de radioterapia é indicada em casos específicos de Leucemia ou de Tumores que atinjam tecidos sólidos. Assim, na primeira avaliação, 10,0\% dos pacientes $(n=3)$ havia recebido irradiação terapêutica por período de três a nove semanas, enquanto na segunda etapa avaliativa, $16,7 \%$ dos voluntários $(n=5)$ tinham realizado pelo menos uma semana deste tipo de terapêutica. 
Com relação a eventos adversos ao cuidado oncológico, 10,0\% dos pacientes $(n=3)$ apresentaram internação em Centro de Terapia Intensiva (recuperação cirúrgica ou agravamento no quadro de saúde), enquanto $26,7 \%$ ( $n=8)$ vivenciaram alguma intercorrência grave derivada de efeitos secundários do tratamento. Ressalta-se ainda que ao fim do estudo, $13,3 \%$ dos participantes $(n=4)$ apresentaram outras patologias associadas ao adoecimento oncológico. Em acréscimo, é importante observar que 13,3\% das crianças e adolescentes deste estudo $(n=4)$ possuíam pelo menos um tratamento oncológico prévio, sendo que, no momento da primeira avaliação, estava em curso o cuidado devido à recidiva da doença neoplásica.

Ainda sobre o processo de cuidado oncológico, na segunda fase deste estudo, seis participantes já haviam finalizado com sucesso o tratamento (20,0\%), e permaneciam em acompanhamento longitudinal pelo serviço de saúde com o intuito de manter vigilância de possíveis efeitos tardios do tratamento. Os outros 24 colaboradores $(80,0 \%)$ seguiam em cuidado oncológico em etapas variadas do tratamento, conforme a especificidade de cada caso.

\subsubsection{Grupo de Comparação $(G 2, n=30)$}

O Grupo de Comparação (G2) foi constituído de modo a ser balanceado em relação à idade, sexo e origem escolar (particular ou pública) dos participantes do Grupo Clínico (G1). Outro critério adotado para a inclusão de voluntários em G2 foi a detecção de indicadores de desenvolvimento típico para sua idade, conforme informações obtidas por instrumento específico de avaliação psicológica respondido por seus pais ou responsáveis (SDQ). Desta maneira, não apresentaram indícios patológicos de hiperatividade, sintomas emocionais, problemas de conduta e de relações interpessoais conforme inventário de levantamento de características atuais da saúde mental.

Para busca e recrutamento desses voluntários de G2 foi utilizada a técnica chamada "bola de neve" (por indicações pessoais de conhecidos dos próprios participantes do estudo e da equipe de pesquisadores), de modo a constituírem grupo balanceado em relação a G1. O pesquisador também recorreu a outras estratégias de arregimentação de potenciais voluntários para G2, tais como divulgação da pesquisa em mídias diversas: redes sociais, rádio universitária e em murais de instituições acadêmicas. Por fim, foi estabelecida parceria com uma escola pública, a partir de contato com a equipe pedagógica e diretoria, que auxiliaram na identificação e convite de potenciais participantes de G2. Foi realizada reunião entre diretoria dessa instituição escolar, familiares de estudantes interessados no estudo e pesquisador, com 
intuito de explicar os objetivos do trabalho e agendar a participação dos voluntários devidamente autorizados. Entre aqueles que concordaram com o estudo houve casos que foram avaliados no mesmo dia da reunião, por preferência dos mesmos, em sala reservada da escola. Outros voluntários apenas tiveram suas avaliações agendadas nesta data, em acordo com a diretora e com os pais. Estas avaliações ocorreram em um dia no qual os alunos estavam presentes na escola, mas não tinham atividades curriculares programadas, em espaço adequado cedido pela própria equipe pedagógica.

Foi contatado um total de 45 possíveis voluntários para compor G2 dessa pesquisa. No entanto, não foi possível acessar ou avaliar quatro desses casos. Um desses adveio pela divulgação do estudo em mídias e, os demais, por indicação da escola com a qual se estabeleceu a parceria. Dentre os interessados em participar da pesquisa que entraram em contato com o pesquisador por meio da divulgação midiática, três não eram elegíveis para o estudo. Em um desses casos a criança estava em processo de investigação diagnóstica com suspeita de neoplasia, e nos outros dois casos a origem escolar da criança (escola particular) não correspondia às características do grupo clínico, razão para sua exclusão nesse grupo de comparação.

Entre crianças e adolescentes indicados para participação na pesquisa por contatos pessoais do pesquisador, quatro participantes foram excluídos, pois apresentaram indícios de significativos problemas de saúde mental, a partir de instrumento preenchido junto com os pais ou responsáveis. Nesses casos o pesquisador informou os achados aos respectivos responsáveis e realizou o encaminhamento da criança ou do adolescente para cuidados específicos a suas necessidades.

Assim como no grupo clínico, também foram excluídos os participantes que obtiveram resultados pouco válidos em um dos instrumentos de avaliação psicológica (três ou mais recusas no método de Rorschach). No grupo de comparação, quatro participantes atingiram esta condição, sendo três casos originários dos contatos pessoais, e um decorrente da parceria com a escola.

Transcorrido o intervalo mínimo de seis meses da primeira avaliação, os participantes foram contatados a fim de serem convidados a participar de segunda avaliação (Fase 2). Do total de 30 participantes do Grupo de Comparação, dois participantes haviam mudado de cidade, quatro famílias tinham mudado seu contato telefônico e/ou endereço, impossibilitando a realização do novo convite, três participantes não responderam aos contatos do pesquisador, e um recusou a proposta de nova colaboração. Com isto, a segunda fase de G2 contou com a participação de 20 voluntários. Essa perda de participantes no processo de reavaliação do 
grupo de comparação (G2) pode ser compreendida pelas transformações pertinentes a rotina, a dinâmica familiar e a cidade em que habitam, impossibilitando uma segunda avaliação de alguns participantes. No entanto, o número final de casos permitiu realizar as análises pretendidas.

Devido às perdas de colaboradores ao longo das etapas avaliativas deste estudo, para que fosse possível a conservação dos parâmetros de comparação entre o Grupo Clínico e o Grupo de Comparação, foram considerados como constituintes deste grupo todos aqueles que realizaram as duas avaliações (G2 ficou com $n=20)$. De forma sintética, o percurso amostral realizado no Grupo de Comparação (G2), em seus dois momentos avaliativos (fase 1 e fase 2), pode ser esquematicamente visualizado na Figura 4.

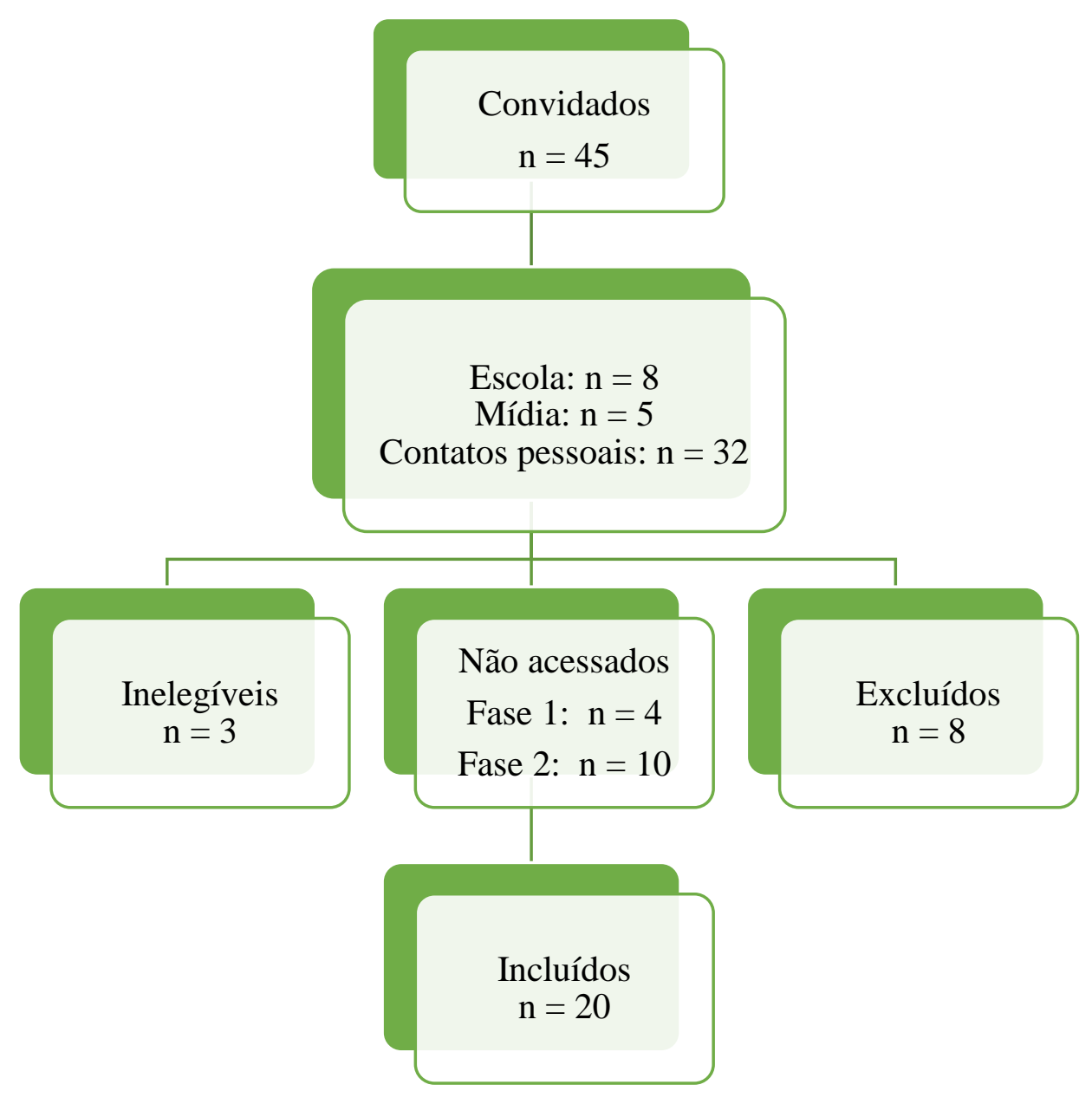

Figura 4. Percurso amostral do grupo de comparação $(n=20)$.

O Grupo de Comparação (G2) ficou formado por pessoas com idade média de 12,1 anos $( \pm 2,6)$ na primeira etapa do estudo, e 12,6 anos $( \pm 2,6)$ na segunda fase, sendo $60,0 \%$ do 
sexo feminino. Todos os colaboradores eram provenientes da região nordeste do estado de São Paulo.

\subsubsection{Caracterização geral da amostra}

A partir dos critérios de seleção estabelecidos neste estudo, foi composta a amostra com o total de 50 pessoas de sete a 17 anos, distribuídas em dois grupos. Foi possível balancear as características entre o grupo clínico e de comparação, priorizando a similaridade em relação à faixa etária e à origem escolar. A Tabela 2 descreve a distribuição dos participantes da primeira avaliação realizada em função do grupo, sexo e idade.

Tabela 2. Caracterização da amostra (primeira avaliação) em função do grupo, sexo e idade.

\begin{tabular}{|c|c|c|c|c|c|c|c|}
\hline \multirow{2}{*}{$\begin{array}{l}\text { Idade } \\
\text { (anos) }\end{array}$} & \multicolumn{3}{|c|}{ Grupo Clínico $(\mathrm{n}=30)$} & \multicolumn{3}{|c|}{ Grupo de Comparação $(n=20)$} & \multirow{2}{*}{ TOTAL } \\
\hline & Masculino & Feminino & Total G1 & Masculino & Feminino & Total G2 & \\
\hline 7 & 1 & 1 & 2 & - & 1 & 1 & 3 \\
\hline 8 & 1 & 1 & 2 & - & 1 & 1 & 3 \\
\hline 9 & 3 & 2 & 5 & - & 2 & 2 & 7 \\
\hline 10 & 4 & - & 4 & 2 & 1 & 3 & 7 \\
\hline 11 & 1 & 1 & 2 & 2 & 1 & 3 & 5 \\
\hline $\begin{array}{l}\text { Parcial } \\
(07-11 \text { anos })\end{array}$ & 10 & 5 & 15 & 4 & 6 & 10 & 25 \\
\hline 12 & 5 & 1 & 6 & 2 & 2 & 4 & 10 \\
\hline 13 & - & 1 & 1 & - & - & - & 1 \\
\hline 14 & 1 & 1 & 2 & 2 & 2 & 4 & 6 \\
\hline 15 & 1 & 2 & 3 & - & - & - & 3 \\
\hline 16 & - & 1 & 1 & - & 1 & 1 & 2 \\
\hline 17 & 1 & 1 & 2 & - & 1 & 1 & 3 \\
\hline $\begin{array}{l}\text { Parcial } \\
\text { (12 - } 17 \text { anos) }\end{array}$ & 8 & 7 & 15 & 4 & 6 & 10 & 25 \\
\hline Total & 18 & 12 & 30 & 8 & 12 & 20 & 50 \\
\hline
\end{tabular}

A amostra final do estudo foi composta, assim, por 50 crianças e adolescentes, de sete a 17 anos, com idade média de 12,2 anos $( \pm 2,7)$ na primeira fase deste estudo e 12,5 anos $( \pm 2,7)$ na segunda fase. A comparação estatística desses dados etários médios entre G1 e G2 (teste $t$ de Student, $p \leq 0,05$ ), nos dois momentos avaliativos, apontou inexistir diferença significativa entre os grupos (fase 1: $t=-0,800$ e $p=0,428$; fase $2: t=-0,087$ e $p=0,931$ ). 
É relevante considerar que a amplitude da faixa etária neste estudo se deve à natureza do fenômeno em questão, pois o câncer infantojuvenil é uma patologia ainda de baixa incidência populacional. Neste sentido, a restrição de um grupo etário específico poderia reduzir o número de participantes ou estender de forma excessiva o tempo necessário para reunir os processos de avaliação psicológica, características que inviabilizariam o desenvolvimento deste estudo.

Foi possível ainda classificar os participantes a partir dos dados do Critério de Classificação Econômica Brasil (CCEB), de sua constituição familiar (monoparental ou biparental) e em função da origem escolar. Essas informações compõem a Tabela 3.

Tabela 3. Distribuição (em frequência simples e porcentagem) dos participantes por origem escolar, composição familiar e classificação econômica em função do grupo do estudo.

\begin{tabular}{lcccccc}
\hline \multirow{1}{*}{ Variável } & \multicolumn{2}{c}{$\begin{array}{c}\text { Grupo Clínico } \\
(\mathrm{n}=30)\end{array}$} & \multicolumn{2}{c}{$\begin{array}{c}\text { Grupo de Comparação } \\
(\mathrm{n}=20)\end{array}$} & \multicolumn{2}{c}{ Total } \\
& $f$ & $\%$ & $f$ & $\%$ & $f$ & $\%$ \\
\hline Sexo & & & & & & \\
Feminino & 17 & 56,6 & 12 & 60 & 29 & 58,0 \\
Masculino & 13 & 43,3 & 8 & 40 & 21 & 42,0 \\
\hline Origem Escolar & & & & & & \\
Escola Pública & 24 & 80,0 & 17 & 85,0 & 41 & 82,0 \\
Escola Particular & 6 & 20,0 & 3 & 15,0 & 9 & 18,0 \\
\hline Composição Familiar & & & & & & \\
Monoparental & 11 & 36,6 & 6 & 30,0 & 17 & 44,0 \\
Biparental & 19 & 63,3 & 14 & 70,0 & 33 & 66,0 \\
\hline Classificação Econômica & & & & & & \\
A & - & - & 2 & 10,0 & 1 & 4,0 \\
B1 & 3 & 10,0 & 5 & 25,5 & 8 & 16,0 \\
B2 & 13 & 43,3 & 9 & 45,0 & 22 & 44,0 \\
C1 & 6 & 20,0 & 4 & 20,0 & 10 & 20,0 \\
C2 & 7 & 23,3 & - & - & 7 & 14,0 \\
D-E & 1 & 3,3 & - & - & 1 & 2,0 \\
\hline
\end{tabular}

No tocante ao sexo, os dois grupos de participantes foram equilibrados, com leve predomínio do sexo feminino tanto em G1 quanto em G2. Quanto a esta variável os grupos podem ser considerados equiparáveis.

A origem escolar dos voluntários foi balanceada a partir dos casos de G1. Desse modo, houve predomínio de estudantes de escolas públicas em ambos os grupos. 
A constituição familiar mais frequente entre os participantes do estudo foi a biparental, ou seja, com presença de figura materna e figura paterna (não obrigatoriamente o pai biológico). Houve relativa maior ocorrência de casos de família monoparental em G1.

No tocante à classificação econômica e poder de compra, pelos dados do Critério de Classificação Econômica Brasil, foi possível constatar similaridade na distribuição de G1 e G2. Apesar do Grupo de Comparação apresentar mais participantes entre a classe A e B1, em ambos os grupos houve maior concentração nos níveis B2 e C1, ou seja, sinalizadores de nível econômico considerado médio e médio-baixo na população do Brasil.

Os participantes foram ainda caracterizados a partir de seu nível intelectual, conforme avaliação específica realizada para essa finalidade (Teste das Matrizes Progressivas de Raven). Foi empregado o teste em duas versões: as Matrizes Coloridas com crianças de sete a 11 anos, e a Escala Geral com os participantes de 12 a 17 anos. É possível observar, na Tabela 4, a distribuição do desempenho intelectual dos participantes por grupo.

Tabela 4. Distribuição (em frequência simples e porcentagem) dos participantes em função do nível intelectual (primeira avaliação).

\begin{tabular}{|c|c|c|c|c|c|c|c|}
\hline & \multirow[t]{2}{*}{ Variável } & \multicolumn{2}{|c|}{$\begin{array}{l}\text { Grupo Clínico } \\
\qquad(\mathrm{n}=30)\end{array}$} & \multicolumn{2}{|c|}{$\begin{array}{l}\text { Grupo de Comparação } \\
\qquad(\mathrm{n}=20)\end{array}$} & \multicolumn{2}{|c|}{ Total } \\
\hline & & $f$ & $\%$ & $f$ & $\%$ & $f$ & $\%$ \\
\hline & Nível intelectual & & & & & & \\
\hline I & $\begin{array}{l}\text { Superior } \\
(\mathrm{P} \geq 95)\end{array}$ & 2 & 6,6 & 1 & 5,0 & 5 & 10,0 \\
\hline II+ & $\begin{array}{l}\text { Definidamente superior } \\
(90 \leq \mathrm{P}<95)\end{array}$ & 1 & 3,3 & 2 & 10,0 & 2 & 4,0 \\
\hline II & $\begin{array}{l}\text { Superior à média } \\
(75 \leq \mathrm{P}<90)\end{array}$ & 0 & 0 & 1 & 5,0 & 1 & 2,0 \\
\hline III+ & $\begin{array}{l}\text { Média } \\
(50 \leq \mathrm{P}<75)\end{array}$ & 8 & 26,6 & 4 & 20,0 & 12 & 24,0 \\
\hline III- & $\begin{array}{l}\text { Média inferior } \\
(25 \leq \mathrm{P}<50)\end{array}$ & 11 & 36,6 & 7 & 35,0 & 18 & 36,0 \\
\hline IV & $\begin{array}{l}\text { Inferior } \\
(10 \leq \mathrm{P}<25)\end{array}$ & 7 & 23,3 & 4 & 20,0 & 11 & 22,0 \\
\hline IV- & $\begin{array}{l}\text { Definidamente inferior } \\
(6 \leq \mathrm{P}<10)\end{array}$ & 0 & 0 & 0 & 0 & 0 & 0 \\
\hline V & $\begin{array}{l}\text { Deficiência mental } \\
(\mathrm{P} \leq 5)\end{array}$ & 1 & 3,3 & 1 & 5,0 & 2 & 4,0 \\
\hline
\end{tabular}


Os dados brutos obtidos no Raven (escala infantil ou geral) foram transformados em escore ponderado (zero a 100 pontos), para permitir a comparação entre os participantes. Deste modo, chegou-se ao escore ponderado médio de 41,4 pontos $( \pm 25,1)$ para o Grupo Clínico e o resultado médio de 42,4 pontos $( \pm 25,6)$ para o Grupo de Comparação, sem diferença estatisticamente significativa entre os grupos $(t=-0,143 ; p=0,887)$.

Percebe-se, entretanto, que a maior parte dos participantes do Grupo Clínico está distribuída na classificação "Média" (III+ e III-) e "Inferior à média" (IV) que, somadas, representam 86,5\% do nível intelectual em G1. É possível identificar o mesmo padrão de distribuição no Grupo de Comparação, com 75\% do desempenho intelectual na faixa já discriminada. No entanto, ressalta-se que G2 apresentou mais participantes na classificação "Superior" (I, II+ e II = 30,0\%), enquanto G1 contou com 9,9\% dos participantes nesta faixa de classificação do nível intelectual.

Diante dessas características observadas nos participantes, no tocante às variáveis sexo, idade, padrão econômico, composição familiar, origem escolar e nível intelectual, podese afirmar que foi possível compor dois grupos similares de voluntários. Este balanceamento nas características grupais permite que as demais variáveis relativas ao funcionamento psíquico e aos recursos pessoais e familiares possam estar vinculadas à variável presença ou não do câncer, permitindo comparação de G1 e de G2 nos indicadores técnicos dos instrumentos utilizados no estudo.

\subsection{Instrumentos}

Para o desenvolvimento desta pesquisa foi necessário consultar os prontuários médicos dos casos selecionados do HC-FMRP-USP, para registro da história clínica dos participantes. Este procedimento foi devidamente autorizado a partir da parceria estabelecida com os profissionais responsáveis por esses serviços clínicos (ANEXO 1). Além disso, foram utilizados os seguintes materiais:

\subsubsection{Termo de Consentimento Livre e Esclarecido (TCLE)}

Material elaborado com a finalidade de esclarecer os objetivos da pesquisa aos pais e/ou responsáveis pelas crianças ou adolescentes, de modo a poderem avaliar a proposta e documentarem seu espontâneo consentimento para a participação de seu(ua) filho(a) na pesquisa. Foi utilizado um TCLE dirigido aos pais e/ou responsáveis do Grupo 1 e outro para 
Grupo 2, respeitando suas características e contextos específicos de vida. Estes materiais estão apresentados nos APÊNDICES A e B.

\subsubsection{Termo de Assentimento}

Documento construído com objetivo de esclarecer a criança ou o adolescente acerca dos objetivos e das atividades que realizadas na pesquisa, de modo a clarificar possíveis dúvidas, garantir o sigilo e a proteção à identidade, e documentar seu consentimento espontâneo. Foi lido e explicado para o participante, quando necessário, de modo a favorecer sua compreensão deste documento (APÊNDICE C).

\subsubsection{Critério de Classificação Econômica Brasil (CCEB)}

Instrumento elaborado pela Associação Brasileira de Empresas de Pesquisa (ABEP). Objetiva estimar o poder de compra das pessoas e famílias urbanas (a partir de itens existentes na casa e da escolaridade do chefe da família), abandonando a pretensão de classificar a população em termos de "classes sociais". Permite a classificação nos seguintes níveis: A1, A2, B1, B2, C1, C2, D, E, sendo que o nível A é de maior poder econômico, decrescendo para nível E. Foi respondido pelos pais ou responsáveis da criança/adolescente, utilizando-se o parâmetro da ABEP (2015) para classificação dos resultados.

\subsubsection{Matrizes Coloridas Progressivas de Raven e Matrizes Progressivas de Raven (Escala Geral)}

Trata-se de teste não verbal, perceptivo e homogêneo, voltado ao exame do nível intelectual. A tarefa proposta é a mesma para todos os itens (completar o que falta), sendo destinado a avaliar a capacidade total de observação para estabelecer comparações e a clareza de pensamento, a partir do desenvolvimento de um método lógico de raciocínio. Apresenta adequados indicadores psicométricos para o contexto do Brasil.

Para o presente estudo, foi utilizada a Escala Geral para os participantes com idade entre 12 e 17 anos (tomando como referência normativa o estudo de Flores-Mendoza, Widaman, Bacelar \& Lelé, 2013), enquanto nas crianças entre sete e 11 anos foi aplicada a versão das Matrizes Progressivas Coloridas, utilizando-se o parâmetro normativo de Angelini, Alves, Custódio, Duarte e Duarte (1999). Esse instrumento foi usado como variável de 
caracterização dos participantes dos dois grupos, sem exclusão de casos a partir dos resultados obtidos nesse instrumento.

\subsubsection{Inventário de Recursos do Ambiente Familiar - RAF (Marturano, 1999)}

Baseado no modelo bioecológico do desenvolvimento, este instrumento tem como objetivo rastrear os recursos encontrados no ambiente familiar, avaliando a interação das crianças com seus pais e familiares, além da contribuição desta relação para seu desenvolvimento cognitivo e psicossocial. Os recursos do ambiente familiar são agrupados em três domínios: recursos que promovem processos proximais, atividades que sinalizam estabilidade na vida familiar e práticas parentais que promovem a ligação família e escola. Está composto por dez tópicos, e foi administrado como entrevista semiestruturada com o informante familiar.

Tendo em vista as mudanças socioculturais desde a publicação original deste instrumento, neste atual trabalho foi realizada adaptação de alguns itens com o intuito de manter sua capacidade de avaliação dos aspectos em estudo. Após a autorização para a realização do procedimento de adaptação da escala por meio de comunicação pessoal, a autora pode revisar os itens, manifestando aprovação diante das modificações introduzidas. Salienta-se que as alterações ocorreram no intuito de atualizar aspectos pertinentes ao lazer e aos recursos, principalmente tecnológicos, com preservação da estrutura e formato original do instrumento.

A pontuação deste inventário se dá pela somatória dos escores, ponderados em função do número de itens para cada tópico avaliado. Segundo Maturano (2006), o instrumento oferece índices psicométricos favoráveis, com boa consistência interna (alfa de Cronbach = $0,84)$.

\subsubsection{Escala de Adversidades Crônicas - EAC (Marturano, 1999)}

Esta escala está composta por 18 itens contendo eventos que aludem a dificuldades crônicas que podem estar ligadas à saúde da criança ou adolescente e de seus familiares, ao temperamento parental e a conflitos no ambiente doméstico. O respondente informa se uma destas situações está presente na vida da pessoa, qual período da vida ocorreu e quanto tempo perdurou. A pontuação deste instrumento deriva da soma dos pontos, ponderados pelo número de itens que compõem cada área de dificuldades crônicas avaliadas pela escala. 


\subsubsection{Escala de Eventos Adversos - EEA (Marturano, 1999)}

Esta escala busca detectar a presença de eventos adversos que possam ter ocorrido na vida da criança ou adolescente no intervalo que compreende os últimos doze meses ou em um período anterior a este. Para sua utilização, o avaliador lê para o familiar ou cuidador principal uma lista contendo 36 situações, estimulando o informante para que aponte se a criança passou por alguma das experiências sugeridas. Os eventos listados podem ser divididos em: a) acontecimentos no contexto familiar, como percalços nos relacionamentos parentais (sete itens), situações associadas à conduta parental (dois itens), realidade financeira (três itens), ademais situações no contexto familiar (10 itens); b) ocorrências na vida da criança, tais como adversidades pessoais (três itens), nos relacionamentos interpessoais (quatro itens) e na vida escolar (quatro itens); c) morte de pessoas significativas (quatro itens) (Pizeta, 2009). O resultado dessa escala é expresso pela soma total de pontos, ponderada pela pontuação total de cada subárea diante da máxima pontuação na escala.

\subsubsection{Questionário de Capacidades e Dificuldades - SDQ}

O Questionário de Capacidades e Dificuldades (Strengths and Difficulties Questonnaire) é instrumento objetivo de avaliação psicológica, construído em 1997 por Goodman e validado no Brasil em 2000 por Fleitlich, Cartázar e Goodman (Saur, Correia, Pasian \& Loureiro, 2009). Tem como objetivo detectar indicadores de problemas na saúde mental infantil e está composto por 25 itens, subdividido em cinco subescalas que avaliam: hiperatividade, sintomas emocionais, problemas de conduta, relações interpessoais e comportamento pró-social (Fleitlich, Cortázar \& Goodman, 2000). Neste trabalho foi utilizada a versão dirigida aos pais, de modo a permitir a identificação dos recursos pessoais e das limitações funcionais cotidianas das crianças e dos adolescentes participantes deste estudo, assim como selecionar participantes para o Grupo de Comparação (Grupo 2, composto por voluntários sem relato de dificuldades significativas a partir do SDQ).

Para cada afirmação do SDQ o respondente deve optar exclusivamente por uma opção de resposta, a saber: falso, mais ou menos verdadeiro, e verdadeiro, e a pontuação é correspondente a 0,1 ou dois pontos. Para as subescalas hiperatividade, sintomas emocionais, problemas de conduta e comportamento pró-social, a pontuação poderá variar de 0 a 10 pontos, enquanto a subescala relativa a relações interpessoais pode variar de 0 a 40 pontos (Saur \& Loureiro, 2012). O resultado final pode ser classificado em normal, limítrofe ou 
anormal, sendo que 16 pontos é a nota de corte entre a normalidade e a presença de comprometimento, conforme estabelece Goodman (1997).

No contexto nacional, Woerner et al. (2004) apresentam dados referentes aos estudos de validade e fidedignidade do instrumento de avaliação, sendo possível constatar sua adequação com relação às propriedades psicométricas.

\subsubsection{Inventário de Percepção do Suporte Familiar - IPSF}

Desenvolvido por Baptista (2005), o IPSF é um instrumento que se propõe a avaliar a forma como o indivíduo percebe sua relação com a família. O inventário é composto por 42 frases, escritas em primeira pessoa, que expressam sentimentos em relação à rede familiar. $\mathrm{O}$ respondente deve indicar a frequência na qual se sente daquela determinada maneira, com as seguintes opções: “Quase nunca ou Nunca” (zero pontos), “Às vezes” (um ponto) ou "Quase sempre ou Sempre” (dois pontos), preenchendo os itens na sequência determinada. O resultado final será a soma dos pontos do conjunto de itens, totalizando entre zero até 84 pontos. A comparação da pontuação final com as normas estabelecidas pelo instrumento permite classificar a percepção de suporte familiar como baixa, médio-baixa, médio-alta ou alta.

A partir deste instrumento, é possível avaliar três dimensões de percepção de suporte familiar, a saber: (1) Afetivo-Consistente, que se refere à expressão de afetividade entre os membros da família, comunicação, acolhimento, empatia, clareza nas regras, resolução de problemas; (2) Inadaptação Familiar, associada a sentimentos e comportamentos negativos frente à família, tais como raiva, isolamento, vergonha, culpabilização diante de conflitos, falta de senso de pertencimento, estabelecimento de relações agressivas; (3) Autonomia, referente a questões que demonstram construção de relações de confiança, liberdade e privacidade entre os membros da família. Há informações de adequados indicadores psicométricos relativos à precisão nas dimensões distintas do IPSF, identificados por seus valores alfa de Cronbach: 0,88 em Inadaptação Familiar, 0,86 em Afetividade Familiar, 0,83 em Consistência Familiar e 0,81 em Autonomia Familiar (Baptista, 2005). Essa estrutura interna do instrumento foi confirmada por análise fatorial das dimensões que o compõe, oferecendo evidências empíricas sobre sua validade.

A utilização deste instrumento deve-se à compreensão de que o processo adaptativo de crianças e de adolescentes ao câncer e ao cuidado oncológico influencia e é influenciado por características específicas da dinâmica familiar. Desta forma, a percepção de suporte familiar 
dos pais ou cuidadores de crianças/adolescentes em tratamento oncológico torna-se importante aspecto no desenvolvimento de suas formas adaptativas. O inventário foi aplicado individualmente com os pais/responsáveis dos participantes de ambos os grupos, e avaliados de acordo com os parâmetros propostos por Baptista (2010).

\subsubsection{Método de Rorschach}

Desenvolvido por Hermann Rorschach (1884-1922), o instrumento é composto por 10 cartões com diferentes manchas de tinta em preto, vermelho e tons coloridos. A partir de mecanismos projetivos pertinentes à tarefa, é possível avaliar recursos relativos a dinâmica e estrutura da personalidade de crianças, adolescentes e adultos. A prova estabelecida por Rorschach solicita que o participante expresse o que cada figura no cartão pode lhe parecer, deixando o indivíduo livre para manipular o material e emitir respostas espontâneas. Após esta etapa é realizado inquérito sobre as interpretações oferecidas aos estímulos, abrindo campo para compreender o elemento determinante da resposta (cor, forma, movimento, sombreamento), em qual parte da prancha foi identificada a resposta (no estímulo todo, em uma parte, em uma pequena parte, ou em sua porção branca), bem como o conteúdo da mesma. Para a aplicação e a interpretação do instrumento recorreu-se aos pressupostos da Escola Francesa do Rorschach, representado por Rausch de Traubenberg (1998) e Anzieu (1986), acrescidos dos parâmetros técnicos e normativos dos estudos de Fernandes (2010), Raspantini (2010), Jardim-Maran (2011) e Cury-Jacquemin (2012), cada qual específico para uma faixa etária.

\subsubsection{Teste das Pirâmides Coloridas de Pfister}

Instrumento projetivo de avaliação de características da personalidade, podendo ser aplicado em crianças até idosos. Baseia-se em atividade não verbal (construção de pirâmides) que possibilita manifestações simbólicas dos sentimentos e da organização afetiva, oferecendo indicadores técnicos relativos a autopercepção, contatos interpessoais, dinâmica afetiva, funções estruturais e cognitivas (Villemor-Amaral \& Franco, 2011). Está composto por três cartões contendo o esquema de uma pirâmide e um jogo de quadrículos coloridos composto por 10 cores subdivididas em 24 tonalidades. A compreensão e análise dos dados são realizadas levando em consideração o modo pelo qual é executada a tarefa, como se coloca os quadrículos e os tipos de arranjos feitos com os mesmos, além da utilização e combinação das 
cores. É importante ressaltar que estudos recentes no Brasil evidenciam suas boas qualidades psicométricas. Destaca-se ainda que foram considerados os referenciais normativos específicos de cada faixa etária avaliada, utilizando-se como norma para crianças os dados da faixa etária de sete a 11 anos (Villemor-Amaral, 2014) e, como padrão normativo de adolescentes, os achados da faixa etária de 12 a 17 anos (Pasian, Barroso \& Theodózio, 2014).

\subsubsection{Ficha de registro do tratamento (para G1)}

Instrumento elaborado pelo pesquisador de modo a sistematizar as informações referentes aos eventos vinculados ao tratamento oncológico, a fim de detectar fatores de risco implícitos nas intervenções médicas e da equipe de saúde, incluindo: tempo de realização de quimioterapia e radioterapia, abordagens cirúrgicas, número de internações em centro de terapia intensiva, possíveis ocorrências de recidivas da doença neoplásica, episódios de intercorrências graves no quadro de saúde, ocorrência de outras patologias devido ao efeito secundário do cuidado oncológico (conforme pode ser visualizado na Figura 3. e Tabela 1.). Esses dados foram levantados a partir dos prontuários médicos dos pacientes autorizados para o estudo (G1), bem como por informações colhidas com os pais ou responsáveis durante processo de avaliação dos casos.

\subsection{Procedimentos}

\subsubsection{Aspectos Éticos}

Esta pesquisa foi submetida à análise e avaliação pelo Comitê de Ética em Pesquisa com Seres Humanos da Faculdade de Filosofia, Ciências e Letras de Ribeirão Preto Universidade de São Paulo. Recebeu parecer favorável para sua realização em abril de 2015 (CAAE no. 42183715.6.3001.54400 - ANEXO 1 e 2).

Os procedimentos adotados neste estudo foram orientados pelos princípios éticos em pesquisa, afirmados pela Resolução no . 466, de 12 de Dezembro de 2012 (Brasil: Ministério da Saúde, Conselho Nacional da Saúde, 2012), que define as diretrizes e normas regulamentadoras de pesquisa com seres humanos. Posteriormente, o projeto foi encaminhado ao Comitê de Ética em Pesquisa com Seres Humanos do Hospital das Clínicas da Faculdade de Medicina de Ribeirão Preto - Universidade de São Paulo, para ciência da referida instituição e autorização para a concretização da coleta de dados envolvendo usuários do 
serviço. Após sua aprovação, os devidos cuidados no sentido de adequada e responsável realização do processo de coleta de dados foram efetivados.

Caso fossem identificadas dificuldades psicológicas consistentes e prejudiciais ao desenvolvimento, em qualquer etapa da realização do estudo, o pesquisador orientaria os responsáveis e encaminharia a criança ou o adolescente (de qualquer um dos grupos) para atendimento psicológico específico na rede de saúde de sua cidade. Cabe destacar, no entanto, que os participantes do Grupo Clínico (G1) já possuem, pela rotina de seu tratamento, equipe multidisciplinar envolvida, contanto com intervenção psicológica específica, pautada por suas necessidades e de seus familiares ou responsáveis.

Nessa direção, a partir dos dados do Questionário de Capacidades e Dificuldades (SDQ), quatro participantes do Grupo de Comparação apresentaram relevantes sinais de dificuldades no desenvolvimento. Em dois casos, o pesquisador esclareceu os responsáveis sobre as particularidades identificadas, orientando e os encaminhando para serviços de atendimento psicológico, disponíveis e acessíveis às famílias. Em relação aos outros dois participantes, um já se encontrava em psicoterapia, e outro havia realizado psicoterapia anteriormente, sendo então orientado o retorno ao seguimento psicológico. De forma geral, a demanda identificada na pesquisa era confirmada pela percepção dos pais, reforçando o planejamento já existente de busca por atendimento psicológico.

Outros responsáveis pelos participantes demonstraram interesse no processo psicoterapêutico para seus filhos, apesar destes não apresentarem indícios de problemas de saúde mental ou de dificuldades no desenvolvimento. Nestes casos foi realizada breve explanação sobre o processo da psicoterapia, no intuito de acolher a necessidade expressa durante o processo de coleta de dados, e foram indicados centros de atendimento à comunidade aos quais poderiam recorrer.

\subsubsection{Coleta de dados}

\subsubsection{Grupo Clínico (G1)}

A fim de que fossem identificados os participantes que se encontrariam em situação condizente com os critérios de inclusão e exclusão preconizados pelo projeto de trabalho, foi realizada busca ativa dos mesmos com a equipe de saúde do Serviço de Oncologia e Hematologia Pediátrica do HC/FMRP-USP. Havendo enquadramento aos parâmetros estabelecidos pela proposta de pesquisa, foi estabelecido contato com a família responsável 
pelo usuário de serviço, de modo a explicar os objetivos e a proposta do trabalho, apresentando o convite a sua participação e a de seu(ua) filho(a).

A partir do consentimento prévio dos pais ou responsáveis, o pesquisador procurou a criança ou o adolescente com intuito de explicar o estudo e solicitar sua participação. Obtidos o aceite da família e do paciente para o estudo, foram definidos datas, local e horários para aplicação dos instrumentos de coleta de dados com pais/responsáveis e os jovens pacientes.

As atividades pertinentes à avaliação psicológica das crianças e adolescentes foram realizadas em uma única sessão individual, previamente agendada com os voluntários. Todavia, em três casos ao longo da primeira avaliação e dois casos na segunda avaliação, os participantes referiram algum tipo de desconforto ou mal-estar físico ou demonstraram grande mobilização emocional frente à tarefa. Nesses casos, a avaliação foi interrompida e finalizada em outro momento, sempre na tentativa de preservar o bem-estar das crianças e adolescentes participantes da pesquisa.

Vale destacar que mesmo com o prévio agendamento do encontro, antes do início da avaliação o participante, seus familiares e a equipe de saúde foram consultados, com o objetivo de garantir que a criança e o adolescente desfrutavam de condições de bem-estar que favorecessem sua colaboração, zelando pelas condições técnicas adequadas para a realização deste tipo de investigação. Em casos em que esta situação não era observada, o pesquisador conversou com os participantes buscando explicar as razões pelo adiamento da atividade e agendando novo encontro para momento oportuno.

A coleta de dados de crianças e adolescentes em processo de cuidado oncológico (Grupo Clínico) ocorreu em sala apropriada, no ambulatório ou enfermaria da Oncologia Pediátrica do HCFMRP/USP. Em caso de preferência dos participantes por outro ambiente que não o de tratamento, a avaliação ocorria no domicílio familiar.

No início do primeiro encontro, após a realização de rapport, foi apresentado pelo pesquisador o Termo de Consentimento Livre e Esclarecido (APÊNDICE A), elucidando as intenções e objetivos deste estudo, a participação livre e voluntária, com garantia de sigilo da identidade dos participantes. Posteriormente, utilizando linguagem adequada, foi apresentado à criança ou ao adolescente o Termo de Assentimento (APÊNDICE C), seguindo o mesmo intuito exposto acima.

Em momentos distintos foi realizada a coleta de dados com o cuidador principal designado pela própria família (pais ou responsáveis), e com a criança ou adolescente, ambos em processos individuais de avaliação. Foram utilizados os seguintes instrumentos com o familiar responsável por acompanhar o processo de cuidado oncológico do jovem paciente, aplicados 
nesta ordem em todos os casos: Critério de Classificação Econômica Brasil, Inventário de Recursos do Ambiente Familiar - RAF, Escala de Eventos Adversos - EEA, Escala de Dificuldades Crônicas - EDC, Questionário de Capacidades e Dificuldades - SDQ, Inventário de Percepção do Suporte Familiar - IPSF. Esses instrumentos foram aplicados em formato assistido, ou seja, o pesquisador permanecia junto ao respondente adotando postura colaborativa de modo a auxiliar na compreensão das atividades e seus itens, sem com isso descaracterizar os enunciados dos instrumentos investigados ou induzir na produção de respostas desejadas.

Com a criança ou adolescente foram administrados: Matrizes Coloridas Progressivas de Raven ou Escala Geral das Matrizes Progressivas de Raven, Método de Rorschach e Teste das Pirâmides Coloridas de Pfister, todos nesta ordem. Para aplicação do conjunto de instrumentos em cada participante foi necessário tempo de 50 a 70 minutos.

Transcorrido o tempo de pelo menos seis meses da primeira participação na pesquisa, familiares e pacientes foram procurados a fim de que pudessem colaborar novamente com o estudo (fase 2 do estudo). É importante esclarecer que ao ser apresentada a proposta de participação, foi esclarecido e acordado que o paciente pediátrico e seus familiares seriam convidados a cooperar em um segundo momento, sem nenhuma oposição a tal proposta. $\mathrm{Na}$ segunda fase avaliativa, todos os colaboradores da pesquisa (pais/responsáveis e estudantes) se mostraram disponíveis, sendo possível efetuar a reavaliação do Grupo Clínico em sua totalidade $(\mathrm{n}=30)$.

A colaboração com a segunda fase do estudo foi realizada em um intervalo de seis a oito meses da primeira avaliação. O intervalo maior em alguns casos se deveu a dinâmica do tratamento oncológico e ao estado clínico do paciente. Neste segundo encontro foi repetida a administração da mesma bateria de escalas e testes psicológicos, com a finalidade de se obter informações de natureza longitudinal (embora com breve intervalo de tempo, necessário para viabilizar o estudo de Doutorado).

\subsubsection{Grupo de Comparação (G2)}

A partir das características de faixa etária, sexo e condição econômica dos participantes do G1, foram recrutados os participantes que compuseram o grupo de comparação (G2). As crianças e adolescentes deste grupo possuíam indicadores de desenvolvimento típico para sua idade, o que foi avaliado previamente ao contato direto com eles, aplicando-se o Questionário de Capacidades e Dificuldades (SDQ) nos pais ou responsáveis pelos possíveis voluntários. A avaliação psicológica dos participantes do G2 
ocorreu no contexto escolar ou na residência dos voluntários, de acordo com o planejamento realizado entre o pesquisador e os pais ou responsáveis.

Os procedimentos de coleta de dados no Grupo de Comparação foram os mesmos que os executados no Grupo Clínico, excetuando-se o local onde o processo de avaliação psicológica foi realizado. Assim como no primeiro grupo, os participantes de G2 passaram por nova avaliação após um intervalo mínimo de seis meses. Devido à rotina de vida dos participantes, das férias escolares que se estendem de dezembro a fevereiro, e o tempo em que alguns deles levaram para responder ao novo convite, o intervalo entre a primeira e segunda avaliação variou de seis a nove meses. No processo de reavaliação, uma terça parte dos participantes que compuseram o Grupo de Comparação havia mudado de cidade, alterado seus contatos telefônicos e endereço, e/ou não responderam ao convite do pesquisador, representando perda amostral deste estudo, como descrito no item referente aos participantes.

Cabe, por fim, informar que a primeira etapa da coleta de dados desta pesquisa (fase 1) foi desenvolvida de fevereiro a novembro de 2015, para ambos os grupos. A segunda etapa (reavaliação dos casos, fase 2) foi realizada de agosto de 2015 a maio de 2016. Os procedimentos adotados em ambos os momentos avaliativos foram os mesmos, visando possibilitar a comparação de seus resultados, tanto entre os grupos quanto dentro de cada um dos grupos examinados.

\subsubsection{Análise dos resultados}

Os dados obtidos foram sistematizados de acordo com as diretrizes disponíveis nos respectivos manuais dos instrumentos utilizados, de modo a investigar as especificidades de produção dos participantes, a partir de seus referenciais normativos. Assim, os instrumentos foram avaliados, categorizados e classificados de acordo com os padrões técnicos específicos.

Após a finalização do processo de coleta de dados e codificação dos instrumentos empregados, foi desenvolvido banco de dados computacional, em planilha do Programa Microsoft Excel. Foram integrados os resultados dos instrumentos utilizados com as crianças, adolescentes e seus pais ou cuidadores, incluindo dados sociodemográficos. Posteriormente, esta planilha foi transposta para o programa estatístico Statistical Package for the Social Sciences (SPSS) 20.0, considerando-se o Grupo Clínico (G1) e Grupo de Comparação (G2).

Foram realizadas análises descritivas e quantitativas (medidas de tendência central e de variabilidade) e inferenciais (testes de hipóteses referentes à eventual similaridade ou não no desempenho médio entre os grupos estudados), a fim de examinar características e o 
funcionamento da personalidade das crianças e adolescentes aqui avaliados. Foram realizadas análises de comparação de médias entre G1 e G2 (teste $t$ de Student), bem como análise comparativa dos dois momentos avaliativos de G1 (teste de Wilcoxon para amostras pareadas), utilizando-se nível de significância de 5\%. Nas análises comparativas foi calculado ainda o tamanho do efeito, conforme características dos testes estatísticos utilizados (d de Cohen ou V de Cramer). Para interpretação do tamanho do efeito considerou-se a diretriz de Marôco (2011), a saber: valores inferiores a 0,2 (efeito pequeno), de 0,2 a 0,5 (efeito médio), de 0,5 a 1,0 (efeito elevado), valor superior a 1,0 (efeito muito elevado).

É importante salientar que, em relação ao Psicodiagnóstico de Rorschach, após sua administração, cada protocolo com as respostas oferecidas pelos participantes e sua subsequente investigação passou por apreciação de avaliadores independentes. Este procedimento metodológico possibilita a realização de comparações entre os examinadores, a fim de avaliar o índice de concordância entre eles, examinando-se índices de precisão nos processos avaliativos da produção dos colaboradores nesta técnica de exame psicológico. Em seguida, visando atingir uma codificação final de cada resposta das crianças e adolescentes avaliados, os casos em que foram detectadas discrepâncias entre a avaliação dos juízes independentes foi consultado um especialista no Método de Rorschach segundo a Escola Francesa, a fim de que pudesse atuar como terceiro avaliador. A partir dessas atividades é que foi possível configurar a classificação final da produção neste instrumento de avaliação psicológica.

Para a execução do processo de classificação das respostas ao Rorschach, houve a colaboração de quatro psicólogos com experiência prévia em processos de avaliação psicológica e com adequado treino na Escola Francesa. Todos eram membros do Centro de Pesquisas em Psicodiagnóstico (CPP) da Faculdade de Filosofia, Ciências e Letras de Ribeirão Preto da Universidade de São Paulo e já haviam participado como avaliadores de protocolos do Rorschach em outros projetos existentes no Grupo de Pesquisa.

Foi possível notar que este grupo de pesquisadores sinalizou adequado nível de concordância (cálculo do Kappa, interpretado a partir de Marôco, 2011) nas quatro principais categorias de codificação do Método de Rorschach, segundo a Escola Francesa. Deste modo, os valores do índice Kappa de concordância entre avaliadores independentes das respostas ao Teste de Rorschach foram: Índice Geral $=94,9 \%$; Localização $=97,5 \%$; Determinantes $=$ 88,0\%; Conteúdos $=97,3 \%$; Banalidades $=97,0 \%$. Estes valores atestam precisão ao processo de classificação das respostas a esse método projetivo, oferecendo segurança adicional aos achados empíricos. 

Neste capítulo serão apresentadas análises descritivas e inferenciais dos achados com Grupo Clínico (G1) e Grupo de Comparação (G2), levando em consideração os diferentes instrumentos de avaliação das crianças e adolescentes, bem como de seus familiares. Vale salientar que o foco será dirigido às características de personalidade de crianças e adolescentes em cuidados oncológicos, além de recursos do grupo familiar, observados ao longo do desenvolvimento (avaliação e reavaliação após seis meses de intervalo, no mínimo), em comparação com grupo de crianças e adolescentes com sinais de desenvolvimento típico.

Com o intuito de explorar o intrincado processo de adaptação pessoal e da família diante da vivência de adoecimento oncológico e cuidado hospitalar ao longo do tempo, assim como compreender quais são as repercussões psíquicas da experiência sobre o jovem paciente, os dados serão agrupados em três eixos. O primeiro eixo denominado "Vida da Família" explorará recursos do ambiente doméstico, qualidade das interações entre os membros do grupo, eventos psicossociais que tenham, por ventura, acometido a trajetória da família, além do modo pelo qual o cuidador principal da criança e do adolescente enfermo ou saudável percebe o suporte recebido de seus familiares. Nesse eixo, então, serão considerados os resultados dos instrumentos: Inventário de Recursos do Ambiente Familiar (RAF), Escala de Eventos Adversos (EEA), Escala de Adversidades Crônicas (EAC) e Inventário de Percepção do Suporte Familiar (IPSF).

A seguir será apresentado o eixo "Indicadores de Saúde Mental Infantojuvenil”. Os subsídios advêm do Questionário de Capacidades e Dificuldades (SDQ) e da observação de comportamentos e atitudes e adolescentes pela ótica do cuidador principal participante do estudo. Será possível, assim, descrever indicadores de saúde mental dos voluntários com diagnóstico de neoplasia em comparação a crianças saudáveis do ponto de vista médico-clínico.

Por fim, o último eixo será denominado "Características de Personalidade de Crianças e Adolescentes" e será composto por indicadores dos métodos projetivos utilizados. Assim, serão apresentados achados com o Método de Rorschach (Escola Francesa) e o Teste das Pirâmides Coloridas de Pfister, nos dois momentos avaliativos do estudo (Fase 1 e Fase 2).

\subsection{Vida da Família}

\subsubsection{Vida da Família (FASE 1)}

Com o intuito de identificar os recursos físicos existentes no ambiente doméstico, e como a família se articula para oferecer estímulos cognitivos e sociais pela supervisão do 
cotidiano e pelo estabelecimento de relações interpessoais, serão apresentados os resultados referentes ao Inventário de Recursos do Ambiente Familiar (RAF) na primeira etapa de avaliação. Na Tabela 5 é possível vislumbrar o resultado médio e a comparação estatística entre Grupo Clínico (G1) e Grupo de Comparação (G2) nos três distintos domínios da RAF, além do resultado total neste instrumento.

Tabela 5. Resultados médios e comparação estatística dos domínios do Inventário de Recursos do Ambiente Familiar (RAF) na primeira etapa do estudo.

\begin{tabular}{|c|c|c|c|c|c|c|c|c|}
\hline \multirow{2}{*}{ RAF } & \multirow{2}{*}{ Grupo } & \multicolumn{4}{|c|}{ Análise Descritiva } & \multicolumn{3}{|c|}{ Análise Comparativa } \\
\hline & & Média & DP & Mínimo & Máximo & $t$ & $p$ & $d$ de Cohen \\
\hline \multirow{2}{*}{$\begin{array}{c}\text { Supervisão e } \\
\text { organização das } \\
\text { rotinas }\end{array}$} & G1 & 6,21 & 1,38 & 1,88 & 9,19 & \multirow[b]{2}{*}{$-0,091$} & \multirow[b]{2}{*}{0,928} & \multirow[b]{2}{*}{$-0,026$} \\
\hline & $\mathrm{G} 2$ & 6,25 & 1,33 & 8,66 & 14,40 & & & \\
\hline \multirow{2}{*}{$\begin{array}{l}\text { Oportunidade } \\
\text { de interação } \\
\text { com os pais }\end{array}$} & G1 & 7,52 & 2,32 & 4,64 & 16,48 & \multirow[b]{2}{*}{$-0,052$} & \multirow[b]{2}{*}{0,959} & \multirow[b]{2}{*}{$-0,015$} \\
\hline & G2 & 7,56 & 2,72 & 2,65 & 14,40 & & & \\
\hline \multirow{2}{*}{$\begin{array}{c}\text { Presença de } \\
\text { recursos no } \\
\text { ambiente físico }\end{array}$} & G1 & 4,82 & 1,16 & 2,08 & 6,47 & \multirow[b]{2}{*}{$-0,369$} & \multirow[b]{2}{*}{0,713} & \multirow[b]{2}{*}{$-0,107$} \\
\hline & G2 & 4,92 & 0,68 & 3,61 & 6,07 & & & \\
\hline \multirow{2}{*}{ TOTAL } & $\begin{array}{l}\text { G1 } \\
\text { G2 }\end{array}$ & $\begin{array}{l}6,18 \\
624\end{array}$ & $\begin{array}{l}1,30 \\
122\end{array}$ & $\begin{array}{l}3,14 \\
404\end{array}$ & $\begin{array}{c}10,00 \\
890\end{array}$ & \multirow[t]{2}{*}{$-0,157$} & \multirow[t]{2}{*}{0,876} & \multirow[t]{2}{*}{$-0,045$} \\
\hline & $\mathrm{G} 2$ & 0,24 & 1,22 & 4,04 & 8,90 & & & \\
\hline
\end{tabular}

Observa-se que tanto as famílias de G1 e G2 apresentam perfis semelhantes no tocante à supervisão e organização das rotinas, oportunidade de interação com os pais e presença de recursos no ambiente físico. Não há indicadores estatísticos de diferenças significativas entre G1 e G2, o que pode se constituir como relevante sinalizador de manutenção dos processos interativos no planisfério do grupo familiar mesmo em vigência do câncer infantojuvenil.

Assim, é factível inferir que, em um primeiro momento de avaliação, não foram identificadas repercussões negativas na organização da família no tocante à presença de brinquedos, objetos escolares, recursos eletrônicos lúdicos, material de leitura como jornais, livros e revistas, monitoramento e suporte da vida escolar, além de atividades cotidianas desenvolvidas em companhia de um ou mais membros da família. Os achados apontaram 
manutenção de aparente e favorável organização dos recursos típicos da família, favorecendo condições naturais de estímulo ao desenvolvimento de crianças e adolescentes.

A seguir, serão apresentados, na Tabela 6, resultado médio e comparação estatística de G1 e G2 na Escala de Eventos Adversos (EEA) e Escala de Adversidades Crônicas (EAC) na primeira etapa da avaliação dos familiares dos participantes do estudo.

Tabela 6. Resultados médios e comparação estatística da Escala de Eventos Adversos (EEA) e Escala de Adversidades Crônicas (EAC) na primeira avaliação.

\begin{tabular}{|c|c|c|c|c|c|c|c|c|}
\hline \multirow{2}{*}{ Instrumento } & \multirow{2}{*}{ Grupo } & \multicolumn{4}{|c|}{ Análise Descritiva } & \multicolumn{3}{|c|}{ Análise Comparativa } \\
\hline & & Média & DP & Mínimo & Máximo & $t$ & $p$ & $d$ de Cohen \\
\hline EEA & G1 & 10,03 & 5,22 & 1 & 20 & & & \\
\hline $\begin{array}{l}\text { Contexto } \\
\text { Familiar }\end{array}$ & $\mathrm{G} 2$ & 7,90 & 4,68 & 0 & 16 & 1,473 & 0,147 & 0,590 \\
\hline EEA & G1 & 6,07 & 2,54 & 3 & 13 & & & \\
\hline $\begin{array}{l}\text { Vida da } \\
\text { Criança }\end{array}$ & $\mathrm{G} 2$ & 2,70 & 1,03 & 1 & 4 & 5,602 & $\leq \mathbf{0 , 0 0 1}$ & 1,617 \\
\hline EEA & G1 & 1,17 & 1,20 & 0 & 4 & & & \\
\hline $\begin{array}{c}\text { Mortes e } \\
\text { Perdas }\end{array}$ & $\mathrm{G} 2$ & 0,70 & 0,57 & 0 & 2 & 1,610 & 0,114 & 0,465 \\
\hline $\begin{array}{c}\text { EEA } \\
\text { TOTAL }\end{array}$ & $\begin{array}{l}\text { G1 } \\
\text { G2 }\end{array}$ & $\begin{array}{l}17,27 \\
11,30\end{array}$ & $\begin{array}{l}6,59 \\
5,31\end{array}$ & $\begin{array}{l}6 \\
2\end{array}$ & $\begin{array}{l}31 \\
20\end{array}$ & 3,379 & $\leq \mathbf{0 , 0 0 1}$ & 0,975 \\
\hline $\mathrm{EAC}$ & G1 & 3,57 & 0,97 & 1 & 5 & & & \\
\hline $\begin{array}{l}\text { Saúde da } \\
\text { Criança }\end{array}$ & $\mathrm{G} 2$ & 1,00 & 1,25 & 0 & 4 & 8,113 & $\leq \mathbf{0 , 0 0 1}$ & 2,348 \\
\hline $\mathrm{EAC}$ & G1 & 1,97 & 1,73 & 0 & 7 & & & \\
\hline $\begin{array}{l}\text { Saúde dos } \\
\text { Familiares }\end{array}$ & $\mathrm{G} 2$ & 1,05 & 1,24 & 0 & 4 & 2,043 & 0,047 & 0,590 \\
\hline EAC & G1 & 5,53 & 1,99 & 3 & 12 & 6,748 & $\leq \mathbf{0 , 0 0 1}$ & 1,948 \\
\hline Total & $\mathrm{G} 2$ & 1,95 & 1,57 & 0 & 5 & ס ד, 0,0 & $=0,01$ & סדיקו \\
\hline
\end{tabular}

A Escala de Eventos Adversos (EEA) investiga a presença de vivências que representem desafio ou importante dificuldade na vida da família, ou ainda eventos que possam assumir caráter estressor ou promotor de vulnerabilidade. Com relação à dimensão Contexto Familiar constituída 
por itens que exploram situações da vida laboral e financeira das famílias, bem como marcos no relacionamento entre os pais, dinâmica das relações interpessoais e saúde dos cuidadores parentais, não é possível apontar diferenças estatisticamente significativas entre os grupos examinados. No tocante às mortes e perdas vivenciadas pelos voluntários, ao longo da primeira avaliação, não houve diferenças estatisticamente significativas na quantidade de experiências de morte de membros da família ou amigos entre G1 e G2.

Entretanto, a mesma similitude não é verificada na avaliação de eventos que incidam sobre a saúde da criança e do adolescente, seus relacionamentos e suas vivências escolares. A comparação entre as médias dos grupos nesse quesito indica robusta diferença estatística entre a experiência de crianças e adolescentes enfermos e os saudáveis, assim como tamanho do efeito muito elevado. Na dimensão denominada Vida da Criança, os eventos desfavoráveis podem estar associados ao adoecimento, já que a partir da investigação diagnóstica o participante é levado à convivência com interações hospitalares, modificando assim o cotidiano da criança e suas possibilidades de manter a vida escolar regular, bem como a convivência com seus pares.

Por fim, ao considerarmos a média total no EEA obtida pelo Grupo Clínico e o Grupo de Comparação, encontra-se diferença estatisticamente significativa entre os grupos. Os pacientes pediátricos que passam por cuidado oncológico experimentam maior número de adversidades, de natureza múltipla, em seu contexto de vida e em sua família.

Com relação ao produto da avaliação derivado da Escala de Adversidades Crônicas (EAC), é possível destacar diferenças estatisticamente significativas entre as médias de G1 e G2 e grande elevação do tamanho do efeito com relação às condições de saúde da criança e do adolescente, bem como em seus familiares. Este resultado pode fazer alusão às perdas experimentadas pelos pacientes oncológicos após entrarem no processo de cuidado terciário de saúde, tendo em vista sua hospitalização recorrente, abordagens invasivas para administração de quimioterápico ou realização de exames ou abordagens cirúrgicas, podendo também utilizar próteses. Ademais, com relação às figuras parentais, os achados sugerem necessidade de rastrear indicadores de saúde mental nos pais/cuidadores, além de possível uso abusivo de substâncias, temperamento difícil ou mesmo conflitos conjugais. É importante considerar que não necessariamente essas variáveis associam-se a adaptação ao contexto de adoecimento, contudo podem representar elementos que dificultem o bom desfecho deste processo.

Com o intuito de compreender como o cuidador familiar percebe o apoio que recebe de sua família tem-se a Tabela 7. Ela apresenta os resultados do Inventário de Percepção do Suporte Familiar (IPSF), na primeira etapa de avaliação. 
Tabela 7. Resultados médios e comparação estatística nas diferentes dimensões do Inventário de Percepção do Suporte Familiar (IPSF) na primeira etapa do estudo.

\begin{tabular}{|c|c|c|c|c|c|c|c|c|}
\hline \multirow{2}{*}{ IPSF } & \multirow{2}{*}{ Grupo } & \multicolumn{4}{|c|}{ Análise Descritiva } & \multicolumn{3}{|c|}{ Análise Comparativa } \\
\hline & & Média & DP & Mínimo & Máximo & $t$ & $p$ & d de Cohen \\
\hline \multirow{2}{*}{$\begin{array}{c}\text { Afetivo- } \\
\text { Consistente }\end{array}$} & G1 & 32,50 & 9,26 & 2,00 & 41,00 & \multirow{2}{*}{$-0,750$} & \multirow{2}{*}{0,457} & \multirow{2}{*}{$-0,216$} \\
\hline & $\mathrm{G} 2$ & 34,20 & 4,96 & 19,00 & 41,00 & & & \\
\hline \multirow{2}{*}{$\begin{array}{c}\text { Inadaptação } \\
\text { Familiar }\end{array}$} & G1 & 21,86 & 5,33 & 3,00 & 26,00 & \multirow{2}{*}{$-0,845$} & \multirow{2}{*}{0,402} & \multirow{2}{*}{$-0,244$} \\
\hline & $\mathrm{G} 2$ & 22,95 & 2,52 & 16,00 & 26,00 & & & \\
\hline \multirow{2}{*}{ Autonomia } & G1 & 13,86 & 3,05 & 6,00 & 16,00 & \multirow{2}{*}{$-1,115$} & \multirow{2}{*}{0,275} & \multirow{2}{*}{$-0,319$} \\
\hline & G2 & 14,70 & 1,71 & 11,00 & 16,00 & & & \\
\hline \multirow{2}{*}{ TOTAL } & G1 & 68,23 & 16,56 & 11,00 & 83,00 & \multirow{2}{*}{$-0,936$} & \multirow{2}{*}{0,354} & \multirow{2}{*}{$-0,270$} \\
\hline & $\mathrm{G} 2$ & 71,85 & 5,81 & 53,00 & 80,00 & & & \\
\hline
\end{tabular}

Os familiares dos participantes com diagnóstico oncológico agrupados em G1, quanto os informantes aparentados dos participantes hígidos que compõem G2, apontam perceber de forma semelhante o apoio recebido da família. Nota-se que no escore total do IPSF e em suas três subescalas não houve diferença estatisticamente significativa entre a média dos resultados de $\mathrm{G} 1$ e $\mathrm{G} 2$.

Os resultados oferecidos pelo fator Afetivo-Consistente indicam que familiares de ambos os grupos percebem que as expressões verbais, comportamentais e relacionais entre os membros do grupo familiar são coerentes com os acordos estabelecidos na interação do dia a dia, sinalizando interesse mútuo e clima caloroso na vida íntima. Já a análise da comparação das médias de resultados no fator Inadaptação Familiar oferece subsídios para asseverar que o informante examinado na primeira etapa do estudo avalia positivamente as relações mantidas pelos membros da família, com sentimento de valorização e pertença ao seu grupo de referência parental, com reduzidas vivências de sentimentos negativos, tal como raiva ou vergonha. Por fim, levando em consideração o fator Autonomia, tanto na situação de adaptação frente ao cuidado quanto no cotidiano típico, os cuidadores usufruem de liberdade e confiança diante da própria família, mantendo a articulação com as pessoas desse contexto.

Depreende-se, portanto, que, nesta etapa de avaliação, a percepção da expressão afetiva e a proximidade entre os diversos componentes da família se mantém relativamente preservados. Assim, mesmo diante das transformações na vida do adulto que desempenha o 
papel de cuidador da criança/adolescente que padece devido à doença oncológica e às repercussões no dia a dia provocada pelo cuidado hospitalar, há elementos para argumentar que a percepção do suporte recebido segue sem alterações profundas. Isso tende a favorecer a importante tarefa de reestabelecer o curso da vida mesmo em face da fatalidade da enfermidade.

\subsubsection{Vida da Família (FASE 2)}

A seguir, passaremos a apresentar os resultados obtidos na segunda etapa de avaliação (seis meses após a primeira) do Grupo Clínico e do Grupo de Comparação. Para tanto, serão apresentados os resultados derivados das escalas RAF, EAC e EEA, demonstrando o resultado médio de G1 e G2 e comparação de suas médias.

A Tabela 8 traz os resultados referentes ao Inventário de Recursos do Ambiente Familiar (RAF) e em suas diferentes subesacalas. Reflete a presença de suporte material e imaterial na família, durante a segunda avaliação dos colaboradores deste estudo.

Tabela 8. Resultados médios e comparação estatística dos domínios do Inventário de Recursos do Ambiente Familiar (RAF) na segunda etapa do estudo.

\begin{tabular}{|c|c|c|c|c|c|c|c|c|}
\hline \multirow{2}{*}{ RAF } & \multirow{2}{*}{ Grupo } & \multicolumn{4}{|c|}{ Análise Descritiva } & \multicolumn{3}{|c|}{ Análise Comparativa } \\
\hline & & Média & DP & Mínimo & Máximo & $t$ & $p$ & d de Cohen \\
\hline \multirow{2}{*}{$\begin{array}{c}\text { Supervisão e } \\
\text { organização das } \\
\text { rotinas }\end{array}$} & G1 & 6,19 & 1,25 & 3,56 & 8,81 & \multirow[b]{2}{*}{$-0,865$} & \multirow[b]{2}{*}{0,392} & \multirow[b]{2}{*}{$-0,250$} \\
\hline & $\mathrm{G} 2$ & 6,50 & 1,21 & 3,63 & 8,06 & & & \\
\hline \multirow{2}{*}{$\begin{array}{l}\text { Oportunidade } \\
\text { de interação } \\
\text { com os pais }\end{array}$} & G1 & 8,59 & 2,77 & 4,23 & 18,08 & \multirow[b]{2}{*}{0,284} & \multirow[b]{2}{*}{0,778} & \multirow[b]{2}{*}{0,082} \\
\hline & $\mathrm{G} 2$ & 8,37 & 2,61 & 4,23 & 13,56 & & & \\
\hline \multirow{2}{*}{$\begin{array}{c}\text { Presença de } \\
\text { recursos no } \\
\text { ambiente físico }\end{array}$} & G1 & 4,38 & 1,12 & 2,58 & 7,04 & \multirow[b]{2}{*}{$-1,952$} & \multirow[b]{2}{*}{$\mathbf{0 , 0 5 7}$} & \multirow[b]{2}{*}{$-0,563$} \\
\hline & $\mathrm{G} 2$ & 4,99 & 0,99 & 2,86 & 6,69 & & & \\
\hline \multirow[t]{2}{*}{ TOTAL } & G1 & 6,36 & 1,33 & 4,18 & 10,52 & \multirow{2}{*}{$-0,715$} & \multirow{2}{*}{0,478} & \multirow{2}{*}{$-0,206$} \\
\hline & $\mathrm{G} 2$ & 6,62 & 1,18 & 4,94 & 9,43 & & & \\
\hline
\end{tabular}


Os dados apontam aparente preservação dos recursos familiares, tanto com relação ao aproveitamento das oportunidades de interação no cotidiano, quanto no tocante a práticas educativas parentais e o estabelecimento de mediação entre o filho e o mundo a sua volta. Isto equivale a considerar que tanto famílias que convivem com o câncer pediátrico quanto famílias sem este diagnóstico guardam similitude com relação à dimensão Supervisão $e$ Organização das Rotinas, quanto Oportunidade de Interação com os Pais. Isto pode ser reflexo dos atributos necessários para o estabelecimento do cuidado familiar em parceria com as práticas de cuidado da equipe multiprofissional em saúde, uma vez que para desenvolver com adequação esta tarefa, pais, irmãos e outros familiares e amigos próximos devem manter a proximidade com o paciente, desempenhando papéis que favoreçam a proteção e encorajem a interação com o mundo a sua volta.

Cumpre destacar que na dimensão Presença de Recursos no Ambiente Físico houve tendência a diferença estatisticamente significativa entre o resultado do Grupo Clínico e o Grupo de Comparação, porém com elevado tamanho do efeito dessa variável. Aparentemente, G1 demonstra resultados inferiores a G2, podendo espelhar não apenas que as crianças e adolescentes ao longo do cuidado oncológico usufruem de menos recursos físicos de estimulação, como jogos, brinquedos, aparelhos eletrônicos, material de leitura ou atividades extracurriculares, mas que devido à rotina de constante afastamento do lar para internações e consultas ambulatoriais, acabam por se afastar de tais estímulos ou desfrutarem pouco de componentes físicos dos recursos familiares.

Apesar dessa particularidade, os resultados gerais na RAF nesse segundo momento avaliativo denotam ausência de diferenças estatísticas significativas entre G1 e G2. Pode-se inferir que, ao longo do processo adaptativo frente à situação de adoecimento e de estabelecimento de cuidado, grupos familiares que têm seu cotidiano afetado pelo câncer conseguem manter bom aproveitamento dos recursos presentes em seu ambiente.

A seguir, na Tabela 9, constam os resultados médios e comparação estatística de ambos os grupos na Escala de Eventos Adversos (EEA) e na Escala de Adversidades Crônicas (EAC) na segunda avaliação desenvolvida com os familiares. 
Tabela 9. Resultados médios e comparação estatística da Escala de Eventos Adversos (EEA) e Escala de Adversidades Crônicas (EAC) na segunda avaliação.

\begin{tabular}{|c|c|c|c|c|c|c|c|c|}
\hline \multirow{2}{*}{ Instrumento } & \multirow{2}{*}{ Grupo } & \multicolumn{4}{|c|}{ Análise Descritiva } & \multicolumn{3}{|c|}{ Análise Comparativa } \\
\hline & & Média & DP & Mínimo & Máximo & $t$ & $p$ & d de Cohen \\
\hline \multirow{2}{*}{$\begin{array}{c}\text { EEA } \\
\text { Contexto } \\
\text { Familiar }\end{array}$} & G1 & 8,90 & 5,18 & 0 & 19 & \multirow[b]{2}{*}{1,213} & \multirow[b]{2}{*}{0,231} & \multirow[b]{2}{*}{0,350} \\
\hline & $\mathrm{G} 2$ & 7,30 & 3,42 & 0 & 13 & & & \\
\hline \multirow{2}{*}{$\begin{array}{c}\text { EEA } \\
\text { Vida da } \\
\text { Criança }\end{array}$} & G1 & 6,13 & 2,73 & 2 & 11 & \multirow[b]{2}{*}{5,424} & \multirow[b]{2}{*}{$\leq \mathbf{0 , 0 0 1}$} & \multirow[b]{2}{*}{1,566} \\
\hline & $\mathrm{G} 2$ & 2,50 & 1,46 & 1 & 7 & & & \\
\hline \multirow{2}{*}{$\begin{array}{c}\text { EEA } \\
\text { Mortes e } \\
\text { Perdas }\end{array}$} & G1 & 1,77 & 1,27 & 0 & 4 & \multirow[b]{2}{*}{3,374} & \multirow[b]{2}{*}{$\leq \mathbf{0 , 0 0 1}$} & \multirow[b]{2}{*}{0,974} \\
\hline & $\mathrm{G} 2$ & 0,70 & 0,73 & 0 & 2 & & & \\
\hline \multirow{2}{*}{$\begin{array}{c}\text { EEA } \\
\text { TOTAL }\end{array}$} & G1 & 16,80 & 6,25 & 8 & 32 & \multirow{2}{*}{4,030} & \multirow{2}{*}{$\leq \mathbf{0 , 0 0 1}$} & \multirow{2}{*}{1,163} \\
\hline & $\mathrm{G} 2$ & 10,50 & 3,79 & 2 & 16 & & & \\
\hline \multirow{2}{*}{$\begin{array}{c}\text { EAC } \\
\text { Saúde da } \\
\text { Criança }\end{array}$} & G1 & 3,57 & 0,81 & 2 & 6 & \multirow[b]{2}{*}{11,536} & \multirow[b]{2}{*}{$\leq \mathbf{0 , 0 0 1}$} & \multirow[b]{2}{*}{3,330} \\
\hline & $\mathrm{G} 2$ & 0,70 & 0,92 & 0 & 3 & & & \\
\hline \multirow{2}{*}{$\begin{array}{c}\text { EAC } \\
\text { Saúde dos } \\
\text { Familiares }\end{array}$} & G1 & 2,17 & 1,76 & 0 & 7 & \multirow[b]{2}{*}{2,692} & \multirow[b]{2}{*}{$\mathbf{0 , 0 1 0}$} & \multirow[b]{2}{*}{$\mathbf{0 , 7 7 7}$} \\
\hline & $\mathrm{G} 2$ & 1,00 & 0,97 & 0 & 3 & & & \\
\hline EAC & G1 & 5,73 & 2,16 & 3 & 12 & \multirow{2}{*}{7,604} & \multirow{2}{*}{$\leq \mathbf{0 , 0 0 1}$} & \multirow{2}{*}{2,195} \\
\hline Total & $\mathrm{G} 2$ & 1,70 & 1,17 & 0 & 4 & & & \\
\hline
\end{tabular}

Os resultados dessa segunda avaliação destacam a quantidade e intensidade de eventos adversos e geradores de dificuldades que incidem no seio familiar de crianças e adolescentes com câncer se comparados a famílias que gozam de saúde. A única exceção foi a dimensão Contexto Familiar da Escala de Eventos Adversos (EEA), onde a média obtida por G1 não apresenta diferenças estatísticas substanciais se comparada a média de G2. Este resultado pode apontar que o curso do adoecimento não altera significativamente a representação de papéis sociais ligados ao contexto do trabalho, tampouco produz efeitos negativos sobre a vida econômica da família, bem como não ressoa de modo a gerar desestruturação nas relações familiares, como separação dos pais ou saída de casa de um dos irmãos saudáveis após briga ou gravidez. 
Entretanto, a supremacia dos resultados obtidos por G1 na dimensão Saúde dos Familiares na EEA oferece indícios que mães e pais que assumem o cuidado de filhos portadores de doenças neoplásicas experimentam repercussões negativas em sua saúde mental, ao longo da vivência de tratamento. Assim, dentro dos alcances e limites deste instrumento avaliativo, é lícito apontar que diante do desafio de lidar com as ameaças à vida do filho, os pais podem experimentar mais situações de conflito conjugal ou familiar, assim como desenvolver psicopatologias ou abuso de substâncias.

O segundo passo analítico volta-se aos fatores Vida da Criança (EEA) e Saúde da Criança (EAC). Nota-se que o comprometimento da saúde de crianças e adolescentes com diagnóstico oncológico (mais expostos a procedimentos médicos invasivos e internações hospitalares ou longa permanência em hospital dia e ambulatórios, ao uso de próteses ou órteses, estigmas físicos associados ao intenso tratamento de saúde) produz repercussões desfavoráveis em seus relacionamentos sociais, desempenho escolar e progressão no universo acadêmico.

Em complemento, a dimensão Mortes e Perdas (EEA) sinaliza que G1 convive mais com a morte de pessoas significativas em relação a G2. Assim, ao adentrar no universo hospitalar e no cuidado oncológico, tanto pais quanto pacientes poderão constituir vínculos importantes com outros casos e seus familiares, que eventualmente podem experimentar agravamento de seu quadro, vindo a falecer. Desta maneira, já em tenra idade passam a conviver com a experiência da morte do outro e processos de luto daí derivados.

Em síntese, os achados empíricos dessa segunda avaliação de G1 e G2 apontaram diferenças estatisticamente significativas na EEA e na EAC. Revelam, portanto, que o processo de adaptação frente à convivência com o fenômeno do adoecimento, ao longo do tempo (seis meses), repercute de modo desfavorável na saúde dos pais, na vida escolar e social da criança e do adolescente, bem como os expõe a mais vivências de perdas e de finitude. Depreende-se que a experiência de conviver com o câncer infantojuvenil parece não produzir prejuízos significativos em como a família se organiza financeiramente ou mantém interações com seus filhos e outros parentes, todavia denota alto custo em outros campos na dinâmica de vida dos familiares.

Em sequência têm-se os dados referentes ao Inventário de Percepção do Suporte Familiar (IPSF) na segunda etapa do estudo. Eles compõem a Tabela 10. 
Tabela 10. Resultados médios e comparação estatística nas diferentes dimensões do Inventário de Percepção do Suporte Familiar (IPSF) na segunda etapa do estudo.

\begin{tabular}{ccccccccc}
\hline \multirow{2}{*}{ IPSF } & Grupo & \multicolumn{5}{c}{ Análise Descritiva } & \multicolumn{3}{c}{ Análise Comparativa } \\
& & Média & DP & Mínimo & Máximo & $t$ & $p$ & $d$ de Cohen \\
\hline Afetivo- & G1 & 32,26 & 8,97 & 8 & 42 & $-1,178$ & 0,245 & $-0,340$ \\
Consistente & G2 & 34,90 & 5,35 & 22 & 42 & & & \\
& & & & & & & & \\
Inadaptação & G1 & 21,63 & 5,05 & 8 & 26 & $-2,123$ & $\mathbf{0 , 0 3 9}$ & $\mathbf{- 0 , 6 1 3}$ \\
Familiar & G2 & 24,15 & 1,89 & 21 & 26 & & & \\
& & & & & & & & \\
Autonomia & G1 & 14,50 & 2,23 & 8 & 16 & $-0,175$ & 0,862 & $-0,050$ \\
& G2 & 14,60 & 1,50 & 12 & 16 & & & \\
TOTAL & G1 & 68,40 & 14,22 & 29 & 84 & $-1,540$ & 0,130 & $-0,445$ \\
& G2 & 73,65 & 6,60 & 60 & 84 & & & \\
\hline
\end{tabular}

No total do IPSF, a percepção que o cuidador principal da criança/adolescente tem acerca do apoio ofertado por sua família, mais uma vez não se diferenciou entre G1 e G2, mesmo após seis meses da primeira avaliação. Entretanto, ao considerarmos a dimensão Inadaptação Familiar, constatamos importante diferença entre os resultados, com elevado tamanho do efeito, tendo G1 resultado médio inferior. Este achado sugere que o cuidador principal de G1 vivencia menos sentimentos negativos nas relações entre os membros da família e maior integração com o grupo a qual pertence, quando comparado a G2. Provavelmente a sensação de acolhimento familiar desse cuidador estaria associada à necessária articulação entre os diversos membros do grupo ao longo do tempo, com o objetivo de manter o cuidado com o paciente pediátrico, fortalecendo vínculos.

\subsubsection{Vida da Família - Comparação FASE 1 e FASE 2 no Grupo Clínico}

Com objetivo de oferecer panorama sobre possíveis efeitos longitudinais do processo de confrontação e adaptação da família diante do cuidado oncológico da criança/adolescente, serão apresentados os resultados médios do Grupo Clínico nos dois momentos avaliativos (Fase 1 e Fase 2), tendo por base os instrumentos RAF, EEA, EAC e IPSF. Portanto, esta estratégia analítica intragrupo (apenas em G1) tem por finalidade examinar possíveis 
mudanças nos achados em função do tempo de desenvolvimento e de cuidado das crianças e adolescentes avaliados.

Inicialmente, na Tabela 11 será possível visualizar a comparação dos resultados do Grupo Clínico (G1) referente ao Inventário de Recursos do Ambiente Familiar (RAF) nas duas etapas do estudo.

Tabela 11. Resultados médios e comparação estatística dos dois momentos avaliativos do Grupo Clínico (G1) no Inventário de Recursos do Ambiente Familiar (RAF).

\begin{tabular}{ccccccccc}
\hline \multirow{2}{*}{ RAF } & Avaliação & \multicolumn{3}{c}{ Análise Descritiva } & \multicolumn{3}{c}{ Análise Comparativa } \\
& & Média & DP & Mínimo & Máximo & $z$ & $p$ & $d$ de Cohen \\
\hline $\begin{array}{c}\text { Supervisão e } \\
\text { organização das } \\
\text { rotinas }\end{array}$ & Fase 1 & 6,21 & 1,38 & 1,88 & 9,19 & & & \\
Fase 2 & 6,19 & 1,25 & 3,56 & 8,81 & $-0,182$ & 0,855 & 0,016 \\
$\begin{array}{c}\text { Oportunidade } \\
\text { de interação } \\
\text { com os pais }\end{array}$ & Fase 1 & 7,52 & 2,32 & 4,64 & 16,48 & & & \\
Fase 2 & 8,59 & 2,77 & 4,23 & 18,08 & $-2,649$ & $\mathbf{0 , 0 0 8}$ & $\mathbf{- 0 , 4 3 8}$ \\
$\begin{array}{c}\text { Presença de } \\
\text { recursos no }\end{array}$ & Fase 1 & 4,82 & 1,16 & 2,08 & 6,47 & & & \\
ambiente físico & Fase 2 & 4,38 & 1,12 & 2,58 & 7,04 & $-2,235$ & $\mathbf{0 , 0 2 5}$ & $\mathbf{0 , 4 5 2}$ \\
& & & & & & & & \\
TOTAL & Fase 1 & 6,18 & 1,30 & 3,14 & 10,00 & $-1,308$ & 0,191 & $-0,157$ \\
& Fase 2 & 6,36 & 1,33 & 4,18 & 10,52 & & & \\
\hline
\end{tabular}

A análise comparativa dos recursos familiares de G1 nos dois momentos avaliativos apontou que o resultado médio em Oportunidade de Interação com os Pais foi mais elevado após seis meses da primeira avaliação, ou seja, na Fase 2 do estudo. Essa maior interação entre os pais e seu filho enfermo pareceu associada ao próprio convívio necessário no ambiente hospitalar, bem como a maior supervisão prestada em ambiente doméstico com o intuito de garantir o bem-estar do jovem paciente em tempo integral. As oportunidades de realização de passeios e interações lúdicas proporcionadas pela equipe de suporte e assistência oncológica ao longo do tratamento também podem ter favorecido esse aumento na interação dos filhos com seus pais, identificado nessa Fase 2.

De forma antagônica, houve diminuição estatisticamente significativa com moderado tamanho do efeito no resultado médio da Presença de Recursos no Ambiente na segunda 
avaliação. Esse achado pode se associar a efeitos colaterais vivenciados após os ciclos de administração de quimioterápico ou por conta de medidas de precaução que visam a menor exposição do paciente oncológico pediátrico diante de intercorrência de saúde, como infecções oportunistas. Isso resultaria em menor aproveitamento de atividades extracurriculares ou mesmo brincadeiras que envolvam intensa movimentação do corpo, as quais são suspensas ou realizadas com extremo cuidado. Esse contexto pode favorecer a percepção de menos recursos físicos disponíveis para interação e estimulação da criança, tais como bicicleta, patinete, bola, corda, animais de estimação, entre outros.

No entanto, de forma global, ao longo do período de intervalo entre as duas avaliações realizadas neste estudo, a família apresentou indícios gerais de manutenção dos recursos ambientais de estimulação do processo evolutivo do filho que convive com a doença neoplásica. Houve manutenção de bom nível de interatividade entre os membros da família e, apesar da dinâmica inconstante da jornada de cuidado a saúde, relativa coesão e estabilidade no cotidiano doméstico, além de práticas educativas favorecedoras do desenvolvimento cognitivo e psicossocial.

A seguir o enfoque será a análise comparativa entre Fase 1 e Fase 2 do Grupo Clínico na Escala de Eventos Adversos (EEA) e na Escala de Adversidades Crônicas (EAC), considerando suas distintas dimensões e escore total. Esses achados compõem a Tabela 12. 
Tabela 12. Resultados médios e comparação estatística dos dois momentos avaliativos do Grupo Clínico (G1) em função da Escala de Eventos Adversos (EEA) e Escala de Adversidades Crônicas (EAC).

\begin{tabular}{ccccccccc}
\hline & & \multicolumn{3}{c}{ Análise Descritiva } & \multicolumn{3}{c}{ Análise Comparativa } \\
Instrumento & Avaliação & Média & DP & Mínimo & Máximo & $z$ & $p$ & $d$ de Cohen \\
\hline EEA & Fase 1 & 10,03 & 5,22 & 1 & 20 & & & \\
Contexto & Fase 2 & 8,90 & 5,18 & 0 & 19 & $-1,918$ & $\mathbf{0 , 0 5 5}$ & $\mathbf{0 , 3 1 2}$ \\
Familiar & & & & & & & & \\
& & & & & & & \\
EEA & Fase 1 & 6,07 & 2,54 & 3 & 13 & & & \\
Vida da & Fase 2 & 6,13 & 2,73 & 2 & 11 & $-0,230$ & 0,818 & $-0,026$ \\
Criança & & & & & & & & \\
& & & & & & & \\
EEA & Fase 1 & 1,17 & 1,20 & 0 & 4 & & \\
Mortes e & Fase 2 & 1,77 & 1,27 & 0 & 4 & $-2,337$ & $\mathbf{0 , 0 1 9}$ & $\mathbf{- 0 , 4 5 2}$ \\
Perdas & & & & & & & & \\
EEA & Fase 1 & 17,27 & 6,59 & 6 & 31 & $-0,748$ & 0,455 & 0,108 \\
TOTAL & Fase 2 & 16,80 & 6,25 & 8 & 32 & & & \\
EAC & Fase 1 & 3,57 & 0,97 & 1 & 5 & & & \\
Saúde da & Fase 2 & 3,57 & 0,81 & 2 & 6 & $-0,420$ & 0,675 & - \\
Criança & & & & & & & & \\
EAC & Fase 1 & 1,97 & 1,73 & 0 & 7 & & & \\
Saúde dos & Fase 2 & 2,17 & 1,76 & 0 & 3 & $-0,781$ & 0,435 & $-0,132$ \\
Familiares & & & & & & & & \\
EAC & Fase 1 & 5,53 & 1,99 & 3 & 12 & $-0,097$ & 0,923 & \\
Total & Fase 2 & 5,73 & 2,16 & 0 & 4 & & & \\
\hline
\end{tabular}

A partir do exame geral de eventos vulnerabilizantes e estressores que podem ter acometido as famílias com filho(a) em cuidados oncológicos, nota-se aparente manutenção dos impactos advindos do diagnóstico oncológico na realidade do paciente ao longo dos dois momentos avaliativos. Este apontamento advém da análise das respostas aos itens que avaliam acometimento físico, vida escolar e relação com os pares na Escala de Eventos Adversos (EEA), bem como do quadro geral de saúde da criança ou adolescente na Escala de Adversidades Crônicas (EAC).

As adversidades trazidas pela primeira etapa de tratamento oncológico podem produzir mudanças no estado de saúde da criança/adolescente, consequências que parecem manter-se relativamente estáveis ao longo do tempo. Foi verificada a manutenção de internações em 
enfermaria clínica para dar seguimento à realização de quimioterapia ou controlar eventos secundários negativos do tratamento farmacológico, mas também se preservam os estigmas físicos advindos de intervenções cirúrgicas ou radioterápicas. Em consequência da perda da saúde em seu sentido mais amplo, por conta da necessidade de manter severos cuidados para prevenir infecções oportunistas, parecem ocorrer também alterações desfavoráveis a sua integração social e participação no universo escolar.

Dentre os eventos psicossociais com os quais se deparam os pacientes que convivem com o câncer infantojuvenil, destaca-se a convivência com a morte de pessoas significativas. O domínio Mortes e Perdas da Escala de Eventos Adversos têm como objetivo identificar se a criança vivenciou a perda de um amigo, avós, pais ou irmãos em algum período de sua vida. Além da imprevisibilidade da perda de membros relevantes da família ao longo do processo evolutivo, ao se instalar na realidade trazida pelo ambiente hospitalar e estabelecer relações com outras famílias que passam por experiências equivalentes, estes pacientes recorrentemente vivenciam a perda de companheiros no transcorrer do tratamento, de modo que serão expostos a vivências de finitude do outro, bem como de luto.

Com o transcorrer de seis meses de cuidado oncológico pediátrico, aparentemente não houve ampliação da incidência dos eventos negativos dentro da dinâmica familiar, na vida econômica e profissional dos pais ou em indicadores de saúde mental dos genitores/substitutos. A partir das pressões durante a primeira etapa de cuidado, a dinâmica da família e de suas relações sociais podem sofrer alterações e produzir repercussões negativas nas vivências socioeconômicas do grupo. Entretanto, por esforços adaptativos diante das exigências e desafios trazidos pelo momento de vida, o grupo tende a estabelecer certa estabilidade em sua dinâmica de interações e busca pela manutenção do novo equilíbrio adquirido.

Por fim, focaliza-se a percepção do suporte familiar por meio dos resultados no IPSF. A Tabela 13 ilustra esses achados, comparando os dois momentos avaliativos do Grupo Clínico (G1). 
Tabela 13. Resultados médios e comparação estatística dos dois momentos avaliativos do Grupo Clínico (G1) a partir do Inventário de Percepção do Suporte Familiar (IPSF).

\begin{tabular}{|c|c|c|c|c|c|c|c|c|}
\hline \multirow{2}{*}{ IPSF } & \multirow{2}{*}{ Avaliação } & \multicolumn{4}{|c|}{ Análise Descritiva } & \multicolumn{3}{|c|}{ Análise Comparativa } \\
\hline & & Média & DP & Mínimo & Máximo & $t$ & $p$ & $d$ de Cohen \\
\hline \multirow{2}{*}{$\begin{array}{c}\text { Afetivo- } \\
\text { Consistente }\end{array}$} & Fase 1 & 32,50 & 9,26 & 2 & 41 & \multirow{2}{*}{$-0,573$} & \multirow{2}{*}{0,566} & \multirow{2}{*}{0,040} \\
\hline & Fase 2 & 32,26 & 8,97 & 8 & 42 & & & \\
\hline \multirow{2}{*}{$\begin{array}{c}\text { Inadaptação } \\
\text { Familiar }\end{array}$} & Fase 1 & 21,86 & 5,33 & 3 & 26 & \multirow{2}{*}{$-0,272$} & \multirow{2}{*}{0,786} & \multirow{2}{*}{0,064} \\
\hline & Fase 2 & 21,63 & 5,05 & 8 & 26 & & & \\
\hline \multirow{2}{*}{ Autonomia } & Fase 1 & 13,86 & 3,05 & 6 & 16 & \multirow{2}{*}{$-1,069$} & \multirow{2}{*}{0,285} & \multirow{2}{*}{$-0,207$} \\
\hline & Fase 2 & 14,50 & 2,23 & 8 & 16 & & & \\
\hline \multirow{2}{*}{ TOTAL } & Fase 1 & 68,23 & 16,56 & 11 & 83 & \multirow{2}{*}{$-0,496$} & \multirow{2}{*}{0,620} & \multirow{2}{*}{$-0,016$} \\
\hline & Fase 2 & 68,40 & 14,22 & 29 & 84 & & & \\
\hline
\end{tabular}

Ao investigar possível efeito do tempo de tratamento sobre a percepção de suporte familiar por parte do cuidador principal da criança/adolescente de G1, depreende-se preservação dos afetos entre os componentes do grupo. Além disso, notou-se possibilidade da comunicação e da manutenção da empatia, sensação de pertença e integração ao coletivo, preservando a independência e privacidade, sem com isso apresentar níveis nocivos de raiva ou vergonha.

As médias dos escores obtidos nas duas avaliações de G1 nos domínios Afetivo-Consistente, Inadaptação Familiar, Autonomia e na totalidade do IPSF sinalizam estratégias de adaptação que recorrem ao mútuo apoio dentro do grupo familiar, seja ele nuclear ou expandido. Assim, a ausência de diferenças estatisticamente significativas entre as médias no IPSF pode indicar busca eficaz de estratégias coletivas para lidar com as agruras do cuidado, seja compartilhando papéis no cenário hospitalar, no compartilhamento de tarefas na cidade de origem e no ambiente doméstico.

\subsubsection{Vida da Família - Síntese}

Diante dos aspectos avaliados pelas escalas e inventários acima expostos, pode-se observar que o diagnóstico de neoplasia, convivência e intimidade com o ambiente hospitalar e abordagens terapêuticas invasivas, tende a produzir rupturas nos processos de interação da criança e do adolescente com seus pares. Esse processo pode afastá-los de situações típicas desta etapa do ciclo vital, tanto ao que tange no aproveitamento de recursos lúdicos e de 
estímulo cognitivo e social disponíveis em seu lar, quanto nos processos interativos de cunho intelectual e social próprios da escola.

Ademais, verifica-se que as famílias que convivem com câncer pediátrico têm presentes em sua história acometimentos socioeconômicos similares daquelas que não vivenciam o cuidado a um familiar que adoece em tenra idade. A mesma similitude entre Grupo Clínico e Grupo de Comparação pode ser identificada no tocante às alterações na estrutura do grupo e na representação dos papéis familiares, como separação e divórcio, necessidade de mediação judicial para o estabelecimento de guarda e pensão, afastamento dos irmãos saudáveis por brigas ou gravidez precoce, a introdução de um terceiro adulto na família, entre outros.

Não obstante, os pais de crianças e adolescentes com câncer aparentemente apresentam mais sinais de vivência de turbulências nas relações conjugais ou familiares, além de indicativos de repercussões negativas nos aspectos mentais de sua saúde derivados da experiência de ocupar o papel de cuidador familiar no contexto hospitalar e doméstico. Nesta direção, pelo menos um dos pais ou responsáveis que compõem G1 apresentam mais indicadores de temperamento difícil, consumo de álcool e drogas e acometimentos de transtornos de saúde mental em relação aos familiares correspondentes em G2.

Apesar do custo inerente à confrontação com o fenômeno da ameaça da saúde e da vida trazido pelo câncer pediátrico, o aproveitamento dos recursos provenientes da família aparentemente figura como importante conjunto de estratégias para lidar com a delicadeza e intensidade da situação. Nesse contexto, parecem recorrer a estratégias de aproximação entre os membros do grupo e o gozo da percepção de pertencimento, o estabelecimento do acolhimento e clima empático entre os familiares, a busca por oportunidades de interação entre os membros saudáveis com a criança ou adolescente portador de doença neoplásica, tanto em ambiente doméstico quanto em situações sociais, além da manutenção da independência e autonomia do cuidador principal. Essas variáveis constituem recursos positivos diante dos desafios vivenciados inerentes ao cuidado oncológico.

Por fim, destaca-se que, ao ser considerada a perspectiva longitudinal, os achados mostram estabilidade temporal dos indicadores de aproveitamento dos recursos familiares, eventos adversos e crônicos de natureza psicossocial e percepção do suporte familiar. Neste sentido, com exceção da maior convivência com a morte pela exposição ao ambiente hospitalar, as repercussões que atingiram paciente e sua família se mantiveram estáveis no intervalo de seis meses. Isto pode fazer pensar que as estratégias de adaptação diante do novo desafio (reagir ao câncer e seu tratamento) são estabelecidas nas primeiras semanas após o diagnóstico, tendendo à manutenção ao longo do curso da assistência oncológica. 


\subsection{Indicadores de Saúde Mental Infantojuvenil}

\subsubsection{Indicadores de Saúde Mental Infantojuvenil (FASE 1)}

$\mathrm{Na}$ tentativa de caracterizar como os pais ou responsáveis que desempenham o papel de cuidador principal observam o comportamento de sua criança/adolescente, foram considerados os achados do Questionário de Capacidades e Dificuldades (SDQ). Isto permitiu descrever e comparar características dos participantes de G1 e G2 no que concerne aos indicadores de hiperatividade, problemas de conduta e de relacionamento com seus pares, sintomas emocionais e comportamento pró-social.

Na Tabela 14 constam os resultados médios e a comparação estatística de G1 e G2 nas diferentes dimensões que compõem o Questionário de Capacidade e Dificuldades. Essa tabela apresenta os achados da primeira avaliação realizada.

Tabela 14. Resultados médios e comparação estatística dos grupos referente ao Questionário de Capacidade e Dificuldades (SDQ) na primeira avaliação.

\begin{tabular}{|c|c|c|c|c|c|c|c|c|}
\hline \multirow{2}{*}{ SDQ } & \multirow{2}{*}{ Grupo } & \multicolumn{4}{|c|}{ Análise Descritiva } & \multicolumn{3}{|c|}{ Análise Comparativa } \\
\hline & & Média & DP & Mínimo & Máximo & $t$ & $p$ & $d$ de Cohen \\
\hline \multirow{2}{*}{ Geral } & Grupo 1 & 12,20 & 5,88 & 2 & 26 & \multirow{2}{*}{2,623} & \multirow{2}{*}{0,012} & \multirow{2}{*}{0,757} \\
\hline & Grupo 2 & 8,20 & 4,20 & 0 & 16 & & & \\
\hline Sintomas & Grupo 1 & 5,26 & 2,31 & 1 & 1 & \multirow{2}{*}{4,350} & \multirow{2}{*}{$\leq \mathbf{0 , 0 0 1}$} & \multirow{2}{*}{1,256} \\
\hline Emocionais & Grupo 2 & 2,65 & 1,66 & 0 & 6 & & & \\
\hline \multirow{2}{*}{$\begin{array}{l}\text { Problemas } \\
\text { de Conduta }\end{array}$} & Grupo 1 & 1,86 & 2,20 & 0 & 8 & \multirow{2}{*}{1,548} & \multirow{2}{*}{0,128} & \multirow{2}{*}{0,047} \\
\hline & Grupo 2 & 1,05 & 0,99 & 0 & 3 & & & \\
\hline \multirow{2}{*}{ Hiperatividade } & Grupo 1 & 3,26 & 2,50 & 0 & 10 & \multirow{2}{*}{$-0,256$} & \multirow{2}{*}{0,799} & \multirow{2}{*}{$-0,074$} \\
\hline & Grupo 2 & 3,45 & 2,43 & 0 & 8 & & & \\
\hline \multirow{2}{*}{$\begin{array}{l}\text { Problemas de } \\
\text { Relacionamento }\end{array}$} & Grupo 1 & 1,80 & 1,60 & 0 & 5 & \multirow{2}{*}{1,821} & \multirow{2}{*}{$\mathbf{0 , 0 7 5}$} & \multirow{2}{*}{0,526} \\
\hline & Grupo 2 & 1,05 & 1,09 & 0 & 4 & & & \\
\hline \multirow{2}{*}{$\begin{array}{l}\text { Comportamento } \\
\text { Pró-social }\end{array}$} & Grupo 1 & 9,03 & 1,56 & 4 & 10 & \multirow{2}{*}{$-1,338$} & \multirow{2}{*}{0,187} & \multirow{2}{*}{$-0,386$} \\
\hline & Grupo 2 & 9,55 & 0,88 & 7 & 10 & & & \\
\hline
\end{tabular}


A partir da avaliação dos pais/cuidadores, as crianças e os adolescentes de G1 apresentaram perfis semelhantes em relação a problemas de conduta, hiperatividade e comportamento pró-social. Esta constatação sugere que pacientes diagnosticados com algum tipo de neoplasia manteriam comportamentos sintonizados às regras e limites das interações sociais, além de conseguir sustentar o foco de sua atenção, preservando positivo engajamento nas relações interpessoais.

Contudo, observa-se diferença estatisticamente significativa entre os dados médios globais do SDQ de G1 e G2 e Sintomas Emocionais, com tamanho do efeito muito elevado, bem como tendência a diferença na dimensão e Problemas de Relacionamento, que sinaliza tamanho de efeito elevado. Em síntese, crianças e adolescentes com câncer manifestariam mais indicadores de problemas de saúde mental. Pela ótica e percepção dos cuidadores familiares, os voluntários em cuidado oncológico apresentariam mais problemas emocionais que seus pares saudáveis, com mais manifestações de labilidade, medo e raiva diante de novos contextos. Os participantes de G1 também parecem permanecer mais tempo sozinhos ou em companhia de adultos, incidindo em dificuldades de relacionamento com seus pares. Isso poderia ser compreendido como reflexo das recomendações médicas visando diminuir a exposição a infecções e doenças oportunistas, favorecendo comportamento superprotetor dos pais.

\subsubsection{Indicadores de Saúde Mental Infantojuvenil (FASE 2)}

Os resultados obtidos pelo Grupo Clínico e o Grupo de Comparação no SDQ, após intervalo de pelo menos seis meses do primeiro exame, podem ser visualizados na Tabela 15. São apresentados, desse modo, os dados médios e a comparação estatística dos achados da segunda aplicação do SDQ (versão pais). 
Tabela 15. Resultados médios e comparação estatística dos grupos referente ao Questionário de Capacidade e Dificuldades (SDQ) na segunda avaliação.

\begin{tabular}{|c|c|c|c|c|c|c|c|c|}
\hline \multirow{2}{*}{ SDQ } & \multirow{2}{*}{ Grupo } & \multicolumn{4}{|c|}{ Análise Descritiva } & \multicolumn{3}{|c|}{ Análise Comparativa } \\
\hline & & Média & D P & Mínimo & Máximo & $t$ & $p$ & $d$ de Cohen \\
\hline \multirow{2}{*}{ Geral } & Grupo 1 & 11,83 & 6,17 & 1 & 29 & \multirow{2}{*}{2,000} & \multirow{2}{*}{$\mathbf{0 , 0 5 1}$} & \multirow{2}{*}{$\mathbf{0 , 5 7 7}$} \\
\hline & Grupo 2 & 8,55 & 4,85 & 1 & 20 & & & \\
\hline \multirow{2}{*}{$\begin{array}{c}\text { Sintomas } \\
\text { Emocionais }\end{array}$} & Grupo 1 & 5,03 & 2,76 & 0 & 10 & \multirow{2}{*}{2,922} & \multirow{2}{*}{0,004} & \multirow{2}{*}{0,864} \\
\hline & Grupo 2 & 2,90 & 1,94 & 0 & 6 & & & \\
\hline \multirow{2}{*}{$\begin{array}{l}\text { Problemas } \\
\text { de Conduta }\end{array}$} & Grupo 1 & 1,56 & 2,04 & 0 & 8 & \multirow{2}{*}{1,552} & \multirow{2}{*}{0,127} & \multirow{2}{*}{0,448} \\
\hline & Grupo 2 & 0,80 & 1,00 & 0 & 3 & & & \\
\hline \multirow{2}{*}{ Hiperatividade } & Grupo 1 & 3,03 & 2,59 & 0 & 10 & \multirow{2}{*}{$-0,419$} & \multirow{2}{*}{0,677} & \multirow{2}{*}{$-0,121$} \\
\hline & Grupo 2 & 3,35 & 2,66 & 0 & 8 & & & \\
\hline \multirow{2}{*}{$\begin{array}{l}\text { Problemas de } \\
\text { Relacionamento }\end{array}$} & Grupo 1 & 2,20 & 1,80 & 0 & 7 & \multirow{2}{*}{1,510} & \multirow{2}{*}{0,138} & \multirow{2}{*}{0,436} \\
\hline & Grupo 2 & 1,50 & 1,23 & 0 & 4 & & & \\
\hline \multirow{2}{*}{$\begin{array}{l}\text { Comportamento } \\
\text { Pró-social }\end{array}$} & Grupo 1 & 9,23 & 1,35 & 4 & 10 & \multirow{2}{*}{$-0,417$} & \multirow{2}{*}{0,679} & \multirow{2}{*}{$-0,120$} \\
\hline & Grupo 2 & 9,40 & 1,42 & 4 & 10 & & & \\
\hline
\end{tabular}

Pela observação dos pais ou responsáveis houve semelhanças entre os grupos no que se refere a problemas de conduta, hiperatividade, relacionamentos interpessoais e comportamento pró-social nesse segundo momento avaliativo. As crianças e adolescentes com câncer, além de manterem objetividade e foco atencional, também sinalizaram bom equilíbrio nas interações sociais, mantendo consonância com as regras estabelecidas na convivência coletiva, buscando relações significativas e satisfatórias.

Entretanto, no resultado geral do SDQ e na dimensão Problemas Emocionais, G1 apresentou resultado médio estatisticamente superior a G2, sendo essa diferença de robusto tamanho de efeito entre as médias dos grupos. Em outras palavras, o Grupo Clínico apresenta mais sinais de comprometimento em saúde mental, refletindo de modo crônico na sua vida familiar e nas vivências sociais, com expressões comportamentais mais frequentes de angústia e tristeza. 


\subsubsection{Indicadores de Saúde Mental Infantojuvenil - Comparação FASE 1 e FASE 2 no Grupo Clínico}

O enfoque a ser apresentado volta-se à comparação dos escores médios obtidos pelo Grupo Clínico (G1) nas duas etapas de avaliação, de modo a verificar o possível efeito do intervalo de seis meses e suas intercorrências nos indicadores de saúde mental dos voluntários do estudo, a partir do SDQ (versão pais). A Tabela 16 traz esses resultados médios do SDQ e a comparação estatística dos escores obtidos pelo Grupo Clínico nas duas etapas da avaliação psicológica.

Tabela 16. Resultados médios e comparação estatística dos dois momentos avaliativos do Grupo Clínico (G1) a partir do Questionário de Capacidade e Dificuldades e (SDQ).

\begin{tabular}{ccccccccc}
\hline \multirow{2}{*}{ SDQ } & Grupo & \multicolumn{5}{c}{ Análise Descritiva } & \multicolumn{3}{c}{ Análise Comparativa } \\
& & Média & DP & Mínimo & Máximo & $z$ & $p$ & $d$ de Cohen \\
\hline \multirow{2}{*}{ Geral } & Fase 1 & 12,20 & 5,88 & 2 & 26 & $-0,687$ & 0,492 & 0,063 \\
& Fase 2 & 11,83 & 6,17 & 1 & 29 & & & \\
Sintomas & Fase 1 & 5,26 & 2,31 & 1 & 1 & $-0,373$ & 0,709 & 0,079 \\
Emocionais & Fase 2 & 5,03 & 2,76 & 0 & 10 & & & \\
& & & & & & & & \\
Problemas & Fase 1 & 1,86 & 2,20 & 0 & 8 & $-1,281$ & 0,200 & 0,161 \\
de Conduta & Fase 2 & 1,56 & 2,04 & 0 & 8 & & & \\
& & & & & & & & \\
Hiperatividade & Fase 1 & 3,26 & 2,50 & 0 & 10 & $-0,754$ & 0,451 & 0,113 \\
& Fase 2 & 3,03 & 2,59 & 0 & 10 & & & \\
Problemas de & Fase 1 & 1,80 & 1,60 & 0 & 5 & $-1,043$ & 0,297 & $-0,204$ \\
Relacionamento & Fase 2 & 2,20 & 1,80 & 0 & 7 & & & \\
Comportamento & Fase 1 & 9,03 & 1,56 & 4 & 10 & $-0,600$ & 0,549 & $-0,107$ \\
Pró-social & Fase 2 & 9,23 & 1,35 & 4 & 10 & & & \\
\hline
\end{tabular}

Não houve diferenças estatisticamente significativas no resultado geral e nos diversos domínios do SDQ em G1, no tempo aqui considerado. Isso equivale a afirmar que, ao longo do intervalo de seis meses entre as avaliações, houve estabilidade na percepção dos cuidadores familiares acerca de sinais e sintomas relacionados à saúde mental de crianças e adolescentes que convivem com o cuidado oncológico. 
Em suma, nota-se que, sob o prisma da família, crianças e adolescentes que convivem com o diagnóstico oncológico e experimentam em seu cotidiano as repercussões advindas do processo de cuidado altamente especializado, durante a primeira etapa avaliativa tendem a vivenciar maior aproximação dos adultos e relativo esgarçamento de suas relações com seus pares. Esta reação pode estar intrinsicamente ligada à etapa de maior frequência de internações e retornos ambulatoriais, assim como maior zelo familiar no intuito de evitar intercorrências associadas a doenças oportunistas. No entanto, na segunda avaliação (Fase 2) não se identificou diferença estatisticamente significativa entre os grupos no tocante aos Problemas de Relacionamento.

A partir da perspectiva longitudinal (distintas fases) deste estudo, pode-se afirmar que jovens pacientes assistidos pelo serviço de Oncologia Pediátrica sinalizam comportamento sintonizado a regras e limites sociais, mantendo integração e valorização do outro em sua vida, além de sinalizarem reflexão e foco em suas atividades cotidianas conforme o esperado para a faixa etária. Contudo, no mesmo intervalo de tempo, aos olhos de seus pais e cuidadores, os participantes de G1 mostram maior mobilização afetiva diante da adversidade de situações e da imprevisibilidade oriunda dos contextos com os quais se deparam. Assim, houve sinais de fragilidade e algumas limitações em termos de saúde mental, com repercussões negativas para a criança/adolescente e para seu grupo familiar de origem. No entanto, esse quadro se instala logo no início das intervenções oncológicas, permanecendo similar após seis meses de acompanhamento dos casos, o que, no geral, estabiliza a psicodinâmica pessoal e familiar, oferecendo um novo patamar de equilíbrio interno durante os tratamentos.

\subsection{Indicadores da Personalidade de Crianças e Adolescentes}

O enfoque dessa etapa do trabalho volta-se à análise comparativa entre o Grupo Clínico (G1) e o Grupo de Comparação (G2) no tocante a variáveis que espelhem a dinâmica e estrutura da personalidade, em termos de funções lógicas e socioafetivas. Neste sentido, a partir do Método de Rorschach (Escola Francesa) e do Teste de Pfister, serão examinados sinais relativos a: captação do mundo a sua volta, abordagem da realidade na vida cotidiana, aproveitamento dos recursos racionais na estruturação do pensamento e na estabilização psíquica, vivência dos impulsos, mobilização e dinâmica dos afetos, estratégias e recursos adaptativos a contextos e exigências internas, relações intra e interpessoais. 
Os achados estão organizados pelo momento da coleta de dados (Fase 1 ou Fase 2), em função dos instrumentos utilizados para exame psicológico. Também se inclui o acompanhamento intragrupo no caso do grupo clínico nas variáveis selecionadas.

\subsubsection{Referentes à primeira avaliação (FASE 1)}

\subsubsection{Método de Rorschach - Primeira Fase}

Inicialmente serão apresentados os índices pertinentes à produtividade e ao ritmo no Método de Rorschach. Estes podem ser avaliados a partir das variáveis: Respostas, Respostas Adicionais, Recusas e Denegações, Tempo de Latência Médio e Tempo de Reação Médio (ritmo). Esses achados estão sistematizados, em termos descritivos e sua comparação estatística, na Tabela 17.

Tabela 17. Resultados médios e comparação estatística dos grupos em função da produtividade e ritmo no Rorschach (primeira avaliação).

\begin{tabular}{|c|c|c|c|c|c|c|c|c|}
\hline \multirow{2}{*}{$\begin{array}{c}\text { Ritmo e } \\
\text { Produtividade }\end{array}$} & \multirow{2}{*}{ Grupo } & \multicolumn{4}{|c|}{ Análise Descritiva } & \multicolumn{3}{|c|}{ Análise Comparativa } \\
\hline & & Média & DP & Mínimo & Máximo & $t$ & $p$ & $d$ de Cohen \\
\hline \multirow{2}{*}{ Respostas } & G1 & 17,13 & 6,61 & 9,0 & 36,0 & \multirow{2}{*}{$-0,093$} & \multirow{2}{*}{0,926} & \multirow{2}{*}{$-0,027$} \\
\hline & G2 & 17,35 & 9,90 & 8,0 & 47,0 & & & \\
\hline \multirow{2}{*}{$\begin{array}{l}\text { Respostas } \\
\text { Adicionais }\end{array}$} & G1 & 0,76 & 0,77 & 0 & 2,0 & \multirow{2}{*}{0,074} & \multirow{2}{*}{0,941} & \multirow{2}{*}{0,021} \\
\hline & $\mathrm{G} 2$ & 0,75 & 0,78 & 0 & 5,0 & & & \\
\hline \multirow{2}{*}{ Recusas } & G1 & 0,26 & 0,58 & 0 & 2,0 & \multirow{2}{*}{0,095} & \multirow{2}{*}{0,924} & \multirow{2}{*}{0,028} \\
\hline & $\mathrm{G} 2$ & 0,25 & 0,63 & 0 & 2,0 & & & \\
\hline \multirow{2}{*}{ Denegações } & G1 & 0,06 & 0,25 & 0 & 1,0 & \multirow{2}{*}{$-0,418$} & \multirow{2}{*}{0,678} & \multirow{2}{*}{$-0,121$} \\
\hline & $\mathrm{G} 2$ & 0,10 & 0,30 & 0 & 1,0 & & & \\
\hline \multirow{2}{*}{$\begin{array}{c}\text { Tempo de } \\
\text { Latência Médio* }\end{array}$} & G1 & 16,55 & 10,61 & 2,3 & 47,5 & \multirow{2}{*}{1,799} & \multirow{2}{*}{0,078} & \multirow{2}{*}{0,519} \\
\hline & $\mathrm{G} 2$ & 11,76 & 6,54 & 4,5 & 43,8 & & & \\
\hline \multirow{2}{*}{$\begin{array}{c}\text { Tempo de } \\
\text { Reação Médio** }\end{array}$} & G1 & 33,72 & 16,09 & 9,8 & 84,3 & \multirow{2}{*}{$-1,764$} & \multirow{2}{*}{0,084} & \multirow{2}{*}{$-0,509$} \\
\hline & G2 & 44,70 & 27,91 & 9,7 & 105,0 & & & \\
\hline
\end{tabular}

* Em segundos. 
Os dados relativos aos indicadores de produção e ritmo dos participantes de G1 e G2 na primeira etapa do estudo foram bastante similares, inexistindo diferenças estatisticamente significativas entre os mesmos. Pode-se inferir que mesmo vivenciando um contexto permeado de incertezas e angústias, expostos a vivências vulnerabilizantes típicas do processo de cuidado oncológico, crianças e adolescentes aqui avaliados mantiveram sinais de adequado funcionamento associativo-interpretativo, produzindo respostas e abstrações derivadas de estímulos do ambiente. Consequentemente, os participantes apresentaram recursos que favorecem a adaptação às exigências do ambiente e o mundo a sua volta, logrando êxito em perceber, interpretar e engajar-se nas atividades e desafios propostos em seu meio.

Em seguida têm-se as análises pertinentes aos Modos de Apreensão do Rorschach (Global=G, Grande Detalhe=D, Pequeno Detalhe=Dd, Detalhe Branco=Dbl), utilizados por ambos os grupos na primeira etapa avaliativa. Estes são definidos por Chabert (2004) como o quadro perceptual no qual se localiza o conteúdo da resposta. Ainda segundo a autora, a análise deste aspecto possibilita avaliar como a pessoa utiliza sua capacidade lógica e de pensamento, criatividade e recursos cognitivos de adaptação ao mundo externo para lidar com sentimentos, fantasias e questões oriundas da realidade. A Tabela 18 sistematiza esses achados relativos aos modos de apreensão do Rorschach na primeira fase do estudo.

Tabela 18. Resultados médios e comparação estatística dos grupos em função dos modos de apreensão do Rorschach (primeira avaliação).

\begin{tabular}{|c|c|c|c|c|c|c|c|c|}
\hline \multirow{2}{*}{$\begin{array}{l}\text { Modos de } \\
\text { Apreensão }\end{array}$} & \multirow{2}{*}{ Grupo } & \multicolumn{4}{|c|}{ Análise Descritiva } & \multicolumn{3}{|c|}{ Análise Comparativa } \\
\hline & & Média & DP & Mínimo & Máximo & $t$ & $p$ & $d$ de Cohen \\
\hline \multirow{2}{*}{$\mathrm{G} \%$} & G1 & 38,79 & 23,98 & 4,76 & 83,33 & \multirow{2}{*}{$-0,779$} & \multirow{2}{*}{0,440} & \multirow{2}{*}{$-0,225$} \\
\hline & $\mathrm{G} 2$ & 44,37 & 26,12 & 3,45 & 100,0 & & & \\
\hline \multirow{2}{*}{$\mathrm{D} \%$} & G1 & 42,15 & 20,01 & 0 & 66,67 & \multirow{2}{*}{0,811} & \multirow{2}{*}{0,421} & \multirow{2}{*}{0,281} \\
\hline & $\mathrm{G} 2$ & 36,46 & 20,55 & 0 & 84,62 & & & \\
\hline \multirow{2}{*}{$\operatorname{Dd} \%$} & G1 & 18,24 & 13,27 & 0 & 50,00 & \multirow{2}{*}{0,974} & \multirow{2}{*}{0,335} & \multirow{2}{*}{$-0,033$} \\
\hline & $\mathrm{G} 2$ & 18,70 & 14,90 & 0 & 62,07 & & & \\
\hline \multirow{2}{*}{$\mathrm{Db} 1 \%$} & G1 & 0,811 & 2,71 & 0 & 11,10 & \multirow{2}{*}{$-0,345$} & \multirow{2}{*}{0,732} & \multirow{2}{*}{0,154} \\
\hline & $\mathrm{G} 2$ & 0,451 & 1,58 & 0 & 6,90 & & & \\
\hline
\end{tabular}


Nota-se que os dois grupos priorizaram a localização das respostas em áreas de Grande Detalhe (D) no processo de interpretação dos estímulos do Teste de Rorschach, seguidos por percepções globais dos cartões. As áreas Dd foram bem menos destacadas nas respostas dos participantes, com mínima utilização das áreas brancas dos estímulos (Dbl). Este achado parece refletir o funcionamento lógico típico desta faixa etária, uma vez que sinalizaram partir da análise dos aspectos concretos da realidade (D) para efetuarem abstrações e generalizações pertinentes a seu entorno. Das percepções globais (G) passaram a examinar minúcias dos estímulos (Dd), seguindose reduzida proporção de perspectivas mais criativas ou particulares de apreciação da realidade. Não houve diferenças estatisticamente significativas entre G1 e G2 nestas variáveis.

$\mathrm{Na}$ sequência da análise da produção diante do Método de Rorschach têm-se as variáveis relacionadas aos determinantes das respostas. Rausch de Traubenberg (1998) define que "determinantes" do Rorschach são as características do estímulo que provocaram a resposta, associando-se a percepção sensorial da forma, cor ou esfumaçado presente na imagem, apreensão de movimento, tridimensionalidade ou profundidade, produzidos pela projeção de conteúdos individuais em cada cartão. As informações relativas aos determinantes das respostas ao Rorschach nos dois grupos avaliados encontram-se na Tabela 19.

Tabela 19. Resultados médios e comparação estatística dos grupos em função dos determinantes do Rorschach (primeira avaliação).

\begin{tabular}{|c|c|c|c|c|c|c|c|c|}
\hline \multirow{2}{*}{ Determinantes } & \multirow{2}{*}{ Grupo } & \multicolumn{4}{|c|}{ Análise Descritiva } & \multicolumn{3}{|c|}{ Análise Comparativa } \\
\hline & & Média & DP & Mínimo & Máximo & $t$ & $p$ & $d$ de Cohen \\
\hline \multirow{2}{*}{$\mathrm{F} \%$} & G1 & 41,28 & 24,42 & 0,0 & 90,0 & \multirow{2}{*}{0,505} & \multirow{2}{*}{0,616} & \multirow{2}{*}{0,146} \\
\hline & $\mathrm{G} 2$ & 38,07 & 17,76 & 0,0 & 76,9 & & & \\
\hline \multirow{2}{*}{$\mathrm{F}+\%$} & G1 & 71,24 & 26,43 & 0,0 & 100,0 & \multirow{2}{*}{$-0,333$} & \multirow{2}{*}{0,741} & \multirow{2}{*}{$-0,0,96$} \\
\hline & G2 & 73,68 & 23,66 & 0,0 & 100,0 & & & \\
\hline \multirow{2}{*}{$\mathrm{F}+\mathrm{Ext} \%$} & G1 & 71,05 & 12,48 & 50,0 & 92,3 & \multirow{2}{*}{$-1,536$} & \multirow{2}{*}{0,131} & \multirow{2}{*}{$-0,443$} \\
\hline & G2 & 76,97 & 14,56 & 51,7 & 100,0 & & & \\
\hline \multirow{2}{*}{ K } & G1 & 1,30 & 1,36 & 0,0 & 5,0 & \multirow{2}{*}{0,899} & \multirow{2}{*}{0,373} & \multirow{2}{*}{0,260} \\
\hline & $\mathrm{G} 2$ & 0,95 & 1,31 & 0,0 & 5,0 & & & \\
\hline \multirow{2}{*}{ kan } & G1 & 1,50 & 1,43 & 0,0 & 6,0 & \multirow{2}{*}{$-2,514$} & \multirow{2}{*}{0,015} & \multirow{2}{*}{$-0,726$} \\
\hline & $\mathrm{G} 2$ & 2,85 & 2,36 & 0,0 & 8,0 & & & \\
\hline & G1 & 0,16 & 0,37 & 0,0 & 1,0 & & & \\
\hline kob & G2 & 0,05 & 0,22 & 0,0 & 1,0 & 1,238 & 0,222 & 0,357 \\
\hline
\end{tabular}




\begin{tabular}{|c|c|c|c|c|c|c|c|c|}
\hline \multirow{2}{*}{ Determinantes } & \multirow{2}{*}{ Grupo } & \multicolumn{4}{|c|}{ Análise Descritiva } & \multicolumn{3}{|c|}{ Análise Comparativa } \\
\hline & & Média & DP & Mínimo & Máximo & $t$ & $p$ & $d$ de Cohen \\
\hline \multirow{2}{*}{$\mathrm{kp}$} & G1 & 0,10 & 0,30 & 0,0 & 1,0 & \multirow{2}{*}{$-0,524$} & \multirow{2}{*}{0,603} & \multirow{2}{*}{$-0,151$} \\
\hline & $\mathrm{G} 2$ & 0,15 & 0,36 & 0,0 & 1,0 & & & \\
\hline \multirow{2}{*}{$\begin{array}{l}\sum_{\text {Cinestesias* }} \text { Pequenas } \\
\text { Cintes }\end{array}$} & G1 & 1,76 & 1,65 & 0,0 & 6,0 & \multirow{2}{*}{$-2,244$} & \multirow{2}{*}{$\mathbf{0 , 0 2 9}$} & \multirow{2}{*}{$-0,648$} \\
\hline & $\mathrm{G} 2$ & 3,05 & 2,39 & 0,0 & 8,0 & & & \\
\hline \multirow{2}{*}{$\mathrm{FC}$} & G1 & 1,76 & 1,65 & 0,0 & 8,0 & \multirow{2}{*}{0,365} & \multirow{2}{*}{0,717} & \multirow{2}{*}{0,105} \\
\hline & G2 & 3,05 & 2,39 & 0,0 & 10,0 & & & \\
\hline \multirow{2}{*}{$\mathrm{CF}$} & G1 & 1,60 & 1,19 & 0,0 & 4,0 & \multirow{2}{*}{0,689} & \multirow{2}{*}{0,494} & \multirow{2}{*}{0,199} \\
\hline & G2 & 1,35 & 1,34 & 0,0 & 4,0 & & & \\
\hline \multirow{2}{*}{$\mathrm{C}$} & G1 & 0,26 & 0,86 & 0,0 & 4,0 & \multirow{2}{*}{1,369} & \multirow{2}{*}{0,177} & \multirow{2}{*}{ - } \\
\hline & $\mathrm{G} 2$ & - & - & 0,0 & 0,0 & & & \\
\hline \multirow{2}{*}{$\sum \mathrm{Cp}^{* *}$} & G1 & 3,56 & 2,18 & 0,5 & 12,0 & \multirow{2}{*}{1,317} & \multirow{2}{*}{0,194} & \multirow{2}{*}{0,380} \\
\hline & G2 & 2,80 & 1,73 & 0,5 & 6,5 & & & \\
\hline \multirow{2}{*}{$\mathrm{FE}$} & G1 & 1,16 & 1,20 & 0,0 & 4,0 & \multirow{2}{*}{$-0,102$} & \multirow{2}{*}{0,919} & 0070 \\
\hline & $\mathrm{G} 2$ & 1,20 & 1,00 & 0,0 & 4,0 & & & $-0,0<9$ \\
\hline $\mathrm{EF}$ & G1 & 0,43 & 0,72 & 0,0 & 3,0 & -1.196 & 0238 & -0345 \\
\hline & G2 & 0,85 & 1,69 & 0,0 & 6,0 & $-1,190$ & 0,250 & $-0,34 J$ \\
\hline $\mathrm{F}$ & G1 & 0,10 & 0,30 & 0,0 & 1,0 & 0628 & 0533 & 0181 \\
\hline L & G2 & 0,05 & 0,22 & 0,0 & 1,0 & $0,0<0$ & נינד & 0,101 \\
\hline$\sum E \mathrm{En} * * *$ & G1 & 1,16 & 1,11 & 0,0 & 4,0 & -869 & 0389 & -0251 \\
\hline$\angle E \mathrm{p}$ & G2 & 1,52 & 1,80 & 0,0 & 7,0 &,- 009 & 0,509 & $-0,251$ \\
\hline FCloh & G1 & 0,16 & 0,37 & 0,0 & 1,0 & 1238 & 0222 & 0357 \\
\hline ГСIOD & $\mathrm{G} 2$ & 0,05 & 0,22 & 0,0 & 1,0 & 1,250 & $0,2<2$ & ו וני, \\
\hline ClobF & G1 & 0,10 & 0,40 & 0,0 & 2,0 & 1107 & 0274 & - \\
\hline C1001 & $\mathrm{G} 2$ & - & - & 0,0 & 0,0 & $1,10 /$ & 0,214 & - \\
\hline Clob & G1 & - & - & - & - & 1,493 & 0,142 & - \\
\hline & $\mathrm{G} 2$ & - & - & - & - & & & \\
\hline
\end{tabular}

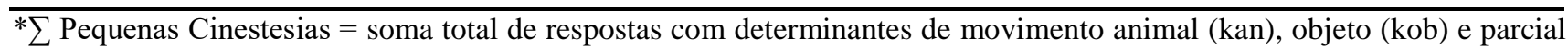
humano (kp).

$* * \sum \mathrm{Cp}=$ soma ponderada das respostas com determinante cor.

$* * * \sum \mathrm{Ep}=$ soma ponderada das respostas com determinante sombreado. 
A análise comparativa dos dados revelou diferença estatisticamente significativa entre os grupos, com elevado tamanho de efeito, em duas variáveis vinculadas aos determinantes do Rorschach: Cinestesia Animal (kan) e Soma das Pequenas Cinestesias. Embora altamente relacionadas, essas variáveis apontaram que o Grupo Clínico ofereceu menos respostas determinadas por movimentos animais ou por pequenas cinestesias em geral. É preciso interpretar esses achados de forma articulada e complementar, relacionadas ao dinamismo interno. Nesse sentido, G2 sinalizou maior número de respostas kan e na soma de pequenas cinestesias, sugestivos de maior espontaneidade e dinamismo no processo de interpretação dos estímulos da realidade, quando comparados a crianças e adolescentes com câncer.

Ao refletir sobre as características próprias do desenvolvimento infantojuvenil, podese considerar, como marca típica da faixa etária, a expressão dos afetos e de suas necessidades de modo autêntico e fluido. Assim, a diminuição de kan e da Soma das Pequenas Cinestesias sugere a ideia do esforço adaptativo das crianças e adolescentes de G1 ao contexto dos cuidados oncológicos, inibindo sua expressão natural e espontaneidade no ambiente.

Vale ressaltar que os participantes de G1 e G2 evidenciaram adequado aproveitamento dos recursos racionais, condizentes com sua faixa etária, conseguindo funcionar logicamente na abordagem crítica e analítica da realidade. Deste modo, pelos critérios estabelecidos nos estudos normativos de Fernandes (2010), Raspantini (2010), Jardim-Maran (2011) e CuryJacquemin (2012), indicadores de boa precisão formal (F\%, F+\%, e F+Ext\%) estão dentro do estimado como típico para pessoas entre sete a 17 anos. Assim, denotaram preservação do pensamento, do investimento intelectual na mediação com o contexto, além de integração favorável da racionalidade e afetividade em seu contato com o ambiente e as pessoas que os cercam.

Os dois grupos sinalizaram adequada utilização da racionalidade para controlar as manifestações de afeto no ambiente, bem como coordenar os influxos afetivos em seu mundo interno. Isso pode ser depreendido pela análise da proporção das variáveis $\mathrm{FC}: \mathrm{CF}+\mathrm{C}$. De forma análoga, a utilização dos recursos lógicos na coordenação e controle da ansiedade e angústias (expressa pela relação $\mathrm{FE}: \mathrm{EF}+\mathrm{E}$ ) exprimiu-se de forma semelhante no Grupo Clínico e no Grupo de Comparação. Assim, G1 quanto G2 apresentaram efetiva coordenação racional das vivências de ansiedade.

$\mathrm{Na}$ continuidade da avaliação das variáveis do Método de Rorschach, faz-se importante descrever os Conteúdos das respostas oferecidas pelos distintos grupos de participantes deste estudo, assim como suas respostas banais. Segundo Rausch de Traubenberg (1998), os conteúdos marcam a essência da resposta frente ao estímulo, e podem 
ser interpretadas tanto de forma isolada como na combinação dinâmica do conjunto da produção do indivíduo. Fornecem indicações a respeito da orientação de interesses e necessidades pessoais, motivações, recursos psíquicos presentes na personalidade, bem como grau de riqueza mental, angústias e conflitos.

Por sua vez, as respostas de conteúdo banal têm por característica fundamental a apresentação de interpretações de grande frequência nos grupos de referência (determinada amostra da população). Elas sinalizam o compartilhamento da forma de pensar e de perceber a realidade com seu grupo de referência sociocultural. Os achados das variáveis associadas aos conteúdos e às banalidades diante do Método de Rorschach foram sistematizados, de forma descritiva e comparativa, na Tabela 20.

Tabela 20. Resultados médios e comparação estatística dos grupos em função dos conteúdos e banalidades do Rorschach (primeira avaliação).

\begin{tabular}{|c|c|c|c|c|c|c|c|c|}
\hline \multirow{2}{*}{ Conteúdos } & \multirow{2}{*}{ Grupo } & \multicolumn{4}{|c|}{ Análise Descritiva } & \multicolumn{3}{|c|}{ Análise Comparativa } \\
\hline & & Média & DP & Mínimo & Máximo & $t$ & $p$ & $d$ de Cohen \\
\hline \multirow{2}{*}{ A } & G1 & 6,60 & 3,88 & 1 & 17 & \multirow{2}{*}{$-0,371$} & \multirow{2}{*}{0,713} & \multirow{2}{*}{$-0,107$} \\
\hline & $\mathrm{G} 2$ & 7,00 & 3,50 & 2 & 13 & & & \\
\hline \multirow{2}{*}{ (A) } & G1 & 1,40 & 2,07 & 0 & 8 & \multirow{2}{*}{1,287} & \multirow{2}{*}{0,204} & \multirow{2}{*}{0,371} \\
\hline & $\mathrm{G} 2$ & 0,75 & 1,07 & 0 & 3 & & & \\
\hline \multirow{2}{*}{ Ad } & G1 & 0,73 & 1,36 & 0 & 6 & \multirow{2}{*}{$-0,494$} & \multirow{2}{*}{0,624} & \multirow{2}{*}{$-0,143$} \\
\hline & $\mathrm{G} 2$ & 0,95 & 1,73 & 0 & 6 & & & \\
\hline \multirow{2}{*}{ (Ad) } & G1 & 0,33 & 0,66 & 0 & 3 & \multirow{2}{*}{$-0,091$} & \multirow{2}{*}{0,928} & \multirow{2}{*}{$-0,026$} \\
\hline & $\mathrm{G} 2$ & 0,35 & 0,58 & 0 & 2 & & & \\
\hline \multirow{2}{*}{$\sum \mathrm{A}$} & G1 & 9,06 & 5,56 & 2 & 29 & \multirow{2}{*}{0,011} & \multirow{2}{*}{0,991} & \multirow{2}{*}{0,003} \\
\hline & $\mathrm{G} 2$ & 9,05 & 4,48 & 2 & 20 & & & \\
\hline \multirow{2}{*}{$\mathrm{A} \%$} & G1 & 51,91 & 19,73 & 20,0 & 90,9 & \multirow{2}{*}{$-0,464$} & \multirow{2}{*}{0,644} & \multirow{2}{*}{$-0,134$} \\
\hline & $\mathrm{G} 2$ & 54,52 & 19,21 & 25,0 & 92,3 & & & \\
\hline \multirow{2}{*}{$\mathrm{H}$} & G1 & 1,26 & 1,11 & 0 & 4 & \multirow{2}{*}{$-0,706$} & \multirow{2}{*}{0,483} & \multirow{2}{*}{$-0,204$} \\
\hline & G2 & 1,50 & 1,19 & 0 & 5 & & & \\
\hline \multirow{2}{*}{ (H) } & G1 & 1,56 & 1,47 & 0 & 5 & \multirow{2}{*}{2,124} & \multirow{2}{*}{$\mathbf{0 , 0 3 9}$} & 0612 \\
\hline & G2 & 0,75 & 1,06 & 0 & 4 & & & 0,013 \\
\hline $\mathrm{Hd}$ & G1 & 0,46 & 0,62 & 0 & 2 & 1255 & 0216 & O 362 \\
\hline & G2 & 0,80 & 1,23 & 0 & 5 & $-1,2 J J$ & 0,210 & $-0,502$ \\
\hline
\end{tabular}




\begin{tabular}{|c|c|c|c|c|c|c|c|c|}
\hline \multirow{2}{*}{ Conteúdos } & \multirow{2}{*}{ Grupo } & \multicolumn{4}{|c|}{ Análise Descritiva } & \multicolumn{3}{|c|}{ Análise Comparativa } \\
\hline & & Média & $\mathrm{DP}$ & Mínimo & Máximo & $t$ & $p$ & d de Cohen \\
\hline$(\mathrm{Hd})$ & $\begin{array}{l}\text { G1 } \\
\text { G2 }\end{array}$ & $\begin{array}{l}0,16 \\
0,05\end{array}$ & $\begin{array}{l}0,37 \\
0,22\end{array}$ & $\begin{array}{l}0 \\
0\end{array}$ & $\begin{array}{l}1 \\
1\end{array}$ & 1,238 & 0,222 & 0,357 \\
\hline$\sum \mathrm{H}$ & $\begin{array}{l}\text { G1 } \\
\text { G2 }\end{array}$ & $\begin{array}{l}3,46 \\
3,10\end{array}$ & $\begin{array}{l}2,38 \\
2,14\end{array}$ & $\begin{array}{l}0 \\
0\end{array}$ & $\begin{array}{c}9 \\
10\end{array}$ & 0,553 & 0,583 & 0,160 \\
\hline $\mathrm{H} \%$ & $\begin{array}{l}\text { G1 } \\
\text { G2 }\end{array}$ & $\begin{array}{l}20,49 \\
19,88\end{array}$ & $\begin{array}{l}14,35 \\
12,18\end{array}$ & $\begin{array}{l}0 \\
0\end{array}$ & $\begin{array}{l}52,9 \\
50,0\end{array}$ & 0,156 & 0,877 & 0,045 \\
\hline Anat & $\begin{array}{l}\text { G1 } \\
\text { G2 }\end{array}$ & $\begin{array}{l}0,56 \\
0,25\end{array}$ & $\begin{array}{l}0,89 \\
0,55\end{array}$ & $\begin{array}{l}0 \\
0\end{array}$ & $\begin{array}{l}3 \\
3\end{array}$ & 1,408 & 0,165 & 0,407 \\
\hline $\mathrm{Sg}$ & $\begin{array}{l}\text { G1 } \\
\text { G2 }\end{array}$ & $\begin{array}{l}0,06 \\
0,05\end{array}$ & $\begin{array}{l}0,36 \\
0,22\end{array}$ & $\begin{array}{l}0 \\
0\end{array}$ & $\begin{array}{l}2 \\
1\end{array}$ & 0,182 & 0,856 & 0,053 \\
\hline Sex & $\begin{array}{l}\text { G1 } \\
\text { G2 }\end{array}$ & $\begin{array}{c}0,03 \\
-\end{array}$ & $\begin{array}{c}0,18 \\
-\end{array}$ & $\begin{array}{l}0 \\
0\end{array}$ & $\begin{array}{l}1 \\
0\end{array}$ & 0,814 & 0,420 & - \\
\hline Obj & $\begin{array}{l}\text { G1 } \\
\text { G2 }\end{array}$ & $\begin{array}{l}1,60 \\
2,20\end{array}$ & $\begin{array}{l}1,32 \\
3,54\end{array}$ & $\begin{array}{l}0 \\
0\end{array}$ & $\begin{array}{c}6 \\
14\end{array}$ & $-0,845$ & 0,402 & $-0,244$ \\
\hline Art & $\begin{array}{l}\text { G1 } \\
\text { G2 }\end{array}$ & - & 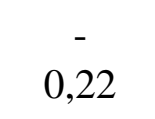 & $\begin{array}{l}0 \\
0\end{array}$ & $\begin{array}{l}0 \\
1\end{array}$ & $-1,231$ & 0,224 & - \\
\hline Arq & $\begin{array}{l}\text { G1 } \\
\text { G2 }\end{array}$ & $\begin{array}{l}0,10 \\
0,30\end{array}$ & $\begin{array}{l}0,30 \\
0,65\end{array}$ & $\begin{array}{l}0 \\
0\end{array}$ & $\begin{array}{l}1 \\
2\end{array}$ & $-1,454$ & 0,152 & $-0,420$ \\
\hline Simb & $\begin{array}{l}\text { G1 } \\
\text { G2 }\end{array}$ & $\begin{array}{l}0,10 \\
0,55\end{array}$ & $\begin{array}{l}0,40 \\
1,43\end{array}$ & $\begin{array}{l}0 \\
0\end{array}$ & $\begin{array}{l}2 \\
6\end{array}$ & $-1,635$ & 0,109 & $-0,472$ \\
\hline Abst & $\begin{array}{l}\text { G1 } \\
\text { G2 }\end{array}$ & - & - & - & - & - & - & - \\
\hline Bot & $\begin{array}{l}\text { G1 } \\
\text { G2 }\end{array}$ & $\begin{array}{l}0,90 \\
0,70\end{array}$ & $\begin{array}{l}0,99481 \\
1,12858\end{array}$ & $\begin{array}{l}0 \\
0\end{array}$ & $\begin{array}{l}3 \\
4\end{array}$ & 0,660 & 0,512 & 0,191 \\
\hline Geo & $\begin{array}{l}\text { G1 } \\
\text { G2 }\end{array}$ & $\begin{array}{l}0,46 \\
0,45\end{array}$ & $\begin{array}{l}0,89 \\
0,82\end{array}$ & $\begin{array}{l}0 \\
0\end{array}$ & $\begin{array}{l}4 \\
3\end{array}$ & 0,066 & 0,947 & 0,019 \\
\hline Nat & $\begin{array}{l}\text { G1 } \\
\text { G2 }\end{array}$ & $\begin{array}{l}0,06 \\
0,10\end{array}$ & $\begin{array}{l}0,25 \\
0,44\end{array}$ & $\begin{array}{l}0 \\
0\end{array}$ & $\begin{array}{l}1 \\
2\end{array}$ & $-0,336$ & 0,738 & $-0,097$ \\
\hline Pais & $\begin{array}{l}\text { G1 } \\
\text { G2 }\end{array}$ & $\begin{array}{l}0,23 \\
0,20\end{array}$ & $\begin{array}{l}0,50 \\
0,41\end{array}$ & $\begin{array}{l}0 \\
0\end{array}$ & $\begin{array}{l}2 \\
1\end{array}$ & 0,246 & 0,807 & 0,071 \\
\hline
\end{tabular}




\begin{tabular}{|c|c|c|c|c|c|c|c|c|}
\hline \multirow{2}{*}{ Conteúdos } & \multirow{2}{*}{ Grupo } & \multicolumn{4}{|c|}{ Análise Descritiva } & \multicolumn{3}{|c|}{ Análise Comparativa } \\
\hline & & Média & DP & Mínimo & Máximo & $t$ & $p$ & $d$ de Cohen \\
\hline \multirow{2}{*}{ Elem } & G1 & 0,23 & 0,77 & 0 & 4 & \multirow{2}{*}{0,731} & \multirow{2}{*}{0,468} & \multirow{2}{*}{0,211} \\
\hline & $\mathrm{G} 2$ & 0,10 & 0,30 & 0 & 1 & & & \\
\hline \multirow{2}{*}{ Elem(fogo) } & G1 & 0,10 & 0,30 & 0 & 1 & \multirow{2}{*}{0,628} & \multirow{2}{*}{0,533} & \multirow{2}{*}{0,181} \\
\hline & $\mathrm{G} 2$ & 0,05 & 0,22 & 0 & 1 & & & \\
\hline \multirow{2}{*}{ Frag } & G1 & 0,20 & 0,61 & 0 & 3 & \multirow{2}{*}{$-0,265$} & \multirow{2}{*}{0,792} & \multirow{2}{*}{$-0,076$} \\
\hline & G2 & 0,25 & 0,71 & 0 & 3 & & & \\
\hline \multirow{2}{*}{ Ban\% } & G1 & 19,19 & 8,50 & 3,2 & 41,1 & \multirow{2}{*}{$-1,189$} & \multirow{2}{*}{0,240} & \multirow{2}{*}{$-0,343$} \\
\hline & $\mathrm{G} 2$ & 22,72 & 12,53 & 0 & 50,0 & & & \\
\hline
\end{tabular}

É possível identificar riqueza de interesses e necessidades psíquicas vivenciadas por ambos os grupos nessa primeira etapa avaliativa, a partir dos conteúdos projetados no Método de Rorschach. A soma da porcentagem das respostas animais, acrescida da porcentagem das respostas humanas $(\mathrm{A} \%+\mathrm{H} \%)$, em ambos os grupos, atingem valores compatíveis aos padrões normativos (cerca de 70,0\% das respostas), deixando margem para expressão de outros conteúdos (pluralidade de necessidades e motivações dos participantes).

As respostas de conteúdo animal representam a maior parcela nos protocolos ( $\mathrm{G} 1=51,9 \%$ e $\mathrm{G} 2=54,5 \%$ ), seguidas pelo conteúdo humano ( $\mathrm{G} 1=20,5 \%$ e G2=19,9\%) nessa primeira avaliação. Neste sentido, é lícito afirmar que esta frequência de conteúdos A\% e H\% apontam para características típicas do desenvolvimento desta faixa etária, como pensamento menos reflexivo e elaborado, com tendência a adotar reações comportamentais e afetivas mais automatizadas em suas vivências cotidianas, mantendo o reconhecimento de si e do outro como seres humanos (Anzieu, 1986).

A análise comparativa de respostas com conteúdos de figuras inteiras $[A,(A), H,(H)]$ e conteúdos parciais [Ad, (Ad), Hd, (Hd)] evidenciou supremacia das primeiras. Assim, G1 e G2 sinalizaram, prioritariamente, objetos íntegros em seu mundo interno, compatíveis com o esperado em termos de adequado desenvolvimento da identidade em etapas iniciais do ciclo vital.

Houve apenas uma variável $(\mathrm{H})$ com indicativo estatístico significativo entre G1 e G2 e elevado tamanho do efeito, sendo que o grupo clínico apresentou maior número médio de respostas nesse conteúdo do Rorschach. As respostas $(\mathrm{H})$ correspondem a representações de seres humanos inteiros, porém não disponíveis na realidade ou que se apresentam desvitalizados. Este conteúdo pode evidenciar atitude psíquica voltada à fantasia, quanto pode 
indicar alguma distorção na imagem interna sobre a figura humana e de se relacionar com seus semelhantes. Pode-se comentar que a experiência de alteração em diversas dimensões da percepção corporal vinculada a doença neoplásica pode ter se refletido aqui no aumento significativo das respostas $(\mathrm{H})$ em G1. Essa hipótese interpretativa deve ser, no entanto, cautelosamente considerada, tendo em vista que se tratou de uma única variável relativa aos conteúdos do Rorschach.

No tocante às banalidades, os participantes de ambos os grupos sinalizaram resultados similares. Sugerem, dessa forma, semelhante condição de compartilhamento do pensar de seu grupo sociocultural de referência.

A seguir, na Tabela 21, são apresentadas a análise descritiva e a comparação dos resultados entre G1 e G2 referentes ao funcionamento afetivo dos participantes do estudo. Esse conjunto de variáveis possibilita conhecer estilos predominantes de vivências afetivas, expressas no Método de Rorschach pelas distintas fórmulas vivenciais. Adotou-se a estratégia de agrupar os estilos afetivos conforme sua abertura para o ambiente (extratensivos) ou para o mundo interno (introversivos), ou ainda aqueles que manifestam algum tipo de dinâmica afetiva ambivalente ou inibitória (representado pelos estilos coartado, coartativo ou ambigual, aqui agrupados na categoria "Outros").

Tabela 21. Distribuição dos participantes e comparação estatística dos grupos em função das Fórmulas Vivenciais do Rorschach (primeira avaliação).

\begin{tabular}{|c|c|c|c|c|c|c|c|c|}
\hline \multirow{2}{*}{\multicolumn{2}{|c|}{ Fórmulas Vivenciais }} & \multicolumn{2}{|c|}{ G1 } & \multicolumn{2}{|c|}{$\mathrm{G} 2$} & \multicolumn{3}{|c|}{ Análise Comparativa } \\
\hline & & \multirow{2}{*}{$\frac{f}{-}$} & \multirow{2}{*}{$\frac{\%}{-}$} & \multirow{2}{*}{$\frac{f}{4}$} & \multirow{2}{*}{$\frac{\%}{20,0}$} & \multirow[t]{2}{*}{$x^{2}$} & \multirow[t]{2}{*}{$p$} & \multirow[t]{2}{*}{ V de Cramer } \\
\hline Tipo de & Introversivo & & & & & & & \\
\hline Ressonância & Extratensivo & 21 & 70,0 & 12 & 60,0 & 6,643 & 0,036 & 0,365 \\
\hline Íntima (TRI) & Outros* & 9 & 30,0 & 4 & 20,0 & & & \\
\hline \multirow{3}{*}{$\begin{array}{c}2^{\mathrm{a}} \text { Fórmula } \\
\text { Afetiva }\end{array}$} & Introversivo & 11 & 36,6 & 13 & 65,0 & \multirow{3}{*}{4,301} & \multirow{3}{*}{0,116} & \multirow{3}{*}{0,293} \\
\hline & Extratensivo & 3 & 10,0 & 2 & 10,0 & & & \\
\hline & Outros* & 16 & 53,3 & 5 & 25,0 & & & \\
\hline \multirow{3}{*}{$\begin{array}{c}3^{\text {a }} \text { Fórmula } \\
\text { Afetiva }\end{array}$} & Introversivo & 11 & 36,6 & 3 & 15,0 & \multirow{3}{*}{2,976} & \multirow{3}{*}{0,226} & \multirow{3}{*}{0,244} \\
\hline & Extratensivo & 8 & 26,6 & 6 & 30,0 & & & \\
\hline & Ambigual & 11 & 36,6 & 11 & 55,0 & & & \\
\hline \multirow{2}{*}{$\begin{array}{l}\text { Fórmula da } \\
\text { Angústia }\end{array}$} & Normal $(\leq 12 \%)$ & 22 & 73,3 & 17 & 85,0 & \multirow{2}{*}{0,952} & \multirow{2}{*}{0,329} & \multirow{2}{*}{0,138} \\
\hline & Elevada $(>12 \%)$ & 8 & 26,6 & 3 & 15,0 & & & \\
\hline
\end{tabular}

*Outros tipos afetivos = coartativo, coartado, ambigual. 
A primeira fórmula é denominada de Tipo de Ressonância Íntima (TRI), composta pela relação da soma das respostas Grandes Cinestesias Humanas com a soma ponderada das respostas Cor (TRI = K: $\sum$ Cp). Segundo Chabert (2004), esta associação entre variáveis de cinestesia e cor exprimiria a interação entre a atitude introversiva e extratensiva da dinâmica da personalidade em relação a si própria e ao mundo a sua volta. Assim, como asseveram as autoras, o TRI se configura como retrato da reverberação íntima do ser diante das vivências, contudo nem sempre ele irá manifestar plenamente a profundidade da sua capacidade de mobilização (Traubenberg, 1998).

Houve predomínio do tipo Extratensivo de ressonância afetiva nos dois grupos, o que remete a maior sensibilização afetiva frente aos estímulos, buscando mais abertamente a expressão da afetividade no mundo externo. Este tipo de sensibilidade e a necessidade de exprimir os sentimentos de forma mais vívida tende a corresponder ao esperado para a infância e adolescência.

Conhecida como Segunda Fórmula Afetiva ou Fórmula das Tendências Latentes, está composta pela relação $\sum \mathrm{k}: \sum \mathrm{Ep}$, contrapondo soma das respostas de Pequenas Cinestesias (kan, kp, kob) e soma ponderada das respostas de sombreado. Por ter natureza complementar ao TRI, é de grande utilidade na avaliação psicológica da personalidade, representando recursos afetivos latentes na dinâmica psíquica, passíveis de desenvolvimento e utilização. Não houve indicadores de diferenças estatisticamente significativas entre o Grupo Clínico e o Grupo de Comparação nessa segunda fórmula afetiva, sugerindo similaridade nos recursos afetivos potencialmente disponíveis aos participantes.

Deste modo, ao contarem com maior frequência de casos Introversivos na segunda fórmula afetiva, ambos os grupos mostram potencial para desenvolverem a capacidade de voltar seu foco ao mundo interior, assumindo postura reflexiva, imaginativa e de simbolização. Vale ponderar que dentro dos 16 casos classificados como "Outros" em G1, 15 são classificados como coartados ou coartativos e apenas um como ambigual. É possível inferir, desse modo, que metade dos participantes de G1 apresentaram tendência a restringir suas manifestações afetivas no ambiente, buscando utilizar o controle inibitório calcado nas funções lógicas. Esse achado sugere eventual intuito defensivo para neutralizar a sensação de vulnerabilidade diante das repercussões afetivas vividas a partir de suas experiências nos cuidados oncológicos.

A Terceira Fórmula ou Índice de Reatividade Afetiva do Rorschach é expressa pela proporção de respostas nas pranchas VIII, IX e X em relação ao total do protocolo. Nessa Terceira Fórmula Afetiva não houve diferença estatisticamente significativa entre os 
indivíduos do Grupo Clínico e Grupo de Comparação no tocante aos estilos afetivos. Em ambos os grupos houve marcante presença do tipo Ambigual (G1=36,6\% e G2=55,0\%), seguido pelo estilo Extratensivo ( $\mathrm{G} 1=26,6$ e $\mathrm{G} 2=30,0 \%)$, sugerindo variabilidade e flexibilidade nas formas de reação afetiva situacional das crianças e adolescentes avaliados.

Ao considerar a Fórmula da Angústia do Rorschach, nota-se que os participantes de ambos os grupos não apresentaram índices médios de ansiedade e angústia prejudiciais ao funcionamento da personalidade. A grande maioria dos casos atingiu valores inferiores a $12 \%$ nessa Fórmula da Angústia, sinalizando possibilidades de aproveitamento dos recursos disponíveis na dinâmica psíquica.

\subsubsection{Teste das Pirâmides Coloridas de Pfister - Primeira Fase}

As informações derivadas do Teste de Pfister permitem caracterizar variáveis relacionadas ao funcionamento lógico e afetivo de indivíduos, bem como sobre sua organização racional. Nesta sessão serão utilizados os indicadores relativos às escolhas cromáticas e às síndromes cromáticas, complementando com a comparação destes resultados aos padrões normativos disponíveis no Brasil para essa faixa etária. Ademais, serão examinados os aspectos formais da execução da prova, incluindo modo de colocação, processo de execução e aspecto formal das pirâmides construídas.

A Tabela 22 traz os dados descritivos e a comparação estatística de G1 e G2 no tocante ao uso das cores do Pfister. Nessa tabela foram consideradas as frequências (em porcentagem) das escolhas cromáticas. 
Tabela 22. Resultados médios (em porcentagem) e comparação estatística dos grupos em função das cores do Teste de Pfister (primeira avaliação).

\begin{tabular}{|c|c|c|c|c|c|c|c|c|}
\hline \multirow{2}{*}{$\begin{array}{l}\text { Cores } \\
\text { Pfister }\end{array}$} & \multirow{2}{*}{ Grupo } & \multicolumn{4}{|c|}{ Análise Descritiva } & \multicolumn{3}{|c|}{ Análise Comparativa } \\
\hline & & Média & DP & Mínimo & Máximo & $t$ & $p$ & d de Cohen \\
\hline \multirow{2}{*}{ Azul } & G1 & 17,47 & 7,32 & 4,0 & 37,7 & \multirow{2}{*}{0,990} & \multirow{2}{*}{0,327} & \multirow{2}{*}{0,286} \\
\hline & $\mathrm{G} 2$ & 15,11 & 9,55 & 0 & 44,4 & & & \\
\hline \multirow{2}{*}{ Vermelho } & G1 & 16,22 & 9,15 & 0 & 40,0 & \multirow{2}{*}{$-0,614$} & \multirow{2}{*}{0,542} & \multirow{2}{*}{$-0,177$} \\
\hline & G2 & 17,66 & 6,30 & 6,6 & 31,1 & & & \\
\hline \multirow{2}{*}{ Verde } & G1 & 16,14 & 9,26 & 0 & 42,2 & \multirow{2}{*}{$-0,030$} & \multirow{2}{*}{0,976} & \multirow{2}{*}{$-0,009$} \\
\hline & $\mathrm{G} 2$ & 16,22 & 8,46 & 6,6 & 44,4 & & & \\
\hline \multirow{2}{*}{ Violeta } & G1 & 12,52 & 6,79 & 0 & 33,3 & \multirow{2}{*}{1,026} & \multirow{2}{*}{0,310} & \multirow{2}{*}{0,296} \\
\hline & $\mathrm{G} 2$ & 10,55 & 6,44 & 0 & 26,6 & & & \\
\hline \multirow{2}{*}{ Laranja } & G1 & 7,63 & 6,99 & 0 & 33,3 & \multirow{2}{*}{$-0,642$} & \multirow{2}{*}{0,524} & \multirow{2}{*}{$-0,185$} \\
\hline & G2 & 8,77 & 4,75 & 0 & 20,0 & & & \\
\hline \multirow{2}{*}{ Amarelo } & G1 & 10,00 & 10,48 & 0 & 48,8 & \multirow{2}{*}{$-0,283$} & \multirow{2}{*}{0,778} & \multirow{2}{*}{$-0,082$} \\
\hline & G2 & 10,77 & 7,74 & 2,2 & 40,0 & & & \\
\hline \multirow{2}{*}{ Marrom } & G1 & 6,66 & 6,67 & 0 & 33,3 & \multirow{2}{*}{0,187} & \multirow{2}{*}{0,852} & \multirow{2}{*}{0,054} \\
\hline & $\mathrm{G} 2$ & 6,33 & 5,41 & 0 & 20,0 & & & \\
\hline \multirow{2}{*}{ Preto } & G1 & 3,99 & 6,23 & 0 & 31,1 & \multirow{2}{*}{$-1,189$} & 0240 & 0343 \\
\hline & G2 & 6,10 & 6,02 & 0 & 24,4 & & $0,2+0$ & $-0,543$ \\
\hline Branco & G1 & 6,14 & 5,82 & 0 & 31,1 & 0683 & 0498 & 0197 \\
\hline & G2 & 5,10 & 4,20 & 0 & 13,3 & S & & \\
\hline Cinza & G1 & 3,18 & 2,96 & 0 & 8,8 & 308 & 0760 & 0080 \\
\hline & G2 & 3,43 & 2,74 & 0 & 6,7 & & & \\
\hline
\end{tabular}

Como é possível observar, participantes de G1 e de G2 apresentaram perfis semelhantes na distribuição da frequência de cores empregadas neste instrumento de avaliação psicológica, não havendo indícios estatísticos de diferenças entre os grupos. Deste modo, tanto participantes com diagnóstico oncológico quanto os saudáveis fizeram uso preferencial da cor azul, verde e vermelho, seguida pelas cores violeta, amarelo, laranja, marrom e, por fim, branco, preto e cinza. 
O complemento analítico das escolhas das cores do Teste de Pfister se faz pela análise dos indicadores relativos às quatro principais síndromes cromáticas, a saber: Síndrome Normal, Síndrome Estímulo, Síndrome Fria e Síndrome Incolor. Esses resultados compõem a Tabela 23.

Tabela 23. Resultados médios (em porcentagem) e comparação estatística dos grupos em função das síndromes cromáticas do Teste de Pfister (primeira avaliação).

\begin{tabular}{|c|c|c|c|c|c|c|c|c|}
\hline \multirow{2}{*}{ Síndromes } & \multirow{2}{*}{ Grupo } & \multicolumn{4}{|c|}{ Análise Descritiva } & \multicolumn{3}{|c|}{ Análise Comparativa } \\
\hline & & Média & DP & Mínimo & Máximo & $t$ & $p$ & $d$ de Cohen \\
\hline \multirow{2}{*}{ Normal } & G1 & 49,85 & 10,61 & 17,8 & 68,8 & \multirow{2}{*}{0,295} & \multirow{2}{*}{0,769} & \multirow{2}{*}{0,085} \\
\hline & $\mathrm{G} 2$ & 49,00 & 8,98 & 37,8 & 71,1 & & & \\
\hline \multirow{2}{*}{ Estímulo } & G1 & 33,85 & 12,50 & 0 & 64,4 & \multirow{2}{*}{$-1,028$} & \multirow{2}{*}{0,309} & \multirow{2}{*}{$-0,297$} \\
\hline & $\mathrm{G} 2$ & 37,22 & 9,34 & 20,0 & 40,0 & & & \\
\hline \multirow{2}{*}{ Fria } & G1 & 46,15 & 9,62 & 22,2 & 66,7 & \multirow{2}{*}{1,448} & \multirow{2}{*}{0,154} & \multirow{2}{*}{0,418} \\
\hline & $\mathrm{G} 2$ & 41,87 & 11,05 & 17,8 & 68,89 & & & \\
\hline \multirow{2}{*}{ Incolor } & G1 & 13,33 & 8,29 & 0 & 33,3 & \multirow{2}{*}{0,953} & \multirow{2}{*}{0,580} & \multirow{2}{*}{$-0,161$} \\
\hline & $\mathrm{G} 2$ & 14,66 & 8,23 & 2,2 & 35,6 & & & \\
\hline
\end{tabular}

Nota-se ausência de diferenças estatisticamente significativas entre Grupo Clínico e Grupo de Comparação em relação à porcentagem média das síndromes cromáticas do Teste de Pfister. Ambos os grupos seguiram a distribuição dessas síndromes cromáticas conforme expectativas dos estudos normativos referentes à faixa etária entre sete e 17 anos (VillemorAmaral, 2014). Nos atuais participantes, a Síndrome Normal (composta pela combinação das cores Azul, Vermelho e Verde) foi a mais frequente, seguida pela Síndrome Fria (formada pela associação das cores Azul, Verde e Violeta).

A Síndrome Normal pode indicar a capacidade de manutenção de conduta adaptada, estabilidade e equilíbrio emocional. Carrega indicadores relativos à presença de mecanismos constritivos e inibitórios dos indivíduos, revelando esforço para preservação do equilíbrio psíquico. Em complemento, a Síndrome Fria pode representar a capacidade de controle ou inibição de impulsos. Nota-se que as Síndromes Estímulo e Fria encontram-se dentro da frequência esperada, denotando manutenção de adequada predisposição ao contato social, 
mantendo o afeto expresso no mundo externo, mas com estabilizadores que permitem introversão e postura reflexiva diante da realidade.

Com intuito de estabelecer comparação entre os escores médios obtidos pelos distintos grupos com os parâmetros instituídos pelos estudos normativos para esta faixa etária nessas variáveis do Pfister, foi construída a Tabela 24. Nessa tabela consta a distribuição dos participantes de G1 e G2 em função de sua posição em relação às expectativas normativas (na média, abaixo ou acima) para as cores e as síndromes cromáticas do Pfister.

Tabela 24. Distribuição dos participantes e comparação estatística dos grupos em função dos parâmetros normativos para cores e síndromes do Pfister (primeira avaliação).

\begin{tabular}{|c|c|c|c|c|c|c|c|c|}
\hline \multirow{2}{*}{\multicolumn{2}{|c|}{$\begin{array}{l}\text { Variáveis Pfister em } \\
\text { relação à norma }\end{array}$}} & \multicolumn{2}{|c|}{ G1 } & \multicolumn{2}{|c|}{$\mathrm{G} 2$} & \multicolumn{3}{|c|}{ Análise Comparativa } \\
\hline & & $f$ & $\%$ & $f$ & $\%$ & $x^{2}$ & $p$ & V de Cramer \\
\hline \multirow{3}{*}{ Azul } & Abaixo & 7 & 23,3 & 7 & 35,0 & \multirow{3}{*}{1,042} & \multirow{3}{*}{0,594} & \multirow{3}{*}{0,114} \\
\hline & Média & 16 & 53,3 & 8 & 40,0 & & & \\
\hline & Acima & 7 & 23,3 & 5 & 25,0 & & & \\
\hline \multirow{3}{*}{ Vermelho } & Abaixo & 8 & 26,6 & 4 & 20,0 & \multirow{3}{*}{0,427} & \multirow{3}{*}{0,808} & \multirow{3}{*}{0,092} \\
\hline & Média & 15 & 50,0 & 10 & 50,0 & & & \\
\hline & Acima & 7 & 23,3 & 6 & 30,0 & & & \\
\hline \multirow{3}{*}{ Verde } & Abaixo & 8 & 26,6 & 7 & 35,0 & \multirow{3}{*}{0,417} & \multirow{3}{*}{0,812} & \multirow{3}{*}{0,091} \\
\hline & Média & 13 & 43,3 & 8 & 40,0 & & & \\
\hline & Acima & 9 & 30,0 & 5 & 25,0 & & & \\
\hline \multirow{3}{*}{ Violeta } & Abaixo & 12 & 40,0 & 9 & 45,0 & \multirow{3}{*}{2,289} & \multirow{3}{*}{0,318} & \multirow{3}{*}{0,214} \\
\hline & Média & 8 & 26,6 & 8 & 40,0 & & & \\
\hline & Acima & 10 & 33,3 & 3 & 15,0 & & & \\
\hline \multirow{3}{*}{ Laranja } & Abaixo & 13 & 43,3 & 4 & 20,0 & \multirow{3}{*}{3,202} & \multirow{3}{*}{0,202} & \multirow{3}{*}{0,253} \\
\hline & Média & 8 & 26,6 & 7 & 35,0 & & & \\
\hline & Acima & 9 & 30,0 & 9 & 45,0 & & & \\
\hline \multirow{3}{*}{ Amarelo } & Abaixo & 16 & 53,3 & 6 & 30,0 & \multirow{3}{*}{5,244} & \multirow{3}{*}{0,073} & \multirow{3}{*}{0,324} \\
\hline & Média & 7 & 23,3 & 3 & 15,0 & & & \\
\hline & Acima & 7 & 23,3 & 11 & 55,0 & & & \\
\hline \multirow{3}{*}{ Marrom } & Abaixo & 10 & 33,3 & 7 & 35,0 & \multirow{3}{*}{0,682} & \multirow{3}{*}{0,711} & \multirow{3}{*}{0,117} \\
\hline & Média & 1 & 3,3 & - & - & & & \\
\hline & Acima & 19 & 63,3 & 13 & 65,0 & & & \\
\hline & Abaixo & 20 & 66,6 & 9 & 45,0 & & & \\
\hline Preto & Média & 6 & 20,0 & 6 & 30,0 & 2,379 & 0,304 & 0,218 \\
\hline & Acima & 4 & 13,3 & 5 & 25,0 & & & \\
\hline
\end{tabular}




\begin{tabular}{|c|c|c|c|c|c|c|c|c|}
\hline \multirow{2}{*}{\multicolumn{2}{|c|}{$\begin{array}{l}\text { Variáveis Pfister em } \\
\text { relação à norma }\end{array}$}} & \multicolumn{2}{|c|}{ G1 } & \multicolumn{2}{|c|}{$\mathrm{G} 2$} & \multicolumn{3}{|c|}{ Análise Comparativa } \\
\hline & & $f$ & $\%$ & $f$ & $\%$ & $x^{2}$ & $p$ & V de Cramer \\
\hline \multirow{3}{*}{ Branco } & Abaixo & 16 & 53,3 & 14 & 70,0 & \multirow{3}{*}{1,441} & \multirow{3}{*}{0,487} & \multirow{3}{*}{0,170} \\
\hline & Média & 3 & 10,0 & 1 & 15,0 & & & \\
\hline & Acima & 11 & 36,6 & 5 & 25,0 & & & \\
\hline \multirow{3}{*}{ Cinza } & Abaixo & 18 & 60,0 & 9 & 45,0 & \multirow{3}{*}{1,797} & \multirow{3}{*}{0,407} & \multirow{3}{*}{0,190} \\
\hline & Média & 4 & 13,3 & 2 & 10,0 & & & \\
\hline & Acima & 8 & 26,6 & 9 & 45,0 & & & \\
\hline \multirow{3}{*}{$\begin{array}{l}\text { Síndrome } \\
\text { Normal }\end{array}$} & Abaixo & 3 & 10,0 & 2 & 10,0 & \multirow{3}{*}{0,025} & \multirow{3}{*}{0,987} & \multirow{3}{*}{0,023} \\
\hline & Média & 22 & 73,3 & 15 & 75,0 & & & \\
\hline & Acima & 5 & 16,6 & 3 & 15,0 & & & \\
\hline \multirow{3}{*}{$\begin{array}{l}\text { Síndrome } \\
\text { Estímulo }\end{array}$} & Abaixo & 5 & 16,6 & 1 & 5,0 & \multirow{3}{*}{2,421} & \multirow{3}{*}{0,298} & \multirow{3}{*}{0,220} \\
\hline & Média & 19 & 63,3 & 12 & 60,0 & & & \\
\hline & Acima & 6 & 20,0 & 7 & 35,5 & & & \\
\hline \multirow{3}{*}{$\begin{array}{l}\text { Síndrome } \\
\text { Fria }\end{array}$} & Abaixo & 6 & 20,0 & 7 & 35,0 & \multirow{3}{*}{1,955} & \multirow{3}{*}{0,376} & \multirow{3}{*}{0,198} \\
\hline & Média & 20 & 66,6 & 12 & 60,0 & & & \\
\hline & Acima & 4 & 13,3 & 1 & 5,0 & & & \\
\hline \multirow{3}{*}{$\begin{array}{l}\text { Síndrome } \\
\text { Incolor }\end{array}$} & Abaixo & 14 & 46,6 & 8 & 40,0 & \multirow{3}{*}{0,267} & \multirow{3}{*}{0,875} & \multirow{3}{*}{0,875} \\
\hline & Média & 10 & 30,0 & 7 & 35,0 & & & \\
\hline & Acima & 6 & 20,0 & 5 & 25,0 & & & \\
\hline
\end{tabular}

É possível comentar que os participantes de G1 e G2 não se diferenciaram de modo estatisticamente significativo em termos das expectativas normativas para as cores e as síndromes do Pfister. Notam-se concentrações das crianças e adolescentes em algumas dessas variáveis do Pfister, mas nada que se constitua em indicador típico de seu funcionamento psicológico.

Assim, no Grupo Clínico houve maior concentração de casos que utilizam as cores violeta, laranja, amarelo, preto, branco e cinza em proporção inferior ao referencial normativo, enquanto a cor marrom concentra-se acima do esperado. As cores azul, verde e vermelho, por sua vez, mostraram-se compatíveis com as expectativas normativas, assim como a Síndrome Normal. Essa concentração dos indivíduos nessas cores destacadas pode ser indicativa de alguma repercussão associada aos cuidados oncológicos, uma vez que esses achados sugerem inibição e controle da vivência espontânea dos afetos no ambiente ( $\downarrow$ amarelo, $\downarrow$ laranja) e da ansiedade ( $\downarrow$ violeta), talvez como forma para diminuir o sofrimento 
e buscar elaboração das experiências. Por outro lado, há diminuição de estabilizadores afetivos da personalidade ( $\downarrow$ preto, $\downarrow$ branco, $\downarrow$ cinza, $\downarrow$ Síndrome Incolor), compensados por mecanismo de controle mais primitivo dos impulsos ( $\uparrow$ marrom), sugerindo movimento de contenção obsessiva dos afetos, provavelmente em busca de amparo e proteção. Já no Grupo de Comparação nota-se que os participantes apresentaram distribuição mais variada em relação às normas esperadas para essas variáveis do Pfister.

A seguir, na Tabela 25 serão apresentados os resultados médios e a comparação dos escores de G1 e G2 com relação à Fórmula Cromática (FC) do Pfister. Essa variável informa a respeito da frequência da utilização das cores ao longo da prova, bem como sua constância, configurando-se como valoroso indicador de o quanto a pessoa é receptiva e suscetível aos estímulos (Villemor Amaral, 2014). Constituída pela variação do emprego das cores nas três pirâmides, a Fórmula Cromática do Pfister é composta de quatro itens, a saber: Constância Absoluta (CA) que representa a quantidade de cores que foram empregadas nas três pirâmides; Constância Relativa (CR) que informa o número de cores utilizadas em pelo menos duas pirâmides; Variabilidade (V) que aponta o número de cores colocadas em apenas uma pirâmide; e Ausência (AUS) que aponta quantas cores não foram empregadas pela pessoa avaliada.

Tabela 25. Resultados médios e comparação estatística dos grupos em relação à Fórmula Cromática no Teste de Pfister (primeira avaliação).

\begin{tabular}{ccccccc}
\hline \multirow{2}{*}{$\begin{array}{c}\text { Algarismos da } \\
\text { Fórmula Cromática }\end{array}$} & Grupo & \multicolumn{2}{c}{ Análise Descritiva } & \multicolumn{2}{c}{ Análise Comparativa } & \\
& & Média & D P & $t$ & $p$ & $d$ de Cohen \\
\hline \multirow{2}{*}{ Constância Absoluta } & G1 & 3,66 & 2,57 & $-0,100$ & 0,921 & $-0,029$ \\
& G2 & 3,77 & 3,32 & & & \\
Constância Relativa & G1 & 2,83 & 1,39 & $-0,035$ & 0,972 & $-0,010$ \\
& G2 & 2,85 & 1,98 & & & \\
Variabilidade & G1 & 1,90 & 1,58 & & \\
& G2 & 2,30 & 1,72 & $-0,846$ & 0,402 & $-0,244$ \\
Ausência & G1 & 1,56 & 1,99 & & & \\
& G2 & 1,10 & 1,61 & 0,871 & 0,388 & 0,252 \\
\hline
\end{tabular}

Não houve diferenças estatisticamente significativas entre os resultados de G1 e G2 nos componentes da FC, sinalizando perfis semelhantes na relação CA:CR:V:AUS. Houve maior dilatação do algarismo de CA, seguido por CR, V e, por fim, AUS, sugestivo de 
estabilidade na escolha das cores utilizadas na construção das três pirâmides, além de denotar receptividade e abertura aos estímulos. Esse padrão pode ser considerado como típico da infância e da adolescência (Villemor-Amaral, Biasi, Pavan, Tavella \& Cardoso, 2016).

Outro modo de examinar as FC do Pfister é por meio de sua classificação em termos de amplitude (restrita, moderada, ampla), variabilidade (lábil, flexível, constante) e de seus desvios internos (à esquerda, à direita, equilíbrio entre os algarismos). As considerações acerca dessa classificação da Fórmula Cromática e a análise comparativa distribuição dos casos de G1 e G2 na primeira avaliação estão retratadas na Tabela 26.

Tabela 26. Distribuição dos participantes e comparação estatística dos grupos em função da classificação da Fórmula Cromática do Teste de Pfister (primeira avaliação).

\begin{tabular}{|c|c|c|c|c|c|c|c|c|}
\hline \multirow{2}{*}{\multicolumn{2}{|c|}{$\begin{array}{l}\text { Classificação da } \\
\text { Fórmula Cromática }\end{array}$}} & \multicolumn{2}{|c|}{ G1 } & \multicolumn{2}{|c|}{$\mathrm{G} 2$} & \multicolumn{3}{|c|}{ Análise Comparativa } \\
\hline & & $f$ & $\%$ & $f$ & $\%$ & $x^{2}$ & $p$ & V de Cramer \\
\hline \multirow{3}{*}{ Amplitude } & Ampla & 24 & 80,0 & 17 & 85,0 & \multirow{3}{*}{0,412} & \multirow{3}{*}{0,814} & \multirow{3}{*}{0,091} \\
\hline & Moderada & 3 & 10,0 & 2 & 10,0 & & & \\
\hline & Restrita & 3 & 10,0 & 1 & 5,0 & & & \\
\hline \multirow{3}{*}{ Variabilidade } & Constante & 6 & 20,0 & 8 & 40,0 & \multirow{3}{*}{13,13} & \multirow{3}{*}{$\leq \mathbf{0 , 0 0 1}$} & \multirow{3}{*}{0,513} \\
\hline & Flexível & 24 & 80,0 & 7 & 35,0 & & & \\
\hline & Lábil & - & - & 5 & 25,0 & & & \\
\hline \multirow{3}{*}{ Desvio } & Esquerda & 16 & 53,3 & 11 & 55,0 & \multirow{3}{*}{0,988} & \multirow{3}{*}{0,610} & \multirow{3}{*}{0,141} \\
\hline & Empate & 4 & 13,3 & 1 & 5,0 & & & \\
\hline & Direita & 10 & 33,3 & 8 & 40,0 & & & \\
\hline
\end{tabular}

Constata-se que os grupos marcam-se por FC consideradas Amplas, reiterando a sensibilidade afetiva dessa etapa do desenvolvimento. Destaca-se, no entanto, diferença estatisticamente significativa entre G1 e G2, com tamanho de efeito moderado, em relação à classificação da Variabilidade: G1 mostrou-se claramente concentrado na categoria Flexível, enquanto G2 não sinalizou estilo predominante de variabilidade nas escolhas cromáticas. Assim, depreende-se uma pista clínica sobre os voluntários que convivem com o diagnóstico oncológico na infância e adolescência: apresentam destaque em termos de flexibilidade, quando comparados com seus pares de G2. A Fórmula Cromática de G1 marcou-se por ser Ampla, Flexível e desviada a Esquerda, denotando receptividade, sensibilidade, boa capacidade de ação e adaptação frente a exigências do ambiente, provavelmente como 
estratégia facilitadora de equilíbrio diante das vivências desafiadoras dos cuidados oncológicos.

O último conjunto de variáveis do Teste de Pfister a serem consideradas neste estudo são os modos de execução da tarefa proposta pelo instrumento, o estilo de colocação dos quadrículos e o aspecto formal das pirâmides construídas. Tratam de elementos formais desse método projetivo, no geral associado ao funcionamento cognitivo do respondente.

O processo de execução corresponde ao estilo de realização da tarefa, verificando-se existência de estratégia mais rígida e uniforme ou se tende a um trabalho mais variável durante o processo de construção das pirâmides. O Processo de Execução pode ser classificado como Metódico, Ordenado, Desordenado/Relaxado.

Já o Modo de Colocação retrata a ordem adotada pela pessoa para dispor os quadrículos nos espaços vazios de cada pirâmide. Nesse estudo os modos de colocação foram agrupados em três categorias distintas: Ascendente (inicia da base rumo ao topo), Descendente (parte do topo da figura e se direciona para a base), Outros (engloba formas de colocação em zigue-zague, simétrica, diagonal ou manto). A esses tipos deve-se juntar a direção da colocação dos quadrículos na pirâmide, a saber: Colocação Direta (da esquerda para a direita); Colocação Inversa (da direita e para a esquerda) ou Outros (direcionamentos mistos, inespecífica).

Por fim, há que examinar o aspecto formal das pirâmides produzidas pelos participantes de G1 e G2, que informa sobre como o indivíduo modula e controla seus impulsos e emoções utilizando seus recursos cognitivos, sua atenção e precisão formal diante da mobilização afetiva das cores do Pfister. A classificação do aspecto formal das pirâmides indica o nível de maturidade dos recursos cognitivos da pessoa.

Na Tabela 27 consta a distribuição de casos e comparação estatística entre os grupos em face do Modo de Execução, Modo de Colocação e Aspecto formal das pirâmides do Pfister. Esses dados correspondem à primeira avaliação dos participantes (Fase 1). 
Tabela 27. Distribuição dos participantes e comparação estatística dos grupos dos Modos de Execução, Modos de Colocação e Aspecto Formal no Teste de Pfister (primeira avaliação).

\begin{tabular}{ccccccccc}
\hline \multirow{2}{*}{ Variável do Pfister } & \multicolumn{2}{c}{ G1 } & \multicolumn{2}{c}{ G2 } & \multicolumn{2}{c}{ Análise Comparativa } \\
& & $f$ & $\%$ & $f$ & $\%$ & $x^{2}$ & $p$ & $\begin{array}{c}\text { V de } \\
\text { Cramer }\end{array}$ \\
\hline \multirow{2}{*}{ Execução } & Metódica & 6 & 20,0 & 9 & 45,0 & & & \\
& Ordenada & 22 & 73,3 & 11 & 55,0 & 4,444 & 0,108 & 0,298 \\
& Relaxada & 2 & 6,6 & 2 & 10,0 & & & \\
& & & & & & & & \\
Colocação* & Ascendente & 41 & 45,5 & 33 & 55,0 & & & \\
& Descendente & 34 & 37,8 & 26 & 38,3 & 8,522 & $\mathbf{0 , 0 1 4}$ & 0,238 \\
& Outros** & 15 & 16,7 & 1 & 1,7 & & & \\
Colocação** & Direta & 37 & 41,1 & 46 & 76,6 & & & \\
& Inversa & 27 & 30,0 & 9 & 15,0 & 18,96 & $\mathbf{0 0 , 0 0 1}$ & 0,356 \\
& Outros*** & 26 & 28,9 & 5 & 8,3 & & & \\
Aspecto & Tapetes & 58 & 64,4 & 40 & 66,6 & & & \\
Formal & Formações & 28 & 31,2 & 18 & 30,0 & 0,153 & 0,926 & 0,032 \\
& Estruturas & 4 & 4,4 & 2 & 3,4 & & & \\
\hline
\end{tabular}

* Referente ao total de pirâmides elaboradas pelos participantes

** Alternada, Simétrica, Diagonal ou Manto.

*** Inespecífica.

No tocante ao Modo de Execução, o Grupo Clínico e o Grupo de Comparação mostraram-se semelhantes, havendo concentração de ambos os grupos no Modo de Execução Ordenada $(\mathrm{G} 1=73,3 \%$ e $\mathrm{G} 2=55,0 \%)$. Esta forma de executar o conjunto do trabalho reflete um padrão de colocação dos quadrículos de forma organizada e estável, admitindo flexibilidade que se reflete na possibilidade de estabelecer algumas variações como trocas e inversões ao longo da tarefa.

Com relação ao Modo de Execução, apesar de haver diferença estatística significativa entre os grupos, o tamanho do efeito foi pequeno. É possível observar que em ambos ocorre concentração dos casos no Modo Ascendente $(\mathrm{G} 1=45,5 \%$ e $\mathrm{G} 2=55,5 \%)$ e Direto $(\mathrm{G} 1=76,6 \%$ e $\mathrm{G} 2=76,6 \%$ ). Sinalizaram, portanto, estilo de trabalho marcado pela lógica e adequada organização na construção das pirâmides, sugerindo eficiência no funcionamento racional.

Apesar de inexistir diferenças estatisticamente significativas entre G1 e G2 no Aspecto Formal das pirâmides, é possível observar aglutinação em Tapetes ( $\mathrm{G} 1=64,4 \%$ e G=66,6\%) e Formações $(\mathrm{G} 1=31,2 \%$ e $\mathrm{G}=30,0 \%)$. Esta distribuição acompanha o esperado no 
desenvolvimento dos recursos racionais das crianças. A importante presença das Formações em G1 e em G2 pode indicar organização intermediária da percepção das diferentes dimensões da figura geométrica, espelhando o nível de evolução e aliança entre seus recursos cognitivos e os afetos. Isso pode ser considerado condizente com os esforços de organização da personalidade dos participantes, em claro processo de desenvolvimento.

\subsubsection{Referentes à segunda avaliação (FASE 2)}

Como pontuado nos objetivos deste trabalho, os resultados a seguir apresentados correspondem ao processo de avaliação dos participantes num segundo momento, realizado após pelo menos seis meses da primeira aplicação dos instrumentos de avaliação psicológica, numa perspectiva de acompanhamento longitudinal dos casos. Assim, os dados serão apresentados em função dos específicos métodos projetivos utilizados (Método de Rorschach e Teste de Pfister), conforme realizado na Fase 1. Com o objetivo de poder explorar, comparativamente, as evidências de G1 e de G2, em relação a sua primeira avaliação neste trabalho, os resultados seguem os mesmos indicadores técnicos inicialmente apresentados sobre o Método de Rorschach e o Teste de Pfister.

\subsubsection{Método de Rorschach - Segunda Fase}

Os dados referentes ao ritmo de trabalho e aos indicadores de produtividade no Método de Rorschach estão sistematizados na Tabela 28. Correspondem aos achados de G1 e G2 na segunda fase do estudo. 
Tabela 28. Resultados médios e comparação estatística dos grupos em função da produtividade e ritmo no Rorschach (segunda avaliação).

\begin{tabular}{ccccccccc}
\hline \multirow{2}{*}{$\begin{array}{c}\text { Ritmo e } \\
\text { Produtividade }\end{array}$} & Grupo & \multicolumn{5}{c}{ Análise Descritiva } & \multicolumn{3}{c}{ Análise Comparativa } \\
& & Média & DP & Mínimo & Máximo & $t$ & $p$ & $d$ de Cohen \\
\hline Respostas & G1 & 16,9 & 6,61 & 6,0 & 31,0 & 0,282 & 0,779 & 0,081 \\
& G2 & 16,3 & 9,78 & 7,0 & 45,0 & & & \\
Respostas & G1 & 0,3 & 0,7 & 0 & 3,0 & & & \\
Adicionais & G2 & 0,5 & 0,7 & 0 & 5,0 & & 0,583 & $-0,160$ \\
& & & & & & & & \\
Recusas & G1 & 0,3 & 0,8 & 0 & 4,0 & $-0,689$ & 0,494 & $-0,199$ \\
& G2 & 0,5 & 1,1 & 0 & 2,0 & & & \\
Denegações & G1 & 0,2 & 0,5 & 0 & 2,0 & 0,927 & 0,358 & 0,268 \\
& G2 & 0,1 & 0,2 & 0 & 1,0 & & & \\
Tempo de & G1 & 14,2 & 8,8 & 5,7 & 40,4 & & & \\
Latência Médio* & G2 & 13,4 & 8,6 & 3,0 & 41,7 & 0,285 & 0,777 & 0,082 \\
Tempo de & G1 & 26,6 & 16,0 & 10,3 & 76,4 & & & \\
Reação Médio* & G2 & 22,3 & 11,8 & 5,4 & 53,4 & 1,028 & 0,309 & 0,297 \\
\hline
\end{tabular}

*Em segundos.

A análise das variáveis referentes ao segundo momento avaliativo mostra que ambos os grupos mantêm boa capacidade associativa e adaptativa ao ambiente. Inexistem diferenças estatisticamente significativas entre G1 e G2 nas variáveis de ritmo e produção no Método de Rorschach.

Com relação a este conjunto de variáveis, depreende-se que mesmo com a prolongada convivência com eventos de relevante mobilização emocional e angústias (no caso do grupo clínico), a possibilidade de interpretar os estímulos imprecisos da realidade, como proposto pelo Método de Rorschach, sinalizou-se adequada. Tem-se, portanto, indícios de preservação dos recursos cognitivos na tarefa adaptativa ao longo do tempo, nos dois conjuntos de crianças e adolescentes.

Os modos de apreensão dos estímulos do Rorschach estão sistematizados na Tabela 29. Novamente são apresentados resultados descritivos e a comparação estatística dos achados entre os grupos nessa segunda avaliação. 
Tabela 29. Resultados médios e comparação estatística dos grupos em função dos modos de apreensão do Rorschach (segunda avaliação).

\begin{tabular}{|c|c|c|c|c|c|c|c|c|}
\hline \multirow{2}{*}{$\begin{array}{l}\text { Modos de } \\
\text { Apreensão }\end{array}$} & \multirow{2}{*}{ Grupo } & \multicolumn{4}{|c|}{ Análise Descritiva } & \multicolumn{3}{|c|}{ Análise Comparativa } \\
\hline & & Média & DP & Mínimo & Máximo & $t$ & $p$ & $d$ de Cohen \\
\hline \multirow{2}{*}{$\mathrm{G} \%$} & G1 & 36,1 & 22,3 & 0 & 81,8 & \multirow{2}{*}{0,423} & \multirow{2}{*}{0,674} & \multirow{2}{*}{0,122} \\
\hline & $\mathrm{G} 2$ & 33,5 & 18,4 & 8,7 & 70,0 & & & \\
\hline \multirow{2}{*}{$\mathrm{D} \%$} & G1 & 43,6 & 19,3 & 10,0 & 82,4 & \multirow{2}{*}{0,230} & \multirow{2}{*}{0,982} & \multirow{2}{*}{0,007} \\
\hline & $\mathrm{G} 2$ & 43,5 & 16,9 & 10,0 & 70,6 & & & \\
\hline \multirow{2}{*}{$\mathrm{Dd} \%$} & G1 & 20,0 & 14,0 & 0 & 54,6 & \multirow{2}{*}{$-0,714$} & \multirow{2}{*}{0,479} & \multirow{2}{*}{$-0,206$} \\
\hline & $\mathrm{G} 2$ & 22,9 & 13,9 & 4,8 & 56,5 & & & \\
\hline \multirow{2}{*}{$\mathrm{Db} 1 \%$} & G1 & 0,3 & 1,8 & 0 & 10,0 & \multirow{2}{*}{0,485} & \multirow{2}{*}{0,630} & \multirow{2}{*}{0,140} \\
\hline & $\mathrm{G} 2$ & 0,1 & 0,6 & 0 & 2,6 & & & \\
\hline
\end{tabular}

Mais uma vez é possível notar a ausência de diferenças estatisticamente significativas entre G1 e G2 nos modos de apreensão deste método projetivo de avaliação psicológica. Pode-se observar o mesmo foco interpretativo entre as crianças e adolescentes de G1 e G2: destacaram as áreas D, depois G e, por fim, as áreas Dd. Ou seja, focalizaram atenção em elementos pregnantes da realidade, depois em aspectos integradores e gerais da mesma, seguindo-se análise complementar de minúcias dos estímulos propostos, com reduzida interpretação do fundo branco dos cartões. Assim, é possível apontar que crianças e adolescentes com câncer, bem como aqueles com plena saúde, demonstraram apreender o seu entorno de forma semelhante, compatível com o esperado para sua etapa de desenvolvimento (Cury-Jacquemin, 2012). Mesmo com o curso da história de adoecimento e a exposição a potenciais fatores de risco presentes no ambiente hospitalar, não foram encontrados elementos sugestivos de repercussões negativas ou prejuízos no processo de discriminação dos estímulos da realidade, preservando funcionalidade atencional.

Os determinantes das respostas nessa segunda aplicação do Método de Rorschach, por sua vez, constituem os dados da Tabela 30. Visualizam-se os resultados médios de G1 e G2, bem como sua comparação estatística. 
Tabela 30. Resultados médios e comparação estatística dos grupos em função dos determinantes do Rorschach (segunda avaliação).

\begin{tabular}{|c|c|c|c|c|c|c|c|c|}
\hline \multirow{2}{*}{ Determinantes } & \multirow{2}{*}{ Grupo } & \multicolumn{4}{|c|}{ Análise Descritiva } & \multicolumn{3}{|c|}{ Análise Comparativa } \\
\hline & & Média & DP & Mínimo & Máximo & $t$ & $p$ & d de Cohen \\
\hline \multirow{2}{*}{$\mathrm{F} \%$} & G1 & 44,0 & 17,5 & 4,6 & 91,7 & \multirow{2}{*}{$-1,263$} & \multirow{2}{*}{0,213} & \multirow{2}{*}{$-0,364$} \\
\hline & $\mathrm{G} 2$ & 50,4 & 18,1 & 15,4 & 90,0 & & & \\
\hline \multirow{2}{*}{$\mathrm{F}+\%$} & G1 & 75,8 & 15,0 & 40,0 & 100,0 & \multirow{2}{*}{$-0,048$} & \multirow{2}{*}{0,962} & \multirow{2}{*}{$-0,014$} \\
\hline & $\mathrm{G} 2$ & 76,0 & 22,3 & 33,3 & 100,0 & & & \\
\hline \multirow{2}{*}{$\mathrm{F}+\mathrm{Ext} \%$} & G1 & 77,1 & 13,2 & 50,0 & 100,0 & \multirow{2}{*}{$-0,215$} & \multirow{2}{*}{0,831} & \multirow{2}{*}{$-0,062$} \\
\hline & G2 & 78,0 & 17,3 & 40,0 & 100,0 & & & \\
\hline \multirow{2}{*}{$\mathrm{K}$} & G1 & 1,1 & 1,2 & 0 & 3,0 & \multirow{2}{*}{0,946} & \multirow{2}{*}{0,349} & \multirow{2}{*}{0,273} \\
\hline & G2 & 0,8 & 1,0 & 0 & 3,0 & & & \\
\hline \multirow{2}{*}{ kan } & G1 & 1,1 & 1,6 & 0 & 7,0 & \multirow{2}{*}{$-0,363$} & \multirow{2}{*}{0,718} & \multirow{2}{*}{$-0,105$} \\
\hline & $\mathrm{G} 2$ & 1,3 & 1,6 & 0 & 6,0 & & & \\
\hline & G1 & 0,2 & 0,6 & 0 & 2,0 & & & \\
\hline kob & G2 & 0,2 & 0,4 & 0 & 1,0 & 0,579 & 0,565 & 0,167 \\
\hline \multirow{2}{*}{$\mathrm{kp}$} & G1 & 0,1 & 0,3 & 0 & 1,0 & \multirow{2}{*}{$-0,163$} & \multirow{2}{*}{0,871} & \multirow{2}{*}{$-0,047$} \\
\hline & G2 & 0,2 & 0,4 & 0 & 1,0 & & & \\
\hline \multirow{2}{*}{$\begin{array}{l}\sum \text { Pequenas } \\
\text { Cinestesias* }\end{array}$} & G1 & 1,5 & 1,7 & 0 & 7,0 & \multirow[b]{2}{*}{$-0,198$} & & \\
\hline & G2 & 1,6 & 1,9 & 0 & 7,0 & & 0,844 & $-0,057$ \\
\hline $\mathrm{FC}$ & G1 & 4,0 & 2,1 & 0 & 7,0 & 1259 & 0214 & 0364 \\
\hline & $\mathrm{G} 2$ & 3,2 & 2,6 & 0 & 9,0 & $1,2 J)$ & & \\
\hline$C F$ & G1 & 1,3 & 1,5 & 0 & 4,0 & 0890 & 0373 & 0260 \\
\hline 1 & G2 & 0,9 & 1,1 & 0 & 4,0 & נינס, & נונד, & 0,200 \\
\hline$C$ & G1 & 0,3 & 0,7 & 0 & 3,0 & 2053 & 0046 & 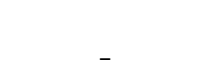 \\
\hline & G2 & - & - & 0 & 0 & & 0 & \\
\hline$\sum \mathrm{Cn}^{* *}$ & G1 & 3,8 & 2,3 & 0 & 8,0 & 1861 & 0069 & 0537 \\
\hline$\angle e p$ & G2 & 2,6 & 2,2 & 0 & 7,0 & & 0,00 & ונת,ט \\
\hline $\mathrm{FE}$ & G1 & 0,9 & 1,4 & 0 & 6,0 & -0.777 & 0.441 & -0.224 \\
\hline & G2 & 1,2 & 1,3 & 0 & 5,0 & & & \\
\hline $\mathrm{EF}$ & G1 & 0,4 & 0,7 & 0 & 2,0 & 1512 & 0.137 & 0,436 \\
\hline & G2 & 0,2 & 0,4 & 0 & 1,0 & & & \\
\hline
\end{tabular}


Análise Descritiva

Análise Comparativa

Determinantes Grupo

Média

DP Mínimo

Máximo

$p$

d de Cohen

$\begin{array}{cccccccc}\text { E } & \text { G1 } & - & - & 0 & 0 & -1,789 & 0,080\end{array}$

$\begin{array}{lllllllll}\Sigma \mathrm{Ep}^{* * *} & \mathrm{G} 1 & 0,9 & 1,2 & 0 & 5,0 & -0,163 & 0,871 & -0,047\end{array}$

FClob

$\begin{array}{ccccccc}\text { G1 } & 0,03 & 0,2 & 0 & 1,0 & 0,814 & 0,420 \\ \text { G2 } & - & - & 0 & 0 & \end{array}$

$\bar{*} \sum$ Pequenas Cinestesias = soma total de respostas com determinantes de movimento animal (kan), objeto (kob) e parcial humano (kp).

** $\sum \mathrm{Cp}=$ soma ponderada das respostas com determinante cor.

$* * * \sum \mathrm{Ep}$ = soma ponderada das respostas com determinante sombreado.

Foi possível identificar apenas uma diferença estatisticamente significativa entre G1 e G2 nos determinantes das respostas ao Rorschach nessa segunda avaliação das crianças e adolescentes. Essa diferença ocorreu na variável C, de baixa incidência nos protocolos, o que minimiza seu efeito na interpretação dos achados. Mais uma vez nota-se similaridade nos determinantes das respostas utilizados pelos participantes, indicando semelhança em seus recursos psíquicos, possibilidades de abertura afetiva e coordenação racional dos impulsos.

Em ambos os grupos houve importante incidência de respostas determinadas exclusivamente pelos aspectos formais dos estímulos do Rorschach (F\%), mas com adequada percepção e discriminação lógica (bons indicadores de F+\% e F+ext\%). Esses índices apontaram adequada precisão formal na abordagem interpretativa da realidade, independentemente das vicissitudes do ambiente, estando em consonância com seu grupo de referência sociocultural (Cury-Jacquemin, 2012).

Em complemento, podem ser destacadas algumas outras variáveis relativas aos determinantes das respostas ao Rorschach. A soma ponderada do determinante Cor apresentou tendência à diferença estatisticamente significativa entre os grupos, tendo G1 maior expressão de respostas cromáticas. Assim, é possível apontar que crianças e adolescentes que convivem com o câncer mantêm adequada coordenação lógica dos afetos em suas vivências, mas tendem a maior mobilização emocional e possibilidade de reações ligadas aos sentimentos (respostas de determinante ligado à cor).

Ao considerarmos a relação de respostas formais e respostas com o determinante cor $(\mathrm{FC}: \mathrm{CF}+\mathrm{C})$, será possível obter subsídios adicionais para a compreensão da capacidade de 
modulação e controle racional dos afetos. Constata-se que, nessa segunda avaliação, os dois grupos sinalizaram predomínio das respostas $\mathrm{FC}$ sobre $\mathrm{CF}+\mathrm{C}$, sendo a relação de 4:1,6 no Grupo Clínico e de 3,2:0,9 no Grupo de Comparação. Ou seja, indicaram manutenção de favorável capacidade de coordenação dos afetos, bem como sua expressão no ambiente.

De modo similar, a relação $\mathrm{FE}: \mathrm{EF}+\mathrm{E}$ apresenta subsídios para compreender o mecanismo de administração das reações de ansiedade e angústia utilizando estratégias do pensamento formal. Deste modo, nesta etapa avaliativa, essa relação foi de 0,9:0,4 em G1 e assumiu valores médios de 1,2:0,3 em G2. Assim, a vivência de ansiedade se encontra sob controle lógico saudável em ambos os grupos, favorecendo ações em prol da própria pessoa.

$\mathrm{Na}$ sequência da análise da segunda avaliação de ambos os grupos, aparecem os resultados médios e comparação estatística dos conteúdos e respostas banais produzidos diante do Método do Rorschach. Esses achados compõem a Tabela 31.

Tabela 31. Resultados médios e comparação estatística dos grupos em função dos conteúdos e banalidades do Rorschach (segunda avaliação).

\begin{tabular}{|c|c|c|c|c|c|c|c|c|}
\hline \multirow{2}{*}{ Conteúdos } & \multirow{2}{*}{ Grupo } & \multicolumn{4}{|c|}{ Análise Descritiva } & \multicolumn{3}{|c|}{ Análise Comparativa } \\
\hline & & Média & $\mathrm{DP}$ & Mínimo & Máximo & $t$ & $p$ & d de Cohen \\
\hline A & $\begin{array}{l}\text { G1 } \\
\text { G2 }\end{array}$ & $\begin{array}{l}6,8 \\
5,9\end{array}$ & $\begin{array}{l}3,6 \\
3,9\end{array}$ & $\begin{array}{l}2,0 \\
1,0\end{array}$ & $\begin{array}{l}15,0 \\
16,0\end{array}$ & 0,831 & 0,410 & 0,240 \\
\hline (A) & $\begin{array}{l}\text { G1 } \\
\text { G2 }\end{array}$ & $\begin{array}{l}0,9 \\
0,6\end{array}$ & $\begin{array}{l}1,0 \\
0,7\end{array}$ & $\begin{array}{l}0 \\
0\end{array}$ & $\begin{array}{l}4,0 \\
2,0\end{array}$ & 1,035 & 0,306 & 0,299 \\
\hline Ad & $\begin{array}{l}\text { G1 } \\
\text { G2 }\end{array}$ & $\begin{array}{l}1,2 \\
1,8\end{array}$ & $\begin{array}{l}1,6 \\
3,5\end{array}$ & $\begin{array}{l}0 \\
0\end{array}$ & $\begin{array}{c}6,0 \\
15,0\end{array}$ & $-0,708$ & 0,483 & $-0,204$ \\
\hline (Ad) & $\begin{array}{l}\text { G1 } \\
\text { G2 }\end{array}$ & $\begin{array}{l}0,2 \\
0,2\end{array}$ & $\begin{array}{l}0,8 \\
0,4\end{array}$ & $\begin{array}{l}0 \\
0\end{array}$ & $\begin{array}{l}4,0 \\
1,0\end{array}$ & 0,273 & 0,786 & 0,079 \\
\hline Soma A & $\begin{array}{l}\text { G1 } \\
\text { G2 }\end{array}$ & $\begin{array}{l}9,1 \\
8,5\end{array}$ & $\begin{array}{l}4,5 \\
5,2\end{array}$ & $\begin{array}{l}2,0 \\
1,0\end{array}$ & $\begin{array}{l}18,0 \\
23,0\end{array}$ & 0,492 & 0,625 & 0,142 \\
\hline $\mathrm{A} \%$ & $\begin{array}{l}\text { G1 } \\
\text { G2 }\end{array}$ & $\begin{array}{l}53,9 \\
53,3\end{array}$ & $\begin{array}{l}19,4 \\
22,7\end{array}$ & $\begin{array}{l}20,0 \\
14,3\end{array}$ & $\begin{array}{c}94,1 \\
100,0\end{array}$ & 0,107 & 0,915 & 0,031 \\
\hline $\mathrm{H}$ & $\begin{array}{l}\text { G1 } \\
\text { G2 }\end{array}$ & $\begin{array}{l}1,5 \\
1,6\end{array}$ & $\begin{array}{l}1,5 \\
1,6\end{array}$ & $\begin{array}{l}0 \\
0\end{array}$ & $\begin{array}{l}5,0 \\
5,0\end{array}$ & $-0,229$ & 0,820 & $-0,066$ \\
\hline$(\mathrm{H})$ & $\begin{array}{l}\text { G1 } \\
\text { G2 }\end{array}$ & $\begin{array}{l}0,7 \\
0,5\end{array}$ & $\begin{array}{l}0,8 \\
0,9\end{array}$ & $\begin{array}{l}0 \\
0\end{array}$ & $\begin{array}{l}3,0 \\
3,0\end{array}$ & 0,635 & 0,528 & 0,183 \\
\hline
\end{tabular}




\begin{tabular}{|c|c|c|c|c|c|c|c|c|}
\hline \multirow{2}{*}{ Conteúdos } & \multirow{2}{*}{ Grupo } & \multicolumn{4}{|c|}{ Análise Descritiva } & \multicolumn{3}{|c|}{ Análise Comparativa } \\
\hline & & Média & DP & Mínimo & Máximo & $t$ & $p$ & d de Cohen \\
\hline \multirow{2}{*}{ Hd } & G1 & 0,7 & 1,1 & 0 & 4,0 & \multirow{2}{*}{$-0,609$} & \multirow{2}{*}{0,545} & \multirow{2}{*}{$-0,176$} \\
\hline & $\mathrm{G} 2$ & 1,0 & 1,4 & 0 & 4,0 & & & \\
\hline \multirow{2}{*}{ (Hd) } & G1 & 0,3 & 0,6 & 0 & 2,0 & \multirow{2}{*}{1,171} & \multirow{2}{*}{0,247} & \multirow{2}{*}{0,338} \\
\hline & $\mathrm{G} 2$ & 0,1 & 0,3 & 0 & 1,0 & & & \\
\hline \multirow{2}{*}{ Soma H } & G1 & 3,2 & 2,6 & 0 & 10,0 & \multirow{2}{*}{0,024} & \multirow{2}{*}{0,981} & \multirow{2}{*}{0,007} \\
\hline & $\mathrm{G} 2$ & 3,2 & 2,0 & 0 & 6,0 & & & \\
\hline \multirow{2}{*}{$\mathrm{H} \%$} & G1 & 18,5 & 14,4 & 0 & 45,5 & \multirow{2}{*}{$-0,920$} & \multirow{2}{*}{0,362} & \multirow{2}{*}{$-0,266$} \\
\hline & G2 & 22,8 & 18,6 & 0 & 71,4 & & & \\
\hline \multirow{2}{*}{ Anat } & G1 & 0,5 & 1,0 & 0 & 3,0 & \multirow{2}{*}{1,259} & \multirow{2}{*}{0,214} & \multirow{2}{*}{0,363} \\
\hline & G2 & 0,2 & 0,5 & 0 & 2,0 & & & \\
\hline \multirow{2}{*}{$\mathrm{Sg}$} & G1 & 0,1 & 0,3 & 0 & 1,0 & \multirow{2}{*}{0,952} & \multirow{2}{*}{0,346} & \multirow{2}{*}{0,275} \\
\hline & G2 & 0,1 & 0,2 & 0 & 1,0 & & & \\
\hline \multirow{2}{*}{ Sex } & G1 & 0,1 & 0,3 & 0 & 1,0 & 1171 & 0247 & - \\
\hline & G2 & - & - & 0 & 0 & & & 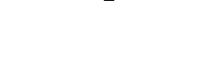 \\
\hline Obj & G1 & 1,2 & 1,4 & 0 & 5,0 & -0.960 & 0.342 & -0.277 \\
\hline & G2 & 1,8 & 2 & 0 & 12,0 & & & \\
\hline Art & G1 & 0,2 & 0,4 & 0 & 1,0 & 2191 & 0033 & - \\
\hline 810 & G2 & - & - & 0 & 0 & 2,1 & 0,000 & \\
\hline Arg & G1 & 0,1 & 0,4 & 0 & 2,0 & -1500 & 0140 & -0433 \\
\hline Аाप & G2 & 0,4 & 0,6 & 0 & 2,0 & ס & טדו & \\
\hline Simb & G1 & 0,3 & 0,5 & 0 & 2,0 & 0095 & 0924 & 0028 \\
\hline & G2 & 0,3 & 0,7 & 0 & 3,0 & & & \\
\hline Abst & G1 & 0,03 & 0,2 & 0 & 1,0 & -0289 & 0.924 & - 083 \\
\hline & G2 & 0,05 & 0,2 & 0 & 1,0 & , & (1) & 0,000 \\
\hline Bot & G1 & 0,9 & 1,3 & 0 & 5,0 & 0.584 & 0.562 & 0.168 \\
\hline & G2 & 0,7 & 1,5 & 0 & 6,0 & & & \\
\hline Geo & G1 & 0,5 & 0,9 & 0 & 3,0 & -0.189 & 0.851 & -0.054 \\
\hline & G2 & 0,6 & 1,0 & 0 & 3,0 & & & \\
\hline Nat & G1 & 0,1 & 0,3 & 0 & 1,0 & $-1,204$ & 0.235 & $-0,347$ \\
\hline & G2 & 0,2 & 0,5 & 0 & 2,0 & & & \\
\hline
\end{tabular}




\begin{tabular}{|c|c|c|c|c|c|c|c|c|}
\hline \multirow{2}{*}{ Conteúdos } & \multirow{2}{*}{ Grupo } & \multicolumn{4}{|c|}{ Análise Descritiva } & \multicolumn{3}{|c|}{ Análise Comparativa } \\
\hline & & Média & DP & Mínimo & Máximo & $t$ & $p$ & d de Cohen \\
\hline \multirow{2}{*}{ Pais } & G1 & 0,2 & 0,4 & 0 & 1,0 & \multirow{2}{*}{1,238} & \multirow{2}{*}{0,222} & \multirow{2}{*}{0,357} \\
\hline & $\mathrm{G} 2$ & 0,05 & 0,2 & 0 & 1,0 & & & \\
\hline \multirow{2}{*}{ Elem } & G1 & 0,3 & 0,8 & 0 & 4,0 & \multirow{2}{*}{1,368} & \multirow{2}{*}{0,178} & \multirow{2}{*}{0,395} \\
\hline & $\mathrm{G} 2$ & 0,05 & 0,2 & 0 & 1,0 & & & \\
\hline \multirow{2}{*}{ Elem(fogo) } & G1 & 0,1 & 0,4 & 0 & 2,0 & \multirow{2}{*}{1,107} & \multirow{2}{*}{0,274} & \multirow{2}{*}{-} \\
\hline & $\mathrm{G} 2$ & - & - & 0 & 0 & & & \\
\hline \multirow{2}{*}{ Frag } & G1 & 0,1 & 0,3 & 0 & 1,0 & \multirow{2}{*}{$-0,962$} & \multirow{2}{*}{0,341} & \multirow{2}{*}{$-0,278$} \\
\hline & $\mathrm{G} 2$ & 0,2 & 0,7 & 0 & 3,0 & & & \\
\hline \multirow{2}{*}{ Ban $\%$} & G1 & 15,4 & 8,9 & 0 & 33,3 & \multirow{2}{*}{$-0,357$} & \multirow{2}{*}{0,723} & \multirow{2}{*}{$-0,103$} \\
\hline & $\mathrm{G} 2$ & 16,3 & 10,3 & 0 & 40,0 & & & \\
\hline
\end{tabular}

Mais uma vez, apenas uma única diferença estatisticamente significativa emergiu da comparação dos conteúdos das respostas de G1 e G2 nessa segunda aplicação do Método de Rorschach. A diferença ocorreu no conteúdo de tipo Artístico (Art), que surge com baixa frequência dentre o conjunto de respostas de ambos os grupos, praticamente anulando especificidades de produção de G1 e G2 quanto aos conteúdos interpretados.

Em relação aos padrões esperados para o grupo de referência sociocultural, ambos os grupos apresentam porcentagem de resposta animal (A\%) dentro do esperado, conforme estabelece Cury-Jacquemin (2012). Neste sentido, constata-se que crianças e adolescentes de G1 e G2 manifestaram indicativos de preservação das características básicas da etapa do ciclo vital em que se encontram. Esta constatação aponta para adaptação à realidade e conformidade com o pensamento expresso pelo grupo social.

De forma análoga, avalia-se que a frequência de respostas de conteúdo humano $[H,(H)$, Hd, (Hd)] obedece a tendência das normas de referência. Segundo Cury-Jacquemin (2012), espera-se que crianças e adolescentes no intervalo de idade de 12 a 14 anos apresentem 22,7\% de respostas humanas, o que é verificado em G2 (22,8\%) e de modo menos intenso em G1 (18,5\%). Em outras palavras, preservam a possibilidade de identificação com o conteúdo humano.

$\mathrm{Na}$ análise comparativa de conteúdos animais e humanos íntegros em relação aos conteúdos parciais, houve mais manifestações de respostas com figuras inteiras em G1 e G2. Isso apontaria para a preservação da integridade dos objetos internalizados e da personalidade. 
Ao focalizar a análise da diversidade dos conteúdos projetados no Método de Rorschach nesta etapa avaliativa, é possível apreender similaridades entre os dois grupos. Os participantes de $\mathrm{G} 1$ apresentaram $[(\mathrm{A} \%+\mathrm{H} \%)=72,4 \%]$, enquanto voluntários de $\mathrm{G} 2$ ofereceram $76,1 \%$ das respostas com estes conteúdos. Isto possibilita inferir que G1 e G2 apresentaram indicativos de diversidade de interesses manifestos, sendo que quase um quarto de suas respostas abordou outros conteúdos, embora todos com baixa incidência, sem destaque interpretativo simbólico.

Ao enfocarmos a presença das respostas banais (Ban\%), é possível depreender que o Grupo Clínico e o Grupo de Comparação apresentaram índices próximos aos referenciais normativos para sua faixa etária. Trata-se de sinal de positivo compartilhamento do pensamento com a coletividade, além de conformidade social.

Em síntese, a partir da avaliação das características dos conteúdos das respostas oferecidas por G1 e G2 ao longo do processo de reavaliação, é possível ponderar que mesmo no curso da intensa convivência com as exigências dos cuidados oncológicos, as crianças e adolescentes mantêm riqueza de interesses, bom contato com a realidade, preservação dos recursos cognitivos e afetivos de elaboração das apreensões dos estímulos. Tendem a acompanhar a forma de pensar de seu grupo de referência, acompanhando expectativas desenvolvimentais de sua faixa etária.

Em continuidade ao exame das variáveis do Rorschach, tem-se, na Tabela 32, a análise descritiva e a comparação dos resultados do Grupo Clínico e do Grupo de Comparação em função das fórmulas vivenciais e estilos afetivos.

Tabela 32. Distribuição dos participantes e comparação estatística dos grupos em função das Fórmulas Vivenciais do Rorschach (segunda avaliação).

\begin{tabular}{|c|c|c|c|c|c|c|c|c|}
\hline \multirow[b]{2}{*}{ Fórmulas } & \multirow[b]{2}{*}{ Vivenciais } & \multicolumn{2}{|c|}{ G1 } & \multicolumn{2}{|c|}{$\mathrm{G} 2$} & \multicolumn{3}{|c|}{ Análise Comparativa } \\
\hline & & $f$ & $\%$ & $f$ & $\%$ & $X^{2}$ & $p$ & $\begin{array}{c}\text { Vde } \\
\text { Cramer }\end{array}$ \\
\hline \multirow{3}{*}{$\begin{array}{c}\text { Tipo de } \\
\text { Ressonância } \\
\text { Íntima (TRI) }\end{array}$} & Introversivo & 2 & 6,6 & 3 & 15,0 & \multirow{3}{*}{4,982} & \multirow{3}{*}{0,083} & \multirow{3}{*}{0,316} \\
\hline & Extratensivo & 24 & 80,0 & 10 & 50,0 & & & \\
\hline & Outros* & 4 & 13,4 & 7 & 35,0 & & & \\
\hline \multirow{3}{*}{$\begin{array}{l}2^{\text {a }} \text { Fórmula } \\
\text { Afetiva }\end{array}$} & Introversivo & 12 & 40,0 & 7 & 35,0 & \multirow{3}{*}{0,329} & \multirow{3}{*}{0,848} & \multirow{3}{*}{0,081} \\
\hline & Extratensivo & 3 & 10,0 & 3 & 15,0 & & & \\
\hline & Outros* & 15 & 50,0 & 10 & 50,0 & & & \\
\hline \multirow{3}{*}{$\begin{array}{c}3^{\text {a }} \text { Fórmula } \\
\text { Afetiva }\end{array}$} & Introversivo & 10 & 33,3 & 4 & 20,0 & \multirow{3}{*}{1,111} & \multirow{3}{*}{0,574} & \multirow{3}{*}{0,149} \\
\hline & Extratensivo & 8 & 26,7 & 7 & 35,0 & & & \\
\hline & Ambigual & 12 & 40,0 & 9 & 45,0 & & & \\
\hline \multirow{2}{*}{$\begin{array}{l}\text { Fórmula da } \\
\text { Angústia }\end{array}$} & Normal $(\leq 12 \%)$ & 22 & 73,3 & 14 & 70,0 & \multirow{2}{*}{0,066} & \multirow{2}{*}{0,797} & \multirow{2}{*}{0,036} \\
\hline & Elevada $(>12 \%)$ & 8 & 26,7 & 6 & 30,0 & & & \\
\hline
\end{tabular}


Ao analisarmos a comparação da distribuição de casos no Tipo de Ressonância Íntima $\left(\mathrm{TRI}=\mathrm{K}: \sum \mathrm{Cp}\right)$ entre G1 e G2, observamos não haver diferença estatística significativa. Os participantes em cuidados oncológicos e aqueles com saúde preservada concentraram-se no tipo Extratensivo como TRI. Ambos os grupos sinalizaram, dessa maneira, modo habitual de expressão de seus pensamentos e sentimentos em forma mais aberta e direta no ambiente e nas relações com o outro. Justamente por ser menos reflexiva e mais expansiva, faz alusão ao estilo típico de TRI encontrando em pessoas nesta faixa etária.

Ao examinar as Tendências Latentes (Segunda Fórmula Afetiva $=\sum \mathrm{k}: \sum E \mathrm{E}$ ), observase não existir indicativos de diferença estatisticamente significativa na distribuição dos casos de G1 e G2. Em ambos os grupos houve predomínio do estilo Coartado/Coartativo (representado na tabela pela categoria Outros), seguido pelo estilo Introversivo, sugerindo recursos internos para desenvolver uma postura mais reflexiva e introversiva na dinâmica psíquica, além de defesas com características repressivas e inibitórias, talvez no intuito de lidar com a variabilidade de experiências e relações interpessoais desse momento de vida.

A comparação da segunda avaliação de G1 e G2 no tocante ao Índice de Reatividade Afetiva (Terceira Fórmula) apontou mais casos do tipo Ambigual, embora sem diferença estatisticamente significativa entre os grupos. Assim, sinalizaram tendência a reações situacionais variadas diante do ambiente, talvez numa postura de cautela e cuidado avaliativo, podendo reagir mais abertamente ou mais refletidamente, conforme a demanda do contexto. Isso pode favorecer adaptabilidade das crianças e dos adolescentes em seus processos de desenvolvimento, embora possa não ser consistente com seu estilo habitual de expressão emocional (como sinalizado pelo TRI).

Por fim, cabe analisar os achados relativos à Fórmula da Angústia nessa segunda aplicação do Método de Rorschach. Não houve diferença estatisticamente significativa entre os grupos, além de se notar predomínio de valores baixos, indicativos de não interferência da ansiedade no funcionamento psíquico das crianças e dos adolescentes avaliados.

\subsubsection{Teste das Pirâmides Coloridas de Pfister - Segunda Fase}

A Tabela 33 traz os dados descritivos das frequências das escolhas cromáticas dessa segunda avaliação por meio do Teste de Pfister, bem como a comparação estatística dos resultados médios dos dois grupos. As análises acompanharão os mesmos passos realizados na Fase 1 (primeira avaliação) dos participantes, de modo a ser possível sua análise comparativa posterior. 
Tabela 33. Resultados médios e comparação estatística dos grupos em função das cores do Teste de Pfister (segunda avaliação).

\begin{tabular}{|c|c|c|c|c|c|c|c|c|}
\hline \multirow{2}{*}{$\begin{array}{l}\text { Cores } \\
\text { Pfister }\end{array}$} & \multirow{2}{*}{ Grupo } & \multicolumn{4}{|c|}{ Análise Descritiva } & \multicolumn{3}{|c|}{ Análise Comparativa } \\
\hline & & Média & DP & Mínimo & Máximo & $t$ & $p$ & $d$ de Cohen \\
\hline \multirow{2}{*}{ Azul } & G1 & 17,0 & 7,7 & 0 & 33,3 & \multirow{2}{*}{0,678} & \multirow{2}{*}{0,501} & \multirow{2}{*}{0,196} \\
\hline & $\mathrm{G} 2$ & 15,6 & 6,3 & 0 & 26,7 & & & \\
\hline \multirow{2}{*}{ Vermelho } & G1 & 15,9 & 8,3 & 0 & 33,3 & \multirow{2}{*}{$-0,872$} & \multirow{2}{*}{0,388} & \multirow{2}{*}{$-0,252$} \\
\hline & $\mathrm{G} 2$ & 17,9 & 6,7 & 11,1 & 37,8 & & & \\
\hline \multirow{2}{*}{ Verde } & G1 & 14,5 & 9,4 & 0 & 42,2 & \multirow{2}{*}{$-0,515$} & \multirow{2}{*}{0,609} & \multirow{2}{*}{$-0,149$} \\
\hline & $\mathrm{G} 2$ & 16,1 & 12,3 & 0 & 46,7 & & & \\
\hline \multirow{2}{*}{ Violeta } & G1 & 11,7 & 8,6 & 0 & 33,3 & \multirow{2}{*}{$-1,543$} & \multirow{2}{*}{0,129} & \multirow{2}{*}{$-0,446$} \\
\hline & $\mathrm{G} 2$ & 15,7 & 9,3 & 2,2 & 37,8 & & & \\
\hline \multirow{2}{*}{ Laranja } & G1 & 8,4 & 6,2 & 0 & 33,3 & \multirow{2}{*}{1,098} & \multirow{2}{*}{0,278} & \multirow{2}{*}{0,317} \\
\hline & G2 & 6,7 & 4,1 & 0 & 13,3 & & & \\
\hline \multirow{2}{*}{ Amarelo } & G1 & 7,9 & 5,9 & 0 & 24,4 & \multirow{2}{*}{0,654} & \multirow{2}{*}{0,516} & \multirow{2}{*}{0,189} \\
\hline & G2 & 6,9 & 3,7 & 2,2 & 17,8 & & & \\
\hline \multirow{2}{*}{ Marrom } & G1 & 6,5 & 6,8 & 0 & 33,3 & \multirow{2}{*}{0,842} & \multirow{2}{*}{0,404} & \multirow{2}{*}{0,243} \\
\hline & $\mathrm{G} 2$ & 5,1 & 4,0 & 0 & 13,3 & & & \\
\hline \multirow{2}{*}{ Preto } & G1 & 5,6 & 4,9 & 0 & 17,8 & \multirow{2}{*}{$-0,240$} & 0812 & _ 060 - \\
\hline & $\mathrm{G} 2$ & 6,0 & 5,5 & 0 & 24,4 & & & \\
\hline Branco & G1 & 8,4 & 7,6 & 0 & 31,1 & 1006 & 0320 & חסר ת \\
\hline Drame & $\mathrm{G} 2$ & 6,4 & 4,9 & 0 & 20,0 & 1,000 & $0, J \approx 0$ & $0,2>0$ \\
\hline Cinza & G1 & 4,1 & 3,8 & 0 & 13,3 & 0466 & 0643 & 0135 \\
\hline & G2 & 3,7 & 3,0 & 0 & 8,9 & & & \\
\hline
\end{tabular}

$\mathrm{Na}$ segunda fase deste estudo, os participantes de G1 e G2 não apresentaram diferenças estatisticamente significativas com relação às escolhas das cores no Teste de Pfister. Do mesmo modo como foi observado na primeira aplicação desse instrumento, ambos os grupos acompanharam o padrão esperado para as escolhas cromáticas do Pfister, a partir dos parâmetros normativos estabelecidos por Villemor-Amaral (2014). Houve predomínio das 
cores verde, vermelho e azul (cores da Síndrome Normal) nos dois grupos, sugerindo preservação da vitalidade nos participantes avaliados.

Cabe ainda examinar a distribuição dos achados em relação às síndromes cromáticas nesse método projetivo de avaliação psicológica. Estes resultados compõem a Tabela 34.

Tabela 34. Resultados médios e comparação estatística dos grupos em função das síndromes cromáticas do Teste de Pfister (segunda avaliação).

\begin{tabular}{ccccccccc}
\hline \multirow{2}{*}{ Síndromes } & Grupo & \multicolumn{5}{c}{ Análise Descritiva } & \multicolumn{3}{c}{ Análise Comparativa } \\
& & Média & DP & Mínimo & Máximo & $t$ & $p$ & $d$ de Cohen \\
\hline \multirow{2}{*}{ Normal } & G1 & 47,4 & 10,3 & 28,9 & 75,6 & $-0,612$ & 0,544 & $-0,177$ \\
& G2 & 49,6 & 14,5 & 13,3 & 88,9 & & & \\
\multirow{5}{*}{ Estímulo } & G1 & 32,1 & 11,4 & 13,3 & 66,7 & 0,249 & 0,805 & 0,072 \\
& G2 & 31,4 & 6,7 & 17,8 & 44,4 & & & \\
\multirow{2}{*}{ Fria } & G1 & 43,2 & 14,0 & 0 & 75,6 & $-1,181$ & 0,243 & $-0,341$ \\
& G2 & 47,3 & 8,5 & 33,3 & 62,2 & & & \\
Incolor & G1 & 18,5 & 10,7 & 0 & 44,4 & 0,676 & 0,503 & 0,195 \\
& G2 & 16,1 & 10,0 & 0 & 44,4 & & & \\
\hline
\end{tabular}

Nessa segunda aplicação do instrumento também não emergiram diferenças estatisticamente significativas entre o Grupo Clínico e de Comparação no tocante às síndromes cromáticas do Teste de Pfister. Os participantes apresentaram proporções, nessas variáveis, compatíveis com os referenciais normativos da faixa etária em estudo, sugerindo preservação das vivências afetivas e do equilíbrio emocional, independentemente de sua condição de saúde.

Imbuídos do objetivo de apreciar a produção no Pfister frente aos parâmetros preconizados pelos estudos normativos, tem-se os dados da Tabela 35. Nela consta a distribuição e a comparação estatística da posição dos casos de G1 e G2 em relação ao referencial normativo (na média, acima ou abaixo) das frequências das cores e síndromes. 
Tabela 35. Distribuição dos participantes e comparação estatística dos grupos em função dos parâmetros normativos para cores e síndromes do Pfister (segunda avaliação).

\begin{tabular}{|c|c|c|c|c|c|c|c|c|}
\hline \multirow{2}{*}{\multicolumn{2}{|c|}{$\begin{array}{l}\text { Variáveis em } \\
\text { relação à norma }\end{array}$}} & \multicolumn{2}{|c|}{ G1 } & \multicolumn{2}{|c|}{$\mathrm{G} 2$} & \multicolumn{3}{|c|}{ Análise Comparativa } \\
\hline & & $f$ & $\%$ & $f$ & $\%$ & $x^{2}$ & $p$ & V de Cramer \\
\hline \multirow{3}{*}{ Azul } & Abaixo & 9 & 30,0 & 5 & 25,0 & \multirow{3}{*}{2,857} & \multirow{3}{*}{0,240} & \multirow{3}{*}{0,239} \\
\hline & Média & 13 & 43,4 & 13 & 65,0 & & & \\
\hline & Acima & 8 & 26,6 & 2 & 10,0 & & & \\
\hline \multirow{3}{*}{ Vermelho } & Abaixo & 10 & 10,0 & 3 & 15,0 & \multirow{3}{*}{2,336} & \multirow{3}{*}{0,311} & \multirow{3}{*}{0,216} \\
\hline & Média & 9 & 30,0 & 9 & 45,0 & & & \\
\hline & Acima & 11 & 36,6 & 8 & 40,0 & & & \\
\hline \multirow{3}{*}{ Verde } & Abaixo & 11 & 36,6 & 10 & 50,0 & \multirow{3}{*}{2,407} & \multirow{3}{*}{0,300} & \multirow{3}{*}{0,219} \\
\hline & Média & 14 & 46,6 & 5 & 25,0 & & & \\
\hline & Acima & 5 & 16,6 & 5 & 25,0 & & & \\
\hline \multirow{3}{*}{ Violeta } & Abaixo & 16 & 53,4 & 8 & 40,0 & \multirow{3}{*}{1,111} & \multirow{3}{*}{0,574} & \multirow{3}{*}{0,149} \\
\hline & Média & 6 & 20,0 & 4 & 20,0 & & & \\
\hline & Acima & 8 & 26,6 & 8 & 40,0 & & & \\
\hline \multirow{3}{*}{ Laranja } & Abaixo & 8 & 26,6 & 10 & 50,0 & \multirow{3}{*}{4,537} & \multirow{3}{*}{0,103} & \multirow{3}{*}{0,301} \\
\hline & Média & 10 & 33,4 & 2 & 10,0 & & & \\
\hline & Acima & 12 & 40,0 & 8 & 40,0 & & & \\
\hline \multirow{3}{*}{ Amarelo } & Abaixo & 15 & 50,0 & 12 & 60,0 & \multirow{3}{*}{2,904} & \multirow{3}{*}{0,234} & \\
\hline & Média & 6 & 20,0 & 6 & 30,0 & & & 0,241 \\
\hline & Acima & 9 & 30,0 & 2 & 10,0 & & & \\
\hline & Abaixo & 9 & 30,0 & 8 & 40,0 & & & \\
\hline Marrom & Média & 4 & 13,4 & 1 & 5,0 & 1,192 & 0,551 & 0,154 \\
\hline & Acima & 17 & 56,6 & 11 & 55,0 & & & \\
\hline & Abaixo & 15 & 50,0 & 9 & 45,0 & & & \\
\hline Preto & Média & 4 & 13,4 & 5 & 25,0 & 1,127 & 0,569 & 0,150 \\
\hline & Acima & 11 & 36,6 & 6 & 30,0 & & & \\
\hline & Abaixo & 14 & 46,6 & 11 & 55,0 & & & \\
\hline Branco & Média & 3 & 10,0 & 3 & 15,0 & 0,978 & 0,613 & 0,140 \\
\hline & Acima & 13 & 43,4 & 6 & 30,0 & & & \\
\hline & Abaixo & 15 & 50,0 & 10 & 50,0 & & & \\
\hline Cinza & Média & 4 & 13,4 & 3 & 15,0 & 0,033 & 0,984 & 0,026 \\
\hline & Acima & 11 & 36,6 & 7 & 35,0 & & & \\
\hline & Abaixo & 7 & 23,4 & 2 & 10,0 & & & \\
\hline Normal & Média & 20 & 66,6 & 15 & 75,0 & 1,554 & 0,460 & 0,176 \\
\hline & Acima & 3 & 10,0 & 3 & 15,0 & & & \\
\hline
\end{tabular}




\begin{tabular}{ccccccccc}
\hline \multicolumn{2}{c}{$\begin{array}{c}\text { Variáveis em } \\
\text { relação à norma }\end{array}$} & $f$ & $\%$ & $f$ & $\%$ & $x^{2}$ & $p$ & V de Cramer \\
\hline & & & & & \multicolumn{2}{c}{$\mathrm{G} 2$} & & \multicolumn{2}{c}{ Análise Comparativa } \\
Síndrome & Abaixo & 9 & 30,0 & 3 & 15,0 & & & \\
Estímulo & Média & 13 & 43,4 & 14 & 70,0 & 3,448 & 0,178 & 0,263 \\
& Acima & 8 & 26,6 & 3 & 15,0 & & & \\
Síndrome & Abaixo & 10 & 33,4 & 3 & 15,0 & & & \\
Fria & Média & 17 & 56,6 & 14 & 70,0 & 2,145 & 0,342 & 0,207 \\
& Acima & 3 & 10,0 & 3 & 15,0 & & & \\
Síndrome & Abaixo & 7 & 23,4 & 2 & 10,0 & & & \\
Incolor & Acima & 20 & 66,6 & 15 & 75,0 & 2,844 & 0,241 & 0,238 \\
& & & 10,0 & 3 & 15,0 & & & \\
\hline
\end{tabular}

Não foram identificadas diferenças estatisticamente significativas entre G1 e G2 nessas variáveis, tendo por base a expectativa normativa de sua faixa etária. Nas cores verde, vermelho e azul a grande maioria dos participantes manteve-se na média esperada, assim como nas quatro principais síndromes cromáticas, sugerindo padrão geral adaptativo em termos de sensibilidade e funcionamento emocional. Apesar disso, como ocorreu na primeira aplicação do Pfister, notam-se alguns aglomerados de participantes em termos de suas frequências de escolhas das cores e das síndromes. Destaque para a alta incidência de casos com violeta e amarelo inferiores à média normativa, juntamente com muitos casos de marrom acima da média, tanto em G1 quanto em G2. Desse modo, nessa faixa etária avaliada pareceu ser comum o aumento da rigidez como estratégia organizadora dos afetos ( $\uparrow$ marrom), bem como esforços de inibição emocional ( $\downarrow$ amarelo, $\downarrow$ violeta).

Adiante, na Tabela 36 são apresentadas as informações referentes à Fórmula Cromática (FC). Os dados representam os algarismos componentes da FC do Pfister, em termos médios, bem como a comparação estatística entre G1 e G2 nessa segunda avaliação. 
Tabela 36. Resultados médios e comparação estatística dos grupos em relação à Fórmula Cromática no Teste de Pfister (segunda avaliação).

\begin{tabular}{|c|c|c|c|c|c|c|}
\hline \multirow{2}{*}{$\begin{array}{c}\text { Algarismos da } \\
\text { Fórmula Cromática }\end{array}$} & \multirow{2}{*}{ Grupo } & \multicolumn{2}{|c|}{ Análise Descritiva } & \multicolumn{2}{|c|}{ Análise Comparativa } & \multirow{2}{*}{$D$ de Cohen } \\
\hline & & Média & $\mathrm{DP}$ & $t$ & $p$ & \\
\hline \multirow{2}{*}{ Constância Absoluta } & G1 & 3,46 & 2,94 & \multirow{2}{*}{$-0,729$} & \multirow{2}{*}{0,469} & \multirow{2}{*}{$-0,211$} \\
\hline & $\mathrm{G} 2$ & 4,05 & 2,48 & & & \\
\hline \multirow{2}{*}{ Constância Relativa } & G1 & 2,76 & 1,96 & \multirow{2}{*}{$-0,259$} & \multirow{2}{*}{0,797} & \multirow{2}{*}{$-0,075$} \\
\hline & $\mathrm{G} 2$ & 2,90 & 1,48 & & & \\
\hline \multirow{2}{*}{ Variabilidade } & G1 & 2,36 & 1,65 & \multirow{2}{*}{0,231} & \multirow{2}{*}{0,818} & \multirow{2}{*}{0,067} \\
\hline & $\mathrm{G} 2$ & 2,25 & 1,88 & & & \\
\hline \multirow{2}{*}{ Ausência } & G1 & 1,40 & 1,99 & \multirow{2}{*}{1,190} & \multirow{2}{*}{0,240} & \multirow{2}{*}{0,344} \\
\hline & G2 & 0,80 & 1,28 & & & \\
\hline
\end{tabular}

Não houve diferenças estatisticamente significativas entre os grupos com relação à Fórmula Cromática. Os valores mais elevados ocorreram no algarismo de $\mathrm{CA}$, seguida pelo valor de $\mathrm{CR}$ e $\mathrm{V}$, com reduzido valor algarismo de AUS, acompanhando o padrão esperado para a faixa etária.

A compreensão destas variáveis pode ser complementada pela análise dos dados da Tabela 37. Ela retrata a análise comparativa da distribuição dos casos do Grupo Clínico e do Grupo de Comparação no tocante às classificações da Fórmula Cromática do Pfister na segunda etapa avaliativa deste estudo.

Tabela 37. Distribuição dos participantes e comparação estatística dos grupos em função da classificação da Fórmula Cromática no Teste de Pfister (segunda avaliação).

\begin{tabular}{ccccccccc}
\hline \multirow{2}{*}{$\begin{array}{c}\text { Classificação da } \\
\text { Fórmula Cromática }\end{array}$} & \multicolumn{2}{c}{ G1 } & \multicolumn{3}{c}{ G2 } & \multicolumn{3}{c}{ Análise Comparativa } \\
& Ampla & 23 & 76,6 & 18 & 90,0 & & \\
\multirow{2}{*}{ Amplitude } & Moderada & 3 & 10,0 & 1 & 5,0 & 1,468 & 0,480 & 0,171 \\
& Restrita & 4 & 13,4 & 1 & 5,0 & & & \\
& & & & & & & & \\
Variabilidade & Constante & 4 & 13,4 & 2 & 10,0 & & & \\
& Flexível & 16 & 53,3 & 13 & 65,0 & 0,670 & 0,715 & 0,116 \\
& Lábil & 10 & 33,3 & 5 & 25,0 & & & \\
& & & & & & & & \\
Eesquerda & 18 & 60,0 & 14 & 70,0 & & & \\
& Empate & 7 & 23,4 & 2 & 10,0 & 1,447 & 0,485 & 0,170 \\
& Direita & 5 & 16,6 & 4 & 20,0 & & & \\
\hline
\end{tabular}


Nota-se similaridade na distribuição dos casos de G1 e G2 em termos de amplitude e variabilidade da FC, com ausência de diferença estatisticamente significativa. Em síntese, predominaram nos dois grupos a Fórmula Cromática classificada como Ampla e Flexível, com desvio à esquerda. Desse modo, pode-se dizer que os participantes de ambos os grupos sinalizaram importante captação e sensibilidade afetiva do ambiente, mantendo favorável adaptação por meio de postura flexível, porém equilibrada e determinada.

Por fim, a Tabela 38 mostra os dados descritivos e comparativos entre G1 e G2 referentes aos Modos de Execução, Modos de Colocação e Aspecto Formal das pirâmides produzidas na segunda fase do estudo.

Tabela 38. Distribuição dos participantes e comparação estatística dos grupos em função dos Modos de Execução, Modos de Colocação e Aspecto Formal no Teste de Pfister (segunda avaliação).

\begin{tabular}{|c|c|c|c|c|c|c|c|c|}
\hline \multirow{2}{*}{\multicolumn{2}{|c|}{ Variável do Pfister }} & \multicolumn{2}{|c|}{ G1 } & \multicolumn{2}{|c|}{$\mathrm{G} 2$} & \multicolumn{3}{|c|}{ Análise Comparativa } \\
\hline & & $f$ & $\%$ & $f$ & $\%$ & $x^{2}$ & $p$ & $\begin{array}{c}\mathrm{V} \text { de } \\
\text { Cramer }\end{array}$ \\
\hline \multirow{3}{*}{ Execução } & Metódica & 3 & 10,0 & 5 & 25,0 & \multirow{3}{*}{3,404} & \multirow{3}{*}{0,182} & \multirow{3}{*}{0,261} \\
\hline & Ordenada & 25 & 83,4 & 12 & 60,0 & & & \\
\hline & Relaxada & 2 & 6,6 & 3 & 15,0 & & & \\
\hline \multirow{3}{*}{ Colocação* } & Ascendente & 40 & 44,4 & 23 & 38,4 & \multirow{3}{*}{3,751} & \multirow{3}{*}{0,153} & \multirow{3}{*}{0,153} \\
\hline & Descendente & 35 & 38,9 & 19 & 31,6 & & & \\
\hline & Outros** & 15 & 16,6 & 18 & 30,0 & & & \\
\hline \multirow{3}{*}{ Colocação* } & Direta & 39 & 43,4 & 39 & 65,0 & \multirow{3}{*}{20,32} & \multirow{3}{*}{$\leq \mathbf{0 , 0 0 1}$} & \multirow{3}{*}{0,368} \\
\hline & Inversa & 31 & 34,4 & 2 & 3,4 & & & \\
\hline & Outros*** & 20 & 22,2 & 19 & 31,6 & & & \\
\hline \multirow{3}{*}{$\begin{array}{l}\text { Aspecto } \\
\text { Formal* }\end{array}$} & Tapetes & 59 & 65,5 & 42 & 70,0 & \multirow{3}{*}{0,348} & \multirow{3}{*}{0,840} & \multirow{3}{*}{0,048} \\
\hline & Formações & 28 & 31,2 & 16 & 22,6 & & & \\
\hline & Estruturas & 3 & 3,3 & 2 & 3,4 & & & \\
\hline
\end{tabular}

Em ambos os grupos ocorreu prioritariamente o Modo de Execução Ordenado, o que reflete adequado funcionamento lógico e execução bem organizada das atividades, sem rigidez. Não houve diferença estatisticamente significativa nesse quesito entre G1 e G2. 
No tocante ao Modo de Colocação, apesar da dispersão dos casos entre as classificações, houve uma diferença estatisticamente significativa entre G1 e G2, embora tamanho de efeito considerado médio. O Grupo de Comparação concentrou-se na colocação direta, enquanto o Grupo Clínico apresentou predomínio desse tipo, mas também com forte proporção da colocação inversa. Em termos de síntese, no entanto, pode-se apontar que G1 e G2 apresentam maior frequência do modo de colocação Ascendente Direta, o que pode ser indicativo de preservação de atitude lógica e estável na execução da tarefa.

A análise do aspecto formal das pirâmides apontou ausência de diferença estatisticamente significativa entre os grupos. Como na primeira etapa deste estudo, os Tapetes foram mais frequentes $(\mathrm{G} 1=65,5 \%$ e $\mathrm{G} 2=70,0 \%)$, sucedido pelas Formações $(\mathrm{G} 1=31,2 \%$ e $\mathrm{G} 2=22,6 \%$ ), sugerindo forma pouco elaborada de organização intelectual dos afetos, comum entre essa faixa etária avaliada.

\subsubsection{Indicadores de Personalidade - Comparação FASE 1 e FASE 2 no Grupo Clínico}

A partir dos objetivos propostos para esta investigação, faz-se relevante examinar os resultados dos dois momentos avaliativos do Grupo Clínico $(n=30)$. Essa estratégia analítica intragrupo tem por finalidade examinar possíveis mudanças nos achados em função do tempo de desenvolvimento e de assistência em saúde das crianças e adolescentes avaliados.

As variáveis consideradas na presente análise são as mesmas selecionadas do Método de Rorschach e do Teste de Pfister. Desse modo, foram comparados os dados relativos a: produtividade, ritmo, modos de apreensão, determinantes, conteúdos, banalidades e fórmulas vivenciais no Rorschach, bem como proporção das escolhas cromáticas e respectivas síndromes, fórmula cromática e aspectos formais no Teste de Pfister.

\subsubsection{Método de Rorschach - Comparação Fase 1 e Fase 2 no Grupo Clínico}

A Tabela 39 apresenta os resultados descritivos e a comparação estatística dos dois momentos avaliativos de G1 no tocante aos indicadores de produtividade e de ritmo diante do Método de Rorschach. 
Tabela 39. Resultados médios e comparação estatística das duas avaliações do grupo clínico (G1) em função da produtividade e ritmo no Rorschach.

\begin{tabular}{|c|c|c|c|c|c|c|c|c|}
\hline \multirow{2}{*}{$\begin{array}{l}\text { Variável } \\
\text { Rorschach }\end{array}$} & \multirow{2}{*}{ Fase } & \multicolumn{4}{|c|}{ Análise Descritiva } & \multicolumn{3}{|c|}{ Análise Comparativa } \\
\hline & & Média & DP & Mínimo & Máximo & $z$ & $p$ & d de Cohen \\
\hline \multirow{2}{*}{ Respostas } & Fase 1 & 17,1 & 6,6 & 9,0 & 36,0 & \multirow{2}{*}{$-0,263$} & \multirow{2}{*}{0,793} & \multirow{2}{*}{0,037} \\
\hline & Fase 2 & 16,9 & 6,5 & 6,0 & 31,0 & & & \\
\hline \multirow{2}{*}{$\begin{array}{l}\text { Respostas } \\
\text { Adicionais }\end{array}$} & Fase 1 & 0,7 & 0,7 & 0 & 2,0 & \multirow{2}{*}{$-2,162$} & \multirow{2}{*}{$\mathbf{0 , 0 3 1}$} & \multirow{2}{*}{0,431} \\
\hline & Fase 2 & 0,3 & 0,7 & 0 & 3,0 & & & \\
\hline \multirow{2}{*}{ Recusas } & Fase 1 & 0,2 & 0,5 & 0 & 2,0 & \multirow{2}{*}{$-0,175$} & \multirow{2}{*}{0,861} & \multirow{2}{*}{-} \\
\hline & Fase 2 & 0,2 & 0,8 & 0 & 4,0 & & & \\
\hline \multirow{2}{*}{ Denegações } & Fase 1 & - & 0,2 & 0 & 1,0 & \multirow{2}{*}{$-1,089$} & \multirow{2}{*}{0,276} & \multirow{2}{*}{$-0,183$} \\
\hline & Fase 2 & 0,1 & 0,5 & 0 & 2,0 & & & \\
\hline \multirow{2}{*}{$\begin{array}{l}\text { Tempo de } \\
\text { Latência } \\
\text { Médio* }\end{array}$} & Fase 1 & 16,5 & 10,6 & 2,3 & 47,5 & \multirow{2}{*}{$-1,604$} & \multirow{2}{*}{0,109} & \multirow{2}{*}{0,297} \\
\hline & Fase 2 & 14,1 & 8,8 & 5,7 & 40,4 & & & \\
\hline \multirow{2}{*}{$\begin{array}{c}\text { Tempo de } \\
\text { Reação Médio* }\end{array}$} & Fase 1 & 33,7 & 16,0 & 9,8 & 84,3 & \multirow{2}{*}{$-2,335$} & \multirow{2}{*}{0,020} & \multirow{2}{*}{$\mathbf{0 , 3 5 7}$} \\
\hline & Fase 2 & 26,5 & 16,0 & 10,3 & 76,3 & & & \\
\hline
\end{tabular}

Ao traçar comparação entre os dois momentos avaliativos dos participantes do Grupo Clínico (com seis meses de intervalo, no mínimo, entre eles), notou-se estabilidade nos indicadores de produtividade e de ritmo diante do Rorschach. Houve sinais de manutenção de adequado aproveitamento de recursos cognitivos, favorecedores do processo de adaptação diante dos desafios colocados pelo meio no qual a criança e o adolescente se inserem após o diagnóstico oncológico.

Todavia, houve significativa diminuição das Respostas Adicionais (RA) entre as duas avaliações, sugerindo que, num segundo momento, crianças e adolescentes não precisaram sinalizar suas respostas como elementos complementares na aplicação do Rorschach. Entretanto, há que destacar a reduzida expressão numérica desta variável e o tamanho médio do efeito dessa diferença entre Fase 1 e Fase 2’.

Outra variável com significativa diferença entre os momentos avaliativos de G1 foi o Tempo de Reação Médio (TRm) ao Rorschach, com diminuição na segunda aplicação, embora com médio efeito. O decréscimo do tempo de reação médio e da frequência de 
respostas adicionais pode ser compreendido como fruto de positivo processo adaptativo empreendido pelos participantes à atividade do Rorschach, sinalizando alguma aprendizagem e maior desenvoltura na segunda avaliação realizada.

A análise comparativa dos dois momentos avaliativos do grupo clínico, no tocante a seus modos de apreensão dos estímulos do Rorschach, consta na Tabela 40.

Tabela 40. Resultados médios e comparação estatística das duas avaliações do grupo clínico (G1) em função dos modos de apreensão do Rorschach.

\begin{tabular}{|c|c|c|c|c|c|c|c|c|}
\hline \multirow{2}{*}{$\begin{array}{l}\text { Modos de } \\
\text { Apreensão }\end{array}$} & \multirow{2}{*}{ Fase } & \multicolumn{4}{|c|}{ Análise Descritiva } & \multicolumn{3}{|c|}{ Análise Comparativa } \\
\hline & & Média & $\mathrm{DP}$ & Mínimo & Máximo & $z$ & $p$ & $d$ de Cohen \\
\hline \multirow{2}{*}{$\mathrm{G} \%$} & Fase 1 & 38,7 & 23,9 & 4,7 & 83,3 & \multirow{2}{*}{$-1,615$} & \multirow{2}{*}{0,106} & \multirow{2}{*}{0,237} \\
\hline & Fase 2 & 36,0 & 22,3 & 0 & 81,8 & & & \\
\hline \multirow{2}{*}{$\mathrm{D} \%$} & Fase 1 & 42,1 & 20,0 & 0 & 66,6 & \multirow{2}{*}{$-0,616$} & \multirow{2}{*}{0,538} & \multirow{2}{*}{$-0,072$} \\
\hline & Fase 2 & 43,5 & 19,2 & 10,0 & 82,3 & & & \\
\hline \multirow{2}{*}{$\mathrm{Dd} \%$} & Fase 1 & 18,2 & 13,2 & 0 & 50,0 & \multirow{2}{*}{$-0,270$} & \multirow{2}{*}{0,787} & \multirow{2}{*}{$-0,086$} \\
\hline & Fase 2 & 20,0 & 13,9 & 0 & 54,5 & & & \\
\hline \multirow{2}{*}{$\mathrm{Db} 1 \%$} & Fase 1 & 0,8 & 2,7 & 0 & 11,1 & \multirow{2}{*}{$-0,921$} & \multirow{2}{*}{0,357} & \multirow{2}{*}{0,183} \\
\hline & Fase 2 & 0,3 & 1,8 & 0 & 10,0 & & & \\
\hline
\end{tabular}

Ao confrontarmos os resultados obtidos entre o teste e o reteste dos participantes de G1, nota-se que os modos de apreensão do Rorschach não apresentam diferenças estatisticamente significativas. Pode-se pensar, portanto, que a pluralidade de repercussões provocadas pelo câncer na vida de crianças e adolescentes não pareceu influenciar seus processos de captação e de discriminação dos estímulos da realidade.

$\mathrm{Na}$ literatura científica referente ao Método de Rorschach, os modos de apreensão são considerados indicadores da estruturação do pensamento formal e do funcionamento de defesas psíquicas. Rausch de Traubenberg (1998) assevera que a primazia de respostas ligadas aos Grandes Detalhes (D) pode traduzir busca de adequação ao contexto social em um contato menos resistente e mais direto com a realidade, para posteriormente integrar percepções e experiências vivenciadas dentro de si, conforme apontariam as respostas Globais. A partir de uma atitude mais circunspecta e racional, advêm análises minuciosas dos fenômenos (pequenos detalhes), que podem ser complementadas por uma análise crítica dos estímulos (o fundo do cartão, detalhe branco = Dbl). 
Ao comparar os atuais achados com a referência normativa estabelecida por CuryJacquemin (2012), é possível notar que os integrantes de G1 examinam e captam os acontecimentos da realidade de forma muito similar. Ao entrarem em contato com o ambiente que lhes cerca, crianças e adolescentes destacam os elementos prioritários e de maior destaque do contexto (grande detalhe $=\mathrm{D}$ ), seguindo-se apreensões do todo, levando a generalizações e abstrações (respostas globais $=\mathrm{G}$ ). A seguir podem refinar seu exame e contato com o mundo pela observação de minúcias (Dd), para então propor respostas ao ambiente de modo mais independente e criativo (Dbl). Em suma, poder-se-ia apontar que a tarefa de adaptação ao tratamento de câncer não pareceu impactar negativamente a percepção e interação com a realidade. Há que se levantar a hipótese de que provavelmente as crianças e adolescentes em cuidados oncológicos recorrem a seus recursos desenvolvidos antes do diagnóstico da neoplasia para lidar com as agruras desta experiência de vida, preservando-os.

Na sequência analítica das variáveis do Método de Rorschach há que considerar os determinantes das respostas. Os resultados dos dois momentos avaliativos do grupo clínico, no tocante a esse conjunto de variáveis, podem ser vistos na Tabela 41.

Tabela 41. Resultados médios e comparação estatística das duas avaliações do grupo clínico (G1) em função dos determinantes do Rorschach.

\begin{tabular}{ccccccccc}
\hline \multirow{2}{*}{ Determinantes } & \multicolumn{5}{c}{ Análise Descritiva } & \multicolumn{3}{c}{ Análise Comparativa } \\
& Fase & Média & DP & Mínimo & Máximo & $z$ & $p$ & $d$ de Cohen \\
\hline \multirow{2}{*}{ F\% } & Fase 1 & 41,2 & 24,4 & 0 & 90,0 & $-0,514$ & 0,607 & $-0,113$ \\
& Fase 2 & 43,9 & 17,5 & 4,5 & 91,6 & & & \\
& & & & & & & & \\
F+\% & Fase 1 & 71,2 & 26,4 & 0 & 100,0 & $-0,421$ & 0,674 & $-0,152$ \\
& Fase 2 & 75,7 & 15,0 & 40,0 & 100,0 & & & \\
F+ext\% & Fase 1 & 71,0 & 12,5 & 50,0 & 92,3 & & & \\
& Fase 2 & 77,0 & 13,2 & 50,0 & 100,0 & $-1,924$ & $\mathbf{0 , 0 5 4}$ & $\mathbf{- 0 , 4 0 1}$ \\
& Fase 1 & 1,3 & 1,4 & 0 & 5,0 & & & \\
K & Fase 2 & 1,1 & 1,2 & 0 & 3,0 & $-0,810$ & 0,418 & 0,143 \\
& Fase 1 & 1,5 & 1,4 & 0 & 6,0 & & & \\
& Fase 2 & 1,1 & 1,6 & 0 & 7,0 & $-1,091$ & 0,275 & 0,184 \\
kan & Fase 1 & 0,1 & 0,4 & 0 & 1,0 & & & \\
& Fase 2 & 0,2 & 0,6 & 0 & 2,0 & $-0,632$ & 0,527 & $-0,114$
\end{tabular}




\begin{tabular}{|c|c|c|c|c|c|c|c|c|}
\hline \multirow{2}{*}{ Determinantes } & \multirow{2}{*}{ Fase } & \multicolumn{4}{|c|}{ Análise Descritiva } & \multicolumn{3}{|c|}{ Análise Comparativa } \\
\hline & & Média & DP & Mínimo & Máximo & $z$ & $p$ & d de Cohen \\
\hline \multirow{2}{*}{$\mathrm{kp}$} & Fase 1 & 0,1 & 0,3 & 0 & 1,0 & \multirow{2}{*}{$-0,378$} & \multirow{2}{*}{0,705} & \multirow{2}{*}{$-0,068$} \\
\hline & Fase 2 & 0,1 & 0,3 & 0 & 1,0 & & & \\
\hline \multirow{2}{*}{$\begin{array}{l}\text { Soma Pequenas } \\
\text { Cinestesias }\end{array}$} & Fase 1 & 1,8 & 1,7 & 0 & 6,0 & \multirow{2}{*}{0,711} & \multirow{2}{*}{0,477} & \multirow{2}{*}{0,144} \\
\hline & Fase 2 & 1,5 & 1,7 & 0 & 7,0 & & & \\
\hline \multirow{2}{*}{ FC } & Fase 1 & 3,1 & 2,1 & 0 & 8,0 & \multirow{2}{*}{$-2,040$} & \multirow{2}{*}{0,041} & \multirow{2}{*}{$-0,375$} \\
\hline & Fase 2 & 4,0 & 2,1 & 0 & 7,0 & & & \\
\hline \multirow{2}{*}{$\mathrm{CF}$} & Fase 1 & 1,6 & 1,2 & 0 & 4,0 & \multirow{2}{*}{$-1,219$} & \multirow{2}{*}{0,223} & \multirow{2}{*}{0,223} \\
\hline & Fase 2 & 1,3 & 1,5 & 0 & 4,0 & & & \\
\hline \multirow{2}{*}{$\mathrm{C}$} & Fase 1 & 0,3 & 0,9 & 0 & 4,0 & \multirow{2}{*}{$-0,302$} & \multirow{2}{*}{0,763} & \multirow{2}{*}{$-0,054$} \\
\hline & Fase 2 & 0,3 & 0,7 & 0 & 3,0 & & & \\
\hline \multirow{2}{*}{ Soma C Ponderada } & Fase 1 & 3,6 & 2,2 & 0,5 & 12,0 & \multirow{2}{*}{$-0,547$} & \multirow{2}{*}{0,584} & \multirow{2}{*}{$-0,080$} \\
\hline & Fase 2 & 3,8 & 2,3 & 0,5 & 8,5 & & & \\
\hline \multirow{2}{*}{ FE } & Fase 1 & 1,2 & 1,2 & 0 & 4,0 & \multirow{2}{*}{$-1,148$} & \multirow{2}{*}{0,251} & \multirow{2}{*}{0,233} \\
\hline & Fase 2 & 0,9 & 1,4 & 0 & 6,0 & & & \\
\hline $\mathrm{EF}$ & Fase 1 & 0,4 & 0,7 & 0 & 3,0 & -0.074 & 0.941 & 0.035 \\
\hline & Fase 2 & 0,4 & 0,7 & 0 & 2,0 & & & \\
\hline $\mathrm{E}$ & Fase 1 & 0,1 & 0,3 & 0 & 1,0 & -1732 & 0083 & - \\
\hline $\mathrm{L}$ & Fase 2 & - & - & 0 & 0 & $-1,1 J 2$ & J,00J & - \\
\hline Soma E Ponderada & Fase 1 & 1,2 & 1,1 & 0,0 & 4,0 & -1241 & 0214 & 0255 \\
\hline somra e r Onueraud & Fase 2 & 0,9 & 1,2 & 0,0 & 5,0 & $-1,241$ & 0,214 & $0,2 J$ \\
\hline FClob & Fase 1 & 0,2 & 0,4 & 0 & 1,0 & -200 & 0046 & 0860 \\
\hline ГC100 & Fase 2 & 0,03 & 0,2 & 0 & 1,0 & $-2,00$ & 0,040 & 0,000 \\
\hline ClobF & Fase 1 & 0,1 & 0,4 & 0 & 2,0 & 1342 & 0180 & - \\
\hline & Fase 2 & - & - & 0 & 0 & 1,042 & 0,100 & 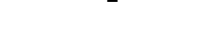 \\
\hline
\end{tabular}

Nota-se que houve duas variáveis com diferenças estatisticamente significativas entre a avaliação e a reavaliação do grupo clínico pelo Método de Rorschach, a saber: F+ext\% e FC, com reduzido tamanho do efeito. Em ambas houve elevação dos valores após seis meses da primeira aplicação do instrumento. $\mathrm{O}$ aumento em $\mathrm{F}+\mathrm{ext} \%$ sugere aprimoramento do rigor lógico ao integrar elementos afetivos. A maior incidência média de FC na segunda avaliação 
sugere mais respostas integrando determinantes afetivos adequadamente coordenados pela razão. Esses dois indícios fazem pensar que, com o passar do tempo, as crianças e os adolescentes de G1 sinalizaram melhoria em seu processo de integração de vivências afetivas e racionais, sugerindo adequado processo adaptativo à realidade. É plausível asseverar que os participantes do grupo clínico do estudo fizeram esforços racionais no sentido de organizar seu mundo interno por meio de processos de racionalização.

Os conteúdos e as banalidades identificados nas duas aplicações do Método de Rorschach estão apresentados na Tabela 42. Os achados estão expressos em resultados médios, incluindo a comparação estatística da fase 1 e fase 2 no grupo clínico de participantes.

Tabela 42. Resultados médios e comparação estatística das duas avaliações do grupo clínico (G1) em função dos conteúdos do Rorschach.

\begin{tabular}{|c|c|c|c|c|c|c|c|c|}
\hline \multirow{2}{*}{ Conteúdos } & \multirow{2}{*}{ Fase } & \multicolumn{4}{|c|}{ Análise Descritiva } & \multicolumn{3}{|c|}{ Análise Comparativa } \\
\hline & & Média & DP & Mínimo & Máximo & $z$ & $p$ & d de Cohen \\
\hline \multirow{2}{*}{ A } & Fase 1 & 6,6 & 3,9 & 1,0 & 17,0 & \multirow{2}{*}{$-0,231$} & \multirow{2}{*}{0,817} & \multirow{2}{*}{$-0,073$} \\
\hline & Fase 2 & 6,8 & 3,6 & 2,0 & 15,0 & & & \\
\hline \multirow{2}{*}{ (A) } & Fase 1 & 1,4 & 2,1 & 0 & 8,0 & \multirow{2}{*}{$-1,591$} & \multirow{2}{*}{0,112} & \multirow[t]{2}{*}{0,326} \\
\hline & Fase 2 & 0,9 & 1,0 & 0 & 4,0 & & & \\
\hline \multirow{2}{*}{ Ad } & Fase 1 & 0,7 & 1,4 & 0 & 6,0 & \multirow{2}{*}{$-1,962$} & \multirow{2}{*}{$\mathbf{0 , 0 5 0}$} & \multirow{2}{*}{$-0,355$} \\
\hline & Fase 2 & 1,2 & 1,6 & 0 & 6,0 & & & \\
\hline \multirow{2}{*}{ (Ad) } & Fase 1 & 0,3 & 0,7 & 0 & 3,0 & \multirow{2}{*}{$-1,414$} & \multirow{2}{*}{0,157} & \multirow{2}{*}{0,263} \\
\hline & Fase 2 & 0,2 & 0,8 & 0 & 4,0 & & & \\
\hline \multirow{2}{*}{ Soma A } & Fase 1 & 9,1 & 5,6 & 2,0 & 29,0 & \multirow{2}{*}{$-0,173$} & \multirow{2}{*}{0,863} & \multirow{2}{*}{$-0,018$} \\
\hline & Fase 2 & 9,1 & 4,5 & 2,0 & 18,0 & & & \\
\hline \multirow{2}{*}{$\mathrm{A} \%$} & Fase 1 & 51,9 & 19,7 & 20,0 & 90,9 & \multirow{2}{*}{$-0,706$} & \multirow{2}{*}{0,480} & \multirow{2}{*}{$-0,0118$} \\
\hline & Fase 2 & 53,9 & 19,4 & 20,0 & 94,1 & & & \\
\hline \multirow{2}{*}{$\mathrm{H}$} & Fase 1 & 1,3 & 1,1 & 0 & 4,0 & \multirow{2}{*}{$-0,636$} & \multirow{2}{*}{0,525} & \multirow{2}{*}{$-0,149$} \\
\hline & Fase 2 & 1,5 & 1,5 & 0 & 5,0 & & & \\
\hline \multirow{2}{*}{ (H) } & Fase 1 & 1,6 & 1,5 & 0 & 5,0 & \multirow{2}{*}{3,358} & \multirow{2}{*}{0,001} & 7770 \\
\hline & Fase 2 & 0,7 & 0,9 & 0 & 3,0 & & & $0,1 / 9$ \\
\hline $\mathrm{Hd}$ & Fase 1 & 0,5 & 0,6 & 0 & 2,0 & -1245 & 0213 & - 0247 \\
\hline 11u & Fase 2 & 0,7 & 1,1 & 0 & 4,0 & 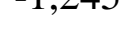 & $0,21 J$ & $-0,2+1$ \\
\hline
\end{tabular}




\begin{tabular}{|c|c|c|c|c|c|c|c|c|}
\hline \multirow{2}{*}{ Conteúdos } & \multirow{2}{*}{ Fase } & \multicolumn{4}{|c|}{ Análise Descritiva } & \multicolumn{3}{|c|}{ Análise Comparativa } \\
\hline & & Média & DP & Mínimo & Máximo & $z$ & $p$ & d de Cohen \\
\hline \multirow{2}{*}{$(\mathrm{Hd})$} & Fase 1 & 0,2 & 0,4 & 0 & 1,0 & \multirow{2}{*}{$-0,812$} & \multirow{2}{*}{0,417} & \multirow{2}{*}{0,140} \\
\hline & Fase 2 & 0,3 & 0,6 & 0 & 2,0 & & & \\
\hline \multirow{2}{*}{ Soma H } & Fase 1 & 3,5 & 2,4 & 0 & 9,0 & \multirow{2}{*}{$-0,910$} & \multirow{2}{*}{0,363} & \multirow{2}{*}{0,121} \\
\hline & Fase 2 & 3,2 & 2,6 & 0 & 10,0 & & & \\
\hline \multirow{2}{*}{$\mathrm{H} \%$} & Fase 1 & 20,5 & 14,4 & 0 & 52,9 & \multirow{2}{*}{$-1,082$} & \multirow{2}{*}{0,279} & \multirow{2}{*}{0,184} \\
\hline & Fase 2 & 18,5 & 14,4 & 0 & 45,5 & & & \\
\hline \multirow{2}{*}{ Anat } & Fase 1 & 0,6 & 0,9 & 0 & 3,0 & \multirow{2}{*}{$-0,351$} & \multirow{2}{*}{0,726} & \multirow{2}{*}{0,085} \\
\hline & Fase 2 & 0,5 & 1,0 & 0 & 3,0 & & & \\
\hline \multirow{2}{*}{$\mathrm{Sg}$} & Fase 1 & 0,1 & 0,4 & 0 & 2,0 & \multirow{2}{*}{$-0,707$} & \multirow{2}{*}{0,480} & \multirow{2}{*}{$-0,128$} \\
\hline & Fase 2 & 0,1 & 0,3 & 0 & 1,0 & & & \\
\hline \multirow{2}{*}{ Sex } & Fase 1 & 0,03 & 0,2 & 0 & 1,0 & \multirow{2}{*}{$-1,000$} & \multirow{2}{*}{0,317} & \multirow{2}{*}{$-0,183$} \\
\hline & Fase 2 & 0,1 & 0,3 & 0 & 1,0 & & & \\
\hline \multirow{2}{*}{ Obj } & Fase 1 & 1,6 & 1,3 & 0 & 6,0 & -1747 & 0.081 & 0262 \\
\hline & Fase 2 & 1,2 & 1,4 & 0 & 5,0 & $-1,147$ & 0,001 & $0, \angle 02$ \\
\hline Art & Fase 1 & - & - & 0 & 0 & -2449 & 0.014 & $-0,492$ \\
\hline Art & Fase 2 & 0,2 & 0,4 & 0 & 1,0 & $-2,449$ & 0,014 & $-0,492$ \\
\hline Arq & Fase 1 & 0,1 & 0,3 & 0 & 1,0 & 378 & 0705 & 0068 \\
\hline Arq & Fase 2 & 0,1 & 0,4 & 0 & 2,0 & $-0,5 / 0$ & U, /US & $-0,000$ \\
\hline Simb & Fase 1 & 0,1 & 0,4 & 0 & 2,0 & $-1,890$ & 0.059 & $-0,361$ \\
\hline & Fase 2 & 0,3 & 0,5 & 0 & 2,0 & & & \\
\hline Abst & Fase 1 & - & - & 0 & 0 & -1000 & 0317 & - \\
\hline HUSt & Fase 2 & 0,03 & 0,2 & 0 & 1,0 & $-1,000$ & 0,311 & - \\
\hline Bot & Fase 1 & 0,9 & 1,0 & 0 & 3,0 & $-0,144$ & 0.886 & -0.031 \\
\hline & Fase 2 & 0,9 & 1,3 & 0 & 5,0 & & & \\
\hline Geo & Fase 1 & 0,5 & 0,9 & 0 & 4,0 & -0.183 & 0.855 & 0.027 \\
\hline & Fase 2 & 0,5 & 0,9 & 0 & 3,0 & 0,10 & & \\
\hline Nat & Fase 1 & 0,1 & 0,3 & 0 & 1,0 & 0 & 1.000 & - \\
\hline & Fase 2 & 0,1 & 0,3 & 0 & 1,0 & & & \\
\hline Pais & Fase 1 & 0,2 & 0,5 & 0 & 2,0 & 0,816 & 0,414 & 0,148 \\
\hline & Fase 2 & 0,2 & 0,4 & 0 & 1,0 & & & \\
\hline
\end{tabular}




\begin{tabular}{ccccccccc}
\hline \multirow{2}{*}{ Conteúdos } & \multirow{2}{*}{ Fase } & \multicolumn{5}{c}{ Análise Descritiva } & \multicolumn{3}{c}{ Análise Comparativa } \\
& & Média & DP & Mínimo & Máximo & $z$ & $p$ & $d$ de Cohen \\
\hline \multirow{2}{*}{ Elem } & Fase 1 & 0,2 & 0,8 & 0 & 4,0 & \multirow{2}{*}{0000} & 0,317 & $-0,183$ \\
& Fase 2 & 0,3 & 0,8 & 0 & 4,0 & & & \\
\multirow{2}{*}{ Elem (fogo) } & Fase 1 & 0,1 & 0,3 & 0 & 1,0 & & & \\
& Fase 2 & 0,1 & 0,4 & 0 & 2,0 & 0 & 1,000 & - \\
\multirow{2}{*}{ Frag } & Fase 1 & 0,2 & 0,6 & 0 & 3,0 & & & \\
& Fase 2 & 0,1 & 0,3 & 0 & 1,0 & 1,633 & 0,102 & 0,307 \\
\multirow{2}{*}{ Ban\% } & Fase 1 & 19,2 & 8,5 & 3,23 & 41,2 & & & \\
& Fase 2 & 15,4 & 8,9 & 0,00 & 33,3 & 1,728 & 0,084 & 0,363 \\
\hline
\end{tabular}

Apesar do número elevado de variáveis examinadas, em apenas três delas foi possível identificar diferenças estatisticamente significativas entre os dois momentos avaliativos dos participantes do grupo clínico, a saber: Ad, (H) e Art. Houve expressiva redução dos conteúdos humanos desvitalizados $[(\mathrm{H})]$ na segunda avaliação com elevado tamanho do efeito, bem como maior utilização de conteúdos artísticos (Art). Notou-se ainda elevação dos conteúdos Ad, porém com diferença de fraco tamanho de efeito.

A diminuição da frequência do conteúdo $(H)$ entre a avaliação e a reavaliação pode sinalizar alguma elaboração da experiência da invasão e modificação corporal vinculada ao tratamento oncológico. Pode-se pensar que, ao longo da convivência com o tratamento, há integração positiva da percepção do próprio corpo com menor necessidade de formulações da fantasia para lidar com sua realidade.

A junção dos dois indicadores (diminuição de humanos desvitalizados e elevação de conteúdos artísticos) faz pensar que, ao longo do tempo, crianças e adolescentes em tratamento oncológico conseguiram diminuir respostas sugestivas de desvitalização em sua identidade, com elevação de mecanismos de abstração e de intelectualização em sua maneira de responder ao Rorschach (sobretudo ao se incluir aqui a tendência à diferença com significância estatística nas respostas de conteúdo simbólico). Por serem apenas duas variáveis, qualquer hipótese interpretativa fica limitada, porém merece a devida análise no conjunto dos indicadores obtidos pelo Método de Rorschach.

Com relação à variação de conteúdos (soma de $\mathrm{A} \%$ e $\mathrm{H} \%$ ) fornecidos ao Método de Rorschach, nota-se que, nas duas avaliações de G1, o valor desse indicador técnico não supera os $75 \%$ das respostas. Ou seja, sinaliza diversidade de interesses desses participantes, com 
recursos mentais ainda em desenvolvimento. Acompanharam as expectativas normativas (Cury-Jacquemin, 2012) no tocante ao total de respostas de conteúdo animal (A\%), mais frequente em crianças e adolescentes, sugestivo de contato mais intuitivo com a realidade, no qual a criança ou o adolescente mantém menor elaboração emocional e cognitiva a partir de suas apreensões. É importante notar ainda que há supremacia de conteúdos inteiros [como A, (A), H, (H)] em relação aos conteúdos parciais [como Ad, (Ad), Hd, (Hd)], o que salienta preservação da integridade dos objetos internalizados em seu mundo interno.

Houve ainda tendência à diferença estatisticamente significativa entre os dois momentos avaliativos de G1 na variável relativa à porcentagem média de respostas banais (Ban\%). Apesar da diminuição de respostas com esta característica, é importante levar em conta que a média no grupo de referência é de 14,8\% (Cury-Jacquemin, 2012), valor próximo ao encontrado na segunda avaliação. Desse modo, pode-se inferir que com o passar do tempo de cuidado em saúde, crianças e adolescentes com câncer mantêm bom compartilhamento de seus pensamentos com a coletividade, apresentando discreta diminuição nos indicadores relativos a conformismo social.

Este conjunto de conteúdos pode sinalizar tendência à canalização dos impulsos para vias intelectuais e racionais. Esta dinâmica foi descrita anteriormente ao serem analisados os determinantes das respostas apresentados nos dois momentos avaliativos, o que reforça as hipóteses interpretativas consideradas neste trabalho.

O último ponto a ser apreciado no Método de Rorschach é a comparação de distribuição de casos segundo a classificação do tipo de Fórmula Vivencial em função das duas avaliações realizadas com o Grupo Clínico. Estas poderão ser visualizadas na Tabela 43. 
Tabela 43. Distribuição dos participantes do Grupo Clínico e comparação estatística das Fórmulas Vivenciais no Rorschach nos dois momentos avaliativos.

\begin{tabular}{|c|c|c|c|c|c|c|c|c|}
\hline \multirow[b]{2}{*}{ Fórmulas } & \multirow[b]{2}{*}{ Vivenciais } & \multicolumn{2}{|c|}{ Fase 1} & \multicolumn{2}{|c|}{ Fase 2} & \multicolumn{3}{|c|}{ Análise Comparativa } \\
\hline & & $f$ & $\%$ & $f$ & $\%$ & $X^{2}$ & $p$ & $\begin{array}{c}\text { Vde } \\
\text { Cramer }\end{array}$ \\
\hline \multirow{3}{*}{$\begin{array}{c}\text { Tipo de } \\
\text { Ressonância } \\
\text { Íntima (TRI) }\end{array}$} & Introversivo & - & - & 2 & 6,6 & \multirow{3}{*}{4,123} & \multirow{3}{*}{0,127} & \multirow{3}{*}{0,262} \\
\hline & Extratensivo & 21 & 70,0 & 24 & 80,0 & & & \\
\hline & Outros* & 9 & 30,0 & 4 & 13,4 & & & \\
\hline \multirow{3}{*}{$\begin{array}{c}2^{\text {a }} \text { Fórmula } \\
\text { Afetiva }\end{array}$} & Introversivo & 11 & 36,6 & 12 & 40,0 & \multirow{3}{*}{0,076} & \multirow{3}{*}{0,963} & \multirow{3}{*}{0,036} \\
\hline & Extratensivo & 3 & 10,0 & 3 & 10,0 & & & \\
\hline & Outros* & 16 & 53,4 & 15 & 50,0 & & & \\
\hline \multirow{3}{*}{$\begin{array}{c}3^{\text {a }} \text { Fórmula } \\
\text { Afetiva }\end{array}$} & Introversivo & 11 & 36,6 & 10 & 33,4 & \multirow{3}{*}{0,091} & \multirow{3}{*}{0,955} & \multirow{3}{*}{0,039} \\
\hline & Extratensivo & 8 & 26,6 & 8 & 26,6 & & & \\
\hline & Ambigual & 11 & 36,6 & 12 & 40,0 & & & \\
\hline \multirow{2}{*}{$\begin{array}{l}\text { Fórmula da } \\
\text { Angústia }\end{array}$} & Normal $(\leq 12 \%)$ & 22 & 73,4 & 22 & 73,4 & \multirow{2}{*}{$\leq 0,001$} & \multirow{2}{*}{1,000} & \multirow{2}{*}{$\leq 0,001$} \\
\hline & Elevada $(>12 \%)$ & 8 & 26,6 & 8 & 26,6 & & & \\
\hline
\end{tabular}

Inexistem diferenças estatisticamente significativas entre a primeira e a segunda distribuição dos casos do Grupo Clínico em termos das fórmulas vivenciais do Rorschach. É viável depreender que o intervalo mínimo de seis meses entre as avaliações aparentemente não repercutiu sobre o desenvolvimento da dinâmica afetiva das crianças e adolescentes, os quais se encontram em fase de desenvolvimento e estruturação da personalidade.

Os achados destacaram que o estilo extratensivo predominou como modo habitual de reação (Tipo de Ressonância Íntima), exprimindo marca da dinâmica afetiva das crianças e dos adolescentes, que se mobilizaram diante dos estímulos advindos do universo a sua volta, expressando de forma franca sentimentos e ideias. Todavia, é relevante considerar que houve considerável frequência do estilo coartado como tendência latente (segunda fórmula afetiva do Rorschach), podendo espelhar tentativas de elaboração das experiências de vida pela diminuição da espontaneidade e inibição emocional, com estratégias de adaptação mais formais.

Por fim, pode-se apontar que os casos com Fórmula da Angústia elevada foram reduzidos. Assim, nota-se que a grande maioria dos participantes do G1 pareceu não ser contaminada pelas vivências de ansiedade, mesmo sendo expostos a situações ambientais estressores em seu tratamento oncológico. 


\subsubsection{Teste de Pfister - Comparação Fase 1 e Fase 2 no Grupo Clínico}

Na sequência das análises comparativas dos dois momentos avaliativos do grupo clínico serão apresentados os resultados provenientes do Teste de Pirâmides Coloridas de Pfister. A distribuição de frequência das escolhas cromáticas na avaliação e reavaliação poderá ser visualizada na Tabela 44, bem como a comparação estatística dos resultados médios.

Tabela 44. Resultados médios e comparação estatística das duas avaliações do grupo clínico (G1) em função das cores no Teste de Pfister.

\begin{tabular}{|c|c|c|c|c|c|c|c|c|}
\hline \multirow{2}{*}{$\begin{array}{l}\text { Cor } \\
\text { Pfister }\end{array}$} & \multirow{2}{*}{ Fase } & \multicolumn{4}{|c|}{ Análise Descritiva } & \multicolumn{3}{|c|}{ Análise Comparativa } \\
\hline & & Média & DP & Mínimo & Máximo & $z$ & $p$ & $d$ de Cohen \\
\hline \multirow{2}{*}{ Azul } & Fase 1 & 17,4 & 7,3 & 4,4 & 37,8 & \multirow{2}{*}{$-0,239$} & \multirow{2}{*}{0,811} & \multirow{2}{*}{0,041} \\
\hline & Fase 2 & 17,0 & 7,7 & 0 & 33,3 & & & \\
\hline \multirow{2}{*}{ Vermelho } & Fase 1 & 15,7 & 9,5 & 0 & 40,0 & \multirow{2}{*}{$-0,108$} & \multirow{2}{*}{0,914} & \multirow{2}{*}{0,021} \\
\hline & Fase 2 & 15,9 & 8,3 & 0 & 33,3 & & & \\
\hline \multirow{2}{*}{ Verde } & Fase 1 & 16,2 & 9,2 & 0 & 42,2 & \multirow{2}{*}{$-0,928$} & \multirow{2}{*}{0,353} & \multirow{2}{*}{0,133} \\
\hline & Fase 2 & 14,5 & 9,4 & 0 & 42,2 & & & \\
\hline \multirow{2}{*}{ Violeta } & Fase 1 & 13,1 & 7,7 & 0 & 33,3 & \multirow{2}{*}{$-0,932$} & \multirow{2}{*}{0,352} & \multirow{2}{*}{0,078} \\
\hline & Fase 2 & 11,7 & 8,6 & 0 & 33,3 & & & \\
\hline \multirow{2}{*}{ Laranja } & Fase 1 & 7,6 & 7,0 & 0 & 33,3 & \multirow{2}{*}{$-0,662$} & \multirow{2}{*}{0,508} & \multirow{2}{*}{$-0,073$} \\
\hline & Fase 2 & 8,4 & 6,2 & 0 & 33,3 & & & \\
\hline \multirow{2}{*}{ Amarelo } & Fase 1 & 10,0 & 10,5 & 0 & 48,9 & \multirow{2}{*}{$-0,395$} & \multirow{2}{*}{0,693} & \multirow{2}{*}{0,194} \\
\hline & Fase 2 & 7,9 & 5,9 & 0 & 24,4 & & & \\
\hline \multirow{2}{*}{ Marrom } & Fase 1 & 6,6 & 6,6 & 0 & 33,3 & \multirow{2}{*}{$-0,243$} & \multirow{2}{*}{0,808} & \multirow{2}{*}{0,027} \\
\hline & Fase 2 & 6,5 & 6,8 & 0 & 33,3 & & & \\
\hline \multirow{2}{*}{ Preto } & Fase 1 & 4,0 & 6,2 & 0 & 31,1 & \multirow{2}{*}{$-2,108$} & 0035 & 0234 \\
\hline & Fase 2 & 5,6 & 4,9 & 0 & 17,8 & & 0,0S3 & $-0,2 \mathrm{~J} 4$ \\
\hline Branco & Fase 1 & 6,1 & 5,8 & 0 & 31,1 & -1806 & 0071 & -0 364 \\
\hline & Fase 2 & 8,4 & 8,4 & 0 & 31,1 & $-1,000$ & 0,011 & $-0,504$ \\
\hline Cinza & Fase 1 & 3,2 & 3,0 & 0 & 8,9 & -1090 & 0276 & 0240 \\
\hline Cinza & Fase 2 & 4,1 & 3,8 & 0 & 13,3 & & 0,210 & $-0,249$ \\
\hline
\end{tabular}


Nota-se apenas uma diferença estatisticamente significativa (na cor preta) e outra tendência (na cor branca) entre as escolhas cromáticas nos dois momentos avaliativos do grupo clínico. As crianças e adolescentes do G1 apresentaram maior frequência média destas cores na reavaliação, após seis meses da primeira aplicação do Teste de Pfister, ainda que com tamanho do efeito médio nessa diferenciação entre as fases.

Ao considerar as ponderações de Capitão, Lopes, Slva e Adib (2012), e VillemorAmaral (2014), estes achados (elevação do branco e do preto) podem significar tentativas de negação das emoções, sugerindo vivências de dificuldade em lidar com as repercussões afetivas das experiências de vida. Pode-se pensar, portanto, que ao longo do tempo as crianças e os adolescentes em tratamento oncológico tenderam a recorrer mais a estratégias defensivas baseadas em mecanismos de negação, favorecendo-lhes adaptação ao contexto de vida.

Em complemento às escolhas das cores, tem-se a comparação dos achados relativos às síndromes cromáticas do Teste de Pfister nos dois momentos avaliativos. Esses dados compõem a Tabela 45.

Tabela 45. Resultados médios e comparação estatística das duas avaliações do grupo clínico (G1) em função das síndromes cromáticas no Teste de Pfister.

\begin{tabular}{ccccccccc}
\hline $\begin{array}{c}\text { Síndromes } \\
\text { Pfister }\end{array}$ & Fase & \multicolumn{3}{c}{ Análise Descritiva } & \multicolumn{3}{c}{ Análise Comparativa } \\
& & Média & DP & Mínimo & Máximo & $z$ & $p$ & $d$ de Cohen \\
\hline \multirow{2}{*}{ Normal } & Fase 1 & 49,33 & 11,35 & 17,80 & 68,90 & $-1,093$ & 0,274 & 0,158 \\
& Fase 2 & 47,40 & 10,34 & 28,90 & 75,60 & & & \\
\multirow{2}{*}{ Estímulo } & Fase 1 & 33,33 & 12,87 & 0,00 & 64,40 & & & \\
& Fase 2 & 32,14 & 11,42 & 13,30 & 66,70 & & & \\
& & & & & & & & \\
Fria & Fase 1 & 46,74 & 9,79 & 22,20 & 66,70 & $-0,606$ & 0,509 & 0,149 \\
& Fase 2 & 43,18 & 14,04 & 0,00 & 75,60 & & & \\
\multirow{2}{*}{ Incolor } & Fase 1 & 13,32 & 8,29 & 0,00 & 33,30 & & & \\
& Fase 2 & 18,15 & 10,74 & 0,00 & 44,40 & $-2,531$ & $\mathbf{0 , 0 1 1}$ & $\mathbf{- 0 , 4 4 6}$ \\
\hline
\end{tabular}

Observa-se diferença estatisticamente significativa nos dados obtidos na primeira e na segunda avaliação do Teste de Pfister na variável relativa à Síndrome Incolor, embora com reduzido efeito. A porcentagem média dessa síndrome elevou-se de modo significativo na reavaliação, fortalecendo os achados específicos da elevação do branco e do preto, anteriormente apontada. Em outras palavras, tem-se novo indício de aumento 
dos mecanismos repressivos e inibitórios dos afetos, com tendência à negação das vivências afetivas com o passar do tempo de vida dessas crianças e adolescentes em tratamento oncológico.

Cabe a ressalva, no entanto, que os valores encontrados para todas as síndromes cromáticas do Teste de Pfister acompanharam os padrões normativos pautados por VillemorAmaral (2014). Desse modo, os participantes apontaram que conseguem se adequar ao padrão de funcionamento socioafetivo existente em grupos de referência, sugerindo preservação do processo adaptativo.

Essas variações nos dados do Pfister obtidos nos dois momentos avaliativos forneceram, portanto, evidências empíricas relativas às estratégias defensivas utilizadas pelas crianças e adolescentes ao longo de seu tratamento oncológico, colocando em uso recursos estabilizadores internos. Esses achados sugerem desenvolvimento de recursos defensivos e aproveitamento da riqueza afetiva em uma direção saudável, abrindo caminho para a adaptação ao universo do tratamento oncológico.

Na sequência ao trabalho de análise dos resultados obtidos pelo Grupo Clínico nas distintas etapas avaliativas tem-se a Tabela 46. Ela traz a classificação das cores e síndromes do Pfister em relação às expectativas normativas, comparando-se as duas aplicações desse método projetivo em G1.

Tabela 46. Distribuição dos participantes do grupo clínico $(n=30)$ e comparação estatística das duas avaliações em função dos parâmetros normativos para cores e síndromes do Pfister.

\begin{tabular}{|c|c|c|c|c|c|c|c|c|}
\hline \multirow{2}{*}{\multicolumn{2}{|c|}{$\begin{array}{l}\text { Variáveis em } \\
\text { relação à norma }\end{array}$}} & \multicolumn{2}{|c|}{ Fase 1} & \multicolumn{2}{|c|}{ Fase 2} & \multicolumn{3}{|c|}{ Análise Comparativa } \\
\hline & & $f$ & $\%$ & $f$ & $\%$ & $x^{2}$ & $p$ & V de Cramer \\
\hline \multirow{3}{*}{ Azul } & Abaixo & 7 & 23,4 & 9 & 30,0 & \multirow{3}{*}{0,627} & \multirow{3}{*}{0,731} & \multirow{3}{*}{0,102} \\
\hline & Média & 16 & 53,3 & 13 & 43,4 & & & \\
\hline & Acima & 7 & 23,4 & 8 & 26,6 & & & \\
\hline \multirow{3}{*}{ Vermelho } & Abaixo & 8 & 26,6 & 10 & 33,3 & \multirow{3}{*}{2,611} & \multirow{3}{*}{0,271} & \multirow{3}{*}{0,209} \\
\hline & Média & 15 & 50,0 & 9 & 30,0 & & & \\
\hline & Acima & 7 & 23,4 & 11 & 36,6 & & & \\
\hline \multirow{3}{*}{ Verde } & Abaixo & 8 & 26,6 & 11 & 36,6 & \multirow{3}{*}{1,654} & \multirow{3}{*}{0,437} & \multirow{3}{*}{0,166} \\
\hline & Média & 13 & 43,4 & 14 & 46,6 & & & \\
\hline & Acima & 9 & 30,0 & 5 & 16,6 & & & \\
\hline \multirow{3}{*}{ Violeta } & Abaixo & 12 & 40,0 & 16 & 53,4 & \multirow{3}{*}{1,079} & \multirow{3}{*}{0,538} & \multirow{3}{*}{0,134} \\
\hline & Média & 8 & 26,6 & 6 & 20,0 & & & \\
\hline & Acima & 10 & 33,4 & 8 & 26,6 & & & \\
\hline
\end{tabular}




\begin{tabular}{|c|c|c|c|c|c|c|c|c|}
\hline \multirow{2}{*}{\multicolumn{2}{|c|}{$\begin{array}{l}\text { Variáveis em } \\
\text { relação à norma }\end{array}$}} & \multicolumn{2}{|c|}{ Fase 1} & \multicolumn{2}{|c|}{ Fase 2} & \multicolumn{3}{|c|}{ Análise Comparativa } \\
\hline & & $f$ & $\%$ & $f$ & $\%$ & $x^{2}$ & $p$ & V de Cramer \\
\hline \multirow{3}{*}{ Laranja } & Abaixo & 13 & 43,4 & 8 & 26,6 & \multirow{3}{*}{2,043} & \multirow{3}{*}{0,360} & \multirow{3}{*}{0,185} \\
\hline & Média & 9 & 30,0 & 10 & 33,4 & & & \\
\hline & Acima & 8 & 26,6 & 12 & 40,0 & & & \\
\hline \multirow{3}{*}{ Amarelo } & Abaixo & 16 & 53,3 & 15 & 50,0 & \multirow{3}{*}{0,359} & \multirow{3}{*}{0,836} & \multirow{3}{*}{0,077} \\
\hline & Média & 7 & 23,3 & 6 & 20,0 & & & \\
\hline & Acima & 7 & 23,3 & 9 & 30,0 & & & \\
\hline \multirow{3}{*}{ Marrom } & Abaixo & 10 & 33,3 & 9 & 30,0 & \multirow{3}{*}{1,964} & \multirow{3}{*}{0,375} & \multirow{3}{*}{0,181} \\
\hline & Média & 1 & 3,3 & 4 & 13,3 & & & \\
\hline & Acima & 19 & 63,4 & 17 & 56,7 & & & \\
\hline \multirow{3}{*}{ Preto } & Abaixo & 20 & 66,7 & 15 & 50,0 & \multirow{3}{*}{4,381} & \multirow{3}{*}{0,112} & \multirow{3}{*}{0,270} \\
\hline & Média & 6 & 20,0 & 4 & 13,4 & & & \\
\hline & Acima & 4 & 13,3 & 11 & 36,6 & & & \\
\hline \multirow{3}{*}{ Branco } & Abaixo & 16 & 53,4 & 14 & 46,6 & \multirow{3}{*}{0,300} & \multirow{3}{*}{0,861} & \multirow{3}{*}{0,071} \\
\hline & Média & 3 & 10,0 & 3 & 10,0 & & & \\
\hline & Acima & 11 & 36,6 & 13 & 43,4 & & & \\
\hline \multirow{3}{*}{ Cinza } & Abaixo & 18 & 60,0 & 15 & 50,0 & \multirow{3}{*}{0,746} & \multirow{3}{*}{0,689} & \multirow{3}{*}{0,112} \\
\hline & Média & 4 & 13,4 & 4 & 13,4 & & & \\
\hline & Acima & 8 & 26,6 & 11 & 36,6 & & & \\
\hline \multirow{3}{*}{$\begin{array}{l}\text { Síndrome } \\
\text { Normal }\end{array}$} & Abaixo & 3 & 10,0 & 7 & 23,3 & & & \\
\hline & Média & 22 & 73,4 & 20 & 66,7 & 2,195 & 0,334 & 0,191 \\
\hline & Acima & 5 & 16,6 & 3 & 10,0 & & & \\
\hline & Abaixo & 5 & 16,6 & 9 & 30,0 & & & \\
\hline $\begin{array}{l}\text { Sindrome } \\
\text { Estímulo }\end{array}$ & Média & 19 & 63,4 & 13 & 43,4 & 2,554 & 0,279 & 0,206 \\
\hline & Acima & 6 & 20,0 & 8 & 26,6 & & & \\
\hline & Abaixo & 6 & 20,0 & 10 & 33,3 & & & \\
\hline $\begin{array}{l}\text { Sindrome } \\
\text { Fria }\end{array}$ & Média & 20 & 66,7 & 17 & 56,7 & 1,386 & 0,500 & 0,152 \\
\hline & Acima & 4 & 13,3 & 3 & 10,0 & & & \\
\hline & Abaixo & 14 & 46,7 & 11 & 36,6 & & & \\
\hline Síndrome & Média & 10 & 33,3 & 6 & 20,0 & 3,939 & 0,140 & 0,256 \\
\hline Incolor & Acima & 6 & 20,0 & 13 & 43,4 & & & \\
\hline
\end{tabular}

Verifica-se que o intervalo de pelo menos seis meses entre as avaliações aparentemente não produziu repercussões significativas na distribuição dos casos no conjunto 
de variáveis em foco. Não houve diferenças estatisticamente significativas entre as duas aplicações do Teste de Pfister nas crianças e nos adolescentes do Grupo Clínico, mantendo suas frequências de escolhas das cores e das síndromes cromáticas ao longo do tempo. Em outras palavras, pode-se comentar que sinalizaram manutenção de seu funcionamento afetivo e lógico, marcado pela reduzida proporção do uso do amarelo, do violeta, do preto, do branco e do cinza, mas com elevação do uso do marrom e da Síndrome Incolor. Apesar dos múltiplos procedimentos de cuidado oncológico, preservaram recursos adaptativos, como mostram as síndromes Normal, Estímulo e Fria na média, elevando a frequência dos casos com Síndrome Incolor aumentada na segunda avaliação.

Na sequência há que se considerar os resultados da Fórmula Cromática (FC) do Pfister nas distintas avaliações realizadas com G1. Esses dados compõem a Tabela 47.

Tabela 47. Resultados médios e comparação estatística das duas avaliações do grupo clínico $(n=30)$ em relação à Fórmula Cromática no Teste de Pfister.

\begin{tabular}{ccccccc}
\hline \multirow{2}{*}{$\begin{array}{c}\text { Algarismos da } \\
\text { Fórmula Cromática }\end{array}$} & Fase & \multicolumn{2}{c}{ Análise Descritiva } & \multicolumn{3}{c}{ Análise Comparativa } \\
& & Média & DP & $z$ & $p$ & $d$ de Cohen \\
\hline \multirow{2}{*}{ Constância Absoluta } & Fase 1 & 3,66 & 2,57 & 0,979 & 0,803 & 0,088 \\
& Fase 2 & 3,46 & 2,94 & & & \\
Constância Relativa & Fase 1 & 2,83 & 1,39 & & & \\
& Fase 2 & 2,76 & 1,96 & 0,944 & 0,115 & 0,028 \\
& Fase 1 & 1,90 & 1,58 & & & \\
Variabilidade & Fase 2 & 2,36 & 1,65 & 0,935 & 0,068 & $-0,272$ \\
& Fase 1 & 1,56 & 1,99 & & & \\
Ausência & Fase 2 & 1,40 & 1,99 & 0,919 & 0,026 & 0,092 \\
\hline
\end{tabular}

Nota-se que não houve diferença estatisticamente significativa entre as duas avaliações de G1 em termos dos dados médios dos algarismos da Fórmula Cromática do Pfister. Na primeira e na segunda aplicação, o algarismo de Constância Absoluta se mantém em destaque, seguido pelos valores da Constância Relativa e Variabilidade, com valores numéricos menores para o algarismo de Ausência. Esses achados sugerem estabilidade das crianças e adolescentes em cuidado oncológico no tocante à captação e processamento dos estímulos advindos do ambiente. 
A seguir, a partir da Tabela 48, pode-se examinar a distribuição dos casos segundo a classificação da Fórmula Cromática do Pfister nas duas avaliações do Grupo Clínico.

Tabela 48. Distribuição da classificação das Fórmulas Cromáticas do Pfister no Grupo Clínico (n=30) e comparação estatística entre dois momentos avaliativos.

\begin{tabular}{clccccccc}
\hline \multirow{2}{*}{$\begin{array}{c}\text { Classificação da } \\
\text { Fórmula Cromática }\end{array}$} & \multicolumn{2}{c}{ Fase 1} & \multicolumn{2}{c}{ Fase 2} & \multicolumn{2}{c}{ Análise Comparativa } \\
& Ampla & 24 & $\%$ & $f$ & $\%$ & $x^{2}$ & $p$ & V de Cramer \\
\hline \multirow{3}{*}{ Amplitude } & Moderada & 3 & 10,0 & 3 & 10,0 & 0,164 & 0,921 & 0,052 \\
& Restrita & 3 & 10,0 & 4 & 13,4 & & & \\
& Constante & 6 & 20,0 & 4 & 13,4 & & & \\
Variabilidade & Flexível & 24 & 80,0 & 16 & 53,3 & 12,00 & $\mathbf{0 , 0 0 2}$ & $\mathbf{0 , 4 4 7}$ \\
& Lábil & - & - & 10 & 33,3 & & & \\
& & & & & & & & \\
Eesquerda & 16 & 53,3 & 18 & 60,0 & & & \\
& Empate & 4 & 13,4 & 7 & 23,4 & 2,602 & 0,272 & 0,208 \\
& Direita & 10 & 33,3 & 5 & 16,6 & & & \\
\hline
\end{tabular}

Houve apenas uma diferença estatisticamente significativa com tamanho do efeito médio entre as duas aplicações do Pfister em G1, a saber: na segunda avaliação houve maior variabilidade na Fórmula Cromática, que se marcava predominantemente como Flexível na fase 1. Este achado pode refletir algum aumento de instabilidade diante dos estímulos vindos do mundo externo após seis meses da primeira aplicação do Pfister.

No entanto, em termos gerais, G1 evidenciou Fórmula Cromática prioritariamente caracterizada por ampla captação emocional, com abertura e permeabilidade. Esses elementos sugerem flexibilidade para obter ajustamento dos voluntários ao contexto de vida, mesmo diante de recorrentes e contínuos estressores associados ao tratamento oncológico.

Por fim, na Tabela 49 traz a distribuição dos modos de execução e de colocação nas pirâmides do Pfister, além de seu resultado formal. São comparados, de modo estatístico, os resultados obtidos nas duas aplicações desse método projetivo em G1. 
Tabela 49. Distribuição dos participantes e comparação estatística dos dois momentos avaliativos do Grupo Clínico $(n=30)$ em função dos Modos de Execução, Modos de Colocação e Aspecto Formal no Teste de Pfister.

\begin{tabular}{|c|c|c|c|c|c|c|c|c|}
\hline & & & & & & & e Com & ativa \\
\hline Variável & do Pfister & $f$ & $\%$ & $f$ & $\%$ & $x^{2}$ & $p$ & $\begin{array}{c}\mathrm{V} \text { de } \\
\text { Cramer }\end{array}$ \\
\hline & Metódica & 6 & 20,0 & 3 & 10,0 & & & \\
\hline Execução & Ordenada & 22 & 73,3 & 25 & 83,3 & 1,191 & 0,551 & 0,141 \\
\hline & Relaxada & 2 & 6,7 & 2 & 6,7 & & & \\
\hline & Ascendente & 41 & 45,5 & 40 & 44,5 & & & \\
\hline Colocação* & Descendente & 34 & 37,8 & 35 & 38,8 & 0,027 & 0,987 & 0,012 \\
\hline & Outros** & 15 & 16,7 & 15 & 16,7 & & & \\
\hline & Direta & 37 & 41,1 & 39 & 43,3 & & & \\
\hline Colocação* & Inversa & 27 & 30,0 & 31 & 34,5 & 1,111 & 0,574 & 0,079 \\
\hline & Outros $* * *$ & 26 & 28,9 & 20 & 22,2 & & & \\
\hline & Tapetes & 58 & 64,4 & 59 & 65,5 & & & \\
\hline Aspecto & Formações & 28 & 31,2 & 28 & 31,2 & 0,151 & 0,927 & 0,029 \\
\hline Formal* & Estruturas & 4 & 4,4 & 3 & 3,3 & & & \\
\hline
\end{tabular}

Novamente verifica-se a estabilidade temporal dos dados advindo da produção do Grupo Clínico em função dos aspectos formais do Teste das Pirâmides de Pfister. Não houve diferenças estatisticamente significativas nos modos de execução, de colocação e nos aspectos formais das pirâmides construídas pelas crianças e adolescentes de G1, mesmo após seis meses da primeira avaliação. Nota-se que as características de integração da lógica com o afeto (execução ordenada), a coordenação dos impulsos e a modulação formal dos estados afetivos (colocação ascendente e direta) estão condizentes com o esperado para o desenvolvimento infantojuvenil, não havendo aparente efeito do tempo de convivência com o processo de cuidado oncológico sobre o aproveitamento dos recursos emocionais e o funcionamento cognitivo.

\subsubsection{Indicadores da Personalidade de Crianças e Adolescentes - síntese}

Em síntese, considerando os achados dos dois momentos avaliativos a partir dos métodos projetivos, notam-se algumas especificidades no grupo constituído por crianças e 
adolescentes diagnosticadas com câncer (Grupo Clínico - G1). As diferenças encontradas entre os grupos não são suficientes para considerar que as repercussões do adoecimento e cuidado são nevrálgicas para a produção de alteração na dinâmica afetiva ou na integração dos recursos cognitivos para a coordenação dos impulsos e afetos. Em ambos os grupos existiram sinais de esforços adaptativos em direção à busca do equilíbrio e com elaboração favorável das experiências de vida.

Entre os dois momentos avaliativos, notou-se estabilidade nos indicadores de produtividade e de ritmo diante do Rorschach, com adequado aproveitamento de recursos cognitivos, que se mostraram compatíveis com o esperado para o desenvolvimento. No tocante aos modos de apreensão, considerados indicadores da estruturação do pensamento formal e do funcionamento de defesas psíquicas, não houve diferenças estatisticamente significativas entre os dois momentos avaliativos, apontando que as repercussões provocadas pelo câncer na vida de crianças e adolescentes não pareceram influenciar seus processos de captação e de discriminação dos estímulos da realidade, pelo menos dentro do período examinado.

Ainda sobe a avaliação da maturação dos aspectos cognitivos e o aproveitamento dos recursos racionais, outras variáveis do Rorschach (F\%, F+\%, Fext\%) possibilitam inferir que em ambas as avaliações houve sinais de adequada precisão formal na abordagem interpretativa da realidade, com preservação da integridade dos perceptos captados (H:Hd / A:Ad.). Entretanto, provavelmente em função da etapa do ciclo vital em que se encontram, denotaram menor disponibilidade para a reflexão e a elaboração das experiências pelo pensamento formal plenamente desenvolvido (A\%, H\%, Aspecto Formal no Pfister), havendo contato mais intuitivo e despojado com a realidade. Assevera-se ainda a existência de apontamentos que sugerem a preservação do compartilhamento da forma de pensar e dos interesses de seu grupo social de referência (Ban\%).

Destaca-se ainda que o maior número médio de respostas de conteúdo humano desvitalizado no Rorschach $[(\mathrm{H})]$, presente na primeira avaliação do Grupo Clínico, não foi verificada na segunda etapa do estudo. Isto sugere que, ao longo do intervalo de seis meses, houve importante elaboração da percepção das modificações corporais trazidas pelo cuidado oncológico, negativamente impactadas num primeiro momento.

Nas duas avaliações realizadas com o Grupo Clínico foi possível encontrar sinais de maior mobilização afetiva ( $\downarrow$ amarelo, $\downarrow$ laranja, $\downarrow$ violeta nas duas aplicações do Pfister, além de C, $\sum \mathrm{Cp}$ na segunda avaliação pelo Rorschach), denotando que as vivências ao longo deste período evocaram repercussões emocionais no jovem paciente. Contudo, o aproveitamento de 
recursos estabilizadores, mesmo que mais primitivos $(\mathrm{FC} \cong \mathrm{CF}+\mathrm{C}, \uparrow$ marrom, $\downarrow$ preto, $\downarrow$ cinza) revelaram os esforços adaptativos de G1 na busca de manter a estrutura e dinamismo do psiquismo próximo a padrões que vivenciavam anteriormente ao adoecimento.

Assim, mantendo receptividade e permeabilidade com relação às experiências advindas do mundo externo (Fórmulas Vivenciais do Rorschach, e Fórmula Cromática no Pfister), sinalizaram boa coordenação dos impulsos e afetos, o que favorece a diminuição das tensões e angústias, e a utilização da ansiedade como motor para a ação. Estes achados propiciaram compreensão relativa a esforços adaptativos de crianças e adolescentes que convivem com o cuidado oncológico. Apontaram a efetividade das estratégias psíquicas adotadas enquanto mecanismos de preservação dos recursos cognitivos e afetivos da estrutura e dinâmica da personalidade, de modo a preservar o percurso positivo de seu desenvolvimento. 

A partir dos objetivos traçados para a condução deste estudo, passaremos agora a confrontar a literatura científica da área com os achados resultantes do processo avaliativo longitudinal de crianças e adolescentes que convivem com o diagnóstico oncológico, bem como seus familiares ou responsáveis que ocupam o papel de cuidador principal. Essa análise será pautada pela comparação do grupo clínico com os voluntários hígidos, visto possuírem características etárias, escolares e econômicas balanceadas.

Assim, com o intuito de contribuir para o aprimoramento da prática do cuidado integral em Oncologia Pediátrica, serão aqui exploradas repercussões do diagnóstico e do tratamento de neoplasias na infância e adolescência sobre as relações familiares e os recursos pessoais. Envolve a análise da percepção do cuidador familiar acerca da saúde mental do jovem paciente, bem como possíveis impactos dos cuidados oncológicos em sua vida psíquica. A realização de avaliações psicológicas em dois momentos distintos permite ainda examinar eventual influência do tempo de exposição aos cuidados de alta complexidade em saúde sobre as vivências socioafetivas dos voluntários do grupo clínico.

Um primeiro elemento a considerar nesse trabalho diz respeito às características do grupo clínico, constituído por conveniência. Os voluntários desse grupo receberam intervenções profissionais variadas, visando ao tratamento da doença em uma perspectiva curativa. O processo de cuidado oncológico sinalizou-se heterogêneo entre os voluntários, atendendo às suas particularidades biopsicossociais. Assim, houve variabilidade no tempo entre o aparecimento dos sintomas até a realização do diagnóstico, na natureza fisiopatológica da doença, na idade como fator interveniente para considerar o agravamento ou atenuação do quadro, no delineamento do protocolo de assistência, incluindo combinação de intervenções mais ou menos invasivas ou com potencial para alterar a qualidade de vida da pessoa. Em síntese, pode-se comentar que os cuidados oncológicos caracterizam-se por vivências de caráter particularizado.

Apesar das variações já enumeradas, é comum a todo paciente de um serviço de Oncologia Pediátrica, a confrontação com questões de vida e morte, rupturas e transformações do cotidiano em face da imersão no universo hospitalar. Esse contexto se torna presente não somente pelas frequentes internações em enfermaria ou consultas ambulatoriais, administração de medicamentos e quimioterápicos, efeitos secundários ao tratamento, como também pela convivência com regras e limites impostos pelas orientações da equipe interdisciplinar visando à diminuição de exposição a doenças oportunistas ou intercorrências no quadro de saúde. 
Nesse campo da Psico-Oncologia Pediátrica, Valle (1997) há muito já apontou aspectos comuns da experiência de adoecimento e cuidados oncológicos. Entre esses, argumentou que o jovem paciente, "independentemente de sua idade e sua capacidade de entendimento, dá-se conta de que algo terrível está lhe sucedendo, afogado pela sensação de perigo, de ameaça de algo desconhecido"(Valle, 1997, p. 69).

Esta perspectiva realça a hipótese de que o processo de cuidados oncológicos seja capaz de imprimir marcas no desenvolvimento infantojuvenil e em seus sistemas familiares. Portanto, neste momento confrontaremos os resultados da avaliação de crianças e adolescentes que convivem com o câncer pediátrico aos achados da literatura científica da área, em comparação a grupo constituído por crianças e adolescentes hígidos.

A primeira esfera de avaliação deste trabalho diz respeito ao suporte familiar autorreferido pelos pais/responsáveis pelas crianças e adolescentes do estudo. Foi possível enumerar variáveis psicossociais e econômicas da família, bem como rastrear conflitos ou sinais de psicopatologia pertinentes aos pais. A reavaliação destas variáveis após o intervalo mínimo de seis meses possibilitou examinar quais destes aspectos poderiam estar associados a convivência com o câncer infantojuvenil, e quais seriam amplificados por esta experiência.

Tomou-se por base a noção de que o suporte às competências cognitivas, afetivas e sociais do desenvolvimento da criança ou adolescente podem ser favorecidas à medida que estão disponíveis de objetos e recursos materiais. Os achados apontaram que famílias que convivem com câncer pediátrico não se diferenciaram de grupos familiares sem tal condição clínica, em relação ao aproveitamento de atividades cotidianas ou de lazer, nem em termos da supervisão e acompanhamento da inserção do jovem paciente no universo escolar.

É possível verificar que, para outros grupos clínicos, a manutenção do suporte familiar não apresenta tanta consistência, como apontaram D'Avila-Bacarji, Marturano e Elias (2005). Compararam crianças de $1^{\circ}$ ao $4^{\circ}$ ano do Ensino Fundamental com queixa de reduzido desempenho escolar com grupos de características balanceadas, porém com desempenho escolar variado. Identificaram diferenças na percepção do suporte familiar dessas crianças, empobrecido no grupo de pior desempenho escolar, em relação a recursos materiais tais como livros, revistas, brinquedos e jogos, além de não usufruírem de interação positiva com seus pais.

De forma análoga, ao considerar os recursos familiares diante de uma condição crônica de saúde de crianças de dois a 7 anos (paralisia cerebral), Morilla, Caldas, Scarpellini e Santos (2017) apontaram que, na perspectiva de mães, o aproveitamento dos recursos materiais e humanos disponíveis na família acompanham relação direta com a condição 
clínica do jovem paciente. Ou seja, a rotina da família e os processos de interação criançarecurso material e criança-meio ambiente organizam-se em torno da necessidade de contínua assistência à saúde, mediada pelo estado geral e pela complexidade dos cuidados a serem prestados à criança. Isso pode levar a adaptações ou a restrições, principalmente no que tange a atividades não programadas, lazer, passeios e supervisão do universo escolar.

É importante reconhecer que, apesar de estereótipos sociais que associam a incidência da neoplasia na infância e adolescência com a decadência das potencialidades orgânicas e a fixação de uma imagem que remete à incapacitação e à aproximação com a morte (Gomes, Lima, Rodrigues, Lima \& Collet, 2013), a vitalidade e a busca ativa pelo aproveitamento de experiências típicas para a faixa etária pareceu ser a tônica dos participantes do grupo clínico do atual trabalho. Os achados derivados do Inventário de Recursos do Ambiente Familiar (RAF), nas duas etapas avaliativas, são claros indicativos que tanto famílias que convivem com o câncer quanto aquelas com filhos sem diagnóstico de doença aguda ou crônica referiram semelhante dinâmica nas interações familiares cotidianas.

Segundo Robinson, Gerhardt, Vannatta e Noll (2007), a exploração dos recursos presentes no ambiente familiar, assim como o aproveitamento constante de oportunidades de estabelecimento da interação entre pai e mãe com o filho com câncer, configuram formidáveis recursos para o fortalecimento dos vínculos. Consequentemente, a percepção de proteção e segurança em um ambiente familiar sentido como acolhedor pareceu influenciar positivamente no ajustamento do paciente frente ao sofrimento trazido pelo contexto hospitalar e pelos procedimentos médicos invasivos. Além disso, tendeu a atuar como dispositivo protetor em relação a angústia vivenciada pelos próprios pais diante das árduas experiências inerentes aos cuidados oncológicos de seu filho.

A única ressalva a ser considerada ocorreu no domínio da RAF denominado Presença de recursos no ambiente físico, no momento da segunda avaliação. Nesse caso, houve apontamentos estatísticos de diferença e moderado tamanho do efeito tanto na comparação de G1 com G2, quanto na comparação dos dois exames realizados com o Grupo Clínico. Este achado pode estar ligado não a indisponibilidade em si de recursos no ambiente físico da família, mas talvez seja uma repercussão de recomendações da equipe de saúde no sentido de zelar pela preservação do jovem paciente, restringindo ao máximo sua exposição a elementos patogênicos nocivos, dada sua fragilidade imunológica derivada da quimioterapia. Isso produziria afastamento de atividades dinâmicas que movimentem o corpo, animais de estimação e atividades extracurriculares, por exemplo (Valle, 2004). Desse modo, não seria 
uma diferença nas condições do ambiente físico dos grupos, mas como os participantes de G1 e G2 podem aproveitar e interagir com os elementos disponíveis em seu contexto de vida.

Ainda na comparação da RAF entre os dois momentos avaliativos do grupo clínico, observou-se diferença estatisticamente significativa em relação a Oportunidade de interação com os pais, apontando para uma média maior deste índice na segunda avaliação (após seis meses da primeira). Nota-se que os itens que compõem a referida dimensão da RAF não fazem alusão ao tempo compartilhado entre pais e filhos no ambiente hospitalar, mas sobretudo a momentos comuns vividos pela família em passeios, durante as refeições, ou pelo interesse em realizar atividades cotidianas em conjunto. Este incremento pode estar associado a intervenções psicossociais como por exemplo a denominada Saindo Para Passear, desenvolvida pelo Grupo de Apoio à Criança com Câncer (GACC Ribeirão Preto), onde os participantes de G1 costumam participar. Essa intervenção tem por objetivo promover a integração entre membros da família do jovem paciente e entre famílias assistidas pelo serviço, bem como a inserção social das mesmas por meio de passeios a pontos turísticos e de lazer presentes na região do município. Além disso, a concentrada atenção na organização da rotina da família em torno da criança ou adolescente acometido pela neoplasia pode favorecer a superproteção por parte dos pais. Essa pode ser sua reação frente às ameaças da integridade física e ao temor de que os rumos da vida do pequeno enfermo saiam da possibilidade de controle da família, o que denota fantasias de culpa, medo da morte, impotência/onipotência (Alves, Guirardello \& Kurashima, 2013; Lopes \& Vale, 2010).

Ao entrevistar, em dois momentos distintos, pais de crianças com diagnóstico de leucemia, Kohlsdorf e Costa Junior (2011) puderam constatar que, logo após a identificação da doença neoplásica, as famílias experimentaram mudanças em seus hábitos e comportamentos. Houve maior dedicação ao cuidado e supervisão da rotina da criança com câncer, com afastamento do exercício do papel profissional, e administração diferenciada dos recursos financeiros da família, de modo a prover eventuais despesas com o filho enfermo ou para lidar com o contingenciamento do orçamento familiar. Após um período de pelo menos seis meses posterior ao diagnóstico, as famílias entrevistadas apresentaram sinais de adaptação frente as novas vicissitudes. Nesse processo sinalizaram ganhos com relação a significados e valores referentes à vida e ao papel dos relacionamentos, mas também experimentaram sofrimentos e risco de adoecimento psíquico.

Deste modo, do ponto de vista das modificações na rotina familiar em prol da estruturação da assistência e supervisão doméstica visando atender as necessidades da criança/adolescente com câncer, tanto o referido trabalho quanto o presente estudo 
reconhecem a necessidade de adaptação dos hábitos dos pais e da rotina familiar, o que acontece prioritariamente no início do tratamento. Em acréscimo, são enunciados indicativos de alterações relevantes nessa dinâmica que produzem efeitos negativos sobre a carreira profissional e a vida financeira da família.

É interessante apreciar que a repercussão econômica do câncer infantojuvenil na família pode fazer alusão a três aspectos principais: a) ao custeio de serviços e artigos de saúde, como medicamentos, alimentação de qualidade e suplementos alimentares, exames laboratoriais, transporte, adequação do ambiente doméstico às orientações da equipe de saúde; b) à perda de possibilidade produtiva, com afastamento do contexto de trabalho pela necessidade de assumir o papel de cuidador. Isso pode se expressar também pela dificuldade em manter negociação com empregador visando a conciliação de atividades laborais dos pais com as necessidades do filho, o que levaria à demissão voluntária ou involuntária do cargo; c) desgastes de ordem psicossocial (Creswell, Wisk, Litzelman, Allchin \& Witt, 2014; MarquesCamargo, 2014; Tsimicalis, Stevens, Ungar, McKeever \& Greenberg, 2011).

Apesar das variáveis econômicas não terem sido consideradas isoladamente neste estudo, pode-se focalizar o tema a partir de itens da Escala de Eventos Adversos (EEA) relacionados a dificuldades financeiras, ingresso dos familiares no mercado de trabalho, afastamento dos pais por mais de oito horas diárias para dedicação a atividade laboral, ou perda do emprego. Nesses itens houve indicativos de importante diferença entre o Grupo Clínico e o Grupo de Comparação.

Ao focalizar as duas avaliações dos referidos quesitos em G1, notou-se diminuição da frequência de eventos psicossociais e econômicos que podem incidir negativamente sobre a criança e o adolescente com câncer, bem como em seus familiares, com o passar do tempo. Neste interim é relevante destacar que todos os colaboradores deste estudo são acompanhados por um serviço de saúde multidisciplinar terciário vinculado ao Sistema Único de Saúde (SUS), que tem por princípio a equidade universalidade de oportunidades de acesso e beneficiamento de cuidado de qualidade à saúde. A oferta integral desse serviço de alta complexidade é realizada de forma gratuita a todos os usuários do setor de Oncologia Pediátrica, sem que os pais precisem arcar diretamente com os altos custos de exames laboratoriais e de imagens, procedimentos cirúrgicos, ou na aquisição de drogas de diversas naturezas. Nota-se, portanto, o efeito protetivo que esse serviço público exerce sobre famílias em contexto de maior vulnerabilidade biológica e econômica. Em acréscimo, há que citar a possibilidade de acesso a outros benefícios econômicos e previdenciários, como, por exemplo, o Benefício da Prestação Continuada (BPC), ou o apoio de organizações sociais que buscam 
complementar as ações governamentais. Essas possibilidades evidenciam o caráter protetivo que políticas públicas podem exercer, em ativa parceria com organismos da comunidade. Assumem, desse modo, o papel de mecanismos de proteção diante da vivência de riscos psicossociais derivados do adoecimento oncológico infantojuvenil (Barr, Feeny \& Furlong, 2004; Brasil, 2009).

No presente trabalho também foram consideradas variáveis relacionadas a vivências estressoras ou vulnerabilizantes de natureza psicológica, interacional ou de cunho social, associadas a experiências conflituosas, comportamentos de risco ou conflito com lei no seio familiar, além de condições de saúde e bem-estar dos pais. Nota-se que logo na primeira avaliação realizada estes variáveis de risco ao desenvolvimento foram mais frequentes em famílias que conviviam com o câncer pediátrico. Esse resultado permaneceu ao longo dos dois momentos avaliativos, mostrando-se estável no tempo, sem agravamento de tais achados após o intervalo de pelo menos seis meses.

Assim, nas famílias do Grupo Clínico houve mais sinais de conflito, bem como situações de choque entre os pais, com incidências de separação e divórcio. Ainda em acréscimo, esses núcleos familiares sinalizaram mais indicadores de quadros psicopatológicos dos pais, associados ao consumo de álcool ou outras drogas ilícitas, ou mesmo temperamento difícil. É lícito ponderar que os eventos elencados podem figurar negativamente no contexto familiar da criança e adolescente que adoece, produzindo alteração na dinâmica das relações interpessoais na família ou gerando repercussões desfavoráveis nos aspectos globais da saúde de todos.

Nessa direção, o estudo conduzido por Rosenberg et al. (2014) com pais que acompanham seus filhos no processo de cuidado oncológico, apontou sinais de sofrimento emocional e alterações desfavoráveis em sua saúde. Restringiram, por fim, o aproveitamento de recursos psicossociais como tentativa adaptativa para enfrentar as agruras trazidas pelo quadro clínico do filho. Nesse processo, muitos destes cuidadores parentais conseguiram bons desfechos na medida em que preservaram seus recursos pessoais para lidar com a situação, mantendo boa adaptabilidade social.

Estas constatações são corroboradas por Amador, Gomes, Reichert e Collet (2011). Ao revisarem a produção da literatura nacional e internacional especializada da área, verificaram o potencial desestruturante do cuidado oncológico do filho sobre a família, confirmando sinais de impactos físicos e psicológicos desse processo. Estas repercussões negativas seriam crescentes em função do prolongamento do exercício do papel de cuidador familiar, da 
vivência de angústias ligadas ao temor da perda e da morte, da modificação das relações entre os membros da família, além da incidência de outros estressores de natureza psicossocial.

Para além da análise dos recursos e de estressores ambientais, faz-se relevante considerar os achados relativos à percepção do suporte familiar por parte dos cuidadores principais dos participantes do estudo. Nesse sentido não houve diferenças estatisticamente significativas entre G1 e G2 em nenhum dos momentos avaliativos. Isto sugere que o familiar ou responsável entrevistado, tanto do Grupo Clínico quanto no Grupo de Comparação, manteve positiva percepção dos afetos entre os membros que compõem sua família, com preservação da empatia, autonomia e privacidade, além de coerência entre aspirações e atitudes, favorecendo consistência na tomada de decisões familiares.

Esses dados derivados do Inventário de Percepção do Suporte Familiar (IPSF) aparentemente contrastam com os descritos anteriormente sobre os recursos e os estressores do ambiente familiar, extraídos dos outros instrumentos de análise de variáveis do contexto da família. No entanto, há que destacar que a percepção do suporte familiar representa a captação referida pelo respondente a respeito de sua família, o que, até certo ponto, pode independer de suas condições materiais. Assim, os cuidadores referiram, tanto em G1 quanto em G2, avaliação positiva acerca da relação de pertença e apoio estabelecida no grupo parental, com ausência de sentimentos negativos como raiva ou vergonha impeditivos para receber apoio de sua família. Beck e Lopes (2007) constataram que o apoio percebido associa-se a disponibilidade e interesse afetivo dos familiares próximos, geralmente demonstrado pelo compartilhamento do cuidado dos filhos saudáveis ou dos afazeres domésticos enquanto os pais permanecem no ambiente hospitalar junto ao filho em cuidado oncológico.

Nessa direção, Baptista, Rueda e Brandão (2017) argumentam que a percepção de suporte vindo da família é importante expediente de absorção dos impactos de estressores e eventos vulnerabilizantes que ocorrem na vida da pessoa. Impulsiona a percepção da estabilidade e estimula o enfrentamento de situações desafiadoras, favorecendo a sensação de bem-estar. Ao levarmos este conceito para o contexto de uma unidade hospitalar pediátrica, compreende-se que o suporte familiar pode facilitar o processo de reorganização e adaptação do paciente infantojuvenil frente aos múltiplos eventos estressores ali presentes (Mombelli, Costa, Marcon \& Moura, 2011).

Os achados do atual trabalho caminham nessa direção, na medida em que o IPSF apontou que o suporte familiar foi percebido de forma eficaz e positiva por quem ocupa o papel de cuidador principal nos dois grupos avaliados. Assim, a percepção de apoio da família ao longo da vivência de crises ou situações difíceis pareceu atuar como fator de proteção ao 
desenvolvimento da pessoa, oferecendo recursos para sua positiva adaptação em detrimento das dificuldades (Baptista, 2010).

Nesse campo do contexto familiar cabe ainda destacar os indicadores relativos ao relacionamento da díade genitor-filho no processo de mediação do universo do cuidado oncológico pediátrico. Os achados do atual estudo indicam que esses familiares experimentam aumento das pressões e angústias, o que pode levar ao sofrimento psíquico e ao desenvolvimento de psicopatologias nos pais. Desse modo, faz-se relevante examinar o processo de seu relacionamento com o filho.

Com essa preocupação, Okado, Tillery, Sharp, Long e Phipps (2016) estudaram 255 díades pai-filho com diagnóstico de neoplasia. Constataram que o agravamento do quadro de saúde mental do familiar elevou a probabilidade de alteração do humor e diminuiu sinais de elaboração das experiências vinculadas aos cuidados oncológicos na criança ou adolescente, constituindo-se como fator de risco ao desenvolvimento infantojuvenil. De forma complementar, o mesmo estudo apontou que, ao se distanciar temporalmente do diagnóstico, a díade pai-criança tem maior chance de desenvolver estabilização das formas de adaptação às dificuldades trazidas pelo contexto de assistência à saúde, bem como de seus afetos em decorrência dos desafios e eventuais repercussões sociofamiliares produzidas pelo diagnóstico da neoplasia.

Nos atuais achados foi possível notar que, na percepção dos pais/responsáveis, as crianças/adolescentes com câncer teriam mais sinais de dificuldades de ordem emocional. No entanto, o aproveitamento dos recursos familiares, a manutenção de relações pró-ativas que ofereçam apoio e supervisão, e a percepção favorável do suporte familiar pareceram assumir a função de mecanismos de proteção neste contexto, favorecendo sobremaneira o processo de adaptação das crianças e adolescentes voluntários deste estudo.

Ainda no tocante ao relato dos pais acerca das condições de saúde física, mental e social das crianças e adolescentes, apreende-se substancial diferença entre aquelas que convivem com o cuidado oncológico e assistência hospitalar e seus pares hígidos. A diferença estatística entre as médias obtidas pelos distintos grupos nos domínios que avaliam as condições de saúde da criança e do adolescente na Escala de Eventos Adversos (EEA), Escala de Adversidades Crônicas (EAC) e no Questionário de Capacidades e Dificuldades (SDQ) se mantêm inalteradas ao longo do tempo entre as avaliações. Esses resultados apontaram que as repercussões na vida do jovem paciente tendem a se instalar em uma etapa inicial do tratamento oncológico. 
Destaca-se, então, que não somente o diagnóstico da enfermidade faz com que G1 e G2 mantenham, segundo seus pais/responsáveis, indicadores diferentes em termos de saúde mental (pior em G1). A frequência de hospitalizações e a submissão a procedimentos invasivos, o eventual uso de próteses e órteses, a modificação corporal em decorrência tanto da doença quanto de efeitos secundários das intervenções terapêuticas constituem variáveis relevantes nesse contexto. Entram ainda nessa realidade as vivências de ameaça à vida e a concretude da morte de colegas que compartilham do processo de cuidado hospitalar. Nesse ambiente não foi incomum, no Grupo Clínico, relato dos pais apontando alterações negativas no aproveitamento do universo escolar, piora na relação com colegas e amigos, sinais de alteração do humor e labilidade, aumento da preocupação, temores diante dos imprevistos pertinentes a vivência de situações novas, resultando em indicadores desfavoráveis em termos de saúde mental das crianças e adolescentes.

Os apontamentos obtidos no atual estudo por meio dos vários instrumentos de avaliação do contexto familiar e da percepção das repercussões do cuidado oncológico no curso de vida da criança e do adolescente seguem os achados da literatura científica no campo da Psico-Oncologia Pediátrica. Ou seja, a exposição a riscos de origem biológica produz efeitos negativos sobre as dimensões psicossociais do paciente pediátrico. As experiências do adoecimento exigem, em contrapartida, em um período precoce da vida, que crianças e adolescentes lidem com alterações significativas em todas as dimensões de sua existência e seu desenvolvimento, bem como em suas relações com os familiares (Françoso, 2005; Alderfer et al., 2010; Cicogna, Nascimento \& Lima, 2010; Sharp, Lindwall, Willard, Long, Martin-Elbahesh \& Phipps, 2017).

Até o momento foram exploradas variáveis relacionadas à apreciação que os pais ou familiares responsáveis pelo cuidado fazem sobre a própria família, seus recursos, dinâmica, relacionamentos, reações diante do universo do cuidado oncológico, bem como observam as repercussões desta experiência sobre seus filhos. Faz-se necessário integrar, nesse contexto, a análise das variáveis associadas às características de personalidade derivadas da avaliação das crianças e adolescentes a partir dos métodos projetivos.

As variáveis pertinentes ao Método de Rorschach e ao Teste das Pirâmides de Pfister podem ser agrupadas em torno de funções pertinentes a estruturação e dinamismo da personalidade, acompanhando o clássico e útil esquema proposto por Loureiro e Romaro (1985). Com base nessa organização das variáveis, observa-se que do ponto de vista da produtividade, ritmo de trabalho, percepção do mundo externo, teste do real e indicadores do funcionamento lógico, não houve indicativos de diferenças estatisticamente significativas e 
clinicamente relevantes entre os participantes do Grupo Clínico e do Grupo de Comparação. Assim, foi possível notar que, mesmo em face das adversidades e desafios produzidos pelos fatores de risco biopsicossocial associados ao diagnóstico e processo de cuidado oncológico, em uma perspectiva longitudinal de avaliação psicológica, crianças e adolescentes com câncer mantiveram sinais de abertura e receptividade aos estímulos do mundo externo, com adequada percepção do ambiente e preservação da sua capacidade associativa e interpretativa, além de engajamento em seu contexto de vida. $\mathrm{O}$ funcionamento perceptual e a relação formal com o ambiente caracterizaram-se por marcas típicas da faixa etária dos participantes deste estudo, pautadas pelo concreto e imediato das situações, para depois avançar em meticulosa análise das particularidades, para então produzir análise mais criativa de sua realidade.

Deste modo é possível inferir que as modificações produzidas pela entrada no universo hospitalar e a prolongada convivência com estressores psicossociais pareceram não alterar a riqueza dos interesses e motivações das crianças e adolescentes do grupo clínico, tampouco desqualificaram seu funcionamento lógico e a abordagem analítica e crítica da realidade, o que costuma ser referido como hipótese associada aos quadros de adoecimento por câncer. Estes dados podem apontar que, mesmo em vigência de estímulos ambientais nocivos e dolorosos, preservam-se o funcionamento da percepção e dos recursos do pensamento.

Ao recorrermos aos estudos que identificaram alterações no funcionamento psicossocial de crianças e adolescentes com câncer, é possível apurar que não só dispositivos ambientais e rupturas no cotidiano podem alterar a estimulação destes aspectos do desenvolvimento humano. A administração de alguns tipos de quimioterápico, corticoides e radioterapia, a realização de medicamentos intratecal, podem se configurar como fatores de risco para a instalação de alterações negativas na integração visomotora, atenção sustentada, velocidade de processamento, função executiva e memória de trabalho. Esses processos tenderiam a resultar em déficits na aprendizagem, principalmente de competências matemáticas e de escrita, promovendo prejuízos neurocognitivos a médio e longo prazo que afetariam as possibilidades de especialização acadêmica e a evolução da carreira profissional do sobrevivente (Askins \& Moore, 2008; Children's Oncology Group, 2013; Goldsby et al, 2010; Kadan-Lottick et al., 2010).

Aparentemente, os resultados com o Grupo Clínico do presente estudo, tanto na avaliação quanto na reavaliação, levam a deduzir que a preservação do suporte familiar, a disponibilidade dos membros da família em manter a estimulação cognitiva por meio de jogos, brinquedos, material gráfico, livros e revistas, bem como o acesso a internet e jogos eletrônicos, além das adaptações que possibilitem algum tipo de continuação dos estudos 
mesmo que afastados da escola, funcionaram como variáveis protetoras a seu desenvolvimento. Além disso, os participantes de G1 receberam contínua e especializada assistência multiprofissional e interdisciplinar desde o momento do diagnóstico do câncer, o que pode ter favorecido a preservação e a estimulação dos recursos cognitivos conforme o esperado para o grupo de referência etário e sociocultural. Em outras palavras, cuidados oncológicos podem ser exigentes para o desenvolvimento infantojuvenil, porém não obrigatoriamente desestruturadores da organização psíquica quando devidamente amparados.

Dentre as possibilidades avaliativas e as informações obtidas pelo Método de Rorschach, é possível explorar como a pessoa percebe a si própria e ao seu corpo. Um conjunto de indicadores pertinentes a percepção global do estímulo, sensibilidade às cores e ao vermelho, banalidades, análise simbólica dos cartões, bem como alguns conteúdos, oferecem relevantes pistas sobre a representação de si e sobre as relações com o ambiente e com o próprio mundo interno (Santos, 2000; Emmanuelli \& Azoulay, 2008; Scortegagna \& Villemor-Amaral, 2009; Verdon, 2009).

No presente trabalho, a respeito de alguns índices técnicos do Rorschach relativos a percepção de si e do corpo, houve importante diferença entre os colaboradores do Grupo Clínico e os participantes do Grupo de Comparação na primeira etapa avaliativa. Assim, a frequência média dos conteúdos humanos distorcidos $[(\mathrm{H})]$ foi significativamente maior nas respostas do Grupo Clínico ao Método de Rorschach. Ao buscar compreender o significado desta variável, tanto Anzieu (1981) quanto Gueli, Jacquemin e Santos (1996), ponderam que o conteúdo humano irreal pode revelar que a percepção de si e do outro se encontra pouco estruturada, marcada pela imaturidade afetiva, ou ainda marcada por desvitalização na introjeção das figuras humanas.

Ao se debruçar sobre a relação do corpo, autoimagem e o câncer, Reich (2008) pondera que ao adoecer dessa patologia, a pessoa é rotineiramente exposta a procedimentos invasivos e dolorosos, fato que repercute negativamente na representação que o ser tem sobre si, além de produzir danos narcísicos que podem conduzir a um estado de dependência e vulnerabilidade. Ademais, o pesquisador argumenta que procedimentos de investigação médica (muitos exames clínicos, abordagem cirúrgica, realização de quimioterapia ou radioterapia), além das alterações devido a doença neoplásica ou pertinentes aos efeitos secundários das intervenções pertinentes ao cuidado (como por exemplo, alopecia, emagrecimento, cicatrizes devido às abordagens cirúrgicas) podem afetar a percepção de si, visto que esta é apreendida a partir do corpo físico, englobando a relação deste corpo com a identidade, os desejos e a imaginação. 
Existem revisões de literatura científica especializada na relação entre autoimagem, imagem corporal e adoecimento oncológico pediátrico. Exemplos disso são os trabalhos de Fan e Eiser (2009) e também a metanálise desenvolvida por Lee, Mu, Tsay, Chou, Chen e Wong (2012). A densidade dos achados nesses trabalhos aponta que as repercussões do adoecimento e cuidado em saúde não se dão de forma absoluta. Irão variar conforme a idade e sexo do paciente, além do tipo de modificação do corpo e das relações interpessoais produzidas pela experiência de convivência com o câncer. Ainda apontam que a amplitude do impacto do adoecimento sobre a imagem de si é um bom preditor de adaptação frente ao desafio produzido pelo adoecimento, uma vez que crianças e adolescentes com câncer que recebem suporte profissional, familiar e social de qualidade tendem a superar o afastamento dos ambientes pertinentes ao contexto de vida saudável.

Cabe, nesse momento, pensar essas considerações da literatura científica da área frente ao dado empírico atual de que a referida diferença estatisticamente significativa entre G1 e G2 nas respostas $(\mathrm{H})$ ao Rorschach, no segundo momento avaliativo (após seis meses), desapareceram. Isto pode sugerir que, com o passar do tempo de cuidados oncológicos, superado o impacto do momento diagnóstico, as crianças e os adolescentes de G1 sinalizaram elaboração favorável da experiência de invasão e modificação do corpo associado ao tratamento de saúde,

Esse achado empírico oferece original contribuição para o campo da Psico-oncologia Pediátrica, visto inexistir no Brasil, salvo maior engano, estudos com métodos projetivos de avaliação psicológica (voltados ao exame de características de personalidade) delineados com acompanhamento longitudinal, como foi o caso desse trabalho. Embora os indicadores técnicos do Rorschach sejam muito específicos, sua densidade teórica possibilita interpretações clinicamente relevantes para compreensão dos processos psíquicos envolvidos na formação da personalidade de crianças e adolescentes acometidos pelo câncer, como inicialmente almejou-se para o presente estudo.

Faz-se necessário, no entanto, tentar integrar o conjunto de variáveis examinadas a partir dos instrumentos projetivos adotados, de modo a caracterizar suas vivências afetivas e o processo de coordenação interna dos impulsos. Em termos gerais e a partir dos dados dos dois momentos avaliativos, G1 aparenta dinâmica afetiva e pulsional análoga a G2. Entretanto, notam-se alguns aspectos de importante mobilização afetiva e consequente organização de estratégias de adaptação que se mostraram característicos da busca de equilíbrio no dinamismo de crianças e adolescentes diagnosticados com doença neoplásica. 
No Grupo Clínico houve suficientes indicadores técnicos sugestivos de maior receptividade aos estímulos do ambiente, com maior mobilização afetiva diante das experiências cotidianas. Apesar de experimentarem maior permeabilidade ao contexto em que se inserem e sensibilidade em relação às incertezas frente ao futuro ou aos imprevistos cotidianos, apresentaram sinais de bom controle dos impulsos e dos afetos, mantendo a coordenação saudável destes conteúdos por defesas psíquicas prioritariamente pautadas pela intelectualização e evitação.

Essa linha interpretativa acompanha achados de estudos conduzidos por Phipps (2007), Willians, Allen e Phipps (2011), Trentacosta, Harper, Albrecht, Taub, Phipps e Penner (2016), ao asseverar que, a fim de conseguirem lidar com os desafios e adversidades da experiência de adoecimento, crianças e adolescentes com câncer utilizam um estilo adaptativo repressivo e evitativo. McWillians (2014) esclarece que estes processos defensivos são adotados por crianças que já apresentam integração madura de seus recursos ideoafetivos na personalidade. Seriam usados em resposta a impulsos e afetos ameaçadores de forma de mantê-los distantes da consciência, preservando boa relação com a realidade. Existiria complementaridade entre mecanismos de intelectualização e de racionalização como estratégias para lidar com a sobrecarga emocional produzida por estressores presentes em seu meio.

As considerações precedentes podem ser articuladas, de algum modo, com a concepção de Harper et al. (2014) ao relatar evidências sobre o funcionamento psíquico do paciente oncológico pediátrico. Segundo esses pesquisadores, este paciente tende a utilizar seu funcionamento executivo para desfocar a atenção de estímulos desagradáveis, bem como para inibir ou ativar comportamentos, passando assim a modular racionalmente suas emoções em decorrência de temores e frustrações. Ao lançar mão desta estratégia defensiva, consegue controlar suas reações afetivas negativas, obtendo maior adaptação a eventos estressantes e angustiantes, de modo a preservar sua qualidade de vida. Embora com alguma interligação, essas interpretações dos achados devem ser ponderadas em suas especificidades técnicoteóricas, visto que advêm de diferentes tipos de instrumentos de avaliação psicológica utilizados nos estudos.

No entanto, apesar da estratégia de adaptação de caráter repressivo propiciar ajuste psicológico a situação estressora, favorecendo a manutenção da qualidade de vida, Compas et al. (2014) argumentam que é possível detectar sinais de tensões, angústias e indicadores depressivos em pacientes oncológicos pediátricos. Essas observações acompanham os achados do presente estudo, tanto no que diz respeito a percepção dos pais sobre os 
indicadores de saúde mental e de afetividade de seus filhos, quanto pela análise dos instrumentos projetivos de avaliação da personalidade. Foi possível notar sinais de acentuada mobilização afetiva nas crianças e adolescentes em cuidados oncológicos, refreada por defesas psíquicas que atuam em prol do equilíbrio da pessoa diante do desafio do cuidado de saúde.

No conjunto de variáveis analisadas, ainda é possível reconhecer que a adoção de estratégias defensivas com base em mecanismos repressivos tendem a se manter ao longo do tempo nas crianças e adolescentes que adoeceram. Assim, como foi possível verificar na primeira etapa do estudo, duas variáveis vinculadas aos determinantes do Rorschach apresentaram diferença estatisticamente significativa entre os grupos na segunda avaliação: Cinestesia Animal (kan) e Soma das Pequenas Cinestesias. Embora altamente relacionadas, essas variáveis apontaram que o Grupo Clínico ofereceu menos respostas determinadas por movimentos animais ou por pequenas cinestesias em geral. É preciso interpretar esses achados de forma articulada e complementar, notando-se que trataram de diferenças identificadas nos grupos e que se relacionam ao uso do dinamismo interno. Nesse sentido, o Grupo de Comparação sinalizou maior número de respostas de movimento animal (kan) e na soma de pequenas cinestesias, sugestivos de maior espontaneidade e menor elaboração no processo de interpretação dos estímulos da realidade, quando comparados a crianças e adolescentes com câncer.

Japur e Jacquemin (1985) argumentaram que a variável $K$ (movimento humano) seria representante da vivência afetiva mais próxima do inconsciente, coordenada e dominada pelos recursos afetivos, ligada a movimentos introversivos da pessoa, correspondendo à expressão de sua capacidade de controlar e adiar a realização dos afetos. De modo complementar, o conjunto das pequenas cinestesias e o próprio kan revelaria que a pessoa dispõe de mais possibilidades para manifestar seus afetos e sentimentos no ambiente, usufruindo de espontaneidade e vivacidade, em uma vida imaginativa ainda por se desenvolver plenamente.

Ao refletir sobre as características próprias do desenvolvimento infantojuvenil, constata-se que a expressão dos afetos e de suas necessidades de modo autêntico e fluido é uma das marcas típicas da faixa etária. Assim, a diminuição de kan e da Soma das Pequenas Cinestesias, associada a preservação de $K$ no Grupo Clínico, sugere a ideia do esforço adaptativo que crianças e adolescentes empreendem ao serem mergulhados em um contexto permeado por elementos invasivos, como o tratamento oncológico.

Nas palavras de Anzieu (1981), a manutenção de $K$ entre crianças e adolescentes poderia ser compreendida como "os desejos não realizados na vida cotidiana. (...) A cinestesia 
representaria a vida imaginária, na medida em que esta constitui uma compensação para fracassos, privações e frustrações” (p. 76). Essa tendência a apresentar maior número de $K$ em G1 e diminuição de respostas de pequena cinestesia acompanharia a explanação de Bézy e Jalenques (2007) sobre a necessidade de pessoas que passam a conviver com o diagnóstico oncológico lançarem mão de estratégias de adaptação para lidar com rupturas e transformações em sua vida e cotidiano, com o intuito de se adaptarem à exigente realidade trazida pela doença neoplásica.

Em direção similar, Hildebrando, Clawson, Alderfer e Marsac (2011), argumentam que a tendência de diminuição da espontaneidade por parte da criança e do adolescente com câncer pode derivar de sua percepção de possível repercussão negativa de suas expressões afetivas no grupo sociofamiliar, principalmente sobre os pais. Os autores debatem que a restrição da demonstração dos medos, angústias, tristeza ou outros sentimentos que denunciem a fragilização do jovem paciente em face das adversidades trazidas pela experiência, foi uma tônica entre as famílias participantes de seu estudo. Assim, sugerem que se recorra à comunicação franca e aberta das vivências afetivas como uma das possibilidades de adaptação e elaboração da experiência.

Ademais, a análise dos indicativos de estrutura e dinâmica psíquica derivados da avaliação longitudinal dos colaboradores deste trabalho (tanto do G1 quanto de G2) vai de encontro com os estudos conduzidos por Patenaude e Kupst (2005); Phipps (2007); Wechsler e Sánchez-Iglesias (2013); Williams, Davis, Hancock, e Phipps (2010); Sharp, Lindwall, Wiliard, Long, Martin-Elbahesh e Phipps (2017). Segundo os autores, pacientes oncológicos pediátricos não demonstram diferenças robustas com relação aos recursos psíquicos e às estratégias adaptativas utilizadas, quando comparados a pessoas saudáveis de sua faixa etária. Eles também sinalizaram que indicadores de ansiedade, depressão ou estresse pós-traumático em crianças e adolescentes em tratamento oncológico mantêm o mesmo perfil epidemiológico de seu grupo de referência. Apontaram ainda que indicadores relativos à qualidade de vida em pacientes oncológicos pediátricos muitas vezes superam aqueles obtidos por crianças e adolescentes nunca expostos a tratamentos médicos intensivos.

Há outras investigações científicas da área de oncologia pediátrica no Brasil que trataram da trajetória de crianças e adolescentes acometidas por câncer, desde a comunicação diagnóstica, suas etapas de cuidado, até alcançarem o fim do tratamento e a sobrevida (Torres, 1997; Valle,1997). Neste tipo de trabalho é possível identificar sentidos e significados que estas pessoas atribuem a essas experiências, assim como repercussões afetivas em suas vivências, sobretudo diante de possíveis recidivas e diante da ameaça de impossibilidade de 
cura e finitude. As evidências empíricas apontam, nesses casos, a presença pungente de sofrimento e angústias ligadas a modificações corporais, rupturas do cotidiano, alterações na composição e dinâmica familiar, nas relações sociais significativas, na possibilidade de representar papéis sociais em diversos contextos, bem como o sofrimento devido aos procedimentos invasivos e o temor diante da morte. Nesses trabalhos não houve recurso a instrumentos sistemáticos de avaliação psicológica, limitando as possibilidades relacionais com os atuais achados empíricos.

No entanto, também foi possível identificar trabalho brasileiro que recorreu a métodos projetivos para avaliar crianças e adolescentes com câncer. Trata-se do estudo de Carvalho (2017), que lançou mão do Teste da Casa-Árvore-Pessoa (HTP) e do Desenho da Pessoa na Chuva, acrescido de entrevistas, para examinar um grupo de 30 crianças de sete a 13 anos, com diagnóstico oncológico, comparativamente a um grupo de pares saudáveis. Seus resultados apontaram que crianças diagnosticadas com doenças neoplásicas vivenciariam grande sobrecarga emocional, afastamento da realidade, dificuldades de obter satisfação em seu mundo, além de relevante desequilíbrio psíquico e adaptação frágil diante dos dissabores produzidos pelo cuidado oncológico. Nota-se um elemento de consistência entre essa investigação e o atual trabalho: refere-se à forte mobilização afetiva das crianças e adolescentes com câncer. Nas demais funções psicológicas consideradas na análise, no entanto, os achados são divergentes, o que pode estar associado à diversidade instrumental, bem como a especificidades das amostras consideradas nos dois estudos.

Considerações semelhantes as realizadas por Carvalho (2017) foram apresentadas por outro estudo desenvolvido no Brasil, como o conduzido por Rezende, Santos, Cerqueira, Viana e Modena (2013). Ao avaliarem 11 pacientes oncológicos entre cinco e 14 anos de idade utilizando técnica gráfica (desenho livre e desenho temático), identificaram sinais de necessidade de proteção e apoio, com vivências de isolamento e pouca vitalidade, além de mostrarem indícios de dificuldade no processo de adaptação e enfrentamento da experiência de adoecimento e cuidado hospitalar.

Já o trabalho desenvolvido por Bigheti e Valle (2008) avaliou cinco adolescentes em processo de cuidado oncológico, utilizando técnica gráfica de expressão, associada a interpretação Fenomenológica-Existencial da produção diante da versão reduzida do Teste de Apercepção Temática (TAT). As autoras puderam constatar que o período inicial de cuidado traz mais rupturas e modificações, além de importante carga de angústia associada à personificação da morte nas alterações corporais, nos procedimentos terapêuticos que causavam dor e perda da qualidade de vida, bem como na percepção diária acerca da 
vulnerabilidade humana. Tal trabalho ainda apontou que a partir da integração das limitações e sofrimentos, os adolescentes conseguem transcender a identidade de pessoa enferma, adaptando-se às vivências extremas com mais plenitude em suas escolhas, usufruindo de liberdade mesmo diante da impossibilidade da vida.

Apesar da variabilidade dos achados com os estudos que utilizaram métodos projetivos para a avaliação de variáveis ligadas a personalidade de crianças e adolescentes com câncer, ressalta-se que o fenômeno de adoecimento oncológico associado ao processo de cuidado de alta complexidade tende a produzir repercussões psíquicas. Apesar das estratégias metodológicas serem diversas nos referidos trabalhos, há certo consenso sobre a necessidade de adoção de esforços pessoais e sociofamiliares no sentido da elaboração positiva das vivências no processo de desenvolvimento de pessoas que experimentam o câncer infantojuvenil.

Neste sentido, Noll e Kupst (2012) argumentaram que as estratégias adaptativas empregadas por crianças e adolescentes em tratamento oncológico desencadeariam desfechos desenvolvimentais positivos. Esses indivíduos com câncer, ao se engajarem na experiência dolorosa e ao tentarem se ajustar às grandes transformações e sofrimentos inerentes ao tratamento oncológico, acabariam por desenvolver respostas positivas de superação da vivência de crise, mostrando-se resilientes. Assim, seria útil considerar, nesse tipo de pacientes, estratégias metodológicas que explorem achados subclínicos e singulares de cada criança ou adolescente, de modo a compreender especificidades deste fenômeno.

Ao integrarmos as informações sobre recursos familiares, repercussões das vivências parentais, percepção do cuidador principal acerca do impacto da atual experiência no comportamento e afetividade da criança e do adolescente, depreende-se predomínio de indicadores que apontam para o empreendimento de importantes esforços no sentido de buscar preservar, dentro do possível, o desenvolvimento saudável. Mesmo que expostos à intrincada gama de fatores de risco biológico, psíquico e social, com estressores que se originam do próprio processo de cuidado hospitalar e familiar e das alterações no dia a dia produzido pela assistência em saúde, crianças e adolescentes que compõem G1 expressaram similaridades a G2 em muitos indicadores de desenvolvimento racional e socioafetivo.

Ao levar em consideração as informações parentais sobre crianças e adolescentes com câncer, podemos refletir que, mesmo vivenciando potentes adversidades e estressores de múltiplas naturezas, os jovens pacientes contam com o suporte dos recursos da família, sejam materiais ou imateriais. Assim, tendem a desenvolver estratégias pessoais e sociais em busca 
da construção e obtenção de um horizonte de bem-estar, acompanhando as considerações de Walsh (2016) acerca da resiliência.

$\mathrm{Na}$ adoção desta perspectiva teórica, pode-se compreender a resiliência como "um sistema que, devido a um conjunto não exclusivo de recursos internos a si-próprio, é capaz de funcionar normalmente, apesar de exposto a um contexto de estresse significativo" (Koller, Antoni \& Capena, 2012, p. 162). Sendo assim, a relação que se estabelece entre o contexto de cuidado oncológico no qual a criança e o adolescente se inserem, e as respostas adaptativas oferecidas pela dialogia entre o grupo familiar e o universo psíquico do jovem paciente, repercutiria de forma a ser caracterizado um processo de resiliência, mesmo em face de desafios de grande magnitude.

Vale considerar que esses achados derivam da amostra de conveniência obtida pelos pacientes atendidos em um serviço especializado e de referência para o tratamento de câncer. Nesse contexto, desde o princípio do processo de investigação diagnóstica, tal qual por todo o percurso de cuidado, tanto o paciente pediátrico quanto seus familiares são acompanhados por equipe de saúde multidisciplinar especializada no ambiente hospitalar, havendo possibilidade de articulação com outros dispositivos e equipamentos sociais dispostos na rede de atenção em saúde e em termos sociais. Deste modo, mesmo que o hospital possa ser identificado como fonte de sofrimento e risco ao desenvolvimento, devido a assistência profissional prestada, ele transita sua identidade para um importante aparato de proteção e apoio. Assim, propicia elaboração da experiência de sofrimento, bem como a preservação e estimulação positiva ao desenvolvimento, dentro daquilo que se reconhece como esperado para o grupo de referência (Crepaldi, Rabuske \& Gabarra, 2006).

A partir das considerações precedentes e dos atuais achados pode-se considerar como variáveis com função protetora no contexto dos cuidados oncológicos: suporte familiar adequado, bom aproveitamento dos recursos físicos em prol da estimulação do brincar e da aprendizagem de conteúdos escolares e do saber humano, aliado a presença dos pais e familiares que podem mediar o mundo a sua volta em interações marcadas pelo zelo, pelo suporte ostensivo, e pela manutenção da dinâmica típica do grupo de origem. A percepção de apoio que o cuidador tem de sua família, assim como o reconhecimento da necessidade de que também deve ser alvo de cuidado, completam um quadro de condições que podem favorecer o desfecho positivo no processo de adaptação e elaboração psíquica da criança e do adolescente frente ao câncer.

Há que destacar, por fim, que o desenho longitudinal deste estudo possibilitou examinar a estabilidade da maioria das variáveis pertinentes às distintas dimensões avaliadas 
tanto com relação a família, quanto na vida do jovem paciente. Estes achados sugerem que nos meses iniciais do processo de cuidado oncológico há maior repercussão e desestabilização da família e do paciente pediátrico, provavelmente por serem defrontados com a necessidade de lidarem com angústias e incertezas de vida e de morte, a adaptação à instituição hospitalar e ao cuidado em saúde, bem como as alterações em diversos âmbitos da vida social. No transcorrer do intervalo entre as duas avaliações (pelo menos seis meses), sinalizaram buscar ativamente a reestruturação do grupo familiar e do funcionamento psíquico. Foi possível identificar esforços adaptativos de crianças e adolescentes que convivem com o diagnóstico oncológico, sendo possível apontar para a efetividade das estratégias psíquicas adotadas, favorecedoras de positivo percurso em seu desenvolvimento. 

A vivência do adoecimento e cuidado oncológico na infância e adolescência envolvem adversidades de natureza biológica, psicológica e social, constituindo-se como importante desafio ao desenvolvimento tanto da pessoa que padece em tenra idade quanto de seus familiares. Nesse contexto, este trabalho buscou investigar possíveis efeitos longitudinais deste processo de assistência oncológica em saúde sobre a dinâmica da família e dos recursos das crianças/adolescentes. Desse modo, procurou-se ainda examinar como os pais percebem indicativos de saúde mental de seus filhos, bem como eventuais repercussões da convivência com a neoplasia pediátrica sobre as características de personalidade.

Em síntese, no primeiro momento avaliativo, tanto crianças e adolescentes com câncer, quanto seus pais, sinalizaram indicadores de alteração no quadro geral de saúde quando comparadas a seus pares hígidos, verificando-se em acréscimo rupturas sociais significativas na vida social do jovem paciente. Apesar desse contexto, associado ao diagnóstico e às rotinas de cuidado hospitalar para o câncer, foi possível identificar preservação dos recursos familiares, tanto materiais quanto de sua capacidade de interagir e acompanhar o cotidiano da criança e do adolescente.

No segundo momento avaliativo (após intervalo mínimo de seis meses da avaliação inicial), percebeu-se tendência das famílias que convivem com o câncer pediátrico aproveitarem menos seus recursos do ambiente físico, provavelmente derivado de interdições pertinentes ao processo de cuidado da criança/adolescente, diminuindo exposição a riscos físicos e patogênicos. Com o passar do tempo de cuidados hospitalares, as condições de vida da criança e da família acumularam adversidades advindas da intensa convivência com a morte, com repercussões na saúde mental dos pais, diminuição do convívio social, além de conflitos familiares e conjugais.

Apesar destas repercussões, no tocante a percepção do cuidador principal acerca do apoio recebido de sua família, foi possível avaliar que não houve diferenças estatisticamente significativas entre genitores de crianças e adolescentes com ou sem diagnóstico oncológico, nem mesmo com o transcorrer do tempo entre os dois exames. Isto seria indicativo de preservação da sensação de acolhimento, autonomia, diálogo e valorização do familiar que foi investido do papel de líder do processo de cuidado, apontando para a adoção de positivas estratégias familiares para lidar com o universo da oncologia pediátrica.

Com relação à percepção dos pais acerca dos indicadores de saúde mental de seus filhos, o Grupo Clínico apontou mais sinais de comprometimento emocional, comportamental e social. Isto equivale a afirmar que, sob a ótica dos cuidadores familiares, os jovens pacientes vivenciaram mobilização afetiva diante do adoecimento oncológico que impactou 
negativamente seu equilíbrio psíquico, com manifestações intensas de medo e angústia, desestabilizando suas interações. No entanto, há que se considerar que, diante da imprevisibilidade proveniente do processo de cuidado oncológico, faz-se natural a identificação desse tipo de reação infantojuvenil.

Apesar dos apontamentos parentais convergirem para a percepção de repercussão desfavorável em alguns indicadores psicossociais de crianças e adolescentes com câncer, foi possível avaliar estabilidade destes apontamentos em uma perspectiva longitudinal. Ou seja, conseguem atingir um patamar de equilíbrio psíquico nesse contexto adverso ao desenvolvimento, ainda que existam marcas de impacto socioafetivo das vivências associadas ao câncer e seu tratamento. Cabe nesse momento destacar que os familiares referiram preservação dos processos de atenção, percepção, consideração de regras sociais e engajamento nas relações interpessoais, comparativamente a padrões reconhecidos em crianças saudáveis. Reafirmam-se, portanto, evidências empíricas das potencialidades das crianças e dos adolescentes para dar continuidade a seu natural processo de desenvolvimento, o que merece o devido apoio familiar e da equipe de cuidadores para seu fortalecimento e concretização.

A avaliação dos indicadores relativos à personalidade apontou que crianças e adolescentes dos distintos grupos apresentaram mais semelhanças do que especificidades. Evidenciaram preservar os processos de captação e de discriminação dos estímulos da realidade, mantendo contato mais intuitivo com o mundo a sua volta, além de compartilhar a forma de pensar de seus semelhantes, favorecendo a adaptação sociointelectual. Tanto os colaboradores de G1 quanto de G2 mostraram sinais de boa integração da racionalidade e do pensamento formal, constituindo-se em valoroso recurso de coordenação dos impulsos e afetos, bem como das ansiedades e angústias.

Foi possível identificar, pelos achados atuais, que crianças e adolescentes com câncer preferencialmente lançam mão de recursos de racionalização para lidar com as repercussões emocionais de sua realidade, tendendo a inibir expressões socioafetivas. Deste modo, sinalizaram um estilo adaptativo repressivo como forma recorrente de busca de equilíbrio diante das tensões internas e vivências externas ameaçadoras, associadas ao câncer e seus cuidados.

Apesar da hipótese inicial deste trabalho considerar a existência de alterações significativas na dinâmica e na formação de características de personalidade de crianças e adolescentes que convivem com o cuidado oncológico, isso não foi aqui confirmado. Assim, ao examinar os achados derivados de avaliações realizadas em dois momentos distintos, 
percebeu-se prioritariamente indicadores de adequação dos esforços adaptativos de crianças e adolescentes que convivem com o câncer. Foi possível apontar para a efetividade das estratégias psíquicas adotadas, favorecedoras de positivo percurso em seu desenvolvimento, ou seja, evidenciaram similaridades e acompanharam os processos adaptativos presentes no grupo de comparação.

Faz-se necessário reconhecer que a variabilidade da faixa etária dos participantes do presente trabalho (de sete a 17 anos), bem como a própria variabilidade interna existente no grupo clínico (em termos diagnósticos e do próprio tempo e tipos de tratamento) impõem fortes limites aos achados desse amplo processo investigativo. Nesse sentido, novas pesquisas no campo se mostram necessárias, preferencialmente considerando estas variáveis. Assim, seria importante examinar possíveis especificidades da repercussão do adoecimento e cuidado oncológico sobre as distintas etapas do desenvolvimento, bem como das diferentes fases e tipos de tratamento. Não se mostrou viável, na realidade estudada, o controle adequado desse conjunto de variáveis intervenientes, impondo obrigatória cautela em tentativas de generalização dos atuais achados.

Há, ainda, que apontar que o serviço de Oncologia Pediátrica, onde foram recrutados os participantes do Grupo Clínico, possui estrutura e funcionamento exemplares nesse campo da Saúde. Ou seja, os resultados encontrados ilustram os impactos socioafetivos do câncer e de seu tratamento nesse contexto institucional altamente protegido e qualificado, onde variáveis familiares e psicossociais são também cuidadas, oferecendo estímulos à minimização dos impactos negativos ao desenvolvimento infanto-juvenil. Seria relevante, desse modo, examinar as variáveis estudadas nesse trabalho em outros serviços de Oncologia Pediátrica do Brasil, de modo a ser possível avaliar os efeitos do câncer e de seu tratamento em crianças e adolescentes.

Por fim, como metáfora aos achados deste estudo, podemos considerar as reflexões do eminente astrofísico Carl Sagan (1934 - 1996) a respeito da pertinência das explorações espaciais com intuito de conhecer outros sistemas planetários e galáxias, bem como encontrar outras existências fora de nosso orbe. Segundo o cientista, a razão por continuar nessa incessante procura se deve ao benefício da observação das aparentes leis da natureza e do funcionamento do cosmos para a compreensão da espécie humana. Em suas palavras, "vida busca a vida".

Deste modo, foi possível empiricamente apontar aqui a busca que crianças e adolescentes empreendem visando reestabelecer condições adequadas de desenvolvimento, mesmo frente às alterações no curso de sua biografia associadas ao adoecimento e 
hospitalização. Diante das pressões advindas do próprio corpo, do ambiente doméstico e relações familiares, do confronto com degeneração de experiências sociais, ameaça de finitude da própria existência, crianças e adolescentes com câncer sinalizaram recursos de adaptação para reaver a vida conhecida antes do diagnóstico de câncer. Assim, esforçam-se para reestabelecer a vida mesmo quando isto parece um intenso desafio.

Como finalização para esse trabalho cabe, portanto, destacar sua contribuição para o campo da Psico-Oncologia Pediátrica. Foi possível aqui documentar, a partir de achados empíricos, a pertinência da vigência de cuidados profissionais voltados à dinâmica familiar, saúde mental e condicionantes socioeconômicos dos pais e familiares que convivem com a criança ou adolescente com câncer, em associação direta com os próprios pacientes. A promoção de estratégias de apoio que levem em consideração o aproveitamento de recursos de suporte familiar, além da assistência especializada multiprofissional e interdisciplinar que reconheça as necessidades socioafetivas do paciente oncológico pediátrico, se mostrou relevante para proteger e promover adaptação e superação de eventos adversos e vulnerabilizantes, abrindo caminho para positivos desfechos no processo de desenvolvimento. 

Alderfer, M. A.; Long, K. A.; Lown, E. A.; Marsland, A. L.; Ostrowski, N. L.; Hock, J. M. \& Ewing, L. J. (2010). Psychosocial adjustment of siblings of children with cancer: a systematic review. Psycho-Oncology, 19(8), 789-805.

Alves, D. F. S.; Guirardello, E. B. \& Kurashima, A. Y. (2013). Estresse relacionado ao cuidado: o impacto do câncer infantil na vida dos pais. Revista Latino-Americana de Enfermagem, 21(1), 356-362.

Amador, D. D.; Gomes, I. P., Reichert, A. P. S. \& Collet, N. (2013). Repercussões do câncer infantil para o cuidador familiar: revisão integrativa. Revista Brasileira de Enfermagem, 66(2), 267-270.

Anaby, D.; Hand, C.; Bradley, L.; DiRezze, B.; Forhan, M.; DiGiacomo, A. \& Law, M. (2013). The effect of the environment on participation of children and youth with disabilities: a scoping review. Disability and Rehabilation, 35(19), 1589-1598.

Angelini, A. L., Alves, I. C. B., Custódio, E. M., Duarte, W. F., \& Duarte, J. L. M. (1999). Manual matrizes progressivas coloridas de Raven: escala especial. São Paulo: Centro Editor de Testes e Pesquisas em Psicologia.

Andréa, M. L. M. (2008). Oncologia pediática. In: Carvalho, V. A.; Franco, M. H. P.; Kovács, M. J.; Liberato, R. et al (Orgs.). Temas em Psico-Oncologia (pp. 477- 495). São Paulo: Summus.

Ariés, P. (1986). História social da criança e da família. Rio de Janeiro: Companhia das Letras.

Askins, M. A. \& Moore, B. D. (2010). Preventing Neurocognitive Late Effects in Childhood Cancer Survivors. Jornal of Child Neurology, 23(10), 1160-1171.

Anzieu, D. (1986). Os métodos projetivos. (M. L. E. Silva, trad.). (5a ed.). Rio de Janeiro: Campus.

Associação Brasileira de Empresas de Pesquisa - ABEP (2013). Critério de Classificação Econômica Brasil (CCEB). Disponível em http://www.abep.org/criterio-brasil, acesso realizado em 12/01/2015.

Baptista, M. N. (2005) Desenvolvimento do Inventário de Percepção de Suporte Familiar (IPSF): estudos psicométricos preliminares. Psico-USF, 10(1), 11-19. 
Baptista, M. N (2010). Inventário de Percepção do Suporte Familiar - Manual. São Paulo: Editora Vetor.

Baptista, M. N.; Rueda, F. J. M. \& Brandão, E. M. (2017). Suporte familiar e autoconceito infantojuvenil em acolhidos, escolares e infratores. Psicologia em Pesquisa, 11(1), 5564.

Barr, R. D.; Feeny, D. \& Furlong, W. (2004). Economic evaluation of treatments for cancer in childhood. European Journal of Cancer, 40(9), 1335-1345.

Beck, A. R. M. \& Lopes, M. H. B. M. (2007). Cuidadores de crianças com câncer: aspectos da vida afetados pela atividade de cuidador. Revista Brasileira de Enfermagem, 60(6), 670-675.

Bézy, O. \& Jalenques, I (2007). De la spécificité du cancer et de ses effets psychiques. Annales Médico-psychologiques, revue psychiatrique, 165(2), 132-135.

Bigheti, A. \& Valle, E. R. M. (2008). Compreendendo as vivências de adolescentes com câncer: análise Fenomenológica do TAT. In: Carvalho, V.A.; Franco, M. H. P.; Kovács, M. J.; Liberato, R. et al. (Orgs.), Temas em psico-oncologia (pp. 218-232). São Paulo: Summus.

Blum, R. W. (1997). Risco e resiliência: sumário para o desenvolvimento de um programa. Adolescência Latinoamericana, 1(1), 16-19.

Bolsoni-Silva, A. T., \& Loureiro, S. R. (2011). Práticas educativas parentais e repertório comportamental infantil: comparando crianças diferenciadas pelo comportamento. Paidéia (Ribeirão Preto), 21(48), 61-71.

Brasil (2006). Lei ${ }^{\circ}$ 11.340. O reconhecimento legal do conceito moderno de família - Lei Maria da Penha. Brasília: Presidência da República.

Brasil. Ministério da Saúde. Instituto Nacional de Câncer \& Instituto Ronald McDonald (2009). Diagnóstico precoce do câncer na criança e no adolescente. Rio de Janeiro: INCA.

Brasil. Ministério da Saúde. Instituto Nacional de Câncer (2016). Estimativa 2016: incidência de câncer no Brasil. Rio de Janeiro: INCA. 
Bronfenbrenner, U. (1996). A ecologia do desenvolvimento humano: experimentos naturais e planejados. São Paulo: Artes Médicas.

Bronfenbrenner, U. (2011). Biotecnologia do desenvolvimento humano. Porto Alegre: Artmed.

Camargo, B. \& Kurashima, A.Y. (2007). Considerações em oncologia pediátrica. In: Camargo, B. \& Kurashima, A.Y. (Orgs.). Cuidados paliativos em oncologia pediátrica: o cuidar além do curar (pp. 23-37). São Paulo: Lemar.

Camargo, B.; Lopes, L. F.; \& Novaes, P. E. (2000). O tratamento multidisciplinar das neoplasias na infância. In: Camargo, B. \& Lopes, L. F. (Orgs.). Pediatria Oncológica: noções fundamentais para Pediatria (pp. 215-229). São Paulo: Lemar.

Camponero, R. (2008). Biologia do câncer. In: Carvalho, V.A.; Franco, M. H. P.; Kovács, M. J.; Liberato, R. et al. (Orgs.), Temas em psico-oncologia (pp. 32-39). São Paulo: Summus.

Capitão, C. G.; Lopes, F.; Silva, M. A. \& Adib, S. A. (2012). O Teste de Pfister e indicadores de depressão em adolescentes. Encontro - Revista de Psicologia, 15(23), 59-72.

Carvalho, A. C. (2017). A criança e o câncer: expressões emocionais envolvidas no processo de adoecimento. Dissertação de Mestrado, Universidade de São Paulo, São Paulo, SP, Brasil.

Children's Oncology Group (2013). Long-Term Follow-Up Guidelines for Survivors of Childhood, Adolescent, and Young Adult Cancers, Version 4.0. Disponível em http://www.survivorshipguidelines.org/, acessado em 18/6/2017.

Cicchetti, D. \& Rogosch, F. A. (2002). A Developmental Psychopathology Perspective on Adolescence. Journal of Consulting and Clinical Psychology, 70(1), 6-20.

Cicogna, E. C., Nascimento, L. C., \& Lima, R. A. G. (2010). Crianças e adolescentes com câncer: experiências com a quimioterapia. Revista Latino-Americana de Enfermagem, 18(5), 864-872.

Clercq, B. D.; Fruyt, F. D.; Koot, H. M.; \& Benoit, Y. (2004). Quality of life in children surviving cancer: a personality and multi-informant perspective. Journal of Pediatric Psychology, 29(8), 579-590. 
Compas, B. E., Desjardins, L., Vannatta, K., Young-Saleme, T., Rodriguez, E. M., Dunn, M., ... Gerhardt, C. A. (2014). Children and Adolescents Coping With Cancer: Self- and Parent Reports of Coping and Anxiety/Depression. Health Psychology: Official Journal of the Division of Health Psychology, American Psychological Association, 33(8), 853861.

Crepaldi, M. A.; Rabuske, M. M. \& Gabarra, L. M. (2006). Modalidades de atuação do psicólogo em psicologia pediátrica. In: Crepaldi, M. A; Linhares, M. B. M. \& Perosa, G. B. (Orgs.), Temas em psicologia pediátrica (pp. 13-56). São Paulo: Casa do Psicólogo.

Creswell, P.D.; Wisk, L.E.; Litzelman, K.; Allchin, A. \& Witt, W. P. (2014). Parental depressive symptoms and childhood cancer: the importance of financial difficulties. Support Care Cancer, 22(2), 503-511.

Cury-Jacquemin, R. (2012). Padrões normativos do Psicodiagnóstico de Rorschach em adolescentes de 12 a 14 anos. Dissertação de Mestrado, Universidade de São Paulo, São Paulo, SP, Brasil.

D’Avila-Bacarji, K. M. G.; Marturano, E. M. \& Elias, L. C. S. (2005). Recursos e adversidades no ambiente familiar de crianças com desempenho escolar pobre. Paidéia, 15(30), 43-55.

Dejong, M. \& Fobonne, E. (2006). Depression in pediatric cancer: an overview. PsychoOncology, 15(7), 553-566.

Diehl, M \& Hay, E. L. (2013). Personality-related risk and resilience factors in coping with daily stress among adult cancer patients. Research in Human Development, 10 (1), 47-69.

Durualp, E. \& Altay, N. (2012). A comparison of emotional indicators and depressive symptom levels of school-age children with and without câncer. Journal of Pediatric Oncology Nursing, 29(4), 232-239

Eiser, C.; Eiser, J. R.; \& Stride, C. B. (2005). Quality of life in children newly diagnosed with cancer and their mothers. Health and Quality of Life Outcomes, 3(29).

Emmanuelli, M. \& Azoulay, C. (2008). As técnicas projetivas na adolescência: abordagem psicanalítica. São Paulo: Vetor.

Fan, S. Y. \& Eiser, C. (2009). Body image of children and adolescents wih câncer: a systematic review. Body Image, 6(4), 247-256. 
Fernandes, S. (2010). Normas do Rorschach em crianças de seis a oito anos. Dissertação de Mestrado, Universidade de São Paulo, São Paulo, SP, Brasil.

Ferriolli, S. H. T., Marturano, E. M. \& Puntel, L. P. (2007). Contexto familiar e problemas de saúde mental infantil no Programa Saúde da Família. Revista de Saúde Pública,41(2), 251-259.

Fleitlich, B.; Cortázar, P. G. \& Goodman, R. (2000). Questionário de Capacidades e Dificuldades (SDQ). Infanto - Revista de Neuropsiquiatria da Infância e Adolescência, 8, 44-50.

Flores-Mendoza, C. E., Bacelar, T. D., Widaman, K. F., \& Lele, A. (2014) Propriedades psicométricas do Raven Geral no contexto de Minas Gerais. Arquivos Brasileiros de Psicologia, 66, 1-16.

Françoso, L. P. C. (2005). Vivências de crianças com câncer no grupo de apoio psicológico: estudo fenomenológico. Tese de Doutorado, Universidade de São Paulo, São Paulo, SP, Brasil.

Gesel, A. (1998). A Criança dos 5 aos 10 anos. São Paulo: Martins Fontes.

Goldsby, R. E.; Liu, Q.; Nathan, P. C.; Bower, D. C.; ... Packer, R. J. (2010). Late-Occurring Neurologic Sequelae in Adult Survivors of Childhood Acute Lymphoblastic Leukemia: A Report From the Childhood Cancer Survivor Study. Journal of Clinical Oncology, 28(2), 324-331.

Gomes, I. P.; Lima, K.A.; Rodrigues, L.V.; Lima, R. A.G. \& Collet, N. (2013). Do diagnóstico à sobrevivência do câncer infantil: perspectiva de crianças. Texto \& Contexto Enfermagem, 22(3), 671-679.

Goodman, R. (1997). The strenghts and difficulties questionnaires: a research note. Journal of Child Psychology and Psychiatry, 38(5), 581-586.

Grabois, M. F.; Oliveira, E. X. G. \& Carvalho, M. S. (2013). Assistência ao câncer entre crianças e adolescentes: mapeamento dos fluxos origem-destino no Brasil. Revista Saúde Pública, 47(2), 368-378.

Guelli, A. V.; Jacquemin, A. \& Santos, M. A. (2009). Análise dos conteúdos de Rorschach de pacientes com distúrbio afetivo bipolar. Medicina Ribeirão Preto, 29(2), 269-277. 
Harper, F. W. K; Goodlett, B. D.; Trentacosta, C. J.; Albrecht, T. L.; Taub, J. W.; Phipps, S. \& Penner, L. A. (2014). Temperament, Personality, and Quality of Life in Pediatric Cancer Patients. Journal of Pediatric Psychology, 39 (4), 459-468.

Harper, F.W.K.; Penner, L.A.; Peterson, A.; Albrecht, T.L. \& Taub, J. (2012). Children's positive dispositional attributes, parents' empathic responses, and children's responses to painful pediatric oncology treatment procedures. Journal of Psychosocial Oncology, 30(5), 593-613.

Hildenbrand, A. K.; Clawson, K. J.; Alderfer, M. A. \& Marsac, M. L. (2011). Coping with pediatric cancer: strategies employed by children and their parents to manage cancerrelated stressors during treatment. Journal of Pediatric Oncology Nursing, 28(6), 344 354.

Hospital do Câncer. (2003). Crianças com câncer: o que devemos saber? São Paulo: Comunique Editorial.

Husson, O.; Zebrack, B. J.; Block, R.; Embry, L.; Aguilar, C.; Hayes-Lattin, B. \& Cole, S. (2017). Health-related quality of life in adolescent and young adult patients with cancer: a longitudinal study. Journal of Clinical Oncology, 35(6), 652-659.

Japur, M. \& Jacquemin, A. (1985). O Psicodiagnóstico de Rorschach: estudo das Fórmulas Vivenciais e dos índices de Conflitos em pré-adolescentes. Arquivos Brasileiro de Psicologia, 37(2), 145-155.

Jardim-Maran, M. L. C. (2011). O Psicodiagnóstico de Rorschach em adolescentes: Normas e evidências de validade. Tese de doutorado, Universidade de São Paulo, São Paulo, SP, Brasil.

Kadan-Lottick, N. S.; Zeltzer, L. K.; Liu, Q.; Yasui, Y.; Ellenberg, L. Gioia, G.; Robison, L. L. \& Krull, K. R. (2010). Neurocognitive Functioning in Adult Survivors of Childhood Non-Central Nervous System Cancers. Journal of the National Cancer Institutei, 102(12), 881-893

Kleim, M. C.; Lehmann, V.; Shultz, E. L.; Winning, A. M.; Rausch, J. R. ... Gerhardt, C. A. (2017). Parent-child communication and adjustment among children with advanced and nonadvanced cancer in the first year following diagnosis or relapse. Journal of Pediatric Psychology, 42(8), 871-881.

Kohlsdorf, M \& Costa Junio, A. L. (2008). Estratégias de enfrentamento de pais e crianças em tratamento de câncer. Estudos de Psicologia (Campinas), 25(3), 417-429. 
Kohlsdorf, M. \& Costa Junior, A. L. (2011). Cuidadores de crianças com leucemia: exigências do tratamento e aprendizagem de novos comportamentos. Estudos de Psicologia (Natal), 16(3), 227-234.

Koller, S.; De Antoni, C. \& Carpena, M. E. F. (2012) Famílias de crianças em situação de vulnerabilidade social. In: Baptista, M. N. \& Teodoro, M. L. M. (Orgs.). Psicologia de família: teoria, avaliação e intervenção. (pp. 156-167). Porto Alegre: Artmed.

Kurtz, B.P. \& Abrams A.N. (2011) Psychiatric aspects of pediatric cancer. Pediatric Clinics of North America, 58(4), 1003-1023.

Ladeia, F.T.; Castro, D. G.; \& Filho, M.A.M. (2010). Princípios da radioterapia. In: Bifulco, V.A.; Júnior, H. J.F. \& Barboza, A.B. (Orgs.). Câncer: uma visão multiprofissional (pp. 177-199). São Paulo: Manole.

Landolt, M.A.; Vollrath, M.; Niggli, F.K.; Gnehm, H. E.; \& Sennhauser, F.H. (2006). Healthrelated quality of life in children with newly diagnosed cancer: a one year follow-up study. Health and Quality of Life Outcomes, 3(29).

Lee, M. Y.; Mu, P. F.; Tsay, S. F.; Chou, S. S.; Chen, Y. C. \& Wong, T. T. (2012). Body image of children and adolescents with cancer: a metasynthesis on qualitative research findings. Nursing \& Health Sciences, 14(3), 381-390.

Lopes, D. P. L. O. \& Vale, E. R. M. (2010). A organização familiar e o acontecer do tratamento da criança com câncer. In: Valle, E. R. M. (Org). Psico-Oncologia Pediátrica (pp. 13-74 ). Casa do Psicólogo: São Paulo.

Loureiro, S.R. \& Romaro, R.A. A (1985). Utilização das Técnicas Projetivas. Bateria de Grafismo de Hammer e Desiderativo como instrumentos de diagnóstico - estudo preliminar. Arquivos Brasileiros de Psicologia, 37(3), 132-41.

Luthar, S. S.; Cicchetti, D. \& Becker, B. (2000). The construct of resilience a critical evaluation and guidelines for future work. Child Development, 71(3), 543-562.

Marôco, J. (2011). Análise estatística com o SPSS Statistics. Pero Pinheiro, Portugal: ReportNumber.

Marques-Camargo, A. R. (2014). Experiência financeira de famílias no cuidado de crianças e adolescentes com câncer. Dissertação de Mestrado. Universidade de São Paulo, São Paulo, SP, Brasil. 
Marturano, E.M. (1999). Recursos no ambiente familiar e dificuldades de aprendizagem na escola. Psicologia, Teoria e Pesquisa, 15(2), 135-142.

Marturano, E. M. (2006). O inventário de recursos do ambiente familiar. Psicologia: Reflexão e Crítica, 19(3), 498-506

Masten, A.S. (2001). Ordinary magic: resilience processes in development. American Psychologist, 56(3), 227-238.

McWillians, N. (2014). Diagnóstico Psicanalítico. Porto Alegre: Artmed.

Miller, K.S.; Vannatta, K.; Compas, B.E.; Vasey, M.; McGoron, K.D.; Salley, C.G. \& Gerhardt, C.A. (2009). The Role of Coping and Temperament in the Adjustment of Children with Cancer. Journal of Pediatric Psychology, 34(10), 1135-1143.

Mitchell, W.; Clarke, S.; \& Sloper, P. (2006). Care and support needs of children and young people with cancer and their parents. Psycho-Oncology, 15(9), 805-816.

Mombelli, M. A.; Costa, J. B.; Marcon, S. S. \& Moura, C. B. (2011). Estrutura e suporte familiar como fatores de risco de stress infantile. Estudos de Psicologia, 28(3), 327-335.

Morilla, C. M.; Caldas, C. A. C. T.; Scarpellini, A. C. A. V. \& Santos, P. L. (2017). Family resources and promotion of development of children with cerebral palsy. Journal of Human Growth and Development, 27(2), 166-174.

Murphy, L. M. B.; Flowers, S.; McNamara, K. A. \& Young-Saleme, T. (2008). Fathers of children with cancer: involvement, coping, and adjustment. Journal of Pediatric Health Care, 22(3), 182-189.

Nascimento, L. C.; Rocha, S. M. H.; Hayes, V. H. \& Lima, R. A. G. (2005). Crianças com câncer e suas famílias. Revista da Escola de Enfermagem da USP, 39(4), 469-474.

Neves, G. R. (2013). Princípios da quimioterapia em Oncologia Pediátrica. In: Melaragno, R \& Camargo, B. (Orgs). Oncologia Pediátrica: diagnóstico e tratamento (pp. 37-48). Atheneu: São Paulo.

Noll, R. B. \& Kupst, M. J. (2007). Commentary: The Psychological Impact of Pediatric Cancer Hardiness, the Exception or the Rule? Journal of Pediatric Psychology, 32(9), 1089-1098. 
Okado, Y.; Tillery, R.; Sharp, K. H.; Long, A. M. \& Phipps, S. (2016). Effects of time since diagnosis on the association between parent and child distress in families with pediatric câncer. Journal of Child Health Care, 45(3), 303-322.

Paludo, S.S. \& Koller, S. H. (2005). Resiliência na rua: um estudo de caso. Psicologia: Teoria e Pesquisa, 21(2), 187-195.

Papalia, D.E.; Olds, S.W. \& Feldman, R.D. (2006). Sobre o desenvolvimento humano. In: Papalia, D.E.; Olds, S.W. \& Feldman, R.D. (Orgs.). Desenvolvimento Humano (pp. 45200). Porto Alegre (RS): Artmed.

Pasian, S. R., Barroso, J. B., \& Theodozio, D. R. (2014). O Teste de Pfister na adolescência. In A. E. Villemor-Amaral. As Pirâmides de Pfister com Crianças e Adolescentes (pp. 107-126). São Paulo: Casa do Psicólogo.

Patenaude, A. F. \& Kupst, M. J. (2005). Psychosocial functioning in pediatric câncer. Journal of Pediatric Psychology, 30(1), 9-27.

Peçanha, D.L.N. (2008). Câncer: recursos de enfrentamento na trajetória da doença. $\underline{I n}$ : Carvalho, V.A.; Franco, M. H. P.; Kovács, M.J.; Liberato, R. et al (Orgs). Temas em Psico-Oncologia (pp. 209- 207). São Paulo: Summus.

Peres, R. S. \& Santos, M. A. (2009). Personalidade e câncer de mama: produção científica em Psico-Oncologia. Psicologia: Teoria e Pesquisa, 25(4), 611-620.

Phipps, S. (2007). Adaptive style in children with cancer: implications for a positive psychology approach. Journal of Pediatric Psychology, 32(9), 1055-1066.

Pizeta, F. A. (2009). Depressão materna associada a múltiplos estressores e a socialização de crianças em idade escolar. Dissertação de Mestrado. Universidade de São Paulo, São Paulo, SP, Brasil.

Poletto, M. \& Koller, S. H. (2011). Resiliência: uma perspectiva conceitual e histórica. In: \& Dell'Aglio, D.D.; Koller, S.H. \& Yunes, M.A.M. (Orgs.). Resiliência e Psicologia Positiva: interfaces do risco à proteção. (pp. 19-44). São Paulo: Casa do Psicólogo.

Raspantini, R. L. (2010). Psicodiagnóstico de Rorschach em crianças de 9 a 11 anos: um estudo normativo. Dissertação de Mestrado, Universidade de São Paulo, São Paulo, SP, Brasil. 
Rausch de Traubenberg, N. (1998). A prática do Rorschach. (A. J. Lelé, trad.). São Paulo: Vetor.

Reich, M. (2009). Cancer et image du corps: identité, représentation et symbolique L'information Psychiatrique 3(85), 247-254.

Reis, R.S.; Santos, M.O.; \& Thuler, L.C.S. (2007). Incidência de tumores pediátricos no Brasil. Revista Brasileira de Cancerologia, 53(1), 5-15.

Rezende, A. M.; Santos, P. P.; Cerqueira, A. C. M.; Viana, J. L. \& Modena, C. M. (2013). A criança e o adolescente com câncer em Casa de Apoio: projetando vivências. Revista da Sociedade Brasileira de Psicologia Hospitalar, 16(1), 3-32.

Robinson, K. E.; Gerhardt, C. A.; Vannatta, K. \& Noll, R. B. (2007). Parent and family factors associated with child adjustment to pediatric câncer. Journal of Pediatric Psychology, 32(4), 400-410.

Rosemberg, A. R.; Baker, K. S.; Syrjala, K. L., Back A. L. \& Wolfe, J. (2013). Promoting resilience among parents and caregivers of children with câncer. Journal of Palliative Medicine, 16(6), 645-652.

Rosenberg, A. R.; Wolfe, J.; Bradford, M. C.; Shaffer, M. L.; Yi-Frazier, J. P.; Curtis, J. R.; Syrjala, K. L. \& Baker, K. S. (2014). Resilience and Psychosocial Outcomes in Parents of Children With Cancer. Pediatric Blood Cancer, 61(3), 552-557

Rutter, M. (1985). Resilience in the face of adversity: protective factors and resistance to psychiatric disorder. British Journal of Psychiatry, 147, 598-611.

Samerrof, A. J. (2000). Developmental systems and psychopathology. Development and Psychopathology, 2000(12), 297-312.

Saint Jude Children's Research Hospital. (2010). Oncopedia. Retrieved February 2, 2010, from http://www.cure4kids.org/ums/oncopedia/

Santos, A. A. A; Martineli, S. C. \& Monteiro, R. M. (2012). Suportes e recursos familiares: relações com o contexto escolar. In: Baptista, M. N. \& Teodoro, M. L. M. (Orgs), Psicologia da família: teoria, avaliação e intervenção (p. 136-144). Porto Alegre: Artmed. 
Santos, L. L. \& Dell'Aglio, D. D. (2011). A constituição de moradas nas ruas como processo de resiliência em adolescentes. In: Dell'Aglio, D.D.; Koller, S.H. \& Yunes, M.A.M. (Orgs.). Resiliência e Psicologia Positiva: interfaces do risco à proteção. (pp. 203-231). São Paulo: Casa do Psicólogo.

Santos, M. A. (2000). A representação de si na esquizofrenia através do psicodiagnóstico de Rorschach. Paidéia, 10(19): 67-81.

Sapienza, G. \& Pedromônico, M. R. M. (2005). Risco, proteção e resiliência no desenvolvimento da criança e do adolescente. Psicologia em Estudo, 10(2), 209-216.

São Paulo (2017). Dário Oficial do Poder Executivo. Sessão I de 7 de dezembro de 2017.

Saur, A.M. \& Loureiro, S.R. (2012). Qualidades psicométricas do Questionário de Capacidades e Dificuldades: revisão da literatura. Estudos de Psicologia, 29(4), 619-629.

Saur, A.; Correia, S.; Pasian, S. \& Loureiro, S. (2009) Questionário de Capacidades e Dificuldades (SQD): revisão de estudos de validade e fidedignidade. In: IV Congresso Brasileiro de Avaliação Psicológica; XIV Conferência Internacional de Avaliação Psicológica; V Congresso Brasileiro de Rorschach e métodos projetivos, Campinas. Avaliação psicológica: formação, atuação e interface, 1. (pp. 463).

Scortegagna, S. A. \& Villemor-Amaral, A. E. (2009). Autopercepção no Rorschach de vítmas de abuso sexual infantil (2009). Psico, 40(3): 328-336.

Seibel, B. L., \& Koller, S. H. (2015). O conceito de resiliência aplicado ao microssistema familiar: Articulações com a Teoria Bioecológica do Desenvolvimento Humano. In R. M. Coimbra, \& N. A. Morais (Orgs.), A resiliência em questão: Perspectivas teóricas, pesquisa e intervenção (pp. 83-98). Porto Alegre: Artmed.

Sharp, K. M. H.; Lindwall, J. J.; Willard, V.W.; Long, A. M.; Martin-Elbahesh, K. M. \& Phipps, S. (2017). Cancer as a stressful life event: Perceptions of children with cancer and their peers. Cancer, 123(17), 3385-3393.

Sociedade Internacional de Oncologia Pediátrica - SIOP (2009). Orientações Sobre Aspectos Psicossociais em Oncologia Pediátrica. Françoso, L.P.C. \& Valle, E.R.M. (Trad.). São Paulo: Mastered.

Soufre, L.A. (2009). The concept of development in developmental psychopathology. Child Development Perspectives, 3(3), 178-183. 
Trentacosta, C. J.; Harper, F. W. K.; Albrecht, T. L.; Taub, J. W.; Phipps, S. \& Penner, 1. (2016). Pediatric cancer patients' treatment-related distress and longer-term anxiety: an individual differences perspective. Journal of Developmental \& Behavioral Pediatrics, 37(9), 753-7561.

Trivette, C. M.; Dunst, C. \& Hamby, D. W. (2010). Influences of family-systems intervention practices on parent-child interactions and child development. Topics in Early Childhood Special Education, 30(1), 3-19.

Tsimicalis, A.; Stevens, B.; Ungar, W. J.; McKeever, P. \& Greenberg, M. (2011). The Cost of Childhood Cancer From the Family's Perspective: A Critical Review. Pediatric Blood Cancer; 56(5), 707-717.

Torres, W. C. (1999). A Criança diante da morte: desafios. São Paulo: Caso do Psicólogo.

Toth, L.S. \& Cicchetti, D. (2010). The historical origins and developmental pathways of the discipline of developmental psychopathology. The Israel Journal of Psychiatry and Related Sciences, 47(2), 95-104.

Verdon, B. (2009). Le corps âgé. Dynamisme et fragilité des destins pulsionnels à l'épreuve du vieillissement. Psychologie clinique et projective, 15, 119-143.

Walsh. F. (2005). Fortalecendo a resiliência familiar. São Paulo: Roca.

Walsh, F. (2016). Diversidade e complexidade das famílias no século XXI. In: Walsh, F. (Org). Processos normativos da família: diversidade e complexidade. (pp. 3-27). Porto Alegre: Artmed

Wechsler, A.M. \& Sánchez-Iglesias, I. (2013). Psychological adjustment of children with cancer as compared with healthy children: a meta-analysis. European Journal of Cancer Care, 22, 314-325.

Williams, A. N.; Allen, M. T. \& Phipps, S. (2011). Adaptive style and physiological reactivity during a laboratory stress paradigm in children with cancer and healthy controls. Journal of Behavioral Medicine, 34(5), 372-380.

Williams, N.A.; Davis, G.; Hancock, M.; \& Phipps, S. (2010). Optimism and pessimism in children with cancer and healthy children: confirmatory factor analysis of the youth life orientation test and relations with health-related quality of life. Journal of Pediatric Psychology, 35(6), 672-682. 
Wodehouse, G. \& McGill, P. (2009). Support for family carers of children and young people with developmental disabilities and challenging behaviour: what stops it being helpful?, 53(7), 644-653.

Woerner, M. et al. (2004). The The strenghts and difficulties questionnaires overseas: evaluations and applications of the SDQ beyond Europe. European Child \& Adolescent Psychiatry. 3(suppl 2), 1147-1154.

World Health Organization. (2014). World cancer report 2014. International Agency for Research on Cancer, WHO. Geneva: WHO.

Valle, E. R M. (1997). Câncer infantil: Compreender e agir. Campinas, SP: Editora Psy

Valle, E. R M. (2004). Acompanhamento psicológico em oncologia pediátrica. In: AngeramiCamon, V. A. (Org.), O atendimento infantil na ótica fenomenológico-existencial. (pp.83107). São Paulo: Pioneira Thopson Learning.

Valle, E. R. N. \& Ramalho, M. A. N. (2008) Câncer Infantil: a difícil trajetória. In: Carvalho, V. A., Franco, M. H. P., Kovács, M. J., \& Liberato, R. (Orgs). Temas em PsicoOncologia (pp. 505- 516). São Paulo: Summus.

Villemor-Amaral, A.E.; Biasi, F. C.; Pavan, P. M. P.; Tavella, R. R. \& Cardoso. L. M. (2016). A fórmula cromática no Teste das Pirâmides Coloridas de Pfister em diferentes faixas etárias. Psicologia em Revista, Belo Horizonte, 22(2), 501-515.

Villemor-Amaral, A.E. \& Franco, R.R.C. (2011). Novas contribuições para o Teste das Pirâmides Coloridas de Pfister. In: Villemor-Amaral, A.E. \& Werlang, B.S.S (Orgs.). Atualizações em métodos projetivos para avaliação psicológica (pp. 413-421). São Paulo: Casa do Psicólogo.

Villemor-Amaral, A. E. (2014). As Pirâmides Coloridas de Pfister Versão para Crianças e Adolescentes. São Paulo: Pearson.

Yunes, M.A.M. (2003). Psicologia positiva e resiliência: o foco no indivíduo e na família. Psicologia em Estudo, 8 (Esp.), 75-84.

Zuccolo, P.F.; Corchs, F.; \& Savoia, M.G. (2013). Psicopatologias e o conceito de personalidade. In: Carvalho, L.F. \& Primi, R. (Orgs.). Perspectiva em psicologia dos transtornos de personalidade (pp. 8-23). São Paulo: Casa do Psicólogo. 



\title{
APÊNDICE A
}

\section{Termo de Consentimento Livre e Esclarecido (TCLE) para pais elou responsáveis autorizarem o estudo com suas crianças/adolescentes}

\author{
UNIVERSIDADE DE SÃO PAULO \\ Faculdade de Filosofia, Ciência e Letras de Ribeirão Preto \\ Departamento de Psicologia - Centro de Pesquisas em Psicodiagnóstico (CPP)

\section{TERMO DE CONSENTIMENTO LIVRE E ESCLARECIDO}

Meu nome é Nichollas Martins Areco e estou desenvolvendo uma pesquisa que se chama: "Fatores de risco e proteção no desenvolvimento da personalidade de crianças $e$ adolescentes com câncer". Este estudo tem como objetivo compreender como a experiência de conviver com o adoecimento e tratamento pode influenciar o desenvolvimento da personalidade do jovem paciente, buscando estabelecer relações sobre o modo como a família lida com o paciente pediátrico e a forma pela qual ele consegue enfrentar esta experiência.

Esse trabalho será desenvolvido por mim, aluno de Doutorado em Psicologia na Faculdade de Filosofia, Ciências e Letras de Ribeirão Preto (FFCLRP) da Universidade de São Paulo (USP), e da Profa. Dra. Sonia Regina Pasian, professora do Departamento de Psicologia desta mesma Faculdade.

Essa pesquisa estudará crianças e adolescentes entre 7 e 17 anos, em vigência de tratamento oncológico, bem como crianças e adolescentes nesta mesma faixa etária, considerados saudáveis. Dessa forma, gostaríamos de convidar seu filho(a) a participar dessa pesquisa. Será combinado, com os responsáveis que concordarem com a participação da criança, horário e local convenientes para a realização das atividades, com duração aproximada de 80 minutos. As crianças que concordarem em participar do estudo realizarão as seguintes tarefas: um exercício de raciocínio; uma atividade de montagem a partir de quadrículos coloridos; uma tarefa de interpretar cartões com manchas de tinta; e algumas perguntas sobre a rotina e modo de viver de suas famílias. Será solicitado aos responsáveis que concordarem com a participação da criança o preenchimento de um questionário sobre o desenvolvimento de seu(ua) filho(a), que consiste em 25 questões que podem me ajudar a conhecê-lo(la) melhor, tanto do ponto de vista de capacidades quanto de dificuldades no desenvolvimento. Também será preenchido um formulário sobre informações econômicas e vida cotidiana da família.

Para que saibamos se o cotidiano de cuidados oncológicos gerou alguma transformação na vida da criança ou adolescente, realizaremos esta atividade novamente pelo menos seis meses após a primeira participação. A fim de que isso seja viável, entrarei em contato com intuito de agendar a realização destas atividades.

Os seus dados ficarão arquivados comigo, que sou a pesquisador responsável, por um período de cinco anos, e após esse tempo serão destruídos, também para a proteção da identidade dos participantes. Uma das vias deste Termo é destinada ao responsável, e a outra deverá ser devolvida para mim. A participação na pesquisa, bem como desistência em qualquer etapa do processo não trará qualquer risco ou prejuízo ao tratamento da criança e em sua relação com o serviço de saúde. O risco de participação no estudo é considerado mínimo, sendo que envolve apenas respostas (de crianças e seus responsáveis) a procedimentos utilizados na Psicologia, exigindo apenas o tempo e atenção às atividades. As informações coletadas nesse estudo são confidenciais e somente serão utilizadas para a investigação 
científica. Os resultados desse trabalho deverão ser divulgados em espaços de comunicação científica, sempre protegendo a identidade dos participantes.

A participação é voluntária, de forma que não serão oferecidos pagamentos ou recompensas, bem como não há custos nessa sua colaboração. Além disso, caso sejam identificadas quaisquer dificuldades psicológicas, orientarei os responsáveis e auxiliarei no encaminhamento da criança, quando adequado, a atendimento psicológico específico na rede de saúde de sua cidade.

A colaboração a essa pesquisa, ainda que não lhe traga benefícios diretos, poderá contribuir para a construção de conhecimentos a respeito de algumas das características de personalidade e enfrentamento diante de uma situação de risco para o desenvolvimento, auxiliando na criação e aperfeiçoamento de intervenções e cuidados voltados a estas crianças e adolescentes. Agradeço desde já sua colaboração e permaneço disponível para possíveis dúvidas e novas informações, em qualquer momento.

Caso deseje obter informações éticas sobre a pesquisa, você poderá entrar em contato com Comitê de Ética em Pesquisa da Faculdade de Filosofia, Ciências e Letras de Ribeirão Preto USP. Ele fica localizado na Avenida Bandeirantes, 3900 - Bloco 23 - Casa 37; CEP 14040901 - Ribeirão Preto - SP - Brasil. O contato telefônico pode ser realizado através do número (16) 3315-4811, e o email é coetp@ffclrp.usp.br

Cordialmente,

\author{
Nichollas Martins Areco \\ Pesquisador - CRP: 06/89966
}

Profa. Dra. Sonia Regina Pasian

Orientadora - CRP: 06/24.018-0

$\mathrm{Eu}$,

declaro que estou de acordo com a participação da criança/adolescente , sob minha responsabilidade, como voluntário no projeto de pesquisa "Fatores de risco e proteção no desenvolvimento da personalidade de crianças e adolescentes com câncer", desenvolvido pelo psicólogo Nichollas Martins Areco e pela Profa. Dra. Sonia Regina Pasian, assim como estou ciente de que os registros relativos a esse trabalho serão utilizados como material de trabalho científico e poderão ser divulgados em congressos e publicados em revistas ou livros especializados, resguardando-se o devido sigilo quanto a nossa identificação.

Ribeirão Preto, de de 201_.

\section{Observação:}

(Assinatura do responsável pela criança)

- Em caso de dúvidas referentes a essa pesquisa, entre em contato com o Departamento de Psicologia da FFCLRP-USP e esclareça-se conosco pelo telefone: (16) 3315-3785 ou pelo email: srpasian@ffclrp.usp.br, ou fale diretamente com Nichollas Martins Areco, pelo telefone celular (16) 99723-8840. 


\title{
APÊNDICE B
}

\section{Termo de Consentimento Livre e Esclarecido (TCLE) para pais elou responsáveis de crianças/adolescentes}

\author{
UNIVERSIDADE DE SÃO PAULO \\ Faculdade de Filosofia, Ciência e Letras de Ribeirão Preto \\ Departamento de Psicologia - Centro de Pesquisas em Psicodiagnóstico (CPP)

\section{TERMO DE CONSENTIMENTO LIVRE E ESCLARECIDO}

Meu nome é Nichollas Martins Areco e estou desenvolvendo uma pesquisa que se chama: "Fatores de risco e proteção no desenvolvimento da personalidade de crianças $e$ adolescentes com câncer". Este estudo tem como objetivo compreender como a experiência de conviver com o adoecimento e tratamento pode influenciar o desenvolvimento da personalidade do jovem paciente, buscando estabelecer relações sobre o modo como a família lida com o paciente pediátrico e a forma pela qual ele consegue enfrentar esta experiência.

Esse trabalho será desenvolvido por mim, aluno de Doutorado em Psicologia na Faculdade de Filosofia, Ciências e Letras de Ribeirão Preto (FFCLRP) da Universidade de São Paulo (USP), e da Profa. Dra. Sonia Regina Pasian, professora do Departamento de Psicologia desta mesma Faculdade.

Essa pesquisa estudará crianças e adolescentes entre 7 e 17 anos, em vigência de tratamento oncológico, bem como crianças e adolescentes nesta mesma faixa etária, considerados saudáveis. Dessa forma, gostaríamos de convidar seu filho(a) a participar dessa pesquisa. Será combinado, com os responsáveis que concordarem com a participação da criança, horário e local convenientes para a realização das atividades, com duração aproximada de 80 minutos. As crianças que concordarem em participar do estudo realizarão as seguintes tarefas: um exercício de raciocínio; uma atividade de montagem a partir de quadrículos coloridos; e uma tarefa de interpretar cartões com manchas de tinta. Será solicitado aos responsáveis que concordarem com a participação da criança o preenchimento de um questionário sobre o desenvolvimento de seu(ua) filho(a), que consiste em 25 questões que podem me ajudar a conhecê-lo(la) melhor, tanto do ponto de vista de capacidades quanto de dificuldades no desenvolvimento. Também será preenchido um formulário sobre informações econômicas e vida cotidiana da família.

Para que saibamos se o cotidiano de cuidados oncológicos gerou alguma transformação na vida da criança ou adolescente, realizaremos esta atividade novamente pelo menos seis meses após a primeira participação. A fim de que isso seja viável, entrarei em contato com intuito de agendar a realização destas atividades.

Os seus dados ficarão arquivados comigo, que sou o pesquisador responsável, por um período de cinco anos, e após esse tempo serão destruídos, também para a proteção da identidade dos participantes. Uma das vias deste Termo é destinada ao responsável, e a outra deverá ser devolvida para mim. A participação na pesquisa, bem como desistência em qualquer etapa do processo não trará qualquer risco ou prejuízo aos voluntários e seus responsáveis. O risco de participação no estudo é considerado mínimo, sendo que envolve apenas respostas (de crianças e seus responsáveis) a procedimentos utilizados na Psicologia, exigindo apenas o tempo e atenção às atividades. As informações coletadas nesse estudo são confidenciais e somente serão utilizadas para a investigação científica. Os resultados desse trabalho deverão ser divulgados em espaços de comunicação científica, sempre protegendo a identidade dos participantes. 
A participação é voluntária, de forma que não serão oferecidos pagamentos ou recompensas, bem como não há custos nessa sua colaboração. Além disso, caso sejam identificadas quaisquer dificuldades psicológicas, orientarei os responsáveis e auxiliarei no encaminhamento da criança, quando adequado, a atendimento psicológico específico na rede de saúde de sua cidade.

A colaboração a essa pesquisa, ainda que não lhe traga benefícios diretos, poderá contribuir para a construção de conhecimentos a respeito de algumas das características de personalidade e enfrentamento diante de uma situação de risco para o desenvolvimento, auxiliando na criação e aperfeiçoamento de intervenções e cuidados voltados a estas crianças e adolescentes. Agradeço desde já sua colaboração e permaneço disponível para possíveis dúvidas e novas informações, em qualquer momento.

Caso deseje obter informações éticas sobre a pesquisa, você poderá entrar em contato com Comitê de Ética em Pesquisa da Faculdade de Filosofia, Ciências e Letras de Ribeirão Preto - USP. Ele fica localizado na Avenida Bandeirantes, 3900 - Bloco 23 - Casa 37; CEP 14040-901 - Ribeirão Preto - SP - Brasil. O contato telefônico pode ser realizado através do número (16) 3315-4811, e o e-mail é coetp@ffclrp.usp.br

Cordialmente,

\author{
Nichollas Martins Areco \\ Pesquisador - CRP: 06/89966
}

\author{
Profa. Dra. Sonia Regina Pasian \\ Orientadora - CRP: 06/24.018-0
}

$\mathrm{Eu}$,

, declaro que fui informado(a) dos objetivos do presente estudo de maneira clara e detalhada e esclareci minhas dúvidas, declarando aceitar participar como voluntário(a) no projeto de pesquisa "Fatores de risco e proteção no desenvolvimento da personalidade de crianças e adolescentes com câncer", desenvolvido pela psicólogo Nichollas Martins Areco e pela Profa. Dra. Sonia Regina Pasian, assim como estou ciente de que os registros relativos a esse trabalho serão utilizados como material de trabalho científico e poderão ser divulgados em congressos e publicados em revistas ou livros especializados, resguardando-se o devido sigilo quanto a minha identificação.

Ribeirão Preto, ___ de ___ de 201_.

(Assinatura do responsável pela criança)

\section{Observação:}

- Em caso de dúvidas referentes a essa pesquisa, entre em contato com o Departamento de Psicologia da FFCLRP-USP e esclareça-se conosco pelo telefone: (16) 3315.3785 ou pelo email: srpasian@ffclrp.usp.br, ou fale diretamente com Nichollas Martins Areco, pelo telefone celular (16) 99723-8840. 


\title{
APÊNDICE C
}

\section{Termo de Assentimento para voluntários da pesquisa}

\author{
UNIVERSIDADE DE SÃO PAULO \\ Faculdade de Filosofia, Ciência e Letras de Ribeirão Preto \\ Departamento de Psicologia - Centro de Pesquisas em Psicodiagnóstico (CPP)
}

\section{TERMO DE ASSENTIMENTO}

Meu nome é Nichollas Martins Areco e estou desenvolvendo uma pesquisa que se chama: "Fatores de risco e proteção no desenvolvimento da personalidade de crianças e adolescentes com câncer". Esse estudo quer entender como crianças e adolescentes se sentem ao longo do tratamento contra o câncer. Também gostaria de saber como entendem o mundo a sua volta, o que pensam, e como resolvem os problemas que aparecem no dia a dia. Além disso, também faremos algumas perguntas aos seus pais ou cuidadores, para que conheçamos um pouco mais de sua família e o modo pelo qual eles cuidam e se relacionam com você.

Com isso queremos saber quais as diferenças e semelhanças entre pessoas que fazem tratamento e outras que não passam por ele.

Estudar esse assunto pode nos ajudar a compreender melhor o impacto que o câncer infanto-juvenil acarreta e favorecer formas de ajudá-los a enfrentar as dificuldades que surgem durante e após o tratamento. Você pode nos ajudar com esse trabalho, motivo do atual convite para participar dessa pesquisa.

Vou lhe propor algumas atividades para fazer comigo, depois da concordância e autorização de seus pais ou responsáveis. Faremos atividades que envolvem algumas perguntas acerca da sua vida familiar e rotina, opiniões sobre figuras mostradas em cartões, exercícios de raciocínio e atividade de montagem a partir de quadrículos coloridos, o que deve demorar em torno de uma hora. Caso você se canse ou tenha dúvidas, podemos parar para descansar e você pode me perguntar o que desejar sobre as atividades. Você está participando da pesquisa como voluntário, portanto, pode desistir dela em qualquer momento, sem qualquer problema, se assim preferir.

Para participar deste estudo, o responsável por você deverá autorizar e assinar um termo de consentimento. Ele também poderá interromper a sua participação se assim quiser. Como estou querendo ajudar a aumentar o conhecimento sobre o câncer infantil, preciso compartilhar os resultados deste trabalho com as outras pessoas que cuidam destas crianças. Por isso, quando o trabalho estiver pronto, escreverei para revistas dirigidas a profissionais da área de saúde, divulgando esses resultados. Mas não se preocupe, pois suas informações pessoais, que deixam saber quem você é, serão guardadas adequadamente, mantendo sua identidade protegida.

Este estudo tem risco mínimo, o que significa que seriam os mesmos riscos ao fazermos nossas atividades do dia a dia, como conversar, estudar, realizar atividades escolares.

Os seus dados ficarão arquivados comigo (pesquisador responsável) por um período de cinco anos, e após esse tempo serão destruídos, também para a proteção da sua identidade. Este termo de assentimento foi impresso em duas vias, sendo que uma cópia será guardada por mim, a pesquisadora responsável, e a outra ficará com você. 
Caso deseje obter informações éticas sobre a pesquisa, você poderá entrar em contato com Comitê de Ética em Pesquisa da Faculdade de Filosofia, Ciências e Letras de Ribeirão Preto - USP. Ele fica localizado na Avenida Bandeirantes, 3900 - Bloco 23 - Casa 37; CEP 14040-901 - Ribeirão Preto - SP - Brasil. O contato telefônico pode ser realizado através do número (16) 3315-4811, e o e-mail é coetp@ffclrp.usp.br

$\mathrm{Eu}$, fui informado(a) dos objetivos do presente estudo de maneira clara e detalhada e esclareci minhas dúvidas, declarando aceitar participar como voluntário no projeto de pesquisa "Fatores de risco $e$ proteção no desenvolvimento da personalidade de crianças e adolescentes com câncer", desenvolvido pelo psicólogo Nichollas Martins Areco e pela Profa. Dra. Sonia Regina Pasian, assim como estou ciente de que os registros relativos a esse trabalho serão utilizados como material de trabalho científico e poderão ser divulgados em congressos e publicados em revistas ou livros especializados, resguardando-se o devido sigilo quanto a minha identificação.

Ribeirão Preto, de de 201

\section{Nichollas Martins Areco}

(Assinatura do pesquisador responsável)

(Assinatura do voluntário)

\section{Observação:}

- Em caso de dúvidas referentes a essa pesquisa, entre em contato com o Departamento de Psicologia da FFCLRP-USP e esclareça-se conosco pelo telefone: (16) 3315-3785 ou pelo email: srpasian@ffclrp.usp.br, ou fale diretamente com Nichollas Martins Areco, pelo telefone celular (16) 99723-8840. 


\begin{abstract}
ANEXO 1
Comprovante de exame e aceite do projeto de pesquisa pelo Comitê de Ética em Pesquisa com Seres Humanos da Faculdade de Filosofia, Ciências e Letras de Ribeirão Preto da Universidade de São Paulo.
\end{abstract}

\title{
\begin{tabular}{|l|l|}
\hline FACULP & FACULDADE DE FILOSOFIA, \\
CIÊNCIAS E LETRAS DE \\
RIBEIRÃO PRETO- USP
\end{tabular} \\ PARECER CONSUBSTANCIADO DO CEP \\ DADOS DO PROJETO DE PESQUISA
}

Título da Pesquisa: Fatores de risco e proteção no desenvolvimento da personalidade de crianças e adolescentes com câncer

Pesquisador: Nichollas Martins Areco

Área Temática:

Versão: 1

CAAE: 42183715.6 .0000 .5407

Instituição Proponente: Faculdade de Filosofia, Ciências e Letras de Ribeirão Preto- USP

Patrocinador Principal: Financiamento Próprio

\section{DADOS DO PARECER}

Número do Parecer: 1.017 .398

Data da Relatoria: $12 / 03 / 2015$

Apresentação do Projeto:

Trata-se de uma pesquisa longitudinal onde os pesquisadores pretendem investigar os fatores de risco e proteção associados ao desenvolvimento da personalidade de crianças e adolescentes com câncer, assistidas no serviço de oncologia pediátrica do HCFMRP-USP, através da aplicação de vários instrumentos estruturados e já validados. O tema é interessante e importante tanto para a comunidade científica quanto para os usuários (pacientes pediátricos com câncer e suas famílias). Serão pesquisados dois grupos, um chamado de Clínico (G1), composto de 30 crianças/adolescentes de 7 a 17 anos, que tenham recebido diagnóstico oncológico há pelo menos um mês, e que não estejam em recidiva ou cuidado paliativo. 0 Grupo de Comparação $(G 2, n=30)$ será constituído por pessoas saudáveis, com idade e sexo pareado ao G1. Os indivíduos dos dois grupos serão avaliados em dois momentos, com intervalo de 6 meses entre as avaliações. Também será investigado um cuidador de cada participante do G1, indicado pelo participante ou pela família. Os dados serão tratados estatisticamente.

Objetivo da Pesquisa:

Ospesquisadores descrevem:

Objetivo Geral: Avaliar, longitudinalmente, efeitos da vivência de adoecimento e cuidado

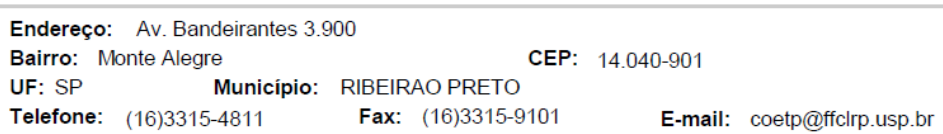




\begin{tabular}{|c|c|c|}
\hline FFELRP & FACULDADE DE FILOSOFIA, \\
CIÊNCIAS E LETRAS DE \\
RIBEIRÃO PRETO- USP
\end{tabular}

Continuação do Parecer: 1.017 .398

oncológico sobre as estratégias de enfrentamento do câncer em crianças e adolescentes, bem como sobre o desenvolvimento de suas características de personalidade.

Objetivos Específicos:

Identificar e caracterizar fatores de risco e de proteção ao desenvolvimento em crianças e adolescentes em tratamento oncológico, comparativamente a um grupo pareado de indivíduos com desenvolvimento considerado típico para sua faixa etária.

Examinar possíveis associações entre características de personalidade de crianças e adolescentes e variáveis identificadas como risco e/ou proteção em suas histórias de vida.

Caracterizar fatores de proteção e de risco na dinâmica familiar e como estes podem influenciar a criação de condições de vulnerabilidade ou resiliência na criança ou adolescente em cuidado oncológico.

\section{Avaliação dos Riscos e Benefícios:}

Os riscos da pesquisa são assim descritos pelo pesquisador: "O risco de participação no estudo é considerado mínimo, sendo que envolve apenas respostas (de crianças e seus responsáveis) a procedimentos utilizados na Psicologia, exigindo apenas o tempo e atenção às atividades. Caso sejam identificadas dificuldades psicológicas consistentes e

prejudiciais ao desenvolvimento, em qualquer etapa da realização do estudo, o pesquisador cuidará de orientar os responsáveis e encaminhará a criança ou adolescente (de qualquer um dos grupos) para atendimento psicológico específico na rede de saúde de sua cidade. Cabe destacar, no entanto, que os participantes do Grupo Clínico (G1) já possuem, pela rotina de seu tratamento, equipe multidisciplinar envolvida, contanto com

intervenção psicológica específica, pautada por suas necessidades e de seus familiares ou responsáveis".

Em relação aos benefícios, o pesquisador relata: "A realização do presente estudo visa contribuir para a construção de conhecimentos a respeito de características de personalidade e maneiras de lidar com o adoecimento em crianças e adolescentes, auxiliando no futuro a criação e aperfeiçoamento de intervenções e formas de cuidados às

famílias que enfrentam um adoecimento crônico".

\section{Comentários e Considerações sobre a Pesquisa:}

Os procedimentos a serem adotados na pesquisa estão descritos de forma clara e suficiente e não sugerem nenhum problema de ordem ética para os participantes. A fundamentação teórica da pesquisa está adequadamente descrita, justificando plenamente a realização do estudo.

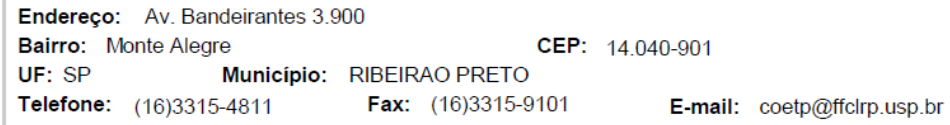




\section{FACULDADE DE FILOSOFIA, CIÊNCIAS E LETRAS DE RIBEIRÃO PRETO- USP}

Continuação do Parecer: 1.017.398

Considerações sobre os Termos de apresentação obrigatória:

Os termos de consentimento e assentimento apresentados estão escritos de forma clara e contêm todas as informações necessárias para a decisão do participante.

Conclusões ou Pendências e Lista de Inadequações:

A pesquisa não apresenta pendências, estando, portanto, aprovada por este Comitê para execução.

Situação do Parecer:

Aprovado

Necessita Apreciação da CONEP:

Não

Considerações Finais a critério do CEP:

O projeto encontra-se APROVADO neste CEP, devendo aguardar a aprovação do CEP do HCFMRP, antes do início da coleta de dados.

Pedimos atenção aos seguintes itens:

1) De acordo com a Resolução CNS n. ${ }^{\circ} 466 / 2012$, o pesquisador deverá apresentar relatórios semestrais (parciais e final, em função da duração da pesquisa);

2) Eventuais emendas (modificações) ao protocolo devem ser apresentadas, com justificativa,

ao CEP de forma clara e sucinta, identificando a parte do protocolo a ser modificada;

3) Sobre o TCLE e TA: caso o termo tenha DUAS páginas ou mais, lembramos que no momento da sua assinatura, tanto o participante da pesquisa (ou seu representante legal) quanto o pesquisador responsável deverão RUBRICAR todas as folhas, colocando as assinaturas na última página.

Assinado por:

Andréia Schmidt

(Coordenador)

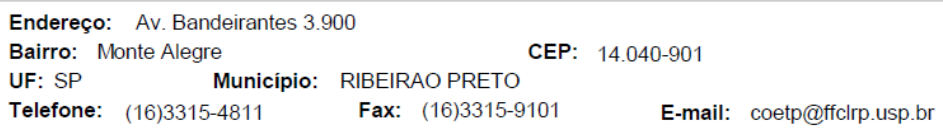




\begin{abstract}
ANEXO 2
Comprovante de exame e aceite do projeto de pesquisa pelo Comitê de Ética em Pesquisa com Seres Humanos do Hospital das Clínicas da Faculdade de Medicina de Ribeirão Preto da Universidade de São Paulo.
\end{abstract}

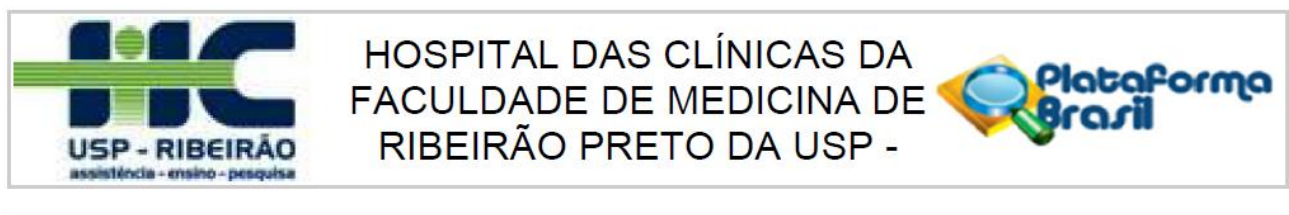

\title{
PARECER CONSUBSTANCIADO DO CEP
}

Elaborado pela Instituição Coparticipante

DADOS DO PROJETO DE PESQUISA

Título da Pesquisa: Fatores de risco e proteção no desenvolvimento da personalidade de crianças e adolescentes com câncer

Pesquisador: Nichollas Martins Areco

Área Temática:

Versão: 1

CAAE: 42183715.6 .3001 .5440

Instituição Proponente: Faculdade de Filosofia, Ciências e Letras de Ribeirão Preto- USP

Patrocinador Principal: Financiamento Próprio

\section{DADOS DO PARECER}

Número do Parecer: 1.041 .811

Data da Relatoria: 10/04/2015

Apresentação do Projeto:

De acordo com o parecer da Instituição Proponente.

Objetivo da Pesquisa:

De acordo com o parecer da Instituição Proponente.

Avaliação dos Riscos e Benefícios:

De acordo com o parecer da Instituição Proponente.

Comentários e Considerações sobre a Pesquisa:

De acordo com o parecer da Instituição Proponente.

Considerações sobre os Termos de apresentação obrigatória:

Apresentou carta de anuência do responsável pelo local de coleta no HCFMRP-USP

Recomendações:

Não há.

Conclusões ou Pendências e Lista de Inadequações:

O CEP tomou ciência e concorda com o parecer da Instituição Proponente.

Situação do Parecer:

Aprovado

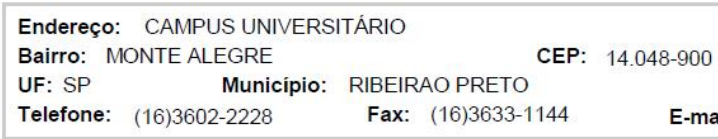




\section{HOSPITAL DAS CLÍNICAS DA
FACULDADE DE MEDICINA DE Plotorformo
USIBEIRÃO PRETO DA USP -}

Continuação do Parecer: 1.041 .811

Necessita Apreciação da CONEP:

Não

Considerações Finais a critério do CEP:

"O CEP do HC e da FMRP-USP concorda com o parecer ético emitido pelo CEP da Instituição Proponente, que cumpre as Resoluções Éticas Brasileiras, em especial a Resolução CNS 466/12. Diante disso, o HCFMRP-USP, como instituição co-participante do referido projeto de pesquisa, está ciente de suas coresponsabilidades e de seu compromisso no resguardo da segurança e bem-estar dos sujeitos desta pesquisa, dispondo de infra-estrutura necessária para a garantia de tal segurança e bem-estar".

RIBEIRAO PRETO, 29 de Abril de 2015

Assinado por:
MARCIA GUIMARÃES VILLANOVA
(Coordenador)

Endereço: CAMPUS UNIVERSITÁRIO

Bairro: MONTE ALEGRE CEP: $14.048-900$

UF: SP Município: RIBEIRAO PRETO

Telefone: (16)3602-2228 Fax: (16)3633-1144 E-mail: cep@hcrp.usp.br 


\section{ANEXO 3 \\ INVENTÁRIO DE RECURSOS DO AMBIENTE FAMILIAR (RAF) \\ Marturano (1999)}

1. O QUE A CRIANÇA OU ADOLESCENTE FAZ QUANDO NÃO ESTÁ NA ESCOLA?

( ) Assiste à TV

( ) Ouve rádio

( ) Tem acesso a jogos eletrônicos (videogame, computador, tablet)

( ) Tem acesso a internet

( ) Lê livros, revistas, gibis

( ) Brinca na rua

( ) Brinca dentro de casa

( ) Outro. Especificar

2. QUAIS PASSEIOS A CRIANÇA OU ADOLESCENTE REALIZOU NOS ÚLTIMOS 12 MESES?

\begin{tabular}{|c|c|c|c|c|c|}
\hline & Pai & Mãe & Irmãos & Familiares & Outro \\
\hline $\begin{array}{l}\text { Evento anual da cidade (feira } \\
\text { típica, rodeio, feira do livro, etc.) }\end{array}$ & $($ ) & $($ ) & ( ) & $($ ) & $($ ) \\
\hline Bosque Municipal & ( ) & ( ) & ( ) & ( ) & ( ) \\
\hline Parques Ambientais & ( ) & ( ) & ( ) & ( ) & ( ) \\
\hline Cinema ou teatro & ( ) & ( ) & ( ) & ( ) & ( ) \\
\hline Museu & ( ) & ( ) & ( ) & ( ) & ( ) \\
\hline $\begin{array}{l}\text { Exposição (pintura, ciências, } \\
\text { etc.) }\end{array}$ & ( ) & ( ) & ( ) & ( ) & ( ) \\
\hline Aeroporto & ( ) & ( ) & ( ) & ( ) & ( ) \\
\hline Circo & ( ) & ( ) & ( ) & ( ) & ( ) \\
\hline Parque de diversões & $($ ) & $($ ) & $($ ) & ( ) & $($ ) \\
\hline Lanchonete & ( ) & ( ) & ( ) & ( ) & ( ) \\
\hline Shopping Center & ( ) & ( ) & ( ) & ( ) & ( ) \\
\hline Praia & ( ) & ( ) & ( ) & ( ) & ( ) \\
\hline Sítio, chácara ou fazenda & ( ) & ( ) & ( ) & ( ) & ( ) \\
\hline $\begin{array}{l}\text { Visitas a parentes ou amigos da } \\
\text { família }\end{array}$ & ( ) & ( ) & ( ) & ( ) & ( ) \\
\hline Viagem para outra cidade & ( ) & ( ) & ( ) & ( ) & ( ) \\
\hline Outro. Especificar: & () & () & ( ) & () & () \\
\hline
\end{tabular}

3. HÁ ATIVIDADES QUE A CRIANÇA OU ADOLESCENTE REALIZA REGULARMENTE?

( ) Faz catecismo, estudos bíblicos, evangelização, estudos religiosos

( ) Frequenta núcleo municipal do bairro

( ) Pratica esportes em clubes, academias, ginásios

( ) Frequenta aula para aprender atividades artesanais (pintura, tapeçaria, etc.)

( ) Tem aulas de piano, violão ou outro instrumento musical

( ) Frequenta programa de atividades para crianças (programas de contra turno escolar)

( ) Tem aulas de inglês ou outro idioma

( ) Faz computação

( ) Outro.

Especificar: 
4. QUAIS ATIVIDADES OS PAIS DESENVOLVEM COM A CRIANÇA OU ADOLESCENTE EM CASA?

\begin{tabular}{|c|c|c|c|c|c|}
\hline & Pai & Mãe & Irmãos & Familiares & Outro \\
\hline Brincar & $($ ( ) & $($ ) & ( ) & () & () \\
\hline $\begin{array}{c}\text { Jogar vídeo game ou outros } \\
\text { jogos }\end{array}$ & ( ) & ( ) & ( ) & ( ) & ( ) \\
\hline $\begin{array}{c}\text { Assistir programas infantis } \\
\text { na TV }\end{array}$ & ( ) & ( ) & ( ) & ( ) & ( ) \\
\hline Assistir filmes ou séries & ( ) & ( ) & ( ) & ( ) & () \\
\hline Contar histórias e casos & ( ) & ( ) & ( ) & ( ) & ( ) \\
\hline Ler livros ou revistas & ( ) & ( ) & ( ) & ( ) & ( ) \\
\hline $\begin{array}{l}\text { Conversar sobre como foi o } \\
\text { dia na escola }\end{array}$ & ( ) & ( ) & ( ) & ( ) & ( ) \\
\hline $\begin{array}{c}\text { Conversar sobre notícias, } \\
\text { filmes e outros programas } \\
\text { de TV }\end{array}$ & ( ) & ( ) & ( ) & ( ) & ( ) \\
\hline $\begin{array}{l}\text { Ouvir histórias da criança } \\
\text { ou adolescente; conversar } \\
\text { sobre assuntos que ele traz }\end{array}$ & ( ) & ( ) & ( ) & ( ) & ( ) \\
\hline $\begin{array}{c}\text { Realizar juntos atividades } \\
\text { domésticas (organizar a } \\
\text { casa, cozinhar, lavar o } \\
\text { carro, etc.) }\end{array}$ & ( ) & ( ) & ( ) & ( ) & ( ) \\
\hline Outras. Especificar: & ( ) & ( ) & ( ) & ( ) & ( ) \\
\hline
\end{tabular}

\section{QUAIS BRINQUEDOS ELE TEM OU JÁ TEVE?}

( ) Uma cama só para ele

( ) Brinquedos de andar (triciclo, bicicleta, patinete)

( ) Brinquedos para movimento do corpo (corda para pular, balanço)

( ) Instrumento musical de brinquedo (tambor, piano)

( ) Brinquedo que lida com números (dado, dominó)

( ) Brinquedo de letras (abecedário, quebra-cabeças com letras)

( ) Brinquedo de aprender cores, tamanhos, formas (quebra-cabeça, encaixes)

( ) Brinquedo para conhecer nomes de animais (livros, miniaturas)

( ) Objetos como giz, lousa, cola, tinta, tesoura, lápis de cor e papel

( ) Aparelho de som

( ) Animal de estimação

( ) Livrinhos de histórias infantis

( ) Jogo de regras (dama, dominó, loto, memória)

( ) Brinquedos de faz de conta (panelinhas, bonecas, ferramentas)

( ) Brinquedos de construção (blocos, lego, pino mágico)

( ) Vídeo game ou similar (computador ou tablet, por exemplo)

( ) Bola, pipa, bola de gude, carrinho de rolemã

( ) Outro.

Especificar: 
6. HÁ JORNAIS E REVISTAS NA SUA CASA?

( ) Não

( ) Sim - tipo:

( ) Jornal

( ) Revista - ( ) de notícia ( ) de TV ( ) feminina ( ) de esporte ( ) religiosa

( ) outra-especifique

7. HÁ LIVROS NA SUA CASA?

( ) Não

( ) Sim - tipo:

( ) Escolares

( ) Romances, contos literatura

( ) Livrinhos infantis

( ) Religiosos

( ) Dicionários

( ) Outros. Especifique:

8. ALGUÉM EM CASA ACOMPANHA A CRIANÇA NOS AFAZERES DA ESCOLA?

\begin{tabular}{|c|c|c|c|c|}
\hline Alguém em sua casa & Ninguém & Mãe & Pai & Outros \\
\hline Verifica se o material escolar está em ordem & $($ ) & $($ ) & $($ ) & $($ ) \\
\hline Avisa quando é hora de ir para a escola & ( ) & ( ) & ( ) & ( ) \\
\hline Supervisiona a lição de casa & ( ) & ( ) & ( ) & ( ) \\
\hline Supervisiona o estudo para as provas & ( ) & ( ) & ( ) & ( ) \\
\hline Comparece às reuniões de escola & ( ) & ( ) & ( ) & ( ) \\
\hline Acompanha as notas e frequência às aulas & ( ) & ( ) & ( ) & ( ) \\
\hline
\end{tabular}

9. SEU FILHO TEM HORA CERTA PARA:

\begin{tabular}{|c|c|c|c|}
\hline & Sempre & $\grave{A s}$ vezes & Nunca \\
\hline Levantar-se de manhã & () & () & $($ ) \\
\hline Tomar banho & ( ) & ( ) & ( ) \\
\hline Brincar & ( ) & ( ) & ( ) \\
\hline Assistir TV & ( ) & ( ) & ( ) \\
\hline Almoçar & ( ) & ( ) & ( ) \\
\hline Fazer a lição de casa & ( ) & ( ) & ( ) \\
\hline Jantar & ( ) & ( ) & ( ) \\
\hline Ir dormir & ( ) & ( ) & ( ) \\
\hline
\end{tabular}


10. SUA FAMÍLIA COSTUMA ESTAR REUNIDA:

Sempre

Às vezes

Nunca

\begin{tabular}{lccc}
\hline No café da manhã & $($ ) & $($ ) & $($ ) \\
No almoço & $($ ) & $($ ) & $($ ) \\
No jantar & $($ ) & $($ ) & $($ ) \\
À noite, para assistir TV & $($ ) & $($ ) & $($ )
\end{tabular}

E nos finais de semana?

\begin{tabular}{|c|c|c|c|}
\hline Em casa & () & () & ( ) \\
\hline Em Passeios & ( ) & ( ) & ( ) \\
\hline
\end{tabular}

11. QUANDO TEM ALGUM PROBLEMA OU DIFICULDADE, A QUEM A CRIANÇA OU ADOLESCENTE RECORRE PARA PEDIR AJUDA OU CONSELHO?
( ) Mãe
( ) Pai
( ) Irmão ou irmã
( ) Avô ou avó
( ) Tio ou tia
( ) Vizinho ou vizinha
( ) Amigo ou amiga
( ) Outro. Especificar:

\section{COMPOSIÇÃO FAMILIAR}

Ao todo, quantas pessoas moram na casa?

Indique as pessoas que moram na casa:
( ) Mãe
( ) Pai
( ) Irmão ou irmã. Quantos?
( ) Avô ou avó
( ) Tio ou tia
( ) Vizinho ou vizinha
( ) Amigo ou amiga
( ) Outro. Especificar: 
ANEXO 4

ESCALA DE EVENTOS ADVERSOS (EEA) - Marturano (1999)

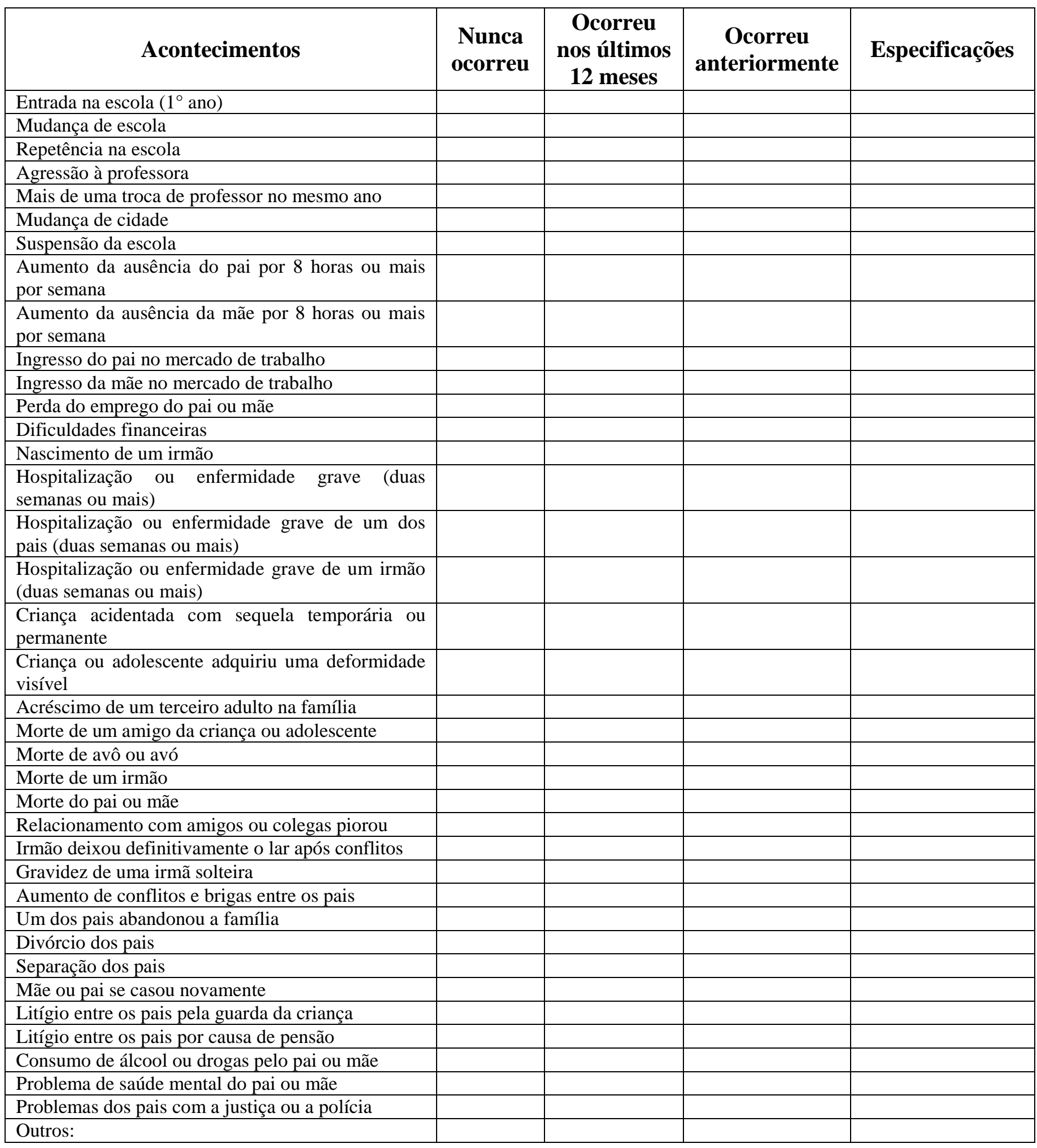




\section{ANEXO 5}

ESCALA DE ADVERSIDADE CRÔNICA (EAC) - Marturano (1999)

\begin{tabular}{|l|c|c|c|c|c|}
\hline \multicolumn{1}{|c|}{ Condição } & Não & Sim & $\begin{array}{c}\text { Duração } \\
\text { em Anos }\end{array}$ & $\begin{array}{c}\text { Período } \\
\text { da vida }\end{array}$ & Especificações \\
\hline Doença crônica na criança & ( ) & ( ) & & & \\
\hline Procedimento médico invasivo & ( ) & ( ) & & & \\
\hline Uso de prótese & ( ) & ( ) & & & \\
\hline Uso de óculos & ( ) & ( ) & & & \\
\hline Criança com visão subnormal & ( ) & ( ) & & & \\
\hline Sinal de nascença visível? & ( ) & ( ) & & & \\
\hline Hospitalização recorrente? & ( ) & ( ) & & & \\
\hline Temperamento difícil (gênio) do pai & ( ) & ( ) & & & \\
\hline Temperamento difícil (gênio) da mãe & ( ) & ( ) & & & \\
\hline Conflitos familiares recorrentes ou crônicos & ( ) & ( ) & & & \\
\hline Conflitos conjugais recorrentes ou crônicos & ( ) & ( ) & & & \\
\hline Transtorno mental crônico do pai ou substituto & ( ) & ( ) & & & \\
\hline Transtorno mental crônico da mãe ou & ( ) & ( ) & & & \\
\hline substituta & & & & & \\
\hline Dependência de drogas do pai ou substituto & ( ) & ( ) & & & \\
\hline Dependência de drogas da mãe ou substituta & ( ) & ( ) & & & \\
\hline Alcoolismo severo do pai ou substituto & ( ) & ( ) & & & \\
\hline Alcoolismo severo da mãe ou substituta & ( ) & ( ) & & & \\
\hline Outros: & ( ) & ( ) & & & \\
\hline
\end{tabular}

